\title{
CAYUCOS COMMUNITY HEALTH PLAN
}

\author{
A Professional Project \\ presented to \\ the Faculty of California Polytechnic State University, \\ San Luis Obispo
}

\author{
In Partial Fulfillment \\ of the Requirements for the Degree \\ Master of City and Regional Planning
}

by

Jennifer Joyce Hill Franich

June 2014 
(C) 2014

Jennifer Joyce Hill Franich

ALL RIGHTS RESERVED 
COMMITTEE MEMBERSHIP

TITLE: Cayucos Community Health Plan

AUTHOR: Jennifer Joyce Hill Franich

DATE SUBMITTED: June 2014

COMMITTEE CHAIR: Kelly D. Main, PhD

Assistant Professor of City and Regional Planning

COMMITTEE MEMBER: Kathleen Karle, MPH

County of San Luis Obispo Health Agency

Health Promotion Division Director

COMMITTEE MEMBER: Charles Stevenson, AICP

Lecturer of City and Regional Planning 


\author{
ABSTRACT \\ Cayucos Community Health Plan \\ Jennifer Joyce Hill Franich
}

Recent, mounting research shows that chronic disease, the leading causes of death and primary driver of health care costs, cannot be effectively addressed through education or preventative health alone. A physical environment that promotes health-through access to healthy food, opportunities for physical activity, quality housing, transportation options, and safe schools-is an integral part of making our communities healthier. This research and accompanying Healthy Community Plans will serve as a way for the County to begin looking in-depth at the ways the built environment (our streets, parks, and neighborhoods) contribute or detract from the health of the community. Though the creation of a healthy general plan may be unattainable for the County in the short term, a focus on a small yet cohesive part of the county presents an opportunity to affect these changes.

Under the direction of the SLO County Health Agency and the Health Commission, we have written Healthy Community Plans for the unincorporated communities of Cayucos and Oceano, California. Both of these plans were greatly informed by their respective communities through input garnered through outreach, interviews, surveys and personal interactions with community members.

This project examines the relationship between the built environment and public health, and explores ways planning professionals are beginning to address health issues through infrastructure, land use, creative zoning, and planning strategies that promote health and active living in policy. The planning documents, modeled after health elements currently being included in general plans throughout California, have integrated the fields of planning and public health to provide Cayucos and Oceano an assessment of its residents' health, a description of the current built environment conditions that may be helping or hindering physical activity and access to nutritious food sources, as well as establish goals, policies and implementation strategies that will set a course of action toward healthier communities.

Key Words: City planning, public health, active living, built environment, community health 


\section{ACKNOWLEDGMENTS}

I would like to thank Kathleen Karle for guidance throughout my exploration of the field of public health, Chuck Stevenson for his planning wisdom and endless knowledge about the County of San Luis Obispo, and Kelly Main for her intellectual and emotional guidance throughout the process. To my project partner, Phillip, thank you for your hard work and dedication, which made co-authoring a breeze. I would also like to thank my family for their constant support, and my cheerleader, William Everett Crenshaw. 


\section{TABLE OF CONTENTS}

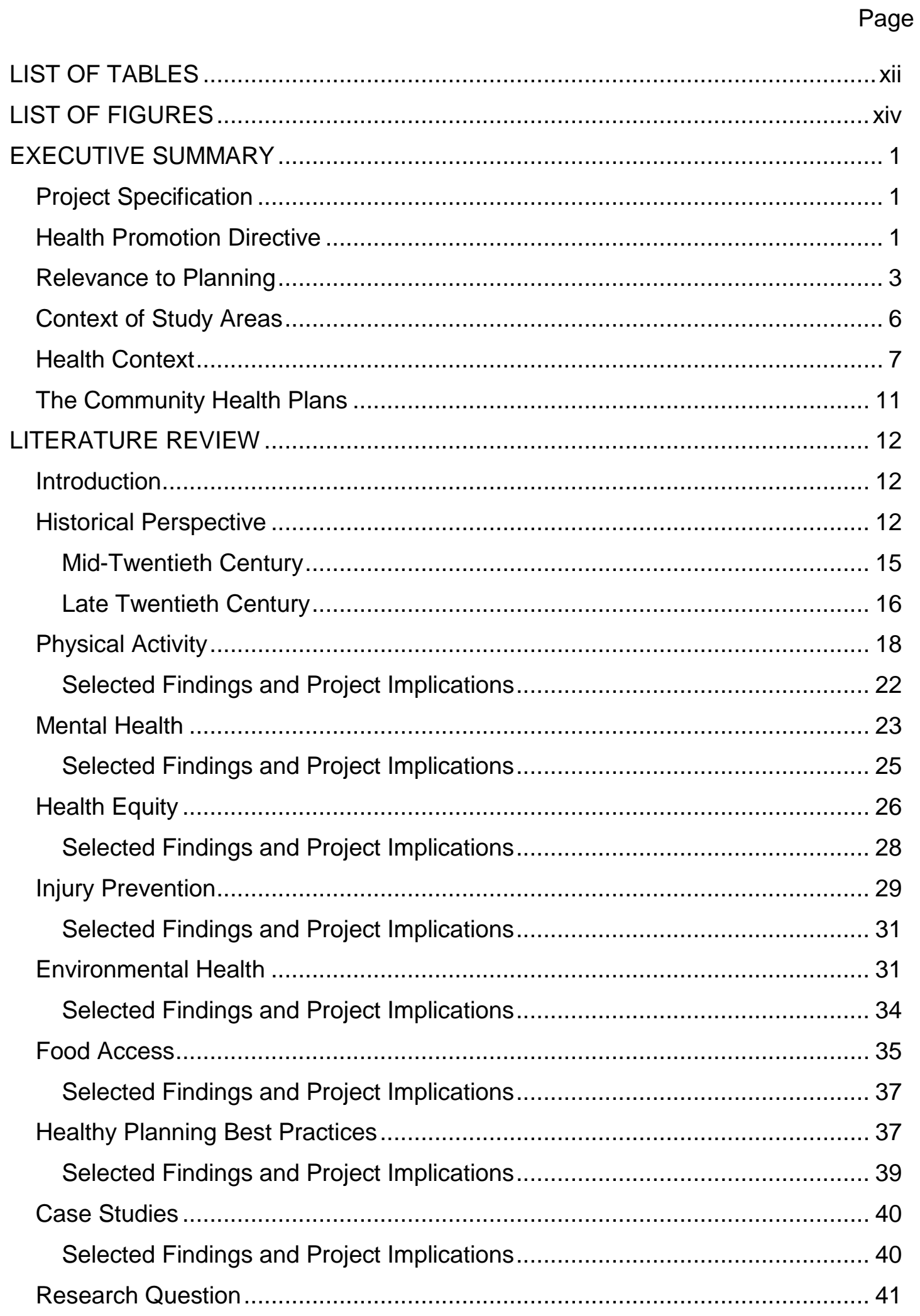




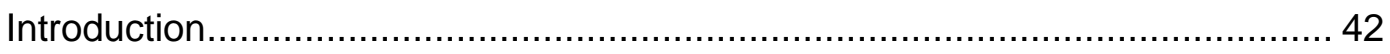

Phase I: Data Collection and Analysis ...................................................... 47

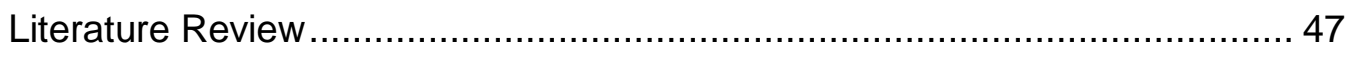

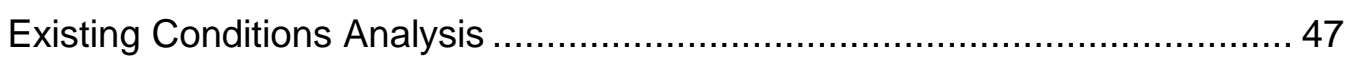

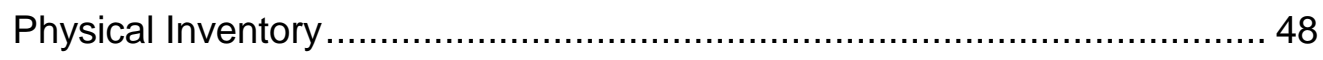

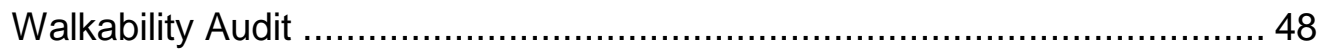

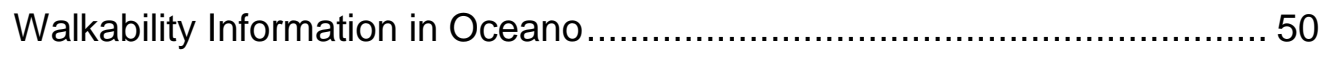

Food and Park Access Assessment......................................................... 51

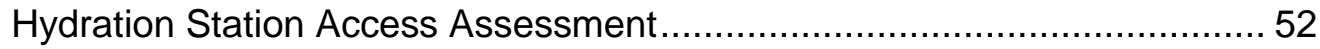

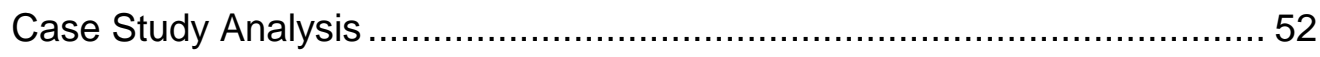

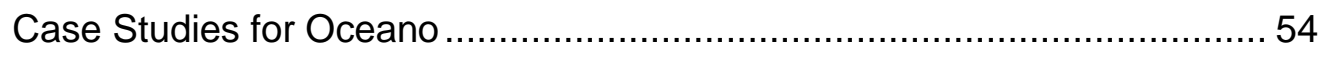

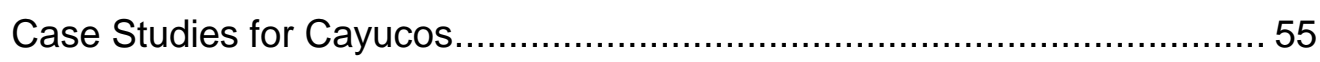

Phase II: Community Inventory and Outreach ………….............................. 56

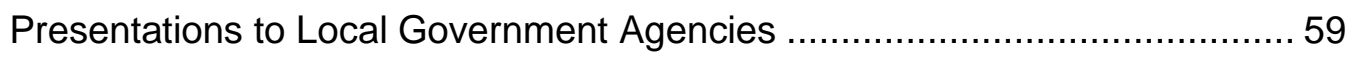

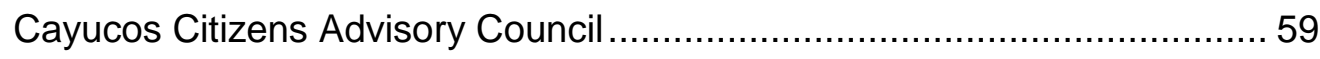

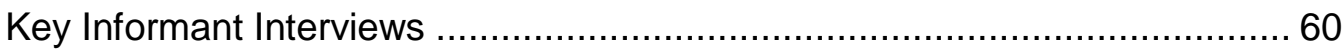

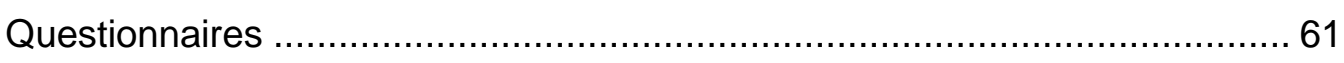

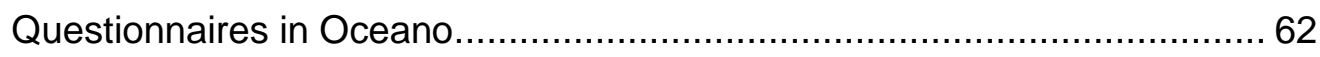

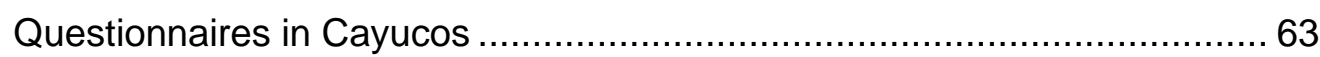

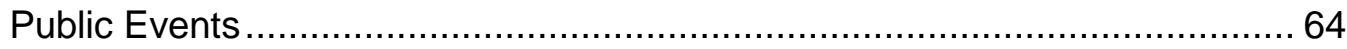

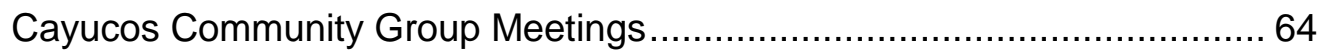

Cayucos Farmers Market: Public Space Improvements ............................... 65

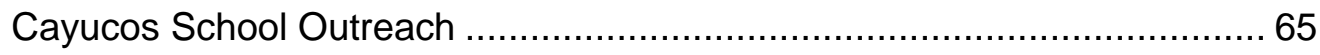

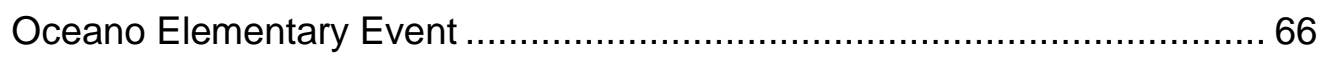

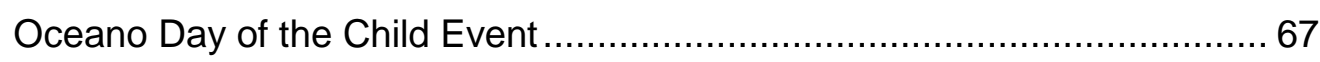

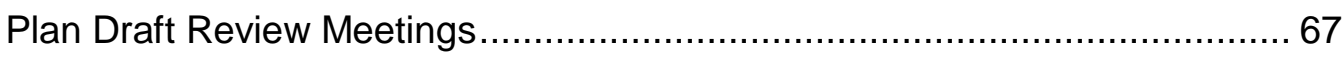

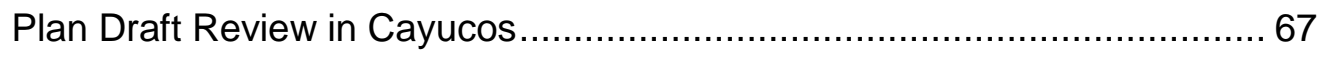

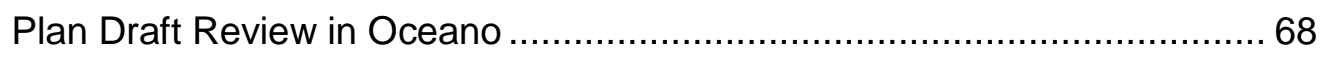

Presentation to San Luis Obispo County Health Commission .......................... 68

Phase III: Goals, Policies, and Implementation Recommendations.................... 68

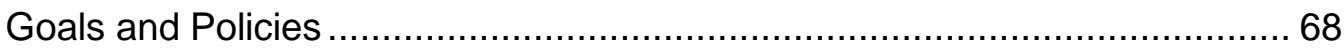

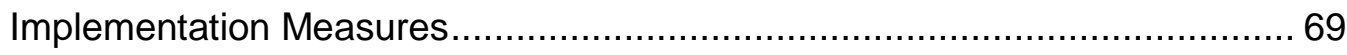

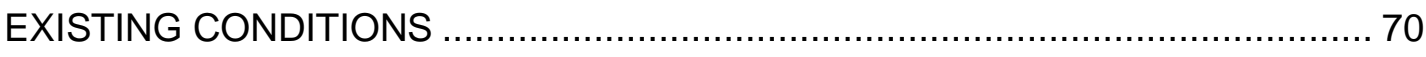

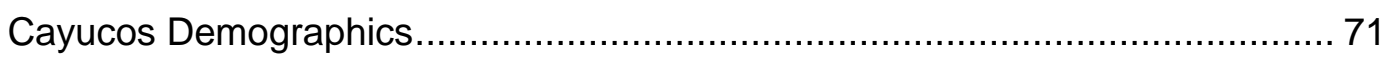




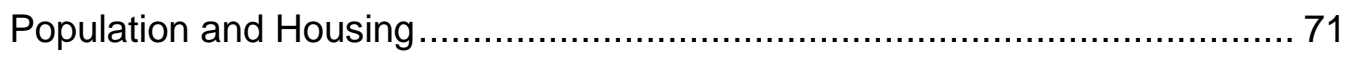

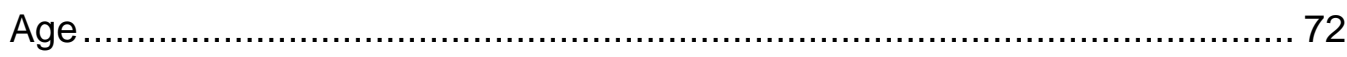

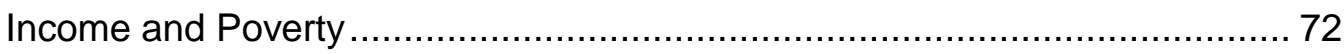

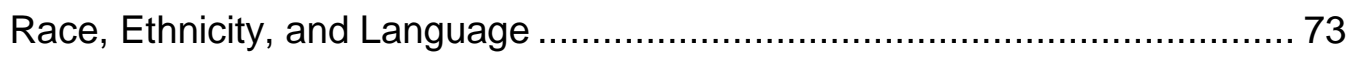

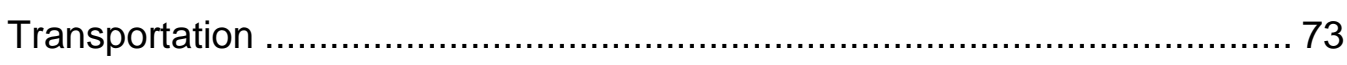

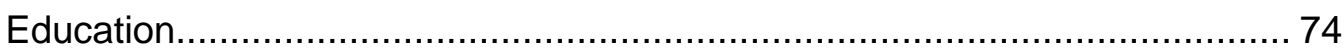

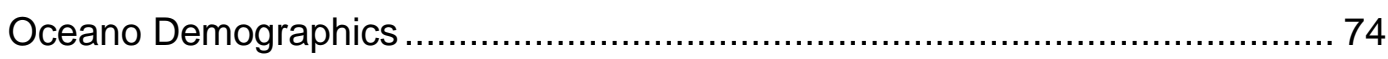

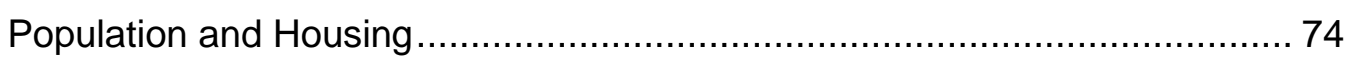

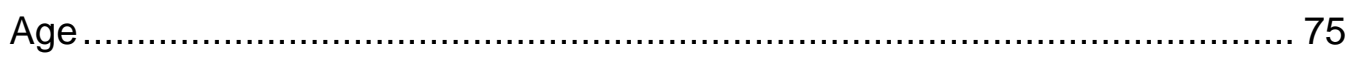

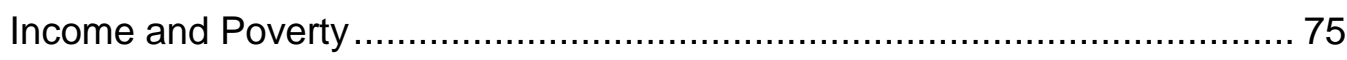

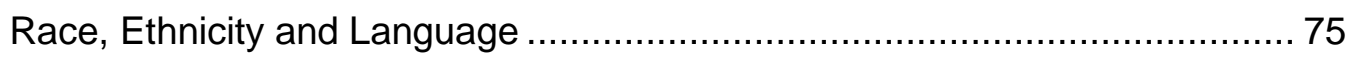

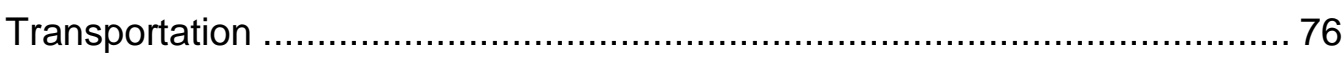

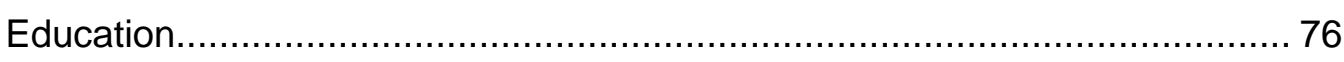

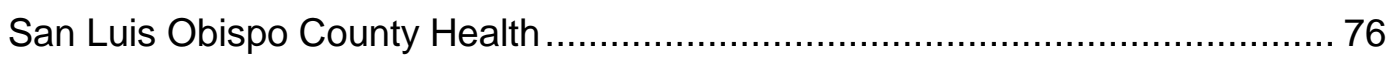

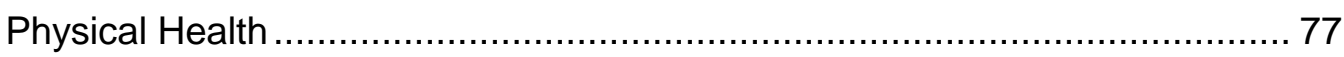

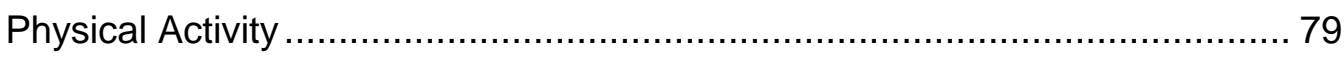

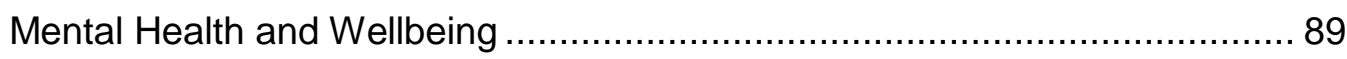

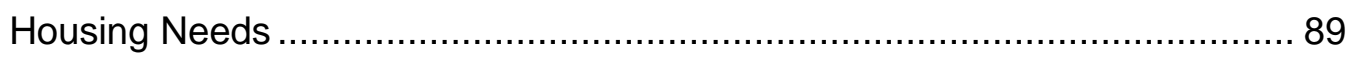

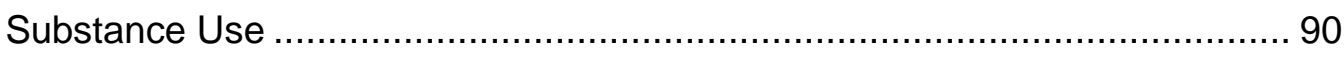

Substance Use among Children and Youth .............................................. 91

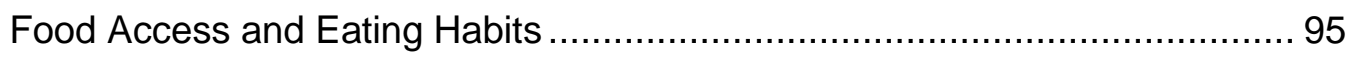

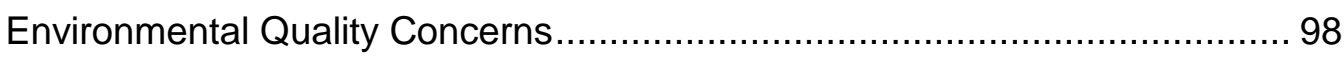

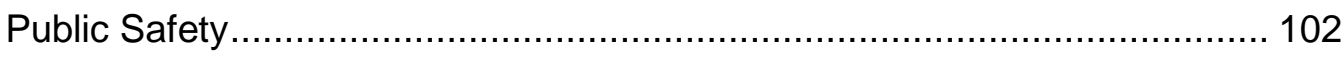

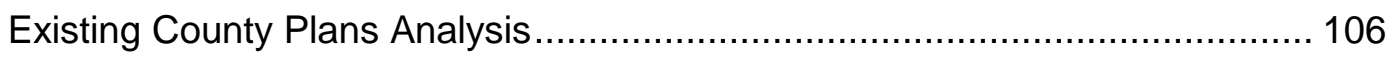

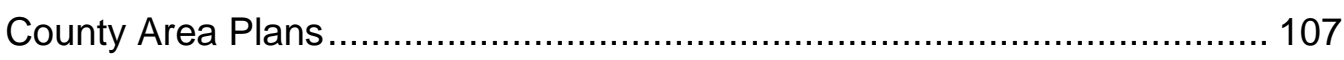

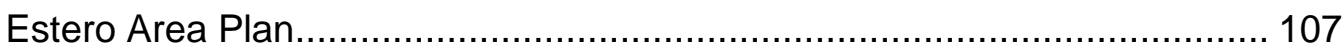

San Luis Bay Coastal Area Plan ........................................................... 109

Oceano Specific Plan.......................................................................... 110

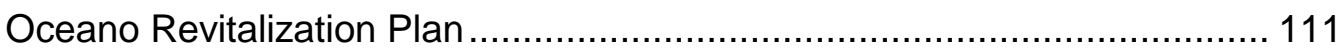

Local Coastal Program ..................................................................... 112

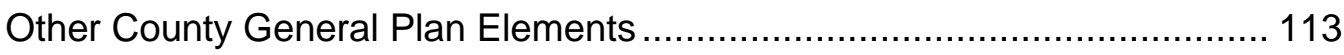

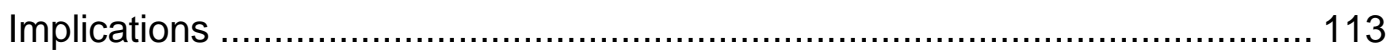

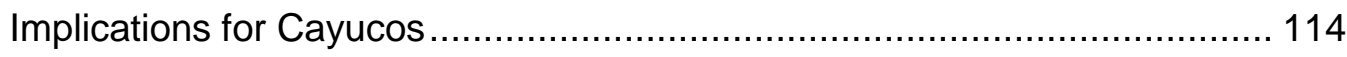

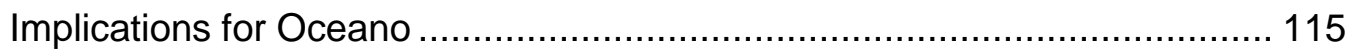

Implications and for Both Communities ................................................ 117 


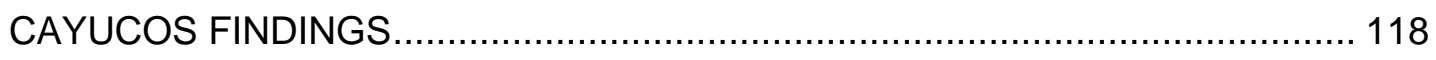

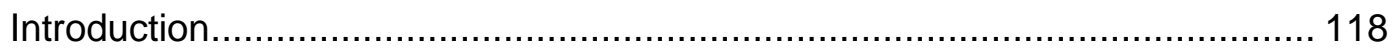

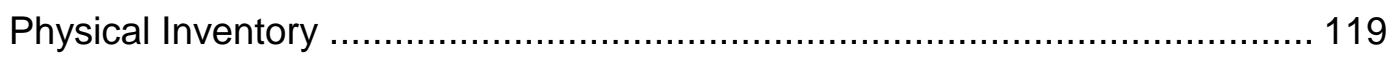

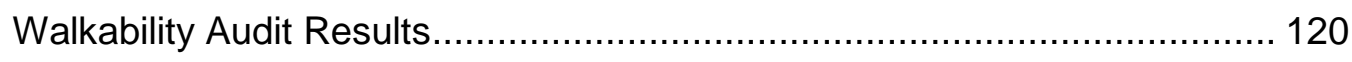

Ease and Comfort of Travel .......................................................... 123

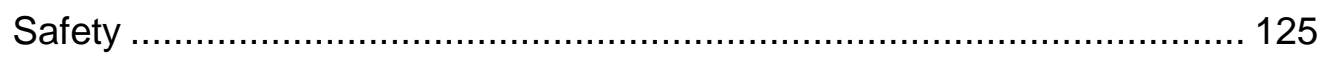

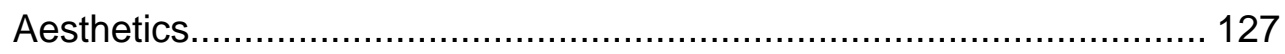

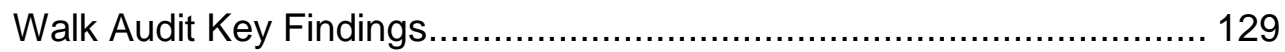

Food Access Assessment................................................................... 130

Food Access Assessment Key Findings .............................................. 134

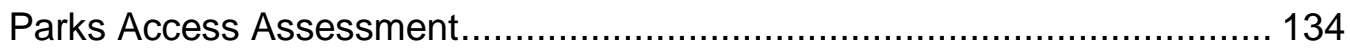

Parks Access Assessment Key Findings ............................................ 139

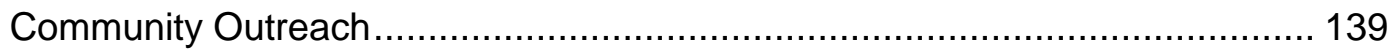

Presentations to Local Government Agencies ……………………......... 140

Local Government Agencies Key Findings ………….......................... 141

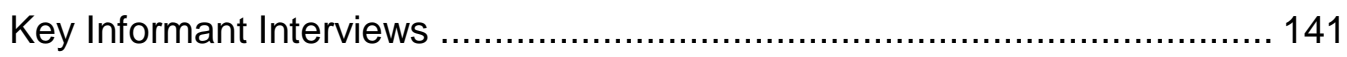

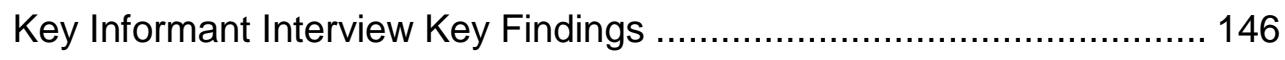

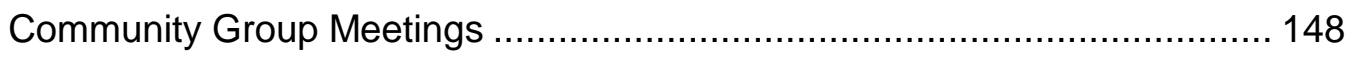

Community Group Meetings Key Findings........................................... 150

Cayucos Community Questionnaires .................................................... 151

Community Health Questionnaire Key Findings …………………..... 159

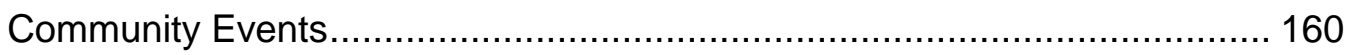

Cayucos Farmers Market: Public Space Improvements.......................... 160

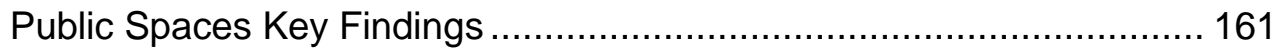

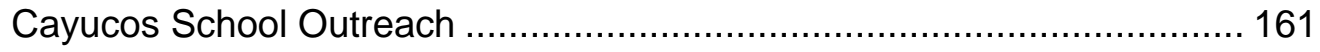

Cayucos School Key Findings ........................................................ 162

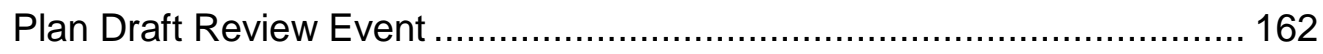

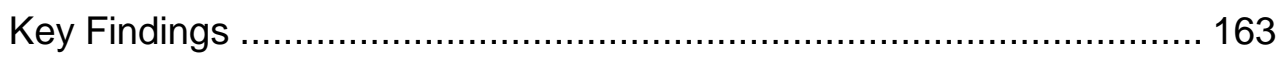

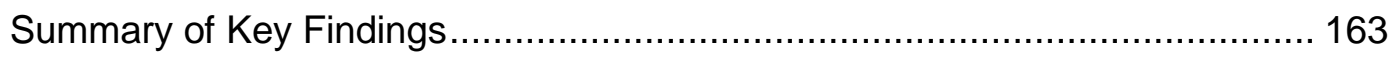

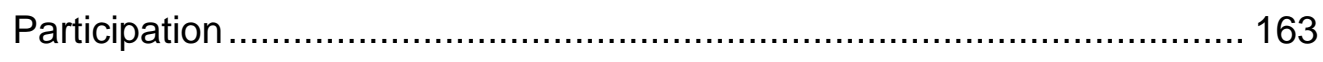

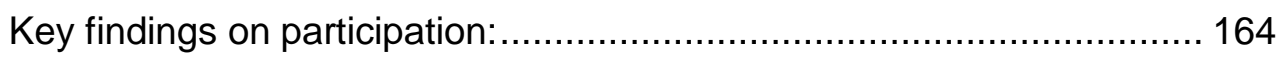

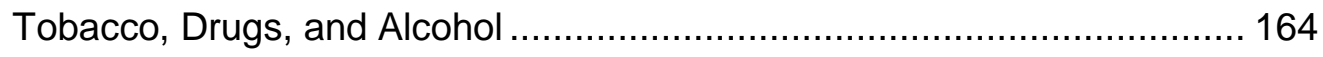

Key findings on tobacco, drugs, and alcohol........................................ 165

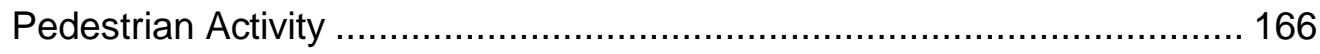


Key Findings on Pedestrian Activity................................................ 166

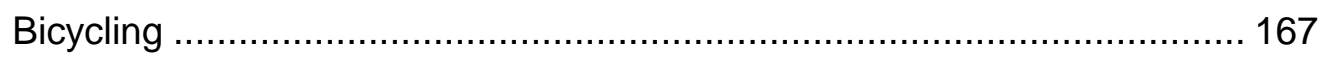

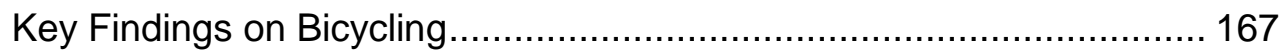

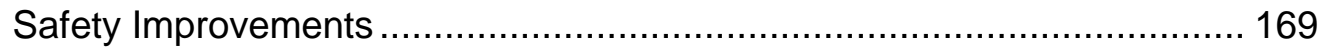

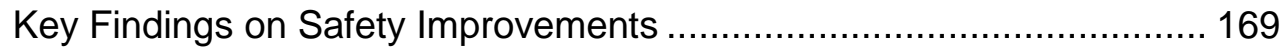

Healthy Design and Development.................................................... 170

Key Findings on Healthy Design and Development............................ 171

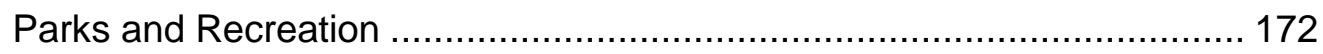

Key Findings on Parks and Recreation............................................... 172

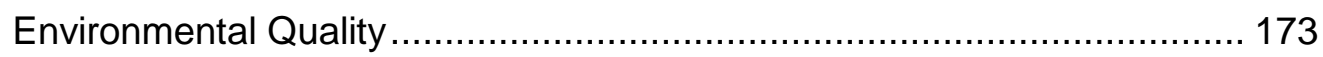

Key Findings on Environmental Quality ............................................... 174

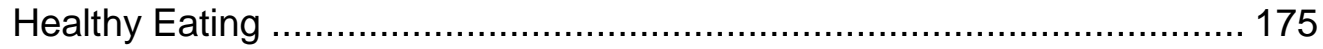

Key Findings on Healthy Eating..................................................... 176

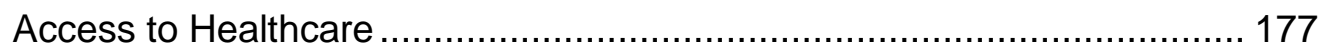

Key Findings on Health Care Access ……....................................... 177

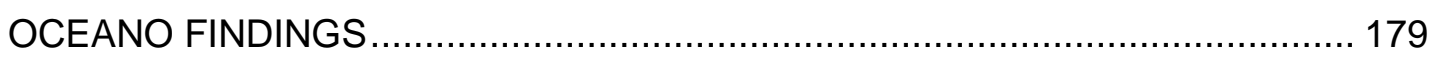

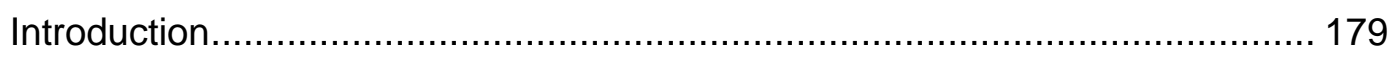

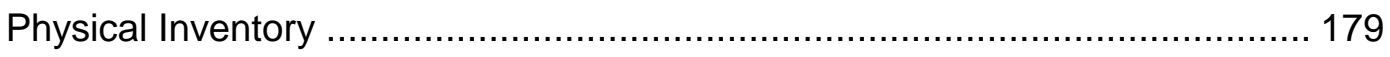

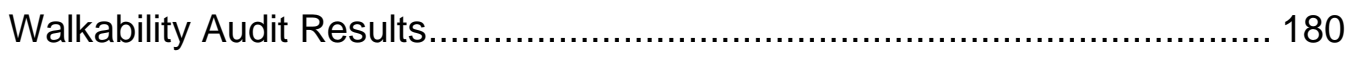

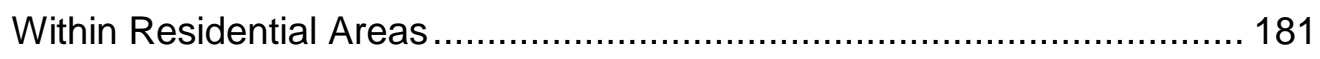

Within the Commercial Retail Core ................................................... 181

Pedestrian Connectivity to the Beach and County Park .......................... 182

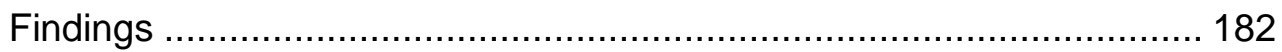

Parks and Hydration Station Access Assessment..................................... 183

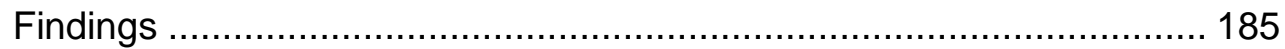

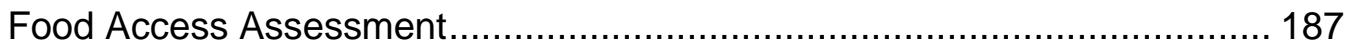

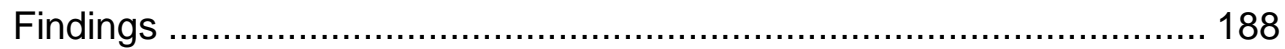

Community Outreach

Local Government Agency Presentations ............................................... 190

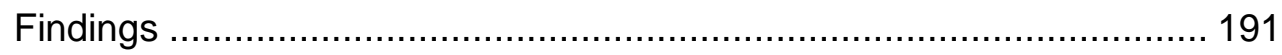

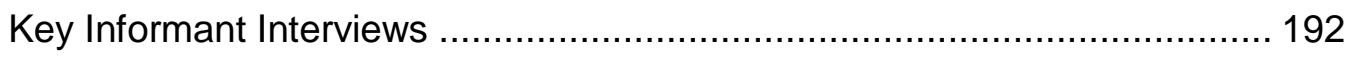

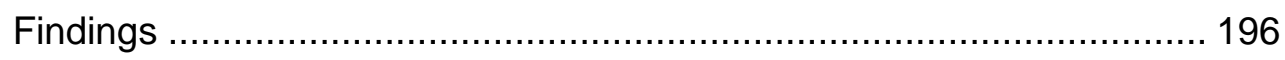

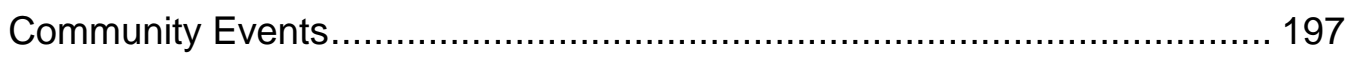




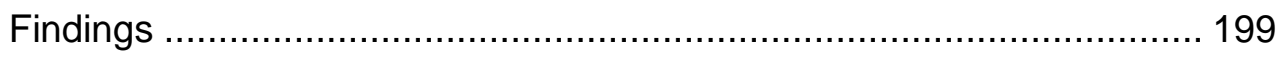

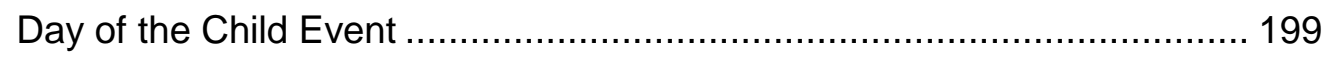

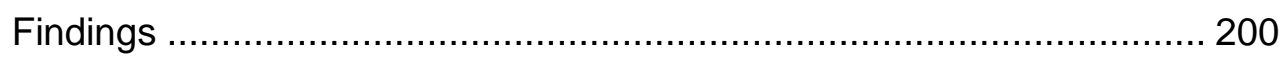

Oceano Community Questionnaire ....................................................... 200

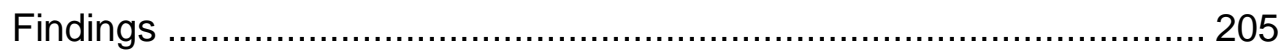

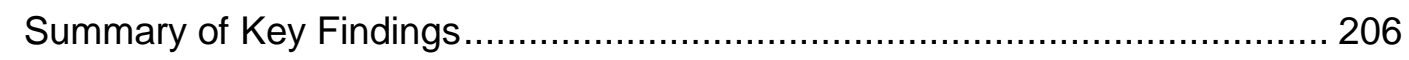

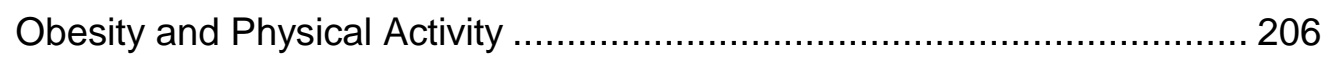

Healthy Food Access and Affordability ................................................ 207

Community Design, Land Use and the Built Environment ........................ 209

Perceptions of Safety and Security ....................................................... 210

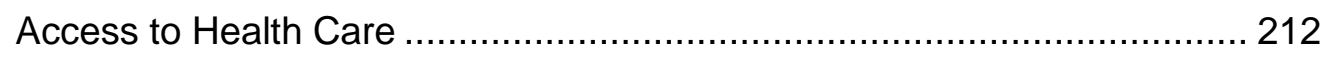

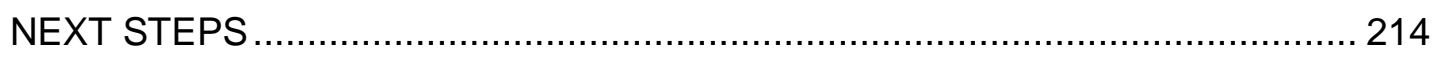

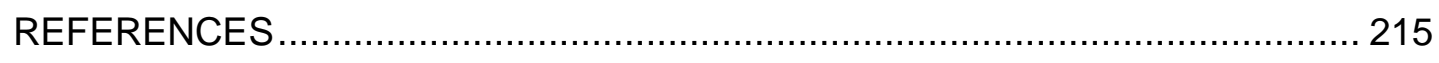

APPENDICES

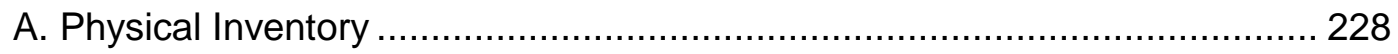

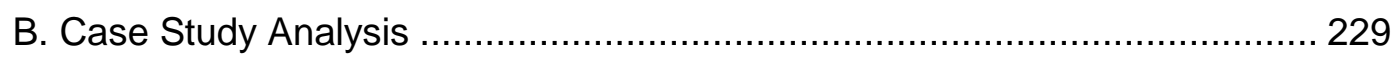

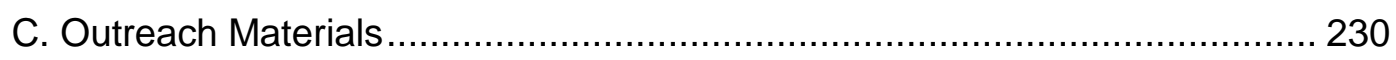

D. Cayucos Community Health Plan .......................................................... 250 


\section{LIST OF TABLES}

Table

Page

Table 1 Community Comparison Table.................................................. 8

Table 2 Leading Causes of Death in the U.S., 1900, 1950, and 2000............. 17

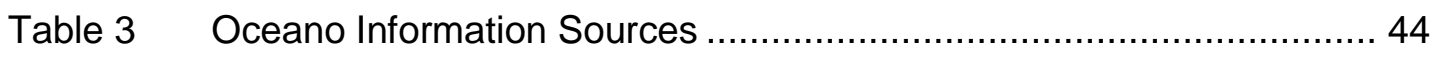

Table 4 Cayucos Information Sources ................................................. 45

Table 5 Cayucos Stakeholder Analysis............................................... 57

Table 6 Oceano Stakeholder Analysis .................................................. 58

Table 7 Leading Causes of Death by ZIP Code of Decedent's Residence....... 78

Table 8 "Which of the following would encourage your children to do more physical activity?" Response by region. ....................................... 80

Table 9 "How do/does your Elementary School child/children usually get to school?" Response by region.

Table 10 "How do/does your Middle or Junior High School child/children usually get to school?" Response by region.

Table 11 "How do/does your High School child/children usually get to school?" Response by region.

Table 12 Responses to "which of the following would encourage your children to walk or bike to school more frequently?"....

Table 13 Responses to "which of the following would encourage your children to walk or bike to school more frequently?" Response by region.

Table 14 Cayucos Elementary District, 2012-13 California Physical Fitness Report Summary of Results.

Table 15 Lucia Mar Unified District, 2012-13 California Physical Fitness Report Summary of Results. 86

Table 16 Oceano Elementary, 2012-13 California Physical Fitness Report Summary of Results

Table 17 "How concerned are you about drug, tobacco, and alcohol abuse in your community?" Response by region. 90

Table 18 "Considering all types of alcoholic beverages, in the past 30 days, about how many times did you have ( 4 if female; 5 if male) or more drinks on an occasion?" Response by region. 
Table 19 Ever Used Cigarettes or Smokeless Tobacco in Lifetime. 92

Table 20 "Do you smoke cigarettes every day, some days, or not at all?" Response by region. 93

Table 21 Selected Alcohol, Tobacco, and Other Drug Use, With Comparisons to 2007 State CSS .... 94

Table 22 Selected Alcohol, Tobacco, and Other Drug Use, With Comparisons to 2007 State CSS and 2007 National YRBS .....

Table 23 "Yes" response for respondent's self, when asked "On average, do you eat 5 or more servings of fruits and vegetables every day?" By region. 96

Table 24 "Yes" response for respondent's children. 96

Table 25 "Yes" response for respondent's teenagers. 96

Table 26 Response to "Yesterday, how many glasses or cans of soda, such as Coke, or other sweetened drinks, such as fruit punch or sport drinks, did you drink?".

Table 27 Response to "Yesterday, how many glasses or cans of soda, such as Coke, or other sweetened drinks, such as fruit punch or sport drinks, did your child drink?" (Child 12 to 17).

Table 28 "How concerned are you about the following issues in your community?" Response by region.

Table 29 Response to "What new recreation opportunities would you like to see in your community?".

Table 30 Comparison of Increases in Population, number of vehicles, and Vehicle Miles Traveled (VMT), in San Luis Obispo County. 100

Table 31 Beach Quality, percentage of Days Receiving "C" or Better. 102

Table 32 "How safe would you say you feel in your neighborhood?" Response by region. 102

Table 33 Cayucos Selected School Safety Related Indicators with Comparisons to 2007 State CCS .104

Table 34 Oceano Selected School Safety Related Indicators with Comparisons to 2007 State CCS.

Table 35 Response to "In your opinion, what do you think is the one most important issue facing San Luis Obispo County in the next few years?" 106

Table 36 Oceano Survey Results 198 


\section{LIST OF FIGURES}

Figure

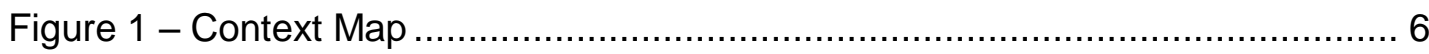

Figure 2 - The Health Benefits of Physical Activity ......................................... 20

Figure 3 - Overall Walkability, Cayucos ..................................................... 122

Figure 4 - Ease of Travel, Cayucos.........................................................124

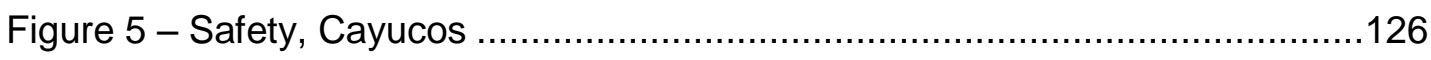

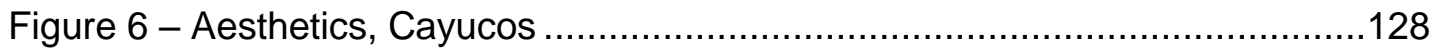

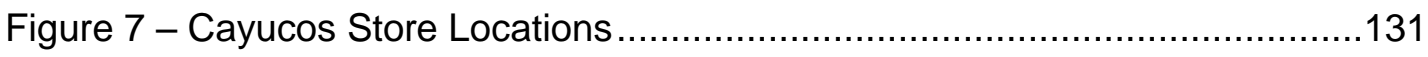

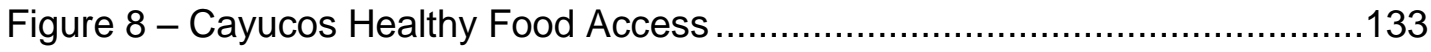

Figure 9 - Cayucos Public Park Access ..................................................... 136

Figure 10 - Cayucos Park and Beach Access ................................................138

Figure 11 - Question 1: Contributors to Quality of Life, Open-Ended Response,

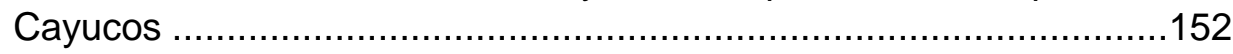

Figure 12 - Question 2: Factors that Detract From Health, Open-Ended Response, Cayucos........................................................... 153

Figure 13 - Question 3: Factors for Improving Quality of Life, Cayucos................154

Figure 14 - Question 4: Greatest Impacts on Community Health, Cayucos..........155

Figure 15 - Question 5: Self-Identified Personal Health Rating, Cayucos.............156

Figure 16 -Question 6, Changes that Could Contribute to Health, Open-Ended Response, Cayucos..........................................................157

Figure 17 - Question 7: Features that Could Contribute to Health, Cayucos ........158

Figure 18 - Oceano Existing Sidewalk Inventory Map ....................................180

Figure 19 - Existing Park and Outdoor Recreation Space Proximity Map..............186

Figure 20 - Existing Park and Outdoor Recreation Space Proximity Map with Proposed Space ................................................................187

Figure 21 - Oceano Healthy Foods Vendor Proximity Map ..............................189

Figure 22 - Unhealthy Food Vendor Proximity Map.......................................190

Figure 23 - Survey Question: Contributors to quality of life in Oceano .................201 
Figure 24 - Survey Question: Factors that detract from health and wellness in

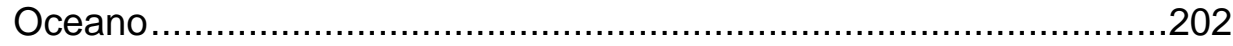

Figure 25 - Survey Question: Perceptions of Personal Health ............................203

Figure 26 - Features that would Improve Personal Health ..................................204

Figure 27 - Prioritized Community Features Most Important to Oceano ................205 


\section{EXECUTIVE SUMMARY}

\section{Project Specification}

The final product of the two masters projects will be the creation of individual Health Plans for the communities of Cayucos and Oceano, California. The Health Plans will be attached to a single background report covering literature on public health and the built environment, findings on existing conditions in each town (from both primary (field analysis) and secondary sources (public health data)), a case study (health element) analysis, and the results of public outreach used to inform the Health Plans for each community.

The Health Plans will provide goals, policies, and implementation measures (recommended courses of action) meant to affect change at the community level. The structure, content, rationale and layout are designed to serve as models for other cities/communities across the County of San Luis Obispo should similar endeavors be undertaken in the future. The documents will be provided to the projects' client, the Health Promotion Office of the County of San Luis Obispo Public Health Department, and will serve as a well-developed starting point and potential catalyst for a larger-scaled application for the county. These plans will also be presented to the County Health Commission, members of HEAL-SLO, and its Healthy Communities Workgroup, and local advisory bodies of each respective town.

\section{Health Promotion Directive}

One of the primary goals of both the San Luis Obispo County Public Health Department and the Health Commission is to enhance the quality of life for all people, specifically making efforts to identify and improve the social and root determinants of health in 
communities throughout the County. As public health advocates, they have acknowledged the need to address the many chronic diseases and preventable health conditions which stem from unhealthy diets and sedentary lifestyles. They have recognized there is a multitude of contributing factors (social determinants of health) that can impact an individual's health status, including the built environment, access to healthy food sources and opportunities for physical activity and recreation, all of which are aspects of community design that fall under the purview of the planning profession.

Over the course of the past two decades, a reintegration of public health and city planning professions has occurred. Health departments have realized that without changes to particular physical determinants of health, behavioral changes cannot be influenced and risk factors contributing to chronic disease can neither be addressed or controlled (California Conference of Local Health Officers [CCLHO] \& County Health Executives Associates of California [CHEAC], 2013). Being such, health departments have begun collaborating with planners in an effort to bring forth changes to community design and land use developments that impact the built environment and in turn, influence public health.

The built environment affects health through providing opportunities for physical activity, social interaction, and access to healthy food, and minimizing the risk for injury. Planning plays a role in all of these aspects of health, and communities seeking to improve the capacity for health can use the existing framework of the general plan. With these assertions, many jurisdictions in California have created Health Elements to include as optional elements into their existing general plans. The Cayucos and Oceano Community Health Plans will attempt to address health in planning as applicable at the small community level, while incorporating characteristics of a health element. 


\section{Relevance to Planning}

City planning's origin can be traced to the late nineteenth century, birthed out of public health concerns that were byproducts of the rampant industrialization, urbanization and expansion of that era. Over the course of the next few decades, the two fields continued to work jointly to tackle the health issues of that day. However, by the first quarter of the twentieth century, the two fields began to diverge. "Public health took on a mainly biomedical focus on individual genetics, biology and behavior and how clinicians could affect those, and on a narrowly biological approach to epidemiology and evidence. Meanwhile the planning of built environments was hijacked by the car” (Lerner, 2010). By the middle of the last century, the two fields became their own specialized professions; each working independently of one another and with its own respective interests.

Today, a growing number of planning professionals and researchers are working to reintegrate public health and planning and contextualize land use decisions as a community health issue. Research has shown what has long been perceived as common sense: there is a strong correlation between the built environment and public health. "The designated use, layout, and design of a community's physical structures including its housing, businesses, transportation systems, and recreational resources affect patterns of living (behaviors) that, in turn, influence health" (Aboelata, 2004). The decisions we make regarding aspects of planning such as land use, vehicle circulation, zoning and street design are all elements that affect individual choices in diet and physical activity. The public health and community planning disciplines intersect in the interest of improving safety, nutrition, environmental quality, physical exercise, and the spread of disease. 
Public health professionals are increasingly approaching health using a social determinant model that considers multiple factors impacting a person's life, including the natural environment, the built environment, living conditions, and the conditions of the community. This way of conducting research recognizes that approaches using the medical model, which emphasize diagnosis of an underlying disease or condition, have achieved limited effectiveness (Morris, 2006, p. 2). Collaboration with public health experts, integrating processes to address public health, and applying community design methods to ensure that the public has a say in the outcomes of planning documents are aspects crucial to the success of these planning efforts.

In addition to barriers to physical activity, planners are discussing food systems because of the way that inadequacies in the food system impact communities, especially in terms of public health. Planners influence the food system issue because food production, transport, and distribution are contingent on land use regulation. Agricultural specialization, technologies that improve shelf-life, and cheap transport has extended the distances that food travels, producing environmental impacts and equitable access concerns. The food system, good or bad, is impactful to the well-being of communities of all socioeconomic kinds, though the poor are generally more vulnerable to problems of food access (Corburn, 2009). Restrictive planning laws and practices have limited the location and construction of health-promoting built environments across metropolitan regions. In a study conducted throughout 1997 and 1998, 22 planning agencies were surveyed on the integration of food systems planning in their activities and comprehensive plans. Their conclusions showed that addressing these problems was usually done in a reactive way, rather than being comprehensive and forward-thinking (Pothukuchi and Kaufman, 2000, pp. 115). Planners are in a unique position to approach 
food access and distribution in a comprehensive, systematic, and inter-disciplinary way (Hodgson, 2009).

Existing methods in planning have the potential to be of use for health-focused planning efforts. Many planning processes and actions do not consider public health issues outright because the decision making processes do not directly address them (Corburn, 2009, pp. 2). For example, the California Environmental Quality Act (CEQA) requires the analysis of impacts to people resulting from changes to the natural environment, but in practice this is usually limited to physical and chemical hazards. It does not include analysis of behaviors that result from the project impacts (Morris, 2006, p. 74). This means that some impacts to public health are not required to be considered through this process of analysis, and because of this, they are not mitigated through development requirements. Requiring adequate analysis of issues of public health and working concerns and issues into the process for creating public policy initiatives could help to ameliorate these shortcomings. On a project specific basis, Health Impact Assessments (HIA) are used as "a means of assessing the health impacts of policies, plans and projects in diverse economic sectors using quantitative, qualitative and participatory techniques" (WHO, 2012). These contain methods for establishing a health baseline, and assessing activities that will affect the baseline. Other methods are used to measure community health as well, and these methods may be integrated into long-term planning processes.

The reintegration of health into planning is being accomplished in California through the Health in All Policies (HiAP) initiative, climate action planning, and health elements in general plans. Each of these policy-affecting documents can help to address the environmental determinants of health, and require collaborative work between planners and public health workers. The goal of this project is to bring these concepts and 
methods to the County of San Luis Obispo, starting at with a community-level health plan that functions as a health element.

\section{Context of Study Areas}

The County of San Luis Obispo includes seven incorporated cities, along with 22 unincorporated census-designated places of which Cayucos and Oceano are categorized. These unincorporated areas are governed by the County Board of Supervisors. As such, neither city possesses a general plan which outlines self-guiding policies and detailed strategies for growth and development.

\section{Figure 1 - Context Map}

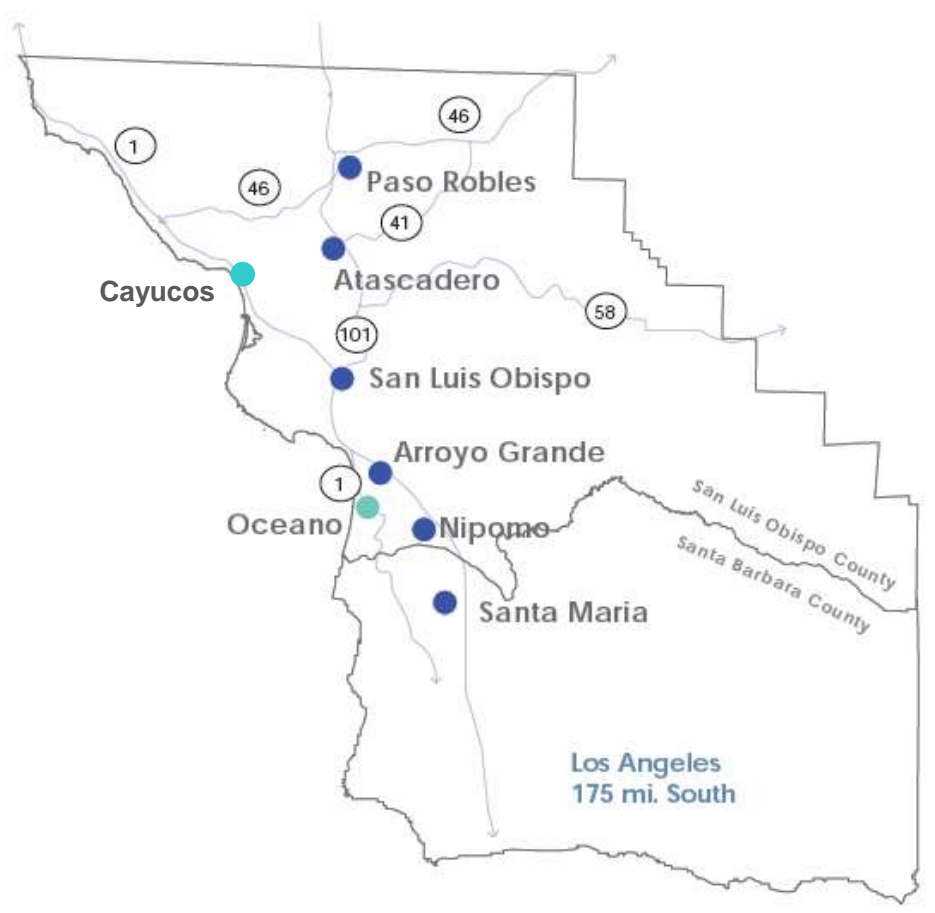

Cayucos is a town of 2,592 people, located in the north coast region. The Second District boundaries extend from the Monterey County line in the north to Los Osos and parts of San Luis Obispo, and it includes the unincorporated communities of San 
Simeon, Harmony, Los Osos, Cayucos, and Cambria (www.slocounty.ca.gov). The Cayucos Citizens Advisory Council advises the District Two supervisor on matters related to planning and development. The community of Cayucos is part of the county Coastal Zone, and more specifically the Estero Planning Area.

As reported in the 2010 census, 87 percent of Cayucos residents identify themselves white, which is approximately 25 percent higher than the rate for San Luis Obispo County. The median age is 57.2 years old, well above the County's (37.4) and state's (45.6) figures. Cayucos' median household income is $\$ 62,961$.

Oceano is a town of 7,286 people, located in the southwest portion of the County. Along with the neighboring communities of Arroyo Grande, Grover Beach, Pismo Beach and Nipomo, it belongs to a larger regional metropolitan area known as the "Five Cities." The town is situated 16 miles south of the City of San Luis Obispo and 18 miles north of the City of Santa Maria in Santa Barbara County. Oceano is part of the South County Coastal Planning Area. Planning and development in Oceano is primarily governed by the Oceano Advisory Council and the Community Service District.

Oceano has a large population (47.8 percent) that identify themselves as Latino or Hispanic. With a median age of just 35.4 years old (45.6 state median age), as well as a median household income of $\$ 41,865$ [2012] ( $\$ 34,938$ for Hispanic or Latino), Oceano can largely be considered a relatively young and low-income community.

\section{Health Context}

Recent statistical data has indicated nearly 42 percent of adults in California are not meeting the recommended guidelines of 150 minutes or more of aerobic physical activity per week (Centers for Disease Control and Prevention, n.d.). Further, 35.3 percent of 
Californians were classified as overweight (BMI 25.0 - 29.9), while another 25 percent were classified as obese $(\mathrm{BMI}>30.0)$ in 2012. These numbers are alarming indicators which place these individuals at high risk for many preventative diseases and health conditions which can lead to premature death.

The places we live and work; the distances we travel; the modes of transportation by which we take; the options we are provided for the foods we eat, as well as the places we relax and be physically active are all altered by the built environment, and ultimately affect the levels of health and wellness we can potentially achieve.

\section{Table 1 Community Comparison Table}

\begin{tabular}{lcccccc}
\hline Pop. & $\begin{array}{c}\text { Median } \\
\text { Household } \\
\text { Income }\end{array}$ & $\begin{array}{c}\text { Median } \\
\text { Age }\end{array}$ & $\begin{array}{c}\text { Poverty } \\
\text { Levels }\end{array}$ & $\begin{array}{c}\text { Education } \\
\text { Attainment } \\
(\geq \text { High } \\
\text { School } \\
\text { Diploma) }\end{array}$ & $\begin{array}{c}\text { Residency } \\
\text { Status } \\
\text { (U.S. } \\
\text { Citizen) }\end{array}$ \\
\hline Oceano & 7,286 & $\begin{array}{c}\$ 41,865 \\
(\$ 34,938 \text { for } \\
\text { Hispanic } \\
\text { Casseholds) } \\
\$ 62,961\end{array}$ & 35.4 & $16.50 \%$ & $\begin{array}{c}73.3 \% \\
(14.7 \%<9 \text { th } \\
\text { grade) }\end{array}$ & $23.20 \%$ \\
\hline
\end{tabular}

Source: 2010 US Census Data.

While Cayucos and Oceano share many similar geographical similarities being coastal towns, the socio-economic profiles are vastly different for each community. The environments, circumstances and context in which these communities exist present different barriers and opportunities. For example, both areas are located in close proximity to the ocean, yet residents in Oceano don't have nearly the same ease of access to the beach, nor the facilities or amenities on it that Cayucos enjoys. The older age demographic in Cayucos presents a different safety concerns in terms of wayfinding signage. The older age demographic in Cayucos presents a different safety concerns in terms of injury prevention and access. While Oceano's relatively young 
median age (35.4 years old) likely indicates a prevalence of young families and parents that would receptive to issues that impact their children. The differences in education attainment levels and residency status may also give indication to potential comprehension issues due to a lack of familiarity with the project subject matter because of different cultural norms and values. These factors will be considered in outreach strategies and in the development of the Health Plans for each respective community.

\section{Background Report}

The Background Report informed the projects, helping to bring into context to the findings and information collected during the process of developing each Health Plan, and providing a basis for the goals, policies and action programs created for each respective community. The Background Report comprises several sections, including the Literature Review, Methodology, Existing Conditions and Findings for each community, and Next Steps.

The Literature Review establishes a knowledge base by examining the current academic literature, professional studies, reports, and best practices from the field. This section reviews the available research and reports on the correlation between health and the built environment, and relates these findings to the local communities. The section begins with an introduction and brief historical perspective on the relationship between city planning and public health. It then explores six separate topics that are relevant to healthy community building: physical activity, mental health, health equity, injury prevention, environmental health, and food access. Takeaway findings are provided at the end of each reviewed topic, relating the information back to specifically known issues within the communities, or raising awareness of certain factors. 
The Methodology section describes the rational basis behind the chosen methodological approaches used to gather the required information needed to adequately inform the projects. The research methods were decided based on initial project questions (see Table 3 and Table 4 on pages 44 and 45) and identification of sources of information that would help answer those questions. The section is then divided into three phases: Phase I: Data Collection and Analysis; Phase II: Community Inventory and Outreach; and Phase III: Goals, Policies, and Action Programs. Each of these phases have corresponding subsections which provide various informational aspects that build a wellinformed understanding of the current context, circumstances and issues each community is facing, which are the basis for the strategies outlined at the end of each community's Health Plan.

The Existing Conditions section provided quantitative information from various sources for Cayucos and Oceano's current demographic makeup, socioeconomic conditions and infrastructure, as well as other conditions of interest related to the project. This section describes the health conditions in Cayucos and Oceano through data and findings outlined in the 2013 ACTION for Healthy Communities Report, released in 2014 by the Community Foundation, public school survey results, public health data, and information from applicable existing plans. This section provides a basis for conducting further research.

The Findings sections describe the multifaceted studies conducted in Cayucos and Oceano to better understand the characteristics of the community, both in terms of the built environment and local knowledge. A physical inventory was conducted to achieve an understanding of the existing built environment in Cayucos, and ample community outreach provided local knowledge to augment this research. The Key Findings section 
combines the most important, relevant, and frequently-encountered findings to present a summary that is useful for the creation of the draft plans.

The Next Steps section briefly describes steps that could follow completion of the Background Report and the plans, focusing on implementation of ideas.

\section{The Community Health Plans}

The Community Health Plans for Cayucos and Oceano are structured similarly for formatting consistency, but feature variances in content in some instances, as well as certain goals and related strategies that were developed uniquely to address the identified needs and community-voiced concerns of each town. Each Health Plan contains an introduction explaining the health promotion directive and purpose of the projects; a summary of goals tailored to that community; historical background on the relationship between health and the built environment; a review of how public health has been previously addressed in existing (local and regional) planning policy documents; a summary of outreach efforts conducted in each town; a health and wellness context section that describes city planning and public health concepts related to the built environment and corresponding relevance to each town; and finally, a series of goals, policies and action programs that will help guide Cayucos and Oceano on paths to becoming healthier communities. The Cayucos Community Health Plan is attached as an appendix. 


\section{LITERATURE REVIEW}

\section{Introduction}

A literature review was conducted in an effort to build a thorough knowledge base of contemporary research and understanding on the relationship between the built environment and public health. Current academic literature, news articles, professional guides, reports, best practices and historical perspectives from the fields of planning and public health were surveyed. The literature review was broken down into six separate subsections that are foundational to understanding and developing a planning document meant to provide guidance in establishing healthier communities: physical activity, mental health, healthy equity, injury prevention, environmental health, and food access. A description of selected findings and its corresponding implications for the project will be discussed at the end of each of subsection. To provide added context regarding the general subject, a historical overview of the relationship between city planning and public health has been provided first.

\section{Historical Perspective}

The bond between city planning and public health can trace its roots to nearly 150 years ago. "The emergence of urban planning as a profession and academic discipline had its basis in nineteenth century public health initiatives, including tenement housing reforms, the construction of urban water supply and sewerage systems, and the design of parks and playgrounds" (Corburn, 2007, p. 688). Due to the burgeoning industrialization and urbanization of that time, major American cities of that day were the antithesis of sanitary and healthy, overrun with human and animal waste, trash and general squalor, major cities were a breeding ground for infectious diseases such as yellow fever, cholera, 
typhoid and tuberculosis. Further, toxic air pollution and run-off from nearby industrial sites, ventilation and lack of clean water sources made living in a city a health risk. "By the end of the nineteenth century, modern American urban planning emerged as a field that used physical interventions to respond to urban public health crisis" (Corburn, 2006, p. 27).

The effort to improve sanitation in U.S. cities was led by Frederick Law Olmstead, the designer of Central Park in New York City and the head of the US Sanitary Commission during the civil war. He believed that the way to improve public health was to abandon the "old-fashioned compact way of building towns and the gradual adoption of a custom of laying them out with much larger spaces open to the sun-light and fresh air." This vision persisted throughout the 20th century, and contributed to the idea that the lowdensity city was ideal for addressing matters of public health (Frank, 2003, pp. 14-16). In this way, public health concerns were a major part of public planning from the birth of the profession.

The first quarter of twentieth century saw many of the basic primitive health issues resolved. Advancements in research and technology led to the understanding of diseases being biological in nature instead of environmental (Drummond, 2013). The two disciplines began to drift into their own separate fields of practice. Public health became the domain of science and medicine focused on controlling and identifying the causes of infectious diseases. City planning became primarily concerned with urban form, land use, growth and zoning.

Improvements in public health corresponded with scientific and technological advancements. Attempting to resolve health issues on a broad scale by physical removal and separation from perceived harmful agents through the built environment 
was no longer favored. Rather, the advent of germ theory, the belief that microorganisms caused infectious diseases, was thought to be the answer to most health problems. As a result, "public health shifted toward specific interventions, such as immunizations and the chlorination of drinking water, to kill disease-carrying microbes" (Corburn, 2007, p. 692). This new scientific understanding proved groundbreaking in how we dealt with diseases such as cholera, typhoid, diphtheria and tuberculosis, and it gave health professionals such as chemists, physicians and biologists, serious clout with the public.

The same period of the twentieth century gave rise to professional city planning and what could be termed as the era of "the City Scientific" (Corburn, 2006, p. 29). Planning was seen as a rationally based technical craft that could bring comprehensive improvement to urban areas via the built environment, whereas planning done in the last half of the nineteenth century was viewed more as reactionary, fragmented in application and arising out of necessity, rather than prescriptive in practice. Early urban planning and design pioneers such as Daniel Burnham, Edward Bennett, Ebenezer Howard (Garden Cities) and Frederick Law Olmstead, helped champion the move to creating beautified, grandiose and orderly cities with the hope that it would promote civility and morality among the citizenry. However, focus on the aesthetic aspects of the city left concerns for public health issues by the wayside. This did not go unnoticed. Benjamin Marsh, then leader of the Committee on the Congestion of Population stated "the planning profession ought to be judged on whether interventions improve the health of the least-well-off city dwellers, not on designing aesthetically pleasing and efficient cities" (Corburn, 2006, p. 28). Marsh stated poignantly in his 1909 book, An Introduction to City Planning: Democracy's Challenge to the American City, "no city is more healthy than the highest death rate in any ward or block and [...] no city is more beautiful than its most 
unsightly tenement. The back yard of a city and not its front lawn is the real criterion for its standards and its efficiency" (Corburn, 2007, p. 694). Nevertheless, despite pushback from some, rationality, science and technical expertise became the driving ideology moving forward.

\section{MID-TWENTIETH CENTURY}

The reliance on science had created an ideological shift of focus in the field of public health and the two historically linked disciplines became disconnected; public health research shifted its focus into finding immunizations and disease interventions for the public; with a few exceptions, planning began to concern itself primarily with zoning codes, promoting suburban development, transportation infrastructure and efficiency (Coburn, 2004, p. 542).

By the mid-twentieth century, the economic expansion and prosperity our country experienced after World War II led to rapid home building and community development. Much of the construction during this period was predicated on the federal government investing into the transportation infrastructure of the country. In 1956, President Eisenhower signed into law the Federal Aid Highway Act, which authorized the construction of more than 40,000 miles of Interstate Highway System roadways. This made traveling wildly popular and car ownership became widespread. This allowed people to move out of the city and into remote surrounding areas that were now easily accessible by highway. As new single-family residential neighborhoods cropped up, so did the call for city planners to allocate land use for needed commercial and retail services as communities became sprawled out. Soon, the provision of sidewalks, bike lanes and pedestrian friendly infrastructure became secondary, as planning began to 
place an emphasis on designs meant to accommodate the automobile such as wider streets and creation of arterial roads for increased traffic flow and capacity.

Such an infrastructure deterred physical activity and the use of pollutionreducing alternate forms of transportation. The end result was widespread traffic congestion; increased commuting time; increased vehicle, pedestrian and biking crashes and injuries; a growing obesity epidemic; a rise in air pollution and respiratory illness; and a growing sense of disconnection between workplaces and homes. (Centers for Disease Control and Prevention, 2009, p.9).

\section{LATE TWENTIETH CENTURY}

Throughout the past 30 years, there has been a reconnection between the planning and public health fields. The infectious disease epidemics of the late nineteenth and early twentieth century are primarily gone in the United States (Table 2). Today, the battles are with chronic and preventable diseases_contemporary health issues that are equally dynamic, interconnected and complex (Northridge \& Freeman, 2011, p. 593). 
Table 2 Leading Causes of Death in the U.S., 1900, 1950, and 2000

\begin{tabular}{|c|c|c|c|}
\hline Ranking & 1900 & 1950 & 2000 \\
\hline 1 & Pneumonia and influenza & Diseases of the heart & Diseases of the heart \\
\hline 2 & Tuberculosis & Malignant neoplasms & Malignant neoplasms \\
\hline 3 & $\begin{array}{l}\text { Diarrhea, enteritis, and } \\
\text { ulceration of the intestines }\end{array}$ & $\begin{array}{l}\text { Vascular lesions affecting } \\
\text { central nervous system }\end{array}$ & Cerebrovascular diseases \\
\hline 4 & Diseases of the heart & $\begin{array}{l}\text { Accidents (unintentional } \\
\text { injuries) }\end{array}$ & $\begin{array}{l}\text { Chronic lower respiratory } \\
\text { diseases }\end{array}$ \\
\hline 5 & $\begin{array}{l}\text { Intracranial lesions of } \\
\text { vascular origin }\end{array}$ & Certain diseases of early infancy & $\begin{array}{l}\text { Accidents (unintentional } \\
\text { injuries) }\end{array}$ \\
\hline 6 & Nephritis, all forms & $\begin{array}{l}\text { Influenza and pneumonia, except } \\
\text { pneumonia of newborn }\end{array}$ & Diabetes mellitus \\
\hline 7 & $\begin{array}{l}\text { All accidents (unintentional } \\
\text { injuries) }\end{array}$ & Tuberculosis, all forms & Influenza and pneumonia \\
\hline 8 & $\begin{array}{l}\text { Cancer and other malignant } \\
\text { tumors }\end{array}$ & General arteriosclerosis & Alzheimer's disease \\
\hline 9 & Senility & $\begin{array}{l}\text { Chronic and unspecified nephri- } \\
\text { tis and other renal sclerosis }\end{array}$ & $\begin{array}{l}\text { Nephritis, nephrotic syndrome, } \\
\text { and nephrosis }\end{array}$ \\
\hline 10 & Diphtheria & Diabetes mellitus & Septicemia \\
\hline
\end{tabular}

(Dannenberg et al., 2011, p. 13)

Starting in the early 1980 s, the Healthy Cities movement began espousing the notion of chronic disease prevention, participatory government, sustainability, health equity and acknowledgment that built environment factors may influence public health (Dannenberg et al., 2011, p. 26). The movement gained traction globally, with the establishment of a program at the European office of the World Health Organization.

In the United States, many of the aforementioned urban health principals established by Healthy Cities have begun being commonly incorporated into planning strategies, such as mixed land use, street connectivity, residential density and active transportation infrastructure across the country.

In California, the reintegration of health into planning is being accomplished through the Health in All Policies (HiAP) initiative, climate action planning, and health elements in general plans. Each of these policy-affecting documents can help to address the 
environmental determinants of health, and require collaborative work between planners and public health workers.

\section{Physical Activity}

The relationship between physical activity and corresponding positive health benefits has been well-researched and strongly correlated. The World Health Organization defines physical activity as "any bodily movement produced by skeletal muscles that requires energy expenditure" (World Health Organization [WHO], 2014). It has been estimated approximately 400,000 premature deaths occur annually in the United States as a result of the negative health outcomes which stem from obesity due to physical inactivity (Mokdad, Marks, Stroup, \& Gerberding, 2004).

According to the Centers for Disease Controls and Prevention (CDC) website, chronic diseases are the leading causes of death and disability in the United States (2014). In California, it's the leading cause of premature morbidity and mortality. A foundational U.S. Surgeon General's Report on Physical Activity and Health (1996), concluded people of all ages who are generally inactive can improve their health and well-being by becoming even moderately active on a regular basis. In addition:

- Reduces the risk for dying prematurely

- Reduces the risk for dying from heart disease

- Reduces the risk for developing diabetes

- Reduces the risk for developing high blood pressure

- Helps reduce blood pressure in people who already have high blood pressure

- Reduces the risk for developing colon cancer 
- Reduces feelings of depression and anxiety

- Helps control weight

- Helps build and maintain healthy bones, muscles, and joints

- Helps older adults become stronger and better able to move about without falling

- Promotes psychological well-being

(U.S. Surgeon General's Report on Physical Activity and Health, 1996)

In 2008, the Physical Activity Guidelines Advisory Committee, a group of 13 leading experts in the field of exercise science and public health, released a report which was a comprehensive review of the published scientific literature relating health to physical activity that had been produced since the 1996 Surgeon General's Report on Physical Activity and Health (Physical Activity Guidelines for Americans, 2008). The committee's research of the data summarized the following major findings: 


\section{Figure 2 - The Health Benefits of Physical Activity}

\section{The Health Benefits of Physical Activity-Major Research Findings}

- Regular physical activity reduces the risk of many adverse health outcomes.

- Some physical activity is better than none.

- For most health outcomes, additional benefits occur as the amount of physical activity increases through higher intensity, greater frequency, and/or longer duration.

- Most health benefits occur with at least 150 minutes a week of moderateintensity physical activity, such as brisk walking. Additional benefits occur with more physical activity.

- Both aerobic (endurance) and muscle-strengthening (resistance) physical activity are beneficial.

- Health benefits occur for children and adolescents, young and middle-aged adults, older adults, and those in every studied racial and ethnic group.

- The health benefits of physical activity occur for people with disabilities.

- The benefits of physical activity far outweigh the possibility of adverse outcomes.

(Physical Activity Guidelines for Americans, 2008)

Growing research has linked chronic diseases to specific risk factors-such as obesity, smoking, poor nutrition and physical activity—which are strongly influenced by economic and education levels, social norms, and the built environment. Specifically, the role of the built environment, which is "defined broadly to include land use patterns, the transportation system, and design features that together provide opportunities for travel and physical activity" (Transportation Research Board [TBR] \& Institute of Medicine [IM], 2005, p. xiii) has been identified by practitioners in both the urban planning and public health fields as major factor in affecting active living behavior. 
Numerous research studies over the past two decades have established a strong foundation of corollary evidence that supports the notion that the built environment impacts physical activity behaviors (TBR \& IM, 2005; Saelens \& Handy, 2008; Feng, Glass, Curriero, Stewart, \& Schwartz, 2010), though no single determinative aspect has been identified. Research by Humpel, Owen, and Leslie (2002) has indicated accessibility and proximity to destinations are strongly associated with increased walking behavior. Suburban neighborhood site designs were found to inhibit active behavior due to an emphasis on automobile road networks, creating inefficient walking routes due to inordinately large block sizes and incomplete sidewalk systems (Hess, Moudon, Snyder, \& Stanilov, 1999). Evidence collected Saelens, Sallis, and Frank (2003), suggests individuals living in communities with higher density, connectivity and mix of land use reported higher rates of pedestrian/cycling for utilitarian purposes versus those from less dense, poorly networked, single land use neighborhoods. Other research has found multi-level social ecological factors such as urban aesthetic, perceived safety, accessibility and opportunity for social interaction to be motivating factors for increased physical activity (Lee\&Moudon, 2004; Brownson, Baker, Housemann, Brennan \& Bacak, 2001). Finally, research findings are not reliably predictable across the board; low socioeconomic status (SES), black and Hispanic minority groups are influenced greatly by access to food stores, exercise facilities and safety versus traditional catalysts such as walkable or compact environments (Lovasi, Hutson, Guerra, \& Neckerman, 2009).

Sallis, Millstein and Carlson (2011), in the seminal compendium Making Healthy Places provide a summary of key points compiled from research related to relationship between urban design and physical activity (p. 33):

- Some built environment attributes are associated with higher levels of physical activity 
- Access to recreation facilities, quality and safety of pedestrian facilities, and aesthetics are poorer in areas with mostly low-income and racial or ethnic minority populations

- Adding or improving recreation facilities may not be enough to lead to their increased use. Activity programs and marketing may also be needed

- Comprehensive interventions that include environmental changes, education, and other components have increased active transport to schools and overall use of bicycles in cities

- Living close to parks, trails, and recreation facilities is related to greater use of facilities and more recreational physical activity (An abbreviated list taken from Sallis et al., 2011, p. 33)

\section{SELECTED FINDINGS AND PROJECT IMPLICATIONS}

- There is no single determinant which will provoke physical activity, but rather a complex mix of ecological factors (Saelens \& Handy, 2008). While land use and aspects of the built environment may play a significant role in health outcomes, planning professionals must be cognizant of the many social ecological aspects that may elicit or inhibit active lifestyles. This is an important consideration when developing community health recommendations for the project. Educational, cultural or other socio-ecological determinants to physical activity should be identified and factored into strategies meant to help resolve health issues in Oceano.

- Low-SES, disadvantaged minority individuals respond to certain built environment characteristics differently than other groups. Research has shown African American and Latino populations that can be classified into these groups 
are influenced greatly by food stores, exercise facilities and safety versus walkable or compact environments (Lovasi et al, 2009). This is both an important and relevant finding when considering Oceano's current socioeconomic demographic profile. A quality food access inventory should be conducted in order to identify the quantity of food vendors and quality of food sources within Oceano community. Likewise, an inventory of park and recreation facilities should be conducted to properly determine the availability and accessibility of these amenities for the local population. Inquiries regarding residents' perception of neighborhood and community safety should be solicited on surveys and key informant interviews in order to gain clearer insight into inhibitors to physical activity.

\section{Mental Health}

According to the American Institute of Stress (2011), an increasing number of Americans are citing personal health and their family's health as a source of stress. Godbey (2009) states an "estimated 75 percent of all visits to primary care physicians are for stressrelated complaints and disorders" (p. 3). Humans have spent thousands of years adapting to the natural environment, but only recently (relatively speaking) in the past few centuries have humans disengaged themselves from nature in favor of the manmade structures found in our urban environments (Maller, Townsend, Pryor, Brown, \& St. Leger, 2005). In the United States, as our population has continued to increase, so has the urbanization of our residential areas, making public parks important assets in keeping us connected with nature. In their book Designing Healthy Communities, authors Richard J. Jackson and Stacy Sinclair describe the following polemically: 
If we set out to create a depression-inducing environment, the key

features would include prevention of exercise, removal of interesting and pleasing natural features, excess noise, chaotically designed and located structures, and the creation of social isolation and anxiety-precisely what we have built in the mid- to late twentieth century. (2012, p. 11)

In Making Healthy Places, Sullivan and Chang (2011) provide the following key points regarding mental health and the built environment (p. 106):

- Places that encourage physical activity can both prevent and treat depression

- The built environment can promote or hinder mental health

- The conditions of modern life place great demands on-and often-exhaust our ability to pay attention. Green settings have the capacity to alleviate mental fatigue and help restore a person's capacity to pay attention

(An abbreviated list taken from Sullivan \& Chang, 2011, p. 106)

Research studies have indicated being in contact, or in the very least, in sight of natural environments has beneficial effects on our mental health (Maller, Townsend, St Leger, Henderson-Wilson, Pryor, Prosser, \& Moore, 2009). Further, Maller et al. (2005) argue that "Empirical, theoretical and anecdotal evidence demonstrates contact with nature positively impacts blood pressure, cholesterol, outlook on life and stress-reduction" ( $p$. 49). The provision of open spaces, green spaces and parks, i.e., the built environment, contribute to overall well-being through increased levels of physical activity, relaxation, recreation and social engagement (Maller et al., 2009, p. 54) and is beneficial across all age groups (Mass, Verheij, Spreeuwenberg, \& de Vries, 2006, p. 590). 
For low-SES communities where residents lack the disposable income to purchase private gym memberships or pay for stress reducing entertainment or activities, parks can serve as a cost-effective means of relieving stress and improving overall well-being. Though, disadvantaged communities which are typically found in over-paved, underdeveloped or industrialized urban areas are especially vulnerable to a lack of public amenities and well-maintained open spaces, parks and recreations areas (Sherer, P. M., 2006, p. 8).

\section{SELECTED FINDINGS AND PROJECT IMPLICATIONS}

- Research findings from Mass et al. (2006) indicate positive health perceptions are directly relational to proximity to green space (p. 591); further, "The relation seen between green space and health was stronger for the less educated group and this is exactly the subgroup that is less likely to have much choice in their neighborhood of residence" (p. 592). Inquire into Oceano's education attainment levels is necessary to account for any added vulnerability due to lack of provision green space, parks or recreation areas. Recommendations developed for the health plan should place an emphasis on adding park and green space amenities within the community. A potentially more feasible alternative could involve the development of a shared use agreement with Oceano Elementary school. This strategy would provide residents permission to use the school grounds after-hours, and could be promoted at school and within the community.

- As it is in Oceano, impoverished communities by definition lack adequate provision of public amenities such as parks and open spaces due to lack of economic resources, with poorly designed land uses and dilapidated buildings, roads, and active transportation infrastructure (if any). These byproducts of 
economic hardship require creative strategies can benefit a community with Oceano's SES profile. Research is required to identify comparable communities that have successfully incorporated healthy community policy strategies that are both feasible in scope and in implementation for a town like Oceano.

\section{Health Equity}

Healthy People 2020 states health equity "is achieving the highest level of health for all people. Health equity entails focused societal efforts to address avoidable inequalities by equalizing the conditions for health for all groups, especially for those who have experienced socioeconomic disadvantage or historical injustices" (Disparities, n.d.).

The roots of both city planning and public health are intertwined, and can be traced back to mutual concerns over widespread health inequities that were prevalent in poor urban living environments of the mid to late nineteenth century in America. During the early to mid-part of the twentieth century, as these two fields diverged into their own respective specialized practices, city planning practices started yielding its own, often insidious, health implications that were largely ignored or discounted at the time. Planners played a major role in determining density, access to parks, highways and stores. Zoning practices were enacted to concentrate certain minority groups into residentially segregated neighborhoods. Land use decisions allowed for residential areas to be located next to toxic industrial areas and waste sites in neglected parts of town.

Health inequalities (or disparities) persist today within populations and by some measures the equality gap is widening despite more than a century of concerted public health interventions (Northridge \& Freeman, 2011, p. 582). 
Not all communities have equal access to physical activity resources or environments that support an active lifestyle. Low-income communities and communities of color have been found to have limited facilities and spaces for physical activity, poor sidewalk and street infrastructure, and disproportionate exposure to violence. These hindrances may deter or limit opportunities for those populations to engage in physical activity. Additionally, the physical activity infrastructure that does exist in many communities, low-income or not, may not be developed with all potential users in mind. As a result, populations with special needs such as the elderly and people with disabilities may not be properly accommodated. (CDC, 2013)

Gordon-Larsen, Nelson, Page, and Popkin (2006) argue that minority and groups of low educational attainment are at the highest risks for obesity and many chronic and preventable diseases (p. 418), and support from their research results indicate high-SES groups have better odds of having access to recreation facilities, while low-SES and high-minority groups have reduced access to the similar facilities, which in turn is associated with reduced rates of physical activity and increased levels of obesity ( $p$. 420).

In addition to inequalities found in the built environment that can affect physical activity levels, low-SES and disadvantaged minority communities face additional difficulties in accessing healthy and nutritious food sources. Research by Moore and Diez Roux (2006) indicates low-income and non-White areas had fewer fresh produce markets, specialty and natural food stores, while liquor stores were much more likely to be found in poor areas versus wealthier ones (p. 329). Further research has shown an association between race and economic status with availability of chain supermarkets-low-income 
neighborhoods had fewer chain supermarkets than middle-income neighborhoods—the availability of chain supermarkets in African American neighborhoods was approximately only half (52 percent) that of White neighborhoods - and even less available in Hispanic neighborhoods (32 percent) (Powell, Slater, Mirtcheva, Bao,\&Chaloupka,2007, p. 190).

\section{SELECTED FINDINGS AND PROJECT IMPLICATIONS}

- Oceano profiles as a low education attaining, low-SES, and disadvantaged minority population. As such, the population is especially sensitive to inequalities found in the built environment and at higher risk for obesity and many chronic and preventable diseases. This can include lack of access to park and green spaces; lack of access to healthy food resources; poor quality infrastructure; and proximity to environmentally hazardous areas. The implications to the project were to ensure health equity encompasses all aspects of planning and public health, factoring it into every strategy, recommendation and policy outlined in the health plan.

- Planners have an influence on the type of food outlets permitted, the location and density of food outlets, as well as controlling access and active transportation options to these food sources. The implication on the project were to develop creative strategies and policies that would help narrow the health inequality gap; increasing access to food outlets by improving active transportation infrastructure and connectivity; providing incentives to attract healthy food retailers and streamlining the permit/application process for these types of businesses; ensuring transit routes have stops at large chain supermarkets. 


\section{Injury Prevention}

In 2008, the Physical Activity Guidelines Advisory Committee reported findings from amalgamated scientific literature on the health benefits of exercise, including that the benefits of activity far outweigh the possibility of adverse outcomes. However, physical activity can expose individuals to risks for injury, due in part to the high priority of accommodation of vehicles and the incomplete adoption of designs and practices for injury prevention in our environments. Injuries are not accidents. The frequency and situations in which they occur can be influenced, controlled, and changed. Planners seldom specifically address injury prevention, though traffic safety measures, building codes, and development standards all exist for user safety-whether explicitly or implicitly. Injuries may be more or less likely dependent on environmental features such as lighting, hazard identification (signs), hazard management (i.e. fencing), and the general design of the built environment. The challenge in thinking about public space is to create environments that help people participate in increased levels of physical activity safely.

Due to several factors, the health of children, elderly populations, and low-income area residents are especially affected by injury occurrences. Some of these factors are attributable to user characteristics such as balance, vision, coordination, or cognitive ability and some may be due to lack of maintenance of areas or inequity issues (NZIPS, 2014).

Pedestrian areas and areas where there are no intersections in particular are important to consider for injury prevention. Falls are the leading cause of injuries reported to emergency rooms. Uneven surfaces are a major cause, along with slippery surfaces, steepness, and stairs that are hard to see or too high. Obstructions such as pavement 
signs, poorly sited street furniture, protruding grates or manhole covers, and litter and other debris, create tripping hazards. Seniors are more susceptible to falls, and a large number of injuries are attributable to falls while using footpaths or sidewalks. Injuries occur on streets due to vehicle speeds and increasing numbers of vehicles

Injuries occur on streets due to vehicle speeds and increasing numbers of vehicles. Pedestrian deaths are higher in the US than Europe, and affect the men over age 85 and women between the ages of 75 and 84 disproportionately-two times more while walking than people between 15 and 24 years of age (CDC, 2013). Minority populations are at the greatest risk, and men of all demographics were two-and-a-half times more likely than women to be killed by a car while walking (CDC, 2010). In 2010, 79 percent of pedestrian fatalities occurred at non-intersections.

The Department of Transportation has studied numerous tactics to reduce injury-byvehicle and promote health, which they call safety countermeasures. These include features that call a driver's attention to a pedestrian area, naturally cause slower speeds, and increases in physical space for pedestrians and bicyclists. The new list of proven safety countermeasures includes:

- Safety Edge

- Roundabouts

- Longitudinal Rumble Strips and Stripes on 2-Lane Roads

- Enhanced Delineation and Friction for Horizontal Curves

- Medians and Pedestrian Crossing Islands in Urban and Suburban Areas

- Pedestrian Hybrid Beacon

- $\quad$ "Road Diets" (Roadway Reconfiguration) (Furst, 2012) 
These measures can increase actual and perceived safety and encourage active use of the built environment.

\section{SELECTED FINDINGS AND PROJECT IMPLICATIONS}

- Injuries occur due to vehicle speeds and the increasing numbers of vehicles, so it is important that future neighborhood designs and improvements to existing areas slow traffic, alert drivers of pedestrian presence, and restrict the numbers of vehicles where appropriate.

- Children and the elderly are especially susceptible to injury, and improvements to footpaths, sidewalks, and stairs will be important to consider in conducting the project.

- Though injury prevention presents its own set of challenges, a built environment that is designed to prevent injury will also serve to encourage active use, helping people participate in increased levels of physical activity.

- There are proven measures for addressing the occurrence of injuries, and these should be incorporated into planning documents where appropriate.

\section{Environmental Health}

Humans are affected by the environmental quality in the places they live, work, and visit. Although the overall health of the environment contributes or detracts from heath in a number of ways, inadequate water and air quality directly affect humans.

Acute and long term air pollution due to ground level ozone and particulate matter has been shown to have negative impacts on health. Ground level ozone is that main component of smog, and is caused by the emissions of industrial facilities and electric utilities, motor vehicle exhaust, gasoline vapors, and chemical solvents (EPA, 2012). 
Long term pollution has been associated with increased mortality and morbidity and specifically with cardiorespiratory mortality (Bell, 2004). Acute exposure to "Particulate matter," also known as particle pollution or PM air pollution is associated with an increase in hospital admissions for ischemic heart failure, myocardial infarction, asthma and chronic obstructive pulmonary disease (Halonen, 2010; Peters, 2001). According to the EPA, the size of particles is directly linked to their potential for causing health problems. Particles 10 micrometers in diameter or smaller generally pass through the throat and nose and enter the lungs and can cause serious health effects including premature death in people with heart or lung disease, nonfatal heart attacks, irregular heartbeat, aggravated asthma, decreased lung function, and increased respiratory symptoms, such as irritation of the airways, coughing or difficulty breathing (EPA, 2012). The effects of air pollution, most of which is attributable to human activities, are directly related to human illness and health problems.

There are several personal choices that communities can make that reduce air pollution, including conserving energy, recycling, planting trees, using public transportation, carpooling, or riding a bike for some trips (EPA, 2014). The San Luis Obispo Air Pollution Control District works from a strategic action plan to meet air quality thresholds and reduce pollution rates for point-source and non-point source pollution, although the agency has encountered challenges due to limited authority to regulate and public resistance to change (APCD, 2012). Best practices for reducing air pollution locally are difficult, since air does not conform to city or county limits, but successful efforts have included social marketing campaigns to affect individual behaviors, enforcing compliance with the Clean Air Act, phasing out polluting sources of energy, and investing in public transit (NYC Global Partners, 2011). 
Storm water runoff, the water that flows to the storm drains during and after a rain event contributes to microbial contamination of water supply. Streams and rivers downstream from developed areas have higher bacterial counts after rainfall (Gannon, 1989). Urban runoff is responsible for a huge amount of the water pollution. As an example, approximately $47 \%$ of the pathogen contamination of the Long Island Sound is attributable to runoff (EPA, 1994). Much of the contamination is from non-point source pollution, with major sources including runoff from farms, parking lots, streets, and golf courses. Contaminants include pesticides, metals, nitrates, pharmaceuticals, and organic chemicals.

There is a strong relationship between large rainfalls and outbreaks of waterborne diseases. More than half of the documented waterborne disease outbreaks since 1948 have followed extreme rainfalls (Curriero, 2001). The extent of water-related illnesses can be from microbial or chemical contamination. Of the 99 million cases of acute gastrointestinal illnesses with vomiting or diarrhea, $6 \%-40 \%$ may be related to drinking water (Payment, 1991). Public water infrastructure may not be adequate to handle increased development; increased development competes for infrastructure dollars. Twenty-six percent of the piping in the US is judged to be - at best - in 'fair' condition (Clark, 1999). Pipe leaks and breaks can be a source of water contamination (Levin, 2002). Water resources are also necessary for the success of agriculture and the health of fisheries, which in turns affects food security. The food system is implicated in the quality of local water, air, and soil, and thereby more widely affects the quality of life than is reflected in efforts to be deliberate about the food system (Pothukuchi and Kaufman, 1999, pg. 214). Waterborne illnesses can be caused not only by drinking contaminated water, but also by eating produce irrigated with untreated water, eating seafood caught 
in contaminated water, and swimming or other recreation in polluted water (Craun, 1999).

Similarly to air quality control, water pollution from runoff and stormwater is difficult to control at a non-point source level. As authorized by the Clean Water Act, the National Pollutant Discharge Elimination System (NPDES) permit program controls water pollution by regulating point sources that discharge pollutants into waters of the United States. The EPA lists and describes a number of best practices for stormwater management, many of which improve the water quality of runoff as well prior to deposit into streams and the ocean. These include bioretention cells or rain garden, eliminating curbs and gutters to increase sheet flow and reduce runoff volumes, grassy swales that help to slow runoff and facilitate infiltration, separation units to remove pollutants, permeable pavement, rain barrels and cisterns that harvest rainwater for reuse, tree box filters, vegetated filter strips, and green roofs (EPA, 2012).

\section{SELECTED FINDINGS AND PROJECT IMPLICATIONS}

- Low air quality in the communities of Cayucos and Oceano may be causing disease and worsening individuals' existing health problems.

- Contaminated water may negatively affect communities that engage in seemingly healthy behaviors such as drinking water, eating seafood, and swimming or surfing. These behaviors should be encouraged by ensuring that the natural environment is as clean and pollution-free as possible.

- Storm water runoff contributes to microbial contamination downstream from developed areas, such as communities near the coast. Though this is a problem that originates regionally, it is important to consider the effects for the local communities and make steps to reduce contaminated runoff. 
- Runoff from area farms, parking lots, streets, golf courses, and lawns may be causing problems in coastal communities such as Oceano and Cayucos. Steps should be determined to reduce non-point source pollution.

- There is a strong relationship between large rainfalls and outbreaks of waterborne diseases. Increasing awareness about this relationship, in addition to taking steps to reduce disease-causing pollutants, are important to consider when creating a plan to improve community health.

\section{Food Access}

Inadequacies in the food system impact communities, especially in terms of public health. In response to the environmental costs of the food system, the popularity of local food is on the rise. "Local" farmers are not inherently better stewards of the environment, though having a smaller area of land to care for or fewer animals increases the this likelihood (Hinrichs, 2003, p. 35). Local food production and sales contributes to higher degrees of social capital and care, resulting from the possibility of face-to-face interaction, mutual knowledge, and the idea that "your farmer" is part of the community (Hinrichs, 2003, p. 36). The proliferation of the term "food miles" to measure the impact of the food system on the environment reinforces the logic of local production. Important too is the energy cost of packaging and preparing food, which is higher than the costs of fresh food that is grown at long distances (Hodgson, 2009). Many foods do not travel a single route, but take many steps along the supply chain from "Field to plate" (Food distribution, 2010, p. 3).

The concentration on local food is important, but it is more significant to concentrate on the impacts of the system as a whole. Fresh, minimally processed, local food is generally the most nutritionally valuable and the least detrimental to the environment. 
Access to affordable grocery stores and farmers markets increases the likelihood that people will eat healthy food, while those surrounded by convenience and liquor stores are less likely to eat healthy food (Corburn, 2009, p. 80). However, the most accessible foods in most areas are high in calories but low in nutritional value (Hodgson, 2009). The food system is impactful to the well-being of communities of all socioeconomic kinds, though the poor are generally more vulnerable to problems of food access (Corburn, 2009). Planners are inherently part of the food system because food production, transport, and distribution are contingent on land use regulation. The lack of analysis of food systems may lead, to use a wide-spread example, to including grocery stores into broader commercial development categories, therefore failing to acknowledge it as a high-priority need for households, and restricting food access.

Pothukuchi and Kaufman offer several ways that planners could help to improve the food system. These include collecting data about the food systems; analyzing this data to come up with concrete terms for issues and to better plan for improvement; assessing the ways that current plans impede the progress of food systems, through such ways as allowing community gardens to be paved and developed; and restricting location of grocery stores or food outlets, or closing food pantries and soup kitchens all negatively impact access to food. Planners could work to remove these and other kinds of barriers and instead create policies that encourage and increase access to food. Additionally, and in relation to these efforts, planners could work to explicitly integrate food security goals into community plans. Specific goals may help to foster relationships between public, private, and non-profit agencies, and between private enterprise and the public. Though planners already have many tools available to plan for better food systems, this undertaking will also require cooperation with their communities and public health experts. 


\section{SELECTED FINDINGS AND PROJECT IMPLICATIONS}

- Inadequacies in the food system impact community health, but food production, transport, and distribution are contingent on land use regulation.

- The environmental impacts of the current food system affect all communities, but addressing these impacts must take place on a regional level.

- The equitable access concerns of our current food system may be limiting the potential for healthy eating in Oceano and Cayucos.

- Problems of food access may be affecting both Oceano and Cayucos, due to location and socio-economic status.

- Unlike most planning documents that integrate food systems planning into their plans in a reactive way, a plan centered on health should strive to include healthy eating priorities in a comprehensive and forward-thinking way.

\section{Healthy Planning Best Practices}

There are several examples of literature and professional documents that discuss planning for healthy communities. Of these, some discuss general plan elements specifically, while others focus on certain aspects of creating programs or policies that allow a greater degree of healthfulness, such as funding for access to local food, achieving a higher degree of active transportation, or identifying and working towards solving equity issues. These guides provide research and practical advice for plan goals, policies, programs, and implementation measures, as well as how to go about conducting community outreach and constructing a healthy plan.

One crucial aspect for health elements or healthy plans is to focus on partnering and collaboration. Daniel Stokols writes about combining two strands of health promotion 
strategies to achieve a greater outcome. In illustrating an example, he writes, "If a community goal is to reduce levels of obesity in the population, then a multi-component program that incorporates health education strategies and the creation of new fitness facilities and outdoor recreational space is likely to be more effective in achieving that goal than a single-component intervention that focuses on either human or material resources for health promotion but not both" (Stokols, p. 9). This highlights the value of maximizing the leveragability or joint influence among multiple program components on key health behaviors and outcomes. Other resources suggest identifying champions of health and leaders in the community, such as recreation programs or members of the healthcare community. Another tip for outreach is to engage stakeholders "where they are," by, for instance, going to standing meetings or events. Another commonly mentioned tip was to work across sectors, especially within government departments or bodies.

As part of outreach, it is recommended that education be utilized. Specifically, this includes the use of an "environmental frame" to demonstrate how places influence health. Because health is thought of as a highly personal matter that is attributable to genetic factors and individual choices, focusing on "root determinants" is crucial to the education component. Another tip is to come to agreement on terms and priorities between public health and planning to eliminate confusion when working with the public. Because public health and planning traditionally focus on very different subjects, it is important that there is a strong level of understanding of the overlapping issues, and that this is appropriately portrayed to the public.

Another best practice for constructing the document itself is to include a summary of existing "knowns" or findings from data. This helps to contextualize the arguments in favor of combining the work of two disciplines and striving to correct some of the health 
issues linked to the built environment. This information should include health data and "non-health data" that characterizes conditions in the community. The narrative should also include health priorities obtained from community outreach and the study of the existing health conditions. The health topics most important to the community should also be tied to the goals and objectives included in the plan.

The literature also included common mistakes to avoid in these efforts, from the initial stages of the project through to implementation. This includes linking surveys and other outreach to goals and policies, which will better support the democratic nature of the planning effort and result in a plan that can be implemented. Also, strategies should be utilized to better integrate health data into the progress of the goals, and use of this information to direct resources and track progress.

Connect priorities to public health. Also related to implementation is the awareness of timing and context, which should be kept in mind for the "next steps" in the project.

\section{SELECTED FINDINGS AND PROJECT IMPLICATIONS}

- As the best practices research suggests, goals included in the Community Health Plans should include multiple components and actions, which will better address the breadth of influences on behavior and health.

- The literature review above demonstrates an understanding of the links between public health and planning, and these connections should be part of the educational component of the project throughout community outreach efforts.

- There should be a focus on communicating the impact of root determinants of health, which will help to contextualize the efforts for community members and evoke local knowledge on specific issues related to the topic. 
- Throughout the outreach process, and as part of the document, data that describes health conditions and other community data should be integrated in order to provide a convenient way of understanding what the plans seek to address.

- The plan should include ways of measuring progress, next steps, and increase the communication lines between public health, planning, and information available to the community.

\section{Case Studies}

Existing health elements in California were examined through a set of criteria to determine which plans will be used as models. A matrix for the elements chosen as case studies was completed to illustrate evaluation criteria to choose a model for the community health plan. The matrix contains evaluation categories to include plan scope, planning outreach process, population size, demographic makeup, extent of goals and policies, implementation strategies, and notable or exceptional aspects. Results of this matrix helped to determine which two or three health elements were used to shape the Cayucos Community Health Plan.

\section{SELECTED FINDINGS AND PROJECT IMPLICATIONS}

- Policies and goals must be community appropriate, taking into account the socio-economic and demographic makeup of the respective community; failure to do so may make some policy solutions ill-fitting.

- Documenting the outreach process and findings in the planning document is a vital component for generating public support for the community health plans; 
failure to do so may alienate the community and make the project to appear topdown without community input.

\section{Research Question}

This project seeks to answer the following research questions:

- What affect do the existing features of the built environment and land uses found in each respective town have on public health?

- What are the unique built or natural environment features, political, cultural or community factors/barriers that may be playing a role in affecting health outcomes?

- What community appropriate strategies and recommendations would provide the greatest benefit in producing positive health outcomes? 


\section{METHODOLOGY}

\section{Introduction}

The objective of this professional project is to begin looking in-depth at the ways the built environment (our streets, parks, and neighborhoods) contributes or detracts from the health of the community through focus on a small yet cohesive part of the San Luis Obispo County: Cayucos and Oceano.

The creation of a scope of work for the project was achieved through the development of the prospectus. Preliminary literature review, direction from the client, and discussions with key groups and individuals helped to determine the scope and schedule of the product. The committee, which includes the client, reviewed and approved of the final scope of work at the prospectus defense meeting. Many methods were employed in both communities, though the unique aspects of each community were considered and resulted in slightly different methods in each. Consulting with the client and key stakeholders occurred throughout the process, adding to the completeness of information in the background report and ensuring that the final product addresses the needs of the community.

The methods were decided based on questions to be answered throughout the development of the project, and the identification of sources of information that would help to answer the questions (see Table 3 and Table 4 of pages 44 and 45). The development of this these projects had several stages which were divided into three phases. The first phase, information gathering, included case study analysis and compilation of a background report. The second used background information to design and implement an outreach plan. The third was to write a set of findings, policy 
recommendations, and implementation measures that make up the community health plan. 


\section{Table 3 Oceano Information Sources}

\begin{tabular}{|c|c|c|}
\hline \multicolumn{3}{|c|}{ Project Questions and Information Sources/Methods } \\
\hline \multicolumn{3}{|c|}{ What have other cities done to address the built environment and public health? } \\
\hline \multicolumn{2}{|c|}{ Sub-questions } & Answer Sources \\
\hline \multicolumn{2}{|c|}{$\begin{array}{l}\text { What other cities have incorporated a stand-alone PHE into its } \\
\text { General Plan? }\end{array}$} & $\begin{array}{l}\text { The Governor's Office of Planning \& Research's } \\
\text { Annual Planning Survey Results - } 2012 \text { Edition }\end{array}$ \\
\hline \multicolumn{2}{|c|}{$\begin{array}{l}\text { Of the cities identified above, are there any comparable } \\
\text { communities to Oceano (i.e. population, demographics, et } \\
\text { cetera)? }\end{array}$} & U.S. Census \\
\hline \multicolumn{2}{|c|}{$\begin{array}{l}\text { What is the scope, policies, goals and strategies typically } \\
\text { included in a PHE? }\end{array}$} & $\begin{array}{l}\text { San Pablo General Plan - } 2030 \\
\text { City of El Monte General Plan }\end{array}$ \\
\hline \multicolumn{2}{|c|}{$\begin{array}{l}\text { Are there any unique recommendations or aspects that would } \\
\text { be appropriate for Oceano? }\end{array}$} & [Identify Specific Case Studies] \\
\hline \multicolumn{2}{|c|}{$\begin{array}{l}\text { What particular outreach efforts or strategies were used to } \\
\text { garner public feedback and participation in the developmental } \\
\text { stage of the PHE? }\end{array}$} & $\begin{array}{c}\text { County of Santa Clara County Planning Office } \\
\text { Building a Healthier Coachella Valley }\end{array}$ \\
\hline \multicolumn{3}{|c|}{ What are the existing conditions in Oceano? } \\
\hline \multicolumn{3}{|c|}{ Sub-questions $\quad$ Answer Sources } \\
\hline $\begin{array}{l}\text { What are the basic profile statistics (age, } \\
\text { ethnicity, gender, family status, employment } \\
\text { status, etc.) on Oceano? }\end{array}$ & & U.S. Census, SLOCOG \\
\hline \multicolumn{3}{|c|}{ What is the community's health status? } \\
\hline $\begin{array}{l}\text { What are the leading causes of death? Who are } \\
\text { the vulnerable populations? What are the } \\
\text { obesity and diabetes rates? What are the rates of } \\
\text { asthma and other respiratory problems? }\end{array}$ & \multirow{2}{*}{\multicolumn{2}{|c|}{$\begin{array}{r}\text { San Luis } \\
\text { Environme } \\
\mathrm{Pc}\end{array}$}} \\
\hline $\begin{array}{l}\text { Are there any existing environmental hazards } \\
\text { (i.e. air quality, toxic ground and water } \\
\text { containments)? }\end{array}$ & & \\
\hline \multicolumn{3}{|c|}{ Infrastructure } \\
\hline $\begin{array}{l}\text { Does Oceano currently have adequate sidewalks, } \\
\text { interconnectivity between neighborhoods and } \\
\text { service areas, bike paths, et cetera? }\end{array}$ & \multicolumn{2}{|c|}{$\begin{array}{l}\text { GIS, County Planning Department, field work/inventory, } \\
\text { County Public Works Department, Community Outreach }\end{array}$} \\
\hline \multicolumn{3}{|c|}{ Opportunities for physical activity? } \\
\hline $\begin{array}{l}\text { What are basic count of public parks, open space } \\
\text { and recreation facilities in Oceano? Are residents } \\
\text { in close proximity to these areas? What } \\
\text { percentage of residents is located within a } \\
\text { quarter-mile to a park? }\end{array}$ & \multirow{2}{*}{\multicolumn{2}{|c|}{$\begin{array}{l}\text { GIS, County Planning Department, field work/inventory, } \\
\text { County Public Works Department, Community outreach }\end{array}$}} \\
\hline $\begin{array}{l}\text { Is there a mix of land uses? Do residents have } \\
\text { safe and easy access to retail stores, schools and } \\
\text { services? }\end{array}$ & & \\
\hline \multicolumn{3}{|c|}{ Access to nutritious food options? } \\
\hline $\begin{array}{l}\text { Are there healthy food options (farmer's } \\
\text { markets, produce markets, community gardens, } \\
\text { etc.)? Is there easy access to them? }\end{array}$ & \multirow{3}{*}{ http://wwv } & publichealthadvocacy.org/RFEl/presskit_RFEl.pdf \\
\hline $\begin{array}{l}\text { How many fast food restaurants and } \\
\text { convenience stores are in the community? }\end{array}$ & & $\begin{array}{l}\text { and } \\
\text { Community outreach }\end{array}$ \\
\hline \multicolumn{2}{|c|}{ What is the retail food environment index (RFEI)? } & \\
\hline \multicolumn{3}{|c|}{ Context-appropriate goals, policies, strategies? } \\
\hline $\begin{array}{l}\text { What goals, policies and strategies are supported } \\
\text { by the community /suggested by? }\end{array}$ & & Community outreach \\
\hline
\end{tabular}


Table 4 Cayucos Information Sources

\section{Case Studies}

How have other communities assessed health and planned to improve the way the built environment affects health?

Sub-questions

- What methods have other communities used to assess community health?

- What similar plans have worked for small unincorporated towns?

- Would these strategies work for Cayucos?

- How is health data procured and incorporated into the strategic planning process?

- What connections has research proven exist between health and the built environment?

Background Report for Cayucos, SLO County What are the health problems in Cayucos?

- Who in Cayucos is most affected by health issues related to the built environment?

- What are the perceived health issues, and are they different that the data shows?
Sources

- Marin Countywide Plan

- Riverside County Health Element, disease prevention framework, and community health profile

- City of El Monte General Plan Health and Wellness Element

- SLO Coastal Plan Policies

- Scholarly Articles-listed below What are the barriers to improving health?

- What resources are lacking?

- Is there political will for improving policies?
- Community outreach

- California Health Interview Survey

- 2010 ACTION for Healthy Communities report

- Food Security Survey and Food Store Survey (STRIDE)
- CCAC

- Community outreach

How is policy already supporting health?

- What does the county general plan provide in terms of support for health?

- Any other sources specific to Cayucos?
- SLO Coastal Plan Policies

- SLO County General Plan

What resources and services exist that address health in Cayucos?

- What is food availability like in Cayucos?

- What is the state of sidewalks and bike lanes?

- How is health addressed at the schools? Sr. Center?
- Food Security Survey and Food Store Survey (STRIDE)

- Census data

- SLOCOG RTP

- Community outreach (Sr. center/PTA)

- Field inventory 
The following sections explain the three phases that served to answer the research questions and complete the plan. The methods discussed in this chapter include:

- Phase I: Data Collection and Analysis

- Literature Review

- Existing Conditions Analysis

- Physical Inventory, including access maps and studies on walkability

- Case Study Analysis

- Phase II: Community Inventory and Outreach

- Stakeholder Analyses

- Presentations to Local Government Agencies

- Key Informant Interviews

- Questionnaires

- Public Events

- Plan Draft Review Meetings

- Phase III: Goals Policies, and Implementation Recommendations

- Goals and Policies

- Implementation Measures

The subsequent documents that immediately follow this section provide the specific details, strategies and findings for each community that relate to and resulted from the various outlined methodological approaches mentioned in this section. 


\section{Phase I: Data Collection and Analysis}

This phase included a literature review, collection of census data, county public health data, and analysis of conditions of the built environment.

\section{LITERATURE REVIEW}

The first step in data collection and analysis phase was to conduct a review of available literature on the correlation between health and the built environment. This was accomplished through the review of professional and academic articles, for the purpose of studying connections between the built environment and health, as well as best practices for achieving healthier communities. This involved identifying state-of-the-art practice from planning documents, practitioners, planning awards, professional associations, and professional publications. In addition, plan examination through a methodological perspective served to identify strengths and weaknesses of contemporary practice. This portion of the project helped to determine the components of the final product and ensure a well-informed final product completed using best practices. The literature review, summary of the readings, findings and relevance to the project community can be found in section Literature Review section of this document.

\section{EXISTING CONDITIONS ANALYSIS}

Information about the communities' socio-economic traits, demographic information, and an analysis of the built environment is included in this step. It helped to provide a basis for the criteria used to assess other health elements and the development of implementation and policy recommendations. Most data was taken from previous surveys and studies, including US Census data, the ACTION for Healthy Communities Report (a countywide survey report), existing planning documents, and various other sources of publicly-available data. This part of data collection and analysis was limited 
because both communities are unincorporated towns. Some data was available for Cayucos and Oceano individually, but much of the data was compiled as county-wide or unincorporated areas.

\section{Physical Inventory}

To augment available health and demographic data, a physical inventory was conducted to achieve an understanding of the existing built environment in Cayucos and Oceano. This process included a walkability audit, and food, parks, and hydration station access assessments.

\section{Walkability Audit}

A walkability audit was conducted in Cayucos to provide an objective evaluation of the walking environment. The information collected was used to identify pedestrian concerns related to safety, access, comfort, and convenience. This was especially important as a factor involved in the availability of transportation-based physical activity. The method for the audit was chosen for its scale and purpose.

Numerous features of the built environment have been associated with physical activity, including residential density, land-use mix, urban sprawl, intersection density, walkability, park availability, and accessibility to physical activity-related resources. (Casagrande, S., et. Al. (2011). Association of Walkability With Obesity in Baltimore City, Maryland. December; 2011101 (Suppl 1): S318-S324). This audit was used to evaluate several qualitative spatial factors that contribute to walkability. To complete this analysis, an existing spatial analysis tool, the Pedestrian Environment Data Scan (PEDS) was utilized to quantify the qualitative aspects of the Cayucos walking environment, including sidewalks quality, traffic, land use patterns, building accessibility, safety, cleanliness, amenities, the degree of urban enclosure, among other factors. 
The Pedestrian Environment Data Scan (PEDS) is an instrument that was developed in 2004 by Dr. Kelly Clifton, University of Maryland; Andria Livi, University of Maryland; and Daniel Rodriguez, University of North Carolina, and supported by a grant from The Robert Wood Johnson Foundation Active Living Research program. The scope was limited to the commercial center of Cayucos, Ocean Avenue and D Street. The audit captures microscale features that are apparent to pedestrians but not easily captured in public data. The data collection instrument is a survey consisting of 36 objective and 4 subjective analysis criteria that the surveyor uses to catalogue the area through six categories: Environment, Pedestrian Facilities, Road Attributes, Bike Facilities, Walking and Cycling Environment.

This particular walkability audit tool was used because of the variety of factors and topics, which included elements of safety, pedestrian suitability and bike-friendliness, as well as elements of urban design. Though the topics are widespread, the number of questions if relatively few-36 questions in all, including a subjective assessment. Some audit tools included over 100 questions. The tool was also user-friendly in that the paper form for use in the field was publicly available, as well as an Audit Protocol guide. The creators of the PEDS audit tool also studied the association between pedestrian activity and the built environment by creating a behavioral model. The study concluded that the PEDS tool can fill a longstanding gap that has impeded the progress of pedestrian research and practice and represent a positive step toward elevating walking as a mode of transportation and source of physical activity (Clifton, Kelly J., Andrea D. Livi Smith, and Daniel Rodriguez. "The development and testing of an audit for the pedestrian environment." Landscape and Urban Planning 80 (2007): 95-110).

The process for the walk audit was comprised of several steps. First. The study region was determined and mapped. The analysis area for this study instrument included 30 
segments in and around the core of Cayucos. Study streets were mapped, coded, and printed for reference in the field. Two researchers underwent self-training by reading through and discussing the instructions for the PEDS analysis tool. The walkability data collection component was completed in the field. The PEDS Data were then encoded into Excel. Though the PEDS survey instrument has been developed and used in the field to collect data, a standard evaluation system for PEDS has not been created. A scoring system was created by assigning a zero to two rating to each survey criteria as outlined in the following chart. The walkability scores for each segment were then determined by combining these ratings and normalizing the aggregated numbers by comparing them to a highest possible score in each of the categories analyzed. The categories analyzed and mapped by the project team include overall walkability, safety, ease and comfort of travel and aesthetics. The tables were joined to the original roadway data and color coded on a gradual scale to show the individual street walkability figures. The walkability figures were then overlaid onto the spatial data allowing for visual correlation with features of the spatial environment. The detailed information for the walkability audit is available in Appendix A: Physical Inventory.

\section{$\underline{\text { Walkability Information in Oceano }}$}

A walking audit was not performed in Oceano as Safe Routes to School San Luis Obispo had recently published the findings of its own infrastructure survey that provided an audit of the half-mile area surrounding Oceano Elementary. Due to Oceano's small size, the central location of its elementary school, and thoroughness of Safe Routes to School's data, it was deemed unnecessary to conduct an additional audit. The results of this study are outlined in the Oceano Findings section. 


\section{Food and Park Access Assessment}

The food and parks access assessments were included in each Health Plan in order to analyze the existing availability of food outlets and to help determine need. The assessment was conducted using GIS data collected from San Luis Obispo County and by visits to each of the stores that sell food or beverages.

To depict and visualize healthy food retail and recreational park access, ArcGIS 10.2 and the network analyst extension were utilized. For the analysis of the food retail environment, data was obtained from the local environmental health department to determine the location and type of stores that exist in the study area. Once a list of existing stores was determined, field work was done to gather in situ data to confirm the accuracy of addresses that were provided and also survey the availability of fresh fruits and vegetables. Similar methodology was used for recreational parks, where the location of parks was identified through aerial imagery and was confirmed through field work.

After the location of the food retail stores and recreational parks were confirmed in the field, the locations were geocoded. The geocoded retail stores and recreational parks were used in conjunction with a road network file to calculate service areas. Because the road network file had no connectivity, a network dataset was made to establish connectivity within the road network file. Once connectivity was established, a quarter mile and half mile service area from recreational parks, and a half mile and one mile service area from food retail stores were determined and visualized. By utilizing network analyst, distances from retail stores and recreational parks were calculated based on Manhattan distances versus Euclidean distances, reflecting realistic paths an individual may use. 


\section{Hydration Station Access Assessment}

Empty calories consumed daily from sugar-sweetened drinks, which include non-diet sodas, fruit drinks, smoothies and any other beverage that uses sugar as a primary additive. One study found that replacement of sugary beverages could cut up to 235 calories per day for the average American child's intake (Wang, 2009).

Empty calorie intake from sugar-sweetened beverages has been identified as a major contributor to the obesity epidemic in the United States (Kushner, 2013, p.1). Water, the healthiest calorie free alternative, is not being consumed enough by U.S. children and adults, according to recent research findings (Goodman, Blanck, Park, Nebeling, \& Yaroch, 2007). Drinking fountains (i.e. hydration stations) are publically accessible water sources that are traditionally found in parks, trails and open spaces in most communities. A small but increasing number of local government agencies are starting to address concerns over public drinking fountain access through comprehensive planning (i.e. general plans), municipal codes and direct initiatives to ensure free water in public spaces in their respective communities.

It was determined a hydration station assessment should be included in the physical inventory to map water fountains and other public sources of drinking water. Field reconnaissance was conducted to confirm an accurate inventory of the hydration stations in the town.

\section{Case Study Analysis}

Due to the difficulty of finding relatable strategic health plan documents to model after, existing health elements found in both city and county general plans across California were used as case studies to help develop each Community Health Plan. The final component of this phase was to review and evaluate health elements using a set of 
criteria. The unit of analysis is defined as the who or what being studied. For this project, the unit of analysis is health elements in general plans, which was reviewed, analyzed, and used as a model for creating a small-scale, context-sensitive version for the communities of Cayucos and Oceano. Existing health elements in California were examined through a set of criteria to determine which plans will be used as models.

An initial audit was conducted to first determine what governments across the state have incorporated a separate or stand-alone health element into its general plan. In Research Annual Planning Survey Results (2012), the Governor's Office of Planning and Research helped facilitate the process by identifying 36 cities and 13 counties in the state that adopted health elements into their respective general plans. At the time of review, a number of jurisdictions were in various stages of development in the creation of their own health element, with a few waiting for public review and adoption. These were not considered due to time constraints for this project.

Of these 49 health elements, eight documents were initially selected based on a range of subjective cursory criteria including, quality of content, aesthetic appeal, readability and thoroughness. A case study matrix consisting of the eight selected health elements was then created to distinguish evaluation criteria used to determine what health elements would be most useful and relevant in providing modeling guidance for Oceano's Healthy Community Plan. A separate matrix was developed for Cayucos to better reflect the needs of this other, quite different community. The matrix contains evaluative categories such as: scope of plan, planning outreach process utilized (if any), population size, jurisdiction area (in sq. mi), comparable demographical makeup, number of goals, number of policies, provision of implementation strategies (if any), and unique or notable plan aspects. Additionally, new health aspects and topics not found in current health elements were incorporated into the final document where deemed 
relevant and community appropriate. Results of this matrix helped to determine which two or three health elements were used to shape each community health plan. The comparative figures for each community are provided in the matrices which can be found in Appendix B: Case Study Analysis.

\section{Case Studies for Oceano}

Based on the criterion provided in the matrix, as well as other nuanced qualitative aspects (aesthetics, quality of content, et cetera), two stand-out health elements were selected for further in-depth case study analysis: the City of San Pablo's Health Element and the City of South Gate's Healthy Community Element. The format, structure and content of these health elements were determined to be specifically relevant, appropriate and applicable to the town of Oceano for a variety of reasons. First, while there are currently no existing health elements that are written for a community with as small a population as Oceano, both health elements were deemed comparable due to their similar demographic, with all three possessing large or predominantly Hispanic or Latino populations. Second, both case study cities have similarly small land areas, with San Pablo being 2.634 square miles and South Gate at 7.353 square miles, in comparison to the 1.547 square mile footprint of Oceano. Finally, consideration was given to South Gate's health element due to the fact it contained stated goals, objectives and policies, as well as details regarding community outreach efforts in the development of the document. San Pablo's document was perceived to have added value in that a matrix was provided that looked at aspects found in other elements within the general plan and how they related to public health. In addition, San Pablo's health element was unique in that it provided implementation or action strategies to enact policies. 


\section{Case Studies for Cayucos}

For construction of the Cayucos Community Health Plan, three health elements were selected for in-depth review and served as a model: El Monte Health and Wellness Element, the San Pablo General Plan, and the Emeryville Public Health Element. Plans were reviewed first and foremost for innovative concepts and thorough approach to this topic, including public outreach efforts, the presence of implementation, and cost and phasing details. El Monte makes a strong case for the connection between public health and the built environment, starting by providing useful tables that number how many convenience, liquor, and fast food restaurants are in the area. It also provides informative blurbs that define key terms for the reader, and a reference list at the end of the document for further reading or research. Emeryville's PHE is found as subsection ("Environmental Health") under the Sustainability section of its GP. Emeryville has been a leader in sustainable design practices in an effort to curb reliance on fossil fuels, decrease consumption of natural resources, and reducing practices that contribute to climate change. Public health is addressed through transportation, increased pedestrian and bike pathways, and specified purchasing and consumption as strategic ways to improve public health and access to healthy foods. Population size was considered as well, although there were no plans found for a town as small as Cayucos. Because the beach and ocean are such a strong part of the character and draw of Cayucos, elements from beach or waterfront communities were also considered as criteria. Emeryville is a waterfront town, though not a beach community. Lastly, it was important to consider using different consultant authors in the selected elements in order to combine the best, most effective components. 


\section{Phase II: Community Inventory and Outreach}

This phase augments information from Phase II and provides further direction for assembling background information. The goal of outreach is to garner valuable perspective and feedback from community members regarding physical activity levels, information about the built environment where they live, work, and play, and perceived barriers to healthful activities and food access. Data is qualitative in nature and questions were developed with the intent of seeking local knowledge.

The outreach plan was informed by the data collection and analysis phase. Information related to the relationship between health and the built environment, the existing health

conditions and built environments of Cayucos and Oceano, and the outreach processes conducted for other health elements were used to modify the draft outreach plans included in this document. In addition, a stakeholder analysis was conducted for each community Health Plan, and is included on the following pages (Table 5 and Table 6 , Pages 57 and 58). 
Table 5 Cayucos Stakeholder Analysis

\begin{tabular}{|c|c|c|c|c|}
\hline Target group & Organization & $\begin{array}{l}\text { Engagement } \\
\text { Venue }\end{array}$ & Type & Purpose \\
\hline Government agency & Advisory Council & $\begin{array}{l}\text { Community } \\
\text { Meeting }\end{array}$ & Public Meeting & $\begin{array}{l}\text { Disseminate } \\
\text { Information/generate } \\
\text { ideas }\end{array}$ \\
\hline $\begin{array}{l}\text { Government } \\
\text { agency/community } \\
\text { group }\end{array}$ & Health Commission & $\begin{array}{l}\text { One-on-one } \\
\text { meeting }\end{array}$ & $\begin{array}{l}\text { Key Informant } \\
\text { Interview }\end{array}$ & $\begin{array}{l}\text { learn opinions/generate } \\
\text { ideas }\end{array}$ \\
\hline Working adults & $\begin{array}{l}\text { Medical industry, } \\
\text { community member }\end{array}$ & $\begin{array}{l}\text { One-on-one } \\
\text { meeting }\end{array}$ & $\begin{array}{l}\text { Key Informant } \\
\text { Interview }\end{array}$ & $\begin{array}{l}\text { learn opinions/generate } \\
\text { ideas }\end{array}$ \\
\hline Government agency & County Planning & $\begin{array}{l}\text { One-on-one } \\
\text { meeting }\end{array}$ & $\begin{array}{l}\text { Key Informant } \\
\text { Interview }\end{array}$ & $\begin{array}{l}\text { learn opinions/generate } \\
\text { ideas }\end{array}$ \\
\hline $\begin{array}{l}\text { Community member } \\
\text { (Young Adult) }\end{array}$ & Freelance Journalist & $\begin{array}{l}\text { One-on-one } \\
\text { meeting }\end{array}$ & $\begin{array}{l}\text { Key Informant } \\
\text { Interview }\end{array}$ & $\begin{array}{l}\text { learn opinions/generate } \\
\text { ideas }\end{array}$ \\
\hline $\begin{array}{l}\text { Community member } \\
\text { (Young Adult)/Health } \\
\text { agency }\end{array}$ & $\begin{array}{l}\text { County Health } \\
\text { Agency }\end{array}$ & $\begin{array}{l}\text { One-on-one } \\
\text { meeting }\end{array}$ & $\begin{array}{l}\text { Key Informant } \\
\text { Interview }\end{array}$ & $\begin{array}{l}\text { learn opinions/generate } \\
\text { ideas }\end{array}$ \\
\hline Seniors & Senior Citizen Club & $\begin{array}{l}\text { One-on-one } \\
\text { meeting }\end{array}$ & $\begin{array}{l}\text { Group } \\
\text { discussion / } \\
\text { Presentation }\end{array}$ & $\begin{array}{l}\text { learn opinions/generate } \\
\text { ideas }\end{array}$ \\
\hline Businesses & $\begin{array}{l}\text { Chamber (also on } \\
\text { CCAC) }\end{array}$ & $\begin{array}{l}\text { Smaller group } \\
\text { meeting }\end{array}$ & $\begin{array}{l}\text { Group } \\
\text { discussion / } \\
\text { Presentation }\end{array}$ & $\begin{array}{l}\text { learn opinions/generate } \\
\text { ideas }\end{array}$ \\
\hline Community Group & Lionesses & $\begin{array}{l}\text { Smaller group } \\
\text { meeting }\end{array}$ & $\begin{array}{l}\text { Group } \\
\text { discussion / } \\
\text { Presentation }\end{array}$ & $\begin{array}{l}\text { learn opinions/generate } \\
\text { ideas }\end{array}$ \\
\hline $\begin{array}{l}\text { Community } \\
\text { Members/Educators } \\
\text { (Families/Children) }\end{array}$ & PTA/School/children & $\begin{array}{l}\text { Smaller group } \\
\text { meeting }\end{array}$ & $\begin{array}{l}\text { Group } \\
\text { discussion / } \\
\text { Presentation }\end{array}$ & $\begin{array}{l}\text { learn opinions/generate } \\
\text { ideas }\end{array}$ \\
\hline Religious orgs & & $\begin{array}{l}\text { One-on-one } \\
\text { meeting }\end{array}$ & Questionnaire & $\begin{array}{l}\text { learn opinions/generate } \\
\text { ideas }\end{array}$ \\
\hline Community Group & $\begin{array}{l}\text { Rotary (also on } \\
\text { CCAC) }\end{array}$ & $\begin{array}{l}\text { Smaller group } \\
\text { meeting }\end{array}$ & $\begin{array}{l}\text { Group } \\
\text { discussion / } \\
\text { Presentation }\end{array}$ & $\begin{array}{l}\text { learn opinions/generate } \\
\text { ideas }\end{array}$ \\
\hline Community members & Library & $\begin{array}{l}\text { One-on-one } \\
\text { meeting }\end{array}$ & Questionnaire & $\begin{array}{l}\text { learn opinions/generate } \\
\text { ideas }\end{array}$ \\
\hline Community members & Skate park & $\begin{array}{l}\text { One-on-one } \\
\text { meeting }\end{array}$ & Questionnaire & $\begin{array}{l}\text { learn opinions/generate } \\
\text { ideas }\end{array}$ \\
\hline Community members & Pier & $\begin{array}{l}\text { One-on-one } \\
\text { meeting }\end{array}$ & Questionnaire & $\begin{array}{l}\text { learn opinions/generate } \\
\text { ideas }\end{array}$ \\
\hline Community members & Cayucos Grocery & $\begin{array}{l}\text { One-on-one } \\
\text { meeting }\end{array}$ & Questionnaire & $\begin{array}{l}\text { learn opinions/generate } \\
\text { ideas }\end{array}$ \\
\hline Community members & Beach & $\begin{array}{l}\text { One-on-one } \\
\text { meeting }\end{array}$ & Questionnaire & $\begin{array}{l}\text { learn opinions/generate } \\
\text { ideas }\end{array}$ \\
\hline Community members & Elementary School & $\begin{array}{l}\text { One-on-one } \\
\text { meeting }\end{array}$ & Questionnaire & $\begin{array}{l}\text { learn opinions/generate } \\
\text { ideas }\end{array}$ \\
\hline Community members & Downtown & $\begin{array}{l}\text { One-on-one } \\
\text { meeting }\end{array}$ & Questionnaire & $\begin{array}{l}\text { learn opinions/generate } \\
\text { ideas }\end{array}$ \\
\hline Community Members & $\begin{array}{l}\text { Public } \\
\text { Place/Pier/Grocery }\end{array}$ & Planned event & Public Event & $\begin{array}{l}\text { present ideas/learn } \\
\text { opinions }\end{array}$ \\
\hline $\begin{array}{l}\text { All/Government } \\
\text { Agency }\end{array}$ & CCAC & $\begin{array}{l}\text { Community } \\
\text { Meeting }\end{array}$ & Public Meeting & $\begin{array}{l}\text { Disseminate } \\
\text { information/present } \\
\text { ideas/learn opinions }\end{array}$ \\
\hline $\begin{array}{l}\text { All/Government } \\
\text { Agency }\end{array}$ & Health Commission & $\begin{array}{l}\text { Community } \\
\text { Meeting }\end{array}$ & Public Meeting & $\begin{array}{l}\text { Present final } \\
\text { plan/findings }\end{array}$ \\
\hline
\end{tabular}


Table 6 Oceano Stakeholder Analysis

\begin{tabular}{|c|c|c|c|}
\hline Organization/Individual & Target Group & $\begin{array}{c}\text { Engagement } \\
\text { Activity }\end{array}$ & Purpose \\
\hline Oceano Elementary & $\begin{array}{c}\text { Oceano youth (preteens; } \\
11-12 \text { year olds) }\end{array}$ & $\begin{array}{l}\text { Class } \\
\text { exercise/survey }\end{array}$ & $\begin{array}{l}\text { Learn opinions/generate } \\
\text { ideas }\end{array}$ \\
\hline Oceano Principal & $\begin{array}{c}\text { School age children ages K- } \\
6\end{array}$ & $\begin{array}{l}\text { Key informant } \\
\text { interview }\end{array}$ & Gain insight to community \\
\hline $\begin{array}{l}\text { Keystone Teen } \\
\text { Program/Boys \& Girls } \\
\text { Club }\end{array}$ & Oceano youth (teenagers) & $\begin{array}{l}\text { Key informant } \\
\text { interview }\end{array}$ & Gain insight to community \\
\hline Oceano PTA & Parents/Teachers & Presentation & $\begin{array}{l}\text { Learn opinions/generate } \\
\text { ideas }\end{array}$ \\
\hline \multicolumn{4}{|c|}{ Low-income, Disadvantaged Community Members } \\
\hline $\begin{array}{l}\text { Oceano Family } \\
\text { Resource Center }\end{array}$ & Families & $\begin{array}{l}\text { Key informant } \\
\text { interviews (2) }\end{array}$ & Gain insight to community \\
\hline \multirow[t]{2}{*}{$\begin{array}{l}\text { S.A.F.E. Oceano Safe } \\
\text { Healthy Starts }\end{array}$} & $\begin{array}{l}\text { Latino families; at-risk and } \\
\text { disadvantaged families }\end{array}$ & Presentation & $\begin{array}{l}\text { Disseminate } \\
\text { information/gain insight to } \\
\text { community/ask for support }\end{array}$ \\
\hline & Local government official & $\begin{array}{l}\text { Key informant } \\
\text { interview }\end{array}$ & Gain insight to community \\
\hline $\begin{array}{l}\text { SLO County Health } \\
\text { Commission }\end{array}$ & Local government official & Presentation & $\begin{array}{l}\text { Present draft of Health } \\
\text { Plan; garner feedback }\end{array}$ \\
\hline $\begin{array}{l}\text { Oceano Advisory } \\
\text { Council }\end{array}$ & $\begin{array}{l}\text { Government body, } \\
\text { community members }\end{array}$ & Presentation & $\begin{array}{l}\text { State intentions/learns } \\
\text { opinions/generate ideas }\end{array}$ \\
\hline $\begin{array}{l}\text { Community Service } \\
\text { District }\end{array}$ & $\begin{array}{l}\text { Government body, } \\
\text { community members }\end{array}$ & Presentation & $\begin{array}{l}\text { State intentions/learns } \\
\text { opinions/generate ideas }\end{array}$ \\
\hline $\begin{array}{l}\text { Oceano Community } \\
\text { Farmers' Market }\end{array}$ & $\begin{array}{l}\text { Those most vulnerable to a } \\
\text { lack of access to nutritious } \\
\text { healthy food sources. Local } \\
\text { business vendors }\end{array}$ & $\begin{array}{l}\text { Presentation/ } \\
\text { Survey }\end{array}$ & $\begin{array}{l}\text { Learn opinions/generate } \\
\text { ideas }\end{array}$ \\
\hline $\begin{array}{l}\text { La Tapatia Market \& } \\
\text { Deli }\end{array}$ & Community members & Survey & $\begin{array}{l}\text { Collect community } \\
\text { feedback }\end{array}$ \\
\hline Central Market & Community members & Survey & $\begin{array}{l}\text { Collect community } \\
\text { feedback }\end{array}$ \\
\hline \multicolumn{4}{|l|}{ TBD } \\
\hline Laguna Park & Community members & Survey & $\begin{array}{l}\text { Collect community } \\
\text { feedback }\end{array}$ \\
\hline $\begin{array}{l}\text { Oceano Branch Public } \\
\text { Library }\end{array}$ & Community members & Survey & $\begin{array}{l}\text { Collect community } \\
\text { feedback }\end{array}$ \\
\hline $\begin{array}{l}\text { Saint Francis of Assisi } \\
\text { Catholic Church }\end{array}$ & Community members & Survey & $\begin{array}{l}\text { Collect community } \\
\text { feedback }\end{array}$ \\
\hline Other Religious Org. & Community members & Survey & $\begin{array}{l}\text { Collect community } \\
\text { feedback }\end{array}$ \\
\hline Oceano beach area & Community members & Survey & $\begin{array}{l}\text { Collect community } \\
\text { feedback }\end{array}$ \\
\hline Door-to-door surveying & Community members & Survey & $\begin{array}{l}\text { Collect community } \\
\text { feedback }\end{array}$ \\
\hline $\begin{array}{l}\text { Oceano Community } \\
\text { Center (Day of the } \\
\text { Child) }\end{array}$ & Community members & Presentation & $\begin{array}{l}\text { Disseminate } \\
\text { information/collect } \\
\text { feedback }\end{array}$ \\
\hline
\end{tabular}




\section{PRESENTATIONS TO LOCAL GOVERNMENT AGENCIES}

Presentations were scheduled with local government agencies of both respective communities. The purpose of these presentations were to announce our presence in each community, to state what our intentions would be while working there, to provide the scope and details of our project and ask for their support, as well as to request information and field questions. This was determined to be an important initial step that was necessary prior to the start of any public outreach efforts.

As unincorporated towns, Oceano and Cayucos lack typical local government bodies such as a city council and planning commission. As such, it was determined that scheduling presentations before the town's primary local government agencies, the Oceano Community Service District (CSD), and the Oceano Advisory Council (OAC) in Oceano, and the Cayucos Citizen Advisory Council in Cayucos, would be an important initial step to be made prior to the onset of any project related work. The Oceano CSD is a multi-service special district that serves both residents and business people of Oceano and neighboring unincorporated community of Halcyon with fire protection, sewer, water services and street lighting. The OAC and the CCAC serve as liaisons between the unincorporated town and the County Board of Supervisors, promoting community involvement and awareness of planning and community development issues, acting in an advisory capacity and not as an approval board.

\section{Cayucos Citizens Advisory Council}

Meeting with the advisory council was the first step in the Cayucos outreach process. It included correspondence with the Cayucos Community Advisory Committee chair prior to the December meeting to secure a time on the agenda. The presentation was organized through a PowerPoint presentation to inform the group about the project, the 
regulatory framework, and the role of the CCAC. Preliminary questions were also asked of this group. They included:

- What days are best to conduct outreach?

- What times and days do most people attend events (especially local government events that are not that fun)?

- What other organizations are involved/know a lot of people in Cayucos?

- Any pressing health issues that you know of that might not readily show up in survey/reporting results?

The presentation was meant to introduce project, meet the committee, and receive direction from this key group of stakeholders. The outcomes of the meetings with the local government agencies are detailed in the Findings section for each community.

\section{KEY INFORMANT INTERVIEWS}

Key Informants were instrumental in gathering local knowledge in both communities. A small number of individuals deemed to have specialized or in-depth knowledge of their respective communities were identified prior to initiating the interview process. Many of these individuals were known in advance as potential candidates to approach, but a few of the interviews came about organically through the recommendations of others, including other key informants themselves. Representatives from the advisory councils, School District, PTA, and community groups were interviewed regarding health issues, community priorities, assets and factors contributing to health, and barriers to improving health in the community.

With assistance from the project's client, a key informant questionnaire was developed in January and February. The questionnaire consisted of eight primary questions with 
additional follow-up questions dependent on how the subject answered the initial probing question. The questionnaire was utilized as a script, but could be deviated from as the conversation and direction of the discussion dictated it. Most interviews were conducted over the phone, though some were held face-to-face. The details and outcomes of these interviews can be found in the Findings chapters for Cayucos and Oceano.

\section{QUESTIONNAIRES}

A questionnaire was drafted and approved by client and advisor in February, 2014 and distributed throughout February, March, and April in an effort to gather quantifiable data that would provide an indication of community health levels, access to healthy foods, and sentiments regarding the built environment in Oceano and Cayucos. The questionnaire was developed and distributed in an effort to gather quantifiable data to give an indication of community health levels, access to healthy foods, and sentiments regarding the built environment in Cayucos and Oceano.

The questionnaire was distributed to any resident of or worker in each of the communities. Effort was made to avoid distributing the questionnaire to infrequent visitors, although some visitors to Cayucos were included, especially if they had strong ties to the community, such as owning a vacation home or visiting family members. Because the questionnaire was not distributed to a sampling of either community, it cannot be called a proper survey. However, an effort was made to reach out to each segment of the community through visiting several locations in each town at different times of day, on both weekdays and weekends. Other methods of outreach, as described further in this section, also were prioritized in order to gather information from different types of people and several groups within each community. 
Some of questions were posed in a scaled answer format in order to better be able to place the respondents in a continuum to provide more nuanced data. The questionnaire was also translated to Spanish in order to better reach Oceano community members. The questionnaire was posted online through Survey Monkey to reach a wider range of residents in both towns. The remainder of questionnaire distribution was through "guerrilla" planning visits to parks, grocery stores, and community gatherings to reach residents. A copy of the questionnaire is included in Appendix C: Outreach Materials. Questions included:

- What contributes most to your quality of life in Cayucos/Oceano?

- What do you think makes it most difficult to be healthy or detracts from overall wellness here?

- What would you want to change in Cayucos/Oceano that could contribute to your personal health or the health of community as a whole?

\section{Questionnaires in Oceano}

In Oceano, questionnaires were informally conducted at predetermined locations of high pedestrian traffic such as Central Market and La Tapatía Market \& Deli, as suggested by the aforementioned local government agencies. Community based groups such as the S.A.F.E. Oceano Healthy Start - Family Resource Center (hereafter: Family Resource Center), Oceano Community Farmers' Market (OCFM) and the Oceano Elementary Parent-Teacher Association (OPTA) were also identified as initial target groups to survey. As described by the Lucia Mar Unified School District website, the Family Resource Center is a school district linked group that coordinates community resources to keep children "safe, healthy, at home, in school and out of trouble" (Family Resource Centers, n.d.). The OCFM is a committee of Oceano residents seeking to establish a 
seasonal, weekly open-air farmers' market, where it is envisioned residents and visitors will be able to purchase fresh produce and learn about healthy living (Charlton, 2013). The OPTA is a formal organization intended to foster interaction and participation of parents of Oceano Elementary students concerning the "welfare of children and youth in home, school, community, and place of worship" ("Mission, Goals and Purpose”, 2014). Both the Family Resource Center and OCFM were inviting and interested in the project, finding common ground with the general promotion of health for Oceano residents and over concerns regarding access to healthy foods. It should be noted, despite multiple efforts through correspondence, there was a failure to elicit interest in the project or survey with the OPTA.

The relationship established with the Family Resource Center proved especially beneficial for this project being particularly connected with the Hispanic and Latino population, the group possesses a far-reaching influence within the community. They showed great interest in assisting with the project, volunteering time and effort to help conduct the surveys. This task was accomplished by dispersing surveys to their constituents, door-knocking and other informal methods to complete the questionnaires.

\section{$\underline{\text { Questionnaires in Cayucos }}$}

In Cayucos, the Healthy Communities class at Cal Poly (CRP 470) assisted with this portion of outreach. As part of the curriculum, the class learned about the projects, practiced outreach methods, and visited three locations to conduct questionnaires on February 21,2014 . The locations were chosen based on proximity to community destinations and spaces. They included 1) the pier and beach, near the Vet's Hall and several restaurants and retail locations, 2) the library, Hardie Park, and Cayucos Elementary School, and 3) the Cayucos Market, near Paul Andrew Park and the Sea 
Shanty. Students were provided training in-class, which included a project introduction, a script for administering the questionnaire, and time to practice administering the questionnaire among their peers. Questionnaires were also distributed to all members of several community groups, including the Cayucos Senior Club, Cayucos Lioness Club, Rotary, and the Cayucos Elementary Parent-Teacher Association. In addition, information about health and the project was distributed to each questionnaire participant. This was attached to a somewhat-healthy treat of individually wrapped trail mix, and included a link to the survey monkey questionnaire and an invitation to encourage the participant's family or friends to participate.

\section{PUBLIC EVENTS}

\section{Cayucos Community Group Meetings}

In order to efficiently gather feedback from community stakeholders, several community groups were contacted to arrange a meeting to discuss the Community Health Plan. Of those contacted, four groups arranged a meeting: the Cayucos Elementary Parent Teacher Association (PTA), the Lioness Club, Rotary, and the Seniors Club, all of which included a presentation about the project and group discussion. Presentation materials can be found in Appendix C: Outreach Materials.

Questionnaires were distributed to individual group members at each meeting. In a large group or in smaller groups, three questions were posed for a short discussion. The questions were:

- What are the top three contributors to the health of the Cayucos community?

- In your experience, what are the top 3 most important health issues in Cayucos? 
- What solutions might you propose to increase physical activity, healthy eating, or to address other "root determinants" of health?

The small groups were then asked to share with the larger group.

\section{Cayucos Farmers Market: Public Space Improvements}

Graduate students in the City and Regional Planning Program at Cal Poly, San Luis Obispo conducted a planning process for the purpose of preserving and improving public space within Cayucos. The project is entitled "Connecting Cayucos: Visions and Actions for Public Space." The proposal includes ideas for parks, streets, and other public spaces. It also considers issues related to parking and economic vitality. This project provided additional public outreach opportunities and community input that helped to inform the Cayucos Community Health Plan.

Outreach included a voting exercise to find out about the desires and needs of community members and visitors, and took place at the Cayucos' Farmers Market on May 23 and May $30^{\text {th }}$. The studio project centered on five main themes as ways of "Connecting Cayucos" through community identity, accessibility, natural resources, health and safety, and economic vitality. These themes were addressed throughout the options for public space improvements illustrated for voting purposes.

\section{Cayucos School Outreach}

Activities at Cayucos Elementary were conducted on May 24, 2014, in conjunction with the graduate studio class. Cal Poly students brought materials to engage a group of eight graders through a mapping activity. The mapping exercise involved students selecting cutout images of things that were representative of what they liked to do for

physical activity; things that would make them feel safer; and things they "wished" were 
present in Cayucos. Students were also asked to indicate the travel mode and route they took to school. The exercise concluded with each group collectively discussing the features they would most like to have in Cayucos.

\section{Oceano Elementary Event}

On February 21, 2014, a survey and mapping exercise was conducted with Mr. Jim Dececco's 6th grade class at Oceano Elementary. Volunteers from Prof. Kelly Main's City and Regional Planning (CRP) 470 class helped facilitate the event. The primary purpose of the event was to get a better understanding of what Oceano children do for physical activity, their eating habits, and inquire about what types of things would potentially motivate them to become more active

A brief survey was conducted prior to the start of the mapping exercise. Along with basic demographic information (gender and age), the questionnaire was comprised of six questions and was developed with the help of the project's chair. Students were asked to complete the questionnaire in its entirety, but informed they didn't have to answer any questions they were unsure of or not comfortable answering. CRP volunteer assistants were available to explain survey questions, but were careful not to guide students into answers.

The class was broken up into small groups for the participatory mapping exercise. Students were asked to select from a pile of images the types of things that represented what they do for physical activity, things that would make them feel safer, and things they would like Oceano to have. They were then asked to glue in place the images on the map relative to where they do the activity or where they would like to have the feature located. Students were also asked indicate the general location of where they lived in the community and the mode of travel and route they took to school and back. At 
the conclusion of the exercise, each group discussed collectively built environment features they would most like Oceano to have.

\section{Oceano Day of the Child Event}

On April 27, 2014, an information booth was reserved for the Day of the Child event held at the Oceano Community Center in Oceano. This free annual event features local nonprofit, community and government agencies concerned with nutrition, exercise and healthcare for children. Easels featuring large graphs of survey results were presented to the public, as well as a PowerPoint presentation that included photos and a description of the mapping exercise held at Oceano Elementary. Additionally, a large scroll of blank paper was provided on the table and visitors were asked to list built environment features they wish they had in Oceano. Lead group members of Oceano S.A.F.E. assisted at the event.

\section{PLAN DRAFT REVIEW MEETINGS}

Outcomes of the outreach process determined the direction of goals, implementation measures, and policy recommendations. The last outreach efforts involved returning to the community with draft goals, policies, and implementation measures for review.

\section{$\underline{\text { Plan Draft Review in Cayucos }}$}

In Cayucos, the final outreach efforts involved returning to the community with draft goals, policies, and implementation measures for review. This process occurred first at an event in a community gathering space, the Veteran's Hall. This event was a joint effort conducted for the purposes of this project and Professor Main's Graduate Studio Class, which focused on public spaces in Cayucos. Because the topics overlap extensively, feedback was gathered for both planning efforts. The feedback from these 
efforts further informed the project about specific community concerns, perceptions, wants and needs, and strategies for improving spaces and would like incorporated into their community. The community feedback was recorded, analyzed and considered in the process of drafting initial policy language.

\section{$\underline{\text { Plan Draft Review in Oceano }}$}

A final event was held on June 23, before the Oceano Advisory Council to present the community with a draft of created goals, policies and action programs developed for Oceano. This event will seek the community's input and record the responses and attitudes towards the policy language outlined in the Health Plan draft. That feedback will then be used to further modify the document accordingly as appropriate.

\section{PRESENTATION TO SAN LUIS OBISPO COUNTY HEALTH COMMISSION}

The project was also presented at the San Luis Obispo County Health Commission

meeting on June 9,2014 . The Health Commission meeting provided a forum for public presentation of the final plan, and was televised locally and via web-streaming.

\section{Phase III: Goals, Policies, and Implementation Recommendations}

\section{GOALS AND POLICIES}

The result of Phase I and II informed the process of creating goals for the communities. These goals refer to those that the community may be able to reach without the adoption of a health element into the County general plan. The goals will synthesize those concerns and desires said by the community during the outreach process, as well as information on existing conditions in Cayucos and Oceano. 
Using outreach results and background information, synthesized goals and policies were developed to increase the capacity for improving the state of health in the built environment throughout the county. These include proposed changes to the San Luis Obispo County General Plan. These considerations serve as a "next steps" portion of the document, and may be helpful to interested parties for gaining traction at the policy level.

\section{IMPLEMENTATION MEASURES}

Based on goals and policies, implementation measures were outlined to achieve changes in the built environment that will improve community health. They were created using information gathered in Phase I, and modeled after aspects from existing health elements considered to be best practices for Cayucos and Oceano, as determined by the case study matrix. Health aspects unique to the communities, as based on findings in Phase II, were also incorporated. 


\section{EXISTING CONDITIONS}

The following sections serve to describe the health conditions in Cayucos and Oceano.

This summary of health conditions in Cayucos, Oceano, and San Luis Obispo County comprises data and findings outlined in the 2013 ACTION for Healthy Communities Report, released in 2014 by the Community Foundation, public school survey results, public health data, and information from applicable existing plans. Existing Conditions topics include the following:

- Demographic information including age, income, race, and educational attainment for each community

- Housing and transportation data for each community

- Death rates by community

- Data on Physical health, countywide and by region

- Physical activity measures and levels, countywide and by community

- Mental health and wellbeing

- Substance use, countywide and by region

- Food Access and eating habits, countywide and by region

- Environmental Quality

- Public Safety, countywide and by region

- Area Plan Analysis

- Oceano Revitalization Plan and Oceano Specific Plan

- Local Coastal Plan information 
As noted in the Methodology Chapter, there are some limits to this information due to the fact that both communities are unincorporated and data is generally only available for the individual cities in the county, with all unincorporated areas presented in aggregate. Community-specific information was taken largely from 2012 US Census data. Implications for Cayucos and Oceano are summarized below.

\section{Cayucos Demographics}

\section{POPULATION AND HOUSING}

There are 2,431 Cayucos residents in the 3.1 square mile community boundary. From 1970 to 1990 , the population grew $67 \%$ from 1770 to 2960 . In 2000 the population was 2,943 , a decrease of $12 \%$. The growth of Cayucos and nearby communities has been limited since the 1980's due to utilities limitations such as water supply in Cayucos and sewage disposal in Los Osos. While permanent residents have decreased, the number of housing units has grown, suggesting a growth in seasonal residents not shown in the census. Cayucos currently has 2,354 total housing units and 1,040 vacant housing units, making up $44 \%$ of the total housing units. Fifty percent of units are vacant, probably due to the use of units as vacation homes and vacation rentals. Much of the vacancy rate can be explained in the 893 seasonal, vacation use homes or second homes. There are 1,214 households, with on average two people per household. Cayucos has a high rate of owner-occupied units at $70 \%$, which is about $20 \%$ higher than the county rate. Seventy-four percent of owner-occupied units are valued at 500,000 or more, and $22 \%$ are over one million, which is more than double the county rate of $7 \%$. 
AGE

The median age in Cayucos is 57.2 about 1.5 times that in San Luis Obispo County, where the median age is 37.4. Sixty-five percent of residents are over fifty years of age, and $76 \%$ of residents are over forty. The number of Cayucos residents under the age of 18 is 337 , comprising only $13 \%$ of the population. This number has decreased from $17 \%$ in 2000 , which illustrates the trend toward an aging population. Almost $10 \%$ of Cayucos residents are military veterans, about 1.5 times the rate of California overall (6.5\%).

\section{INCOME AND POVERTY}

Income overall is high in Cayucos, with per capita income at $\$ 42,000$ per year. This is about 1.4 times the amount in the county and California overall, which is about $\$ 30,000$ per capita. Median income is a little higher than the amount in the County and California. However, higher incomes are more prevalent in Cayucos than in the county overall. The percentage of Cayucos households with an income of $\$ 50,000-\$ 100,000$ is $10 \%$ higher than the county at about $1 / 3$ of households, and the percentage with an income of $\$ 100,000-\$ 200,000$ is $20 \%$ higher at one quarter of the population. Approximately $81.6 \%$ of those who work in Cayucos travel outside of Cayucos to reach their place of employment, making Cayucos a "bedroom community". Tourism is an important economic driver in Cayucos. Most businesses cater towards local residents and tourists' retail and service needs. Cayucos is home to many home vacation rentals, as well as 12 hotels and motels (U.S. Census Bureau, Census Bureau, 2008-2012 American Community Survey, 2011 ZIP Code Business Patterns). The poverty rate, however, is higher than that of the County at $15.8 \%$, as opposed to the County's $13.7 \%$. Twelve percent of seniors 65 and over are below the poverty line, more than double the rate in the County as a whole. Children under 18 also have a high poverty rate in Cayucos at 
$36 \%$, which is also more than double that in the County, and 1.5 times the rate in California as a whole. It is important to note that these statistics could be skewed by the small sample size surveyed in Cayucos.

\section{RACE, ETHNICITY, AND LANGUAGE}

The community in Cayucos $87 \%$ white as reported in the 2010 census. This rate is about 25\% higher than San Luis Obispo County, and more than double the rate in California as a whole. Hispanic respondents of any race were represented at $7 \%$ of the population, and 3\% responded Asian. Cayucos residents also speak English at home almost exclusively, with $3 \%$ of the 18 and over population speaking Indo-European languages, and $2 \%$ of the population speaking Spanish at home among adults 18 and over. The percent speaking English at home is nearly double that of California overall.

\section{TRANSPORTATION}

Highway 1 serves as the principal arterial or main access roadway to both the northern and southern portions of Cayucos. The central street of the town, Ocean Avenue, is classified as an arterial roadway, serving as the major artery of Cayucos. Other major roadways, classified as collectors, include Cayucos Drive, Pacific Ave, 13th Street, 24th Street, Studio Drive, and Old Creek Road. All other roadways within the town are classified as residential, designating lighter and slower vehicular traffic. Commercial activity is mostly restricted to the CBD and along Ocean Avenue, the main route into the CBD (Estero Area Plan, 2009). Mean travel time to work in Cayucos is similar to the figure for county residents at 18.2 minutes, and about 10 minutes less than the mean travel time for California as a whole. Mode of transportation to work was also comparable to that of county workers with $75 \%$ driving alone. Fourteen percent carpooled, as opposed to $11 \%$ countywide. Cayucos currently has one bus route that 
serves the community. The San Luis Obispo Regional Transit Authority (SLO RTA) bus route 15 passes by the town of Cayucos. There are four main stops in Cayucos heading northbound and southbound.

\section{EDUCATION}

Educational attainment in Cayucos is high, with $94.5 \%$ having attained a high school diploma or higher degree of education. This is higher than both the county rate of $91.3 \%$ and the statewide rate of $81 \%$. Residents hold bachelor degrees at a rate of $40.5 \%$, compared to $30.5 \%$ in California. Seventeen percent of residents hold a post-grad degree, compared to $12 \%$ in the county and $11 \%$ in the state.

\section{Oceano Demographics}

\section{POPULATION AND HOUSING}

There are 7,286 Oceano residents in the 1.547 square mile boundary. There are 2,603 households, with nearly three people (2.80) per household on average. Fourty-four percent of households are married couples, which is slightly below the County and state percentages of 48.7 and 49.4 percent. In Oceano 34.5 percent of households are nonfamily, compared to 22 percent in the county and 15 percent in California overall. There are an estimated 3,081 housing units in Oceano, with an occupancy rate of $88.7 \%$. A large mobile home community accounts for 23.8 percent (732 units) of the total housing units in Oceano. 90.7 percent of the homes in Oceano are valued at $\$ 500 \mathrm{~K}$ or less; 62.4 percent of the homes are valued less than $\$ 300 \mathrm{~K}$, a figure which is dramatically higher than both county (23.3 percent) and state (36.6 percent) levels. 
AGE

According to the 2010 U.S. Census, the median age of Oceano is just 35.4 years old, falling well below the state median age of 45.6 years old. In contrast to Cayucos, only 14 percent of the population is over 50 years of age, and only approximately 20 percent are over the age of 40 .

\section{INCOME AND POVERTY}

Oceano can largely be considered a relatively young, low-income, community with a median household income of $\$ 41,865$ (\$34,938 for Hispanic or Latino) and a per capita income of only $\$ 19,724$. These numbers are well below the County's figures of $\$ 59,628$ and $\$ 30,218$ respectively. According to the 2008-2012 American Community Survey, Oceano has an estimated poverty rate of 16.3 percent, with those identifying themselves as Hispanic or Latino (of any race) at a slightly higher rate of 16.5 percent. In addition, a significant percentage (13.6 percent) of seniors age 65 and older is living below the poverty line; a markedly larger number than the County's figure of 5.8 percent.

\section{RACE, ETHNICITY AND LANGUAGE}

The 2008-2012 American Community Survey 5-year estimates indicate 50.7 percent of the Oceano population identify themselves as Hispanic or Latino (of any race). This percentage is approximately 2.5 times greater than the County rate of 20.8 percent. About 45 percent of the population identify themselves as white. At 66 percent, the majority of residents speak English only, with the largest remaining percentage (32.6 percent) of residents speaking Spanish. A large portion (76.8 percent) of the population is not U.S. citizens. This is likely a reflection of the large number of migrant workers in the community. 


\section{TRANSPORTATION}

The drive-alone rate for Oceano workers age 16 years and over is 69.3 percent. A significantly high percentage (22.1 percent) of workers carpooled to work, in contrast to both County and state figures of 10.6 and 11.5 percent. The percentage of Oceano workers that walked to work (4 percent) is greater than the state (2.8 percent), but less than the County (4.3 percent).

\section{EDUCATION}

Educational attainment in Oceano is poor, with just 73.3 percent of the population possessing a high school diploma or higher degree of education. Sixteen percent of residents hold a bachelor's degree or higher, approximately two times less than both the County (31.5 percent) and state (40.5 percent) percentages. Less than five percent of the population holds a post-graduate degree.

\section{San Luis Obispo County Health}

The ACTION for Healthy Communities report was a major source of information for this chapter. ACTION for Healthy Communities, San Luis Obispo County is identifies community needs and improve health through a collaborative effort. The 2013 report is the sixth update to the project, which began in 1999. The report is helpful because of its comprehensive information, and because it represents a statistically significant survey study of health indicators for the county. The report details overall trends for the whole county, but also gives data separately for four county regions: North Coast, North County, San Luis Obispo, and South County. Cayucos is part of the North Coast region along with Baywood, Cambria, Harmony, Los Osos, Morro Bay, and San Simeon. Oceano is included in the South County area along with Arroyo Grande, Halcyon, Grover 
Beach, Nipomo, Pismo Beach, and Shell Beach (ACTION, 2013). Other data was drawn from the US Census, California Healthy Kids Survey, California Department of Health Services, and other publicly available sources.

\section{PHYSICAL HEALTH}

In 2011-12, 92\% of California Health Interview Survey respondents in San Luis Obispo County said their health was "excellent", "very good", or "good," compared to $87 \%$ in 2001. Approximately one-third of Spanish-Speaking face-to-face ACTION survey respondents (31\%) and homeless respondents (35\%) reported having "fair" or "poor" health in 2013 (ACTION, 2013).

A body mass index (BMI) of 30 kilograms/meter or more is considered obese, and overweight is considered to be a BMI of $25 \mathrm{~kg} / \mathrm{m}$ or more. According to the California Health Interview Survey, in 2011-2012 48\% of adults in San Luis Obispo County were overweight or obese, which was lower than the state of California as a whole $(60 \%)$.

The county cancer death rate declined, though it continues to be the leading cause of death in the county. San Luis Obispo County had higher death rates that California for stroke, unintentional injury, suicide, motor vehicle accidents, firearms, and drug-related causes (CDHS, 2010). These trends were similar in Cayucos and Oceano for 20082010, where cancer and heart disease were the leading cause of death (See Table 7). 
Table 7 Leading Causes of Death by ZIP Code of Decedent's Residence

\begin{tabular}{|c|c|c|c|c|c|c|c|c|}
\hline & \multicolumn{4}{|c|}{ Cayucos } & \multicolumn{4}{|c|}{ Oceano } \\
\hline & 2008 & 2009 & 2010 & Total & 2008 & 2009 & 2010 & Total \\
\hline Cancer & 10 & 6 & 8 & 24 & 15 & 11 & 10 & 36 \\
\hline Diseases of the Heart & 11 & 7 & 5 & 23 & 13 & 7 & 15 & 35 \\
\hline $\begin{array}{l}\text { Chronic Lower } \\
\text { Respiratory Disease }\end{array}$ & 1 & 2 & 3 & 6 & 2 & 9 & 0 & 11 \\
\hline Injury & 1 & 1 & 3 & 5 & 3 & 4 & 0 & 7 \\
\hline Stroke & 2 & 0 & 2 & 4 & 3 & 2 & 2 & 7 \\
\hline Suicide & 0 & 3 & 1 & 4 & 1 & 2 & 2 & 5 \\
\hline $\begin{array}{l}\text { Essential Hypertension \& } \\
\text { Hypertensive Renal } \\
\text { Disease }\end{array}$ & 2 & 0 & 1 & 3 & 3 & 0 & 1 & 4 \\
\hline Alzheimer's Disease & 1 & 1 & 0 & 2 & 0 & 0 & 4 & 4 \\
\hline Diabetes & 0 & 1 & 1 & 2 & 1 & 2 & 1 & 4 \\
\hline $\begin{array}{l}\text { Chronic Liver Disease } \\
\text { and Cirrhosis }\end{array}$ & 0 & 0 & 2 & 2 & 2 & 0 & 1 & 3 \\
\hline Influenza and Pneumonia & 0 & 1 & 0 & 1 & 1 & 1 & 2 & 4 \\
\hline $\begin{array}{l}\text { Nephritis, Nephrotic } \\
\text { Syndrome and Nephrosis }\end{array}$ & 0 & 0 & 0 & 0 & 0 & 1 & 1 & 2 \\
\hline Other & 6 & 4 & 2 & 12 & 8 & 14 & 15 & 37 \\
\hline Total & 34 & 26 & 28 & 88 & 52 & 53 & 54 & 159 \\
\hline
\end{tabular}

(County Health Status Profiles, California Department of Health Services and California Conference of Local Health Officers, 2003-2011).

The percentage of county residents with health insurance and those with a regular source of healthcare decreased since 2010 . The percentage of people with an inability to receive medical care due to cost increased, and $73.4 \%$ of those without insurance do not have it because they cannot afford it or it is too expensive. In the North Coast region $85 \%$ of residents have health insurance, and $35.4 \%$ of them have insurance through a state or federal program such as Medicare or Medi-Cal (ACTION, 2013). The nearest hospitals to Cayucos are the Sierra Vista and French Hospitals located in the City of San 
Luis Obispo. California Highway Patrol and a privately-owned company provide helicopter transportation to the hospitals. The Cayucos Fire Protection District, the Morro Bay Fire Department, and County Fire all provide emergency medical response to the area, including surf rescue (Estero Area Plan, 2009). In the South County Region, $77.9 \%$ of respondents have health insurance, and $28.2 \%$ receive insurance through a state or federal program. Oceano has no general hospital or family health center. The closest hospital facility is the Arroyo Grande Community Hospital located in Arroyo Grande. The Oceano Community Service District provides fire and water services for the town (Oceano Specific Plan, 2001). Incidence of teen births and low birth weights decreased in the County, and more mothers reported receiving adequate prenatal care (ACTION, 2013).

\section{PHYSICAL ACTIVITY}

Just over half (53\%) of ACTION telephone survey respondents participated in five or more days of physical activity for at least 30 minutes in 2013. Five-point two percent reported that they engaged in no physical activity in 2013, down from $6.8 \%$ in 2010 . When asked if their employer tries to help employees with healthier eating and physical activity, including weight reduction programs, subsidizing health club memberships, or providing stress management classes, $41.4 \%$ responded yes, down from $47.9 \%$ in 2006 . When asked what would help their children to exercise more, $43 \%$ of 2013 telephone survey respondents listed activities at school and after-school, 30.4\% listed a park or playground closer to home, and $25.6 \%$ said safer streets for children to walk to destinations.

The response rate by region shows that there is a disparity between answers for those living in the North Coast region and those in the South County. More people in the South 
County responded that housing closer to a school or park would help increase physical activity for their children. More people also responded that awareness of the benefits would help to increase physical activity. In 2013, more North Coast respondents said that a park or playground closer to their home would help, although the percentages for this option changed drastically from 2010 to 2013 .

Table 8 "Which of the following would encourage your children to do more physical activity?" Response by region.

\begin{tabular}{|c|c|c|c|c|c|c|c|c|}
\hline \multirow[b]{2}{*}{ Response } & \multicolumn{2}{|c|}{ North Coast } & \multicolumn{2}{|c|}{ North County } & \multicolumn{2}{|c|}{ San Luis Obispo } & \multicolumn{2}{|c|}{ South County } \\
\hline & 2010 & 2013 & 2010 & 2013 & 2010 & 2013 & 2010 & 2013 \\
\hline $\begin{array}{l}\text { Housing that I Like and Can } \\
\text { Afford Closer to a School or } \\
\text { Park }\end{array}$ & $26.4 \%$ & $14.5 \%$ & $22.2 \%$ & $13.1 \%$ & $21.3 \%$ & $12.5 \%$ & $40.3 \%$ & $22.1 \%$ \\
\hline $\begin{array}{l}\text { A Park or Playground Located } \\
\text { Closer to My Existing Home }\end{array}$ & $31.9 \%$ & $33.6 \%$ & $44.8 \%$ & $43.8 \%$ & $31.2 \%$ & $15.0 \%$ & $55.4 \%$ & $21.0 \%$ \\
\hline $\begin{array}{l}\text { Safer Streets for Children to } \\
\text { Walk to Destinations }\end{array}$ & $44.9 \%$ & $30.4 \%$ & $46.9 \%$ & $27.8 \%$ & $37.5 \%$ & $13.9 \%$ & $51.2 \%$ & $27.5 \%$ \\
\hline $\begin{array}{l}\text { Increased School, After-School } \\
\text { or Other Play and Sports } \\
\text { Programs }\end{array}$ & $60.9 \%$ & $48.6 \%$ & $57.1 \%$ & $42.6 \%$ & $58.8 \%$ & $34.4 \%$ & $38.8 \%$ & $46.6 \%$ \\
\hline $\begin{array}{l}\text { More Awareness of Benefits of } \\
\text { Physical Activity for Your Child } \\
\text { or Children }\end{array}$ & $40.7 \%$ & $12.7 \%$ & $32.3 \%$ & $24.9 \%$ & $47.5 \%$ & $21.3 \%$ & $29.3 \%$ & $35.0 \%$ \\
\hline Kids are Already Active & NA & $0.0 \%$ & NA & $1.1 \%$ & NA & $10.3 \%$ & NA & $0.0 \%$ \\
\hline Other & $17.6 \%$ & $14.6 \%$ & $8.9 \%$ & $12.5 \%$ & $0.0 \%$ & $22.9 \%$ & $12.4 \%$ & $14.2 \%$ \\
\hline Total Respondents & 48 & 40 & 73 & 83 & 37 & 51 & 59 & 61 \\
\hline
\end{tabular}

Source: ACTION for Healthy Communities, Telephone Survey, 2010 and 2013.

Note: This was a multiple response question which enabled respondents to select more than one response.

The most common way to get to school was by car, followed by taking the school bus. About a quarter of elementary school children in the North Coast and San Luis Obispo regions walk to school, and $13 \%$ of those in the North Coast region bike. In the South County region, $12 \%$ walk to school and $3 \%$ bike. 
Table 9 "How do/does your Elementary School child/children usually get to school?" Response by region.

\begin{tabular}{|c|c|c|c|c|c|c|c|c|c|c|}
\hline \multirow[b]{2}{*}{ Response } & \multicolumn{2}{|c|}{ Overall } & \multicolumn{2}{|c|}{ North Coast } & \multicolumn{2}{|c|}{ North County } & \multicolumn{2}{|c|}{$\begin{array}{c}\text { San Luis } \\
\text { Obispo }\end{array}$} & \multicolumn{2}{|c|}{ South County } \\
\hline & 2010 & 2013 & 2010 & 2013 & 2010 & 2013 & 2010 & 2013 & 2010 & 2013 \\
\hline Driven to School & $60.5 \%$ & $65.5 \%$ & $60.6 \%$ & $44.9 \%$ & $75.4 \%$ & $72.9 \%$ & $42.4 \%$ & $60.5 \%$ & $63.7 \%$ & $66.2 \%$ \\
\hline School Bus & $14.2 \%$ & $14.6 \%$ & $9.1 \%$ & $15.5 \%$ & $6.1 \%$ & $15.2 \%$ & $22.0 \%$ & $8.5 \%$ & $19.4 \%$ & $15.6 \%$ \\
\hline Walk & $19.3 \%$ & $14.4 \%$ & $19.7 \%$ & $26.6 \%$ & $14.3 \%$ & $8.5 \%$ & $25.4 \%$ & $25.1 \%$ & $16.8 \%$ & $12.1 \%$ \\
\hline Ride Bike & $5.0 \%$ & $3.4 \%$ & $10.6 \%$ & $13.0 \%$ & $4.1 \%$ & $0.0 \%$ & $5.1 \%$ & $6.0 \%$ & $0.0 \%$ & $3.0 \%$ \\
\hline $\begin{array}{l}\text { Public } \\
\text { Transportation }\end{array}$ & $1.0 \%$ & $2.1 \%$ & $0.0 \%$ & $0.0 \%$ & $0.0 \%$ & $3.3 \%$ & $5.1 \%$ & $0.0 \%$ & $0.0 \%$ & $3.0 \%$ \\
\hline $\begin{array}{l}\text { Total } \\
\text { Respondents }\end{array}$ & 145 & 170 & 31 & 29 & 45 & 60 & 27 & 33 & 41 & 42 \\
\hline
\end{tabular}

Source: ACTION for Healthy Communities, Telephone Survey, 2010 and 2013.

Walking was even more prevalent in the North Coast region for Middle or Junior High

School children at $38.1 \%$. The percentage for South County respondents was higher as well at $18.7 \%$ walking to school.

Table 10 "How do/does your Middle or Junior High School child/children usually get to school?" Response by region.

\begin{tabular}{|c|c|c|c|c|c|c|c|c|c|c|}
\hline \multirow[b]{2}{*}{ Response } & \multicolumn{2}{|c|}{ Overall } & \multicolumn{2}{|c|}{ North Coast } & \multicolumn{2}{|c|}{ North County } & \multicolumn{2}{|c|}{$\begin{array}{c}\text { San Luis } \\
\text { Obispo }\end{array}$} & \multicolumn{2}{|c|}{ South County } \\
\hline & 2010 & 2013 & 2010 & 2013 & 2010 & 2013 & 2010 & 2013 & 2010 & 2013 \\
\hline Driven to School & $66.3 \%$ & $51.8 \%$ & $79.3 \%$ & $33.0 \%$ & $59.4 \%$ & $70.4 \%$ & $50.0 \%$ & $24.2 \%$ & $62.5 \%$ & $40.6 \%$ \\
\hline School Bus & $14.7 \%$ & $22.8 \%$ & $0.0 \%$ & $28.9 \%$ & $20.3 \%$ & $7.3 \%$ & $15.0 \%$ & $49.1 \%$ & $27.5 \%$ & $33.3 \%$ \\
\hline Walk & $12.7 \%$ & $17.3 \%$ & $10.3 \%$ & $38.1 \%$ & $15.6 \%$ & $10.9 \%$ & $20.0 \%$ & $19.2 \%$ & $10.0 \%$ & $18.7 \%$ \\
\hline $\begin{array}{l}\text { Public } \\
\text { Transportation }\end{array}$ & $1.0 \%$ & $1.5 \%$ & $0.0 \%$ & $0.0 \%$ & $4.7 \%$ & $0.0 \%$ & $0.0 \%$ & $0.0 \%$ & $0.0 \%$ & $7.3 \%$ \\
\hline Ride Bike & $5.1 \%$ & $1.3 \%$ & $10.3 \%$ & $0.0 \%$ & $0.0 \%$ & $0.0 \%$ & $15.0 \%$ & $7.5 \%$ & $0.0 \%$ & $0.0 \%$ \\
\hline $\begin{array}{l}\text { Total } \\
\text { Respondents }\end{array}$ & 66 & 88 & 13 & 14 & 30 & 35 & 9 & 17 & 19 & 17 \\
\hline
\end{tabular}

Source: ACTION for Healthy Communities, Telephone Survey, 2010 and 2013 
Table 11 "How do/does your High School child/children usually get to school?" Response by region.

\begin{tabular}{|c|c|c|c|c|c|c|c|c|c|c|}
\hline \multirow[b]{2}{*}{ Response } & \multicolumn{2}{|c|}{ Overall } & \multicolumn{2}{|c|}{ North Coast } & \multicolumn{2}{|c|}{ North County } & \multicolumn{2}{|c|}{$\begin{array}{c}\text { San Luis } \\
\text { Obispo }\end{array}$} & \multicolumn{2}{|c|}{ South County } \\
\hline & 2010 & 2013 & 2010 & 2013 & 2010 & 2013 & 2010 & 2013 & 2010 & 2013 \\
\hline Driven to School & $50.7 \%$ & $45.1 \%$ & $35.0 \%$ & $72.8 \%$ & $60.2 \%$ & $40.4 \%$ & $49.1 \%$ & $29.7 \%$ & $68.1 \%$ & $48.9 \%$ \\
\hline $\begin{array}{l}\text { Drive } \\
\text { Themselves to } \\
\text { School }\end{array}$ & $22.1 \%$ & $19.3 \%$ & $42.5 \%$ & $11.9 \%$ & $7.2 \%$ & $19.8 \%$ & $15.8 \%$ & $18.3 \%$ & $11.2 \%$ & $23.2 \%$ \\
\hline School Bus & $9.6 \%$ & $14.0 \%$ & $0.0 \%$ & $7.6 \%$ & $4.8 \%$ & $7.1 \%$ & $24.6 \%$ & $38.8 \%$ & $9.6 \%$ & $11.6 \%$ \\
\hline Walk & $8.4 \%$ & $10.1 \%$ & $7.7 \%$ & $7.6 \%$ & $20.5 \%$ & $15.4 \%$ & $5.3 \%$ & $13.2 \%$ & $6.4 \%$ & $0.9 \%$ \\
\hline $\begin{array}{l}\text { Public } \\
\text { Transportation }\end{array}$ & $6.0 \%$ & $2.9 \%$ & $13.1 \%$ & $0.0 \%$ & $7.2 \%$ & $4.3 \%$ & $0.0 \%$ & $0.0 \%$ & $0.0 \%$ & $3.9 \%$ \\
\hline Ride Bike & $5.0 \%$ & $2.9 \%$ & $1.6 \%$ & $0.0 \%$ & $0.0 \%$ & $4.3 \%$ & $5.3 \%$ & $0.0 \%$ & $4.8 \%$ & $3.9 \%$ \\
\hline $\begin{array}{l}\text { Total } \\
\text { Respondents }\end{array}$ & 122 & 125 & 28 & 17 & 39 & 46 & 26 & 25 & 29 & 33 \\
\hline
\end{tabular}

Source: ACTON for Heathy Communifies, Telephone Survey, 2010 and 2013

When asked specifically about what would encourage active transportation to school, the largest numbers of responses were living closer to school, sidewalk or street improvements, and crossing guards. 
Table 12 Responses to "which of the following would encourage your children to walk or bike to school more frequently?"

\begin{tabular}{l|c|c} 
Response & $\mathbf{2 0 1 0}$ & $\mathbf{2 0 1 3}$ \\
\hline Living Closer to School & $65.2 \%$ & $56.0 \%$ \\
\hline $\begin{array}{l}\text { Sidewalk or Street } \\
\text { Improvements For Safety }\end{array}$ & $43.8 \%$ & $28.7 \%$ \\
$\begin{array}{l}\text { Traffic Crossing Guards on } \\
\text { Duty }\end{array}$ & $24.9 \%$ & $20.1 \%$ \\
\hline $\begin{array}{l}\text { Slower Traffic Speeds on } \\
\text { Streets }\end{array}$ & $23.8 \%$ & $16.3 \%$ \\
$\begin{array}{l}\text { Increased Feeling of Safety } \\
\text { From Crime }\end{array}$ & $26.7 \%$ & $14.1 \%$ \\
\hline $\begin{array}{l}\text { Change In Attitude, So That It's } \\
\text { a Cool Thing to Do }\end{array}$ & $26.4 \%$ & $14.1 \%$ \\
\hline Other & $6.2 \%$ & $20.6 \%$ \\
\hline $\begin{array}{l}\text { Total Respondents } \\
\text { Total Responses }\end{array}$ & $\mathbf{2 0 4}$ & $\mathbf{2 5 8}$ \\
\hline
\end{tabular}

Source: ACTION for Healthy Communities, Telephone Survey, 2010 and 2013.

Note: This was a multiple response question which enabled respondents to select more than one response.

Table 13 Responses to "which of the following would encourage your children to walk or bike to school more frequently?" Response by region.

\begin{tabular}{|c|c|c|c|c|c|c|c|c|}
\hline \multirow[b]{2}{*}{ Response } & \multicolumn{2}{|c|}{ North Coast } & \multicolumn{2}{|c|}{ North County } & \multicolumn{2}{|c|}{ San Luis Obispo } & \multicolumn{2}{|c|}{ South County } \\
\hline & 2010 & 2013 & 2010 & 2013 & 2010 & 2013 & 2010 & 2013 \\
\hline Living Closer to School & $63.4 \%$ & $49.9 \%$ & $59.9 \%$ & $53.6 \%$ & $55.1 \%$ & $50.9 \%$ & $73.4 \%$ & $64.2 \%$ \\
\hline $\begin{array}{l}\text { Sidewalk Or Street } \\
\text { Improvements for Safety }\end{array}$ & $48.0 \%$ & $29.0 \%$ & $46.5 \%$ & $34.2 \%$ & $36.2 \%$ & $12.3 \%$ & $41.2 \%$ & $29.5 \%$ \\
\hline $\begin{array}{l}\text { Traffic Crossing Guards on } \\
\text { Duty }\end{array}$ & $25.6 \%$ & $15.3 \%$ & $31.3 \%$ & $17.4 \%$ & $34.8 \%$ & $16.8 \%$ & $15.9 \%$ & $28.4 \%$ \\
\hline $\begin{array}{l}\text { Slower Traffic Speeds on } \\
\text { Streets }\end{array}$ & $22.1 \%$ & $17.7 \%$ & $30.5 \%$ & $11.2 \%$ & $24.6 \%$ & $19.1 \%$ & $22.1 \%$ & $20.4 \%$ \\
\hline $\begin{array}{l}\text { Increased Feeling of Safety } \\
\text { From Crime }\end{array}$ & $27.7 \%$ & $16.5 \%$ & $44.1 \%$ & $11.2 \%$ & $14.5 \%$ & $8.4 \%$ & $25.3 \%$ & $21.2 \%$ \\
\hline $\begin{array}{l}\text { Change In Attitude, So That It's } \\
\text { a Cool Thing to Do }\end{array}$ & $32.3 \%$ & $15.3 \%$ & $31.3 \%$ & $13.1 \%$ & $26.1 \%$ & $10.7 \%$ & $15.9 \%$ & $16.3 \%$ \\
\hline Other & $2.8 \%$ & $25.1 \%$ & $2.4 \%$ & $21.3 \%$ & $8.7 \%$ & $23.9 \%$ & $12.0 \%$ & $15.7 \%$ \\
\hline Total Respondents & 50 & 46 & 58 & 88 & 32 & 54 & 58 & 63 \\
\hline
\end{tabular}

Source: ACTION for Heathy Communities, Telephone Survey, 2010 and 2013.

Note: This was a multiple response question which enabled respondents to select more than one response. 
In both years, more respondents chose "living closer to school" in the South County Region than the North Coast. In 2013, more South County respondents selected "crossing guards on duty," and "increased feeling of safety from crime."

The California Highway Patrol maintains the Statewide Integrated Traffic Records System, which collect and process data gathered from a collision scene. Though the online records database does not maintain totals for Cayucos alone, totals for this area only were accessible via records request. The total number of injury and fatal collisions, total number of pedestrian-vehicle collisions, injuries, and deaths, and total number of bicyclist-vehicle collisions, injuries, and deaths all for the previous 10 years were requested. According to the results, there were nine pedestrian-vehicle collisions resulting in injuries since 2004, and two of these collisions resulted in death. There were eight bicycle/vehicles collisions since 2004, and of these seven resulted in injuries (CHP, 2014).

The Physical Fitness Test, or FITNESSGRAM, for students in California schools, uses criterion-referenced standards to evaluate fitness performance. There are tests for aerobic capacity, body composition, strength, and flexibility. In 2011, aerobic capacity and body composition fitness areas were classified into three general areas: "in the healthy fitness zone (HFZ), "needs improvement," and "needs improvement-high risk." Performance for the other four fitness areas as well as previous years 2006-1999 is classified into two general areas: "HFZ" and "needs improvement." The standards were established to represent a level of fitness that offers some degree of protection against diseases that result from sedentary living (DOE, 2011).

Of 18 5th Graders tested at Cayucos Elementary during the 2012-2013 school years, $17 \%$ were classified in the "needs improvement health risk" category for body 
composition. In the aerobic capacity area, 39\% were classified as "needs improvement". According to the California Department of Education, Aerobic Capacity is perhaps the most important indicator of physical fitness and assesses the capacity of the cardiorespiratory system by measuring endurance. Of 34 Cayucos $7^{\text {th }}$ Graders, $21 \%$ were classified in the "needs improvement health risk" category for body composition, and $6 \%$ were classified as "needs improvement" under aerobic capacity.

Table 14 Cayucos Elementary District, 2012-13 California Physical Fitness Report Summary of Results

\begin{tabular}{|c|c|c|c|c|c|}
\hline \multicolumn{6}{|c|}{ Cayucos 5th Graders } \\
\hline $\begin{array}{l}\text { Physical } \\
\text { Fitness Area }\end{array}$ & $\begin{array}{l}\text { Total } \\
\text { Tested }\end{array}$ & $\begin{array}{l}\text { Number } \\
\text { in HFZ }\end{array}$ & $\begin{array}{l}\text { \% } \\
\text { Students in } \\
\text { HFZ }\end{array}$ & $\begin{array}{l}\text { \% Needs } \\
\text { Improvement }\end{array}$ & $\begin{array}{l}\text { \% Needs Improvement - } \\
\text { Health Risk }\end{array}$ \\
\hline $\begin{array}{l}\text { Aerobic } \\
\text { Capacity }\end{array}$ & 18 & 11 & 61.1 & 38.9 & 0 \\
\hline $\begin{array}{l}\text { Body } \\
\text { Composition }\end{array}$ & 18 & 12 & 66.7 & 16.7 & 16.6 \\
\hline $\begin{array}{l}\text { Abdominal } \\
\text { Strength }\end{array}$ & 18 & 17 & 94.4 & 5.6 & $\mathrm{~N} / \mathrm{A}$ \\
\hline $\begin{array}{l}\text { Trunk } \\
\text { Extension } \\
\text { Strength }\end{array}$ & 18 & 1 & 5.6 & 94.4 & $\mathrm{~N} / \mathrm{A}$ \\
\hline $\begin{array}{l}\text { Upper Body } \\
\text { Strength }\end{array}$ & 18 & 5 & 27.8 & 72.2 & $\mathrm{~N} / \mathrm{A}$ \\
\hline Flexibility & 18 & 18 & 100 & 0 & $\mathrm{~N} / \mathrm{A}$ \\
\hline
\end{tabular}

\begin{tabular}{|c|c|c|c|c|c|}
\hline \multicolumn{6}{|c|}{ Cayucos 7th Graders } \\
\hline & $\begin{array}{l}\text { Total } \\
\text { Tested }^{1}\end{array}$ & $\begin{array}{l}\text { Number } \\
\text { in } \mathrm{HFZ}^{2}\end{array}$ & \% in HFZ & $\begin{array}{l}\text { \% in Needs } \\
\text { Improvement }\end{array}$ & $\begin{array}{l}\text { \% Needs Improvement - } \\
\text { Health Risk }\end{array}$ \\
\hline $\begin{array}{l}\text { Aerobic } \\
\text { Capacity }\end{array}$ & 34 & 30 & 88.2 & 5.9 & 5.9 \\
\hline $\begin{array}{l}\text { Body } \\
\text { Composition }\end{array}$ & 34 & 25 & 73.5 & 5.9 & 20.6 \\
\hline $\begin{array}{l}\text { Abdominal } \\
\text { Strength }\end{array}$ & 34 & 34 & 100 & 0 & $\mathrm{~N} / \mathrm{A}$ \\
\hline $\begin{array}{l}\text { Trunk } \\
\text { Extension } \\
\text { Strength }\end{array}$ & 34 & 34 & 100 & 0 & N/A \\
\hline $\begin{array}{l}\text { Upper Body } \\
\text { Strength }\end{array}$ & 34 & 0 & 0 & 100 & $\mathrm{~N} / \mathrm{A}$ \\
\hline Flexibility & 34 & 34 & 100 & 0 & $\mathrm{~N} / \mathrm{A}$ \\
\hline
\end{tabular}

California Department of Education. (2013). Physical Fitness Testing (PFT). Accessed April 29, 2014 at: http://www.cde.ca.gov/ta/tg/pf/ 
For students at Lucia Mar Elementary, the school that Oceano children attend, $29 \%$ of 5th graders and $31 \%$ of 7 th Graders were classified in the "needs improvement health risk" category for body composition during the 2012-2013 school year. In the aerobic capacity area, $19 \%$ of 5 th Graders were classified as "needs improvement" and $9 \%$ were classified as "needs improvement health risk". In that same category, $15 \%$ of 7 th Graders fell under the "needs improvement health risk" category. Students in the 9th Grade were also tested for fitness. Of 863 9th Graders, $21 \%$ were classified in the "needs improvement health risk" category for body composition and $11 \%$ for aerobic capacity.

Table 15 Lucia Mar Unified District, 2012-13 California Physical Fitness Report Summary of Results

\begin{tabular}{llllll}
\hline Lucia Mar $\mathbf{5}^{\text {th }}$ Graders & & & & \\
\hline & $\begin{array}{l}\text { Total } \\
\text { Tested }\end{array}$ & $\begin{array}{l}\text { Number } \\
\text { in HFZ }\end{array}$ & $\begin{array}{l}\text { \% } \\
\text { Students in } \\
\text { HFZ }\end{array}$ & $\begin{array}{l}\text { \% Needs } \\
\text { Improvement }\end{array}$ & $\begin{array}{l}\text { \% Needs Improvement - } \\
\text { Health Risk }\end{array}$ \\
$\begin{array}{l}\text { Aerobic } \\
\text { Capacity }\end{array}$ & 711 & 511 & 71.9 & 19.3 & 8.8 \\
$\begin{array}{l}\text { Body } \\
\text { Composition }\end{array}$ & 711 & 415 & 58.4 & 12.5 & 29.1 \\
$\begin{array}{l}\text { Abdominal } \\
\text { Strength }\end{array}$ & 711 & 606 & 85.2 & 14.8 & $\mathrm{~N} / \mathrm{A}$ \\
$\begin{array}{l}\text { Trunk } \\
\text { Extension }\end{array}$ & 711 & 554 & 77.9 & 22.1 & $\mathrm{~N} / \mathrm{A}$ \\
$\begin{array}{l}\text { Strength } \\
\begin{array}{l}\text { Upper Body } \\
\text { Strength }\end{array}\end{array}$ & 711 & 520 & 73.1 & 26.9 & $\mathrm{~N} / \mathrm{A}$ \\
\begin{tabular}{l} 
Flexibility \\
\hline
\end{tabular} & 711 & 623 & 87.6 & 12.4 & $\mathrm{~N} / \mathrm{A}$ \\
\hline
\end{tabular}




\begin{tabular}{|c|c|c|c|c|c|}
\hline \multicolumn{6}{|c|}{ Lucia Mar 7th Graders } \\
\hline & $\begin{array}{l}\text { Total } \\
\text { Tested }\end{array}$ & $\begin{array}{l}\text { Number } \\
\text { in HFZ }\end{array}$ & $\begin{array}{l}\% \\
\text { Students in } \\
\text { HFZ }\end{array}$ & $\begin{array}{l}\text { \% Needs } \\
\text { Improvement }\end{array}$ & $\begin{array}{l}\text { \% Needs Improvement - } \\
\text { Health Risk }\end{array}$ \\
\hline $\begin{array}{l}\text { Aerobic } \\
\text { Capacity }\end{array}$ & 810 & 569 & 70.2 & 15.1 & 14.7 \\
\hline $\begin{array}{l}\text { Body } \\
\text { Composition }\end{array}$ & 810 & 440 & 54.3 & 15.2 & 30.5 \\
\hline $\begin{array}{l}\text { Abdominal } \\
\text { Strength }\end{array}$ & 810 & 759 & 93.7 & 6.3 & $\mathrm{~N} / \mathrm{A}$ \\
\hline $\begin{array}{l}\text { Trunk } \\
\text { Extension } \\
\text { Strength }\end{array}$ & 810 & 739 & 91.2 & 8.8 & $\mathrm{~N} / \mathrm{A}$ \\
\hline $\begin{array}{l}\text { Upper Body } \\
\text { Strength }\end{array}$ & 810 & 661 & 81.6 & 18.4 & $\mathrm{~N} / \mathrm{A}$ \\
\hline Flexibility & 810 & 675 & 83.3 & 16.7 & $\mathrm{~N} / \mathrm{A}$ \\
\hline
\end{tabular}

\begin{tabular}{llllll}
\hline Lucia Mar 9th Graders & & & & \\
\hline & $\begin{array}{l}\text { Total } \\
\text { Tested }\end{array}$ & $\begin{array}{l}\text { Number } \\
\text { in HFZ }\end{array}$ & $\begin{array}{l}\text { \% } \\
\text { Students in } \\
\text { HFZ }\end{array}$ & $\begin{array}{l}\text { \% Needs } \\
\text { Improvement }\end{array}$ & $\begin{array}{l}\text { \% Needs Improvement - } \\
\text { Health Risk }\end{array}$ \\
$\begin{array}{l}\text { Aerobic } \\
\text { Capacity }\end{array}$ & 863 & 650 & 75.3 & 13.7 & 11 \\
$\begin{array}{l}\text { Body } \\
\text { Composition }\end{array}$ & 863 & 574 & 66.5 & 12.3 & 21.2 \\
$\begin{array}{l}\text { Abdominal } \\
\text { Strength }\end{array}$ & 863 & 805 & 93.3 & 6.7 & N/A \\
$\begin{array}{l}\text { Trunk } \\
\text { Extension }\end{array}$ & 863 & 813 & 94.2 & 5.8 & N/A \\
$\begin{array}{l}\text { Strength } \\
\begin{array}{l}\text { Upper Body } \\
\text { Strength }\end{array}\end{array}$ & 863 & 706 & 81.8 & 18.2 & N/A \\
\begin{tabular}{l} 
Flexibility \\
\hline
\end{tabular} & 863 & 821 & 95.1 & 4.9 & N/A \\
\hline
\end{tabular}

California Department of Education. (2013). Physical Fitness Testing (PFT). Accessed April 29, 2014 at: http://www.cde.ca.gov/ta/tg/pf/

San Luis Obispo Council of Governments released Safe Routes to School data which provided 2013-2014 PFT results. Students in grades 5-7, from 29 schools, of five different school districts across the county were tested. 64 Oceano Elementary 5th graders participated in the test. 
Table 16 Oceano Elementary, 2012-13 California Physical Fitness Report Summary of Results

\begin{tabular}{llllll}
\hline \multicolumn{3}{l}{ Oceano Elementary 5th Graders } & & & \\
\hline & $\begin{array}{l}\text { Total } \\
\text { Tested }\end{array}$ & $\begin{array}{l}\text { Number } \\
\text { in HFZ }\end{array}$ & $\begin{array}{l}\text { \% } \\
\text { Students in } \\
\text { HFZ }\end{array}$ & $\begin{array}{l}\text { \% Needs } \\
\text { Improvement }\end{array}$ & $\begin{array}{l}\text { \% Needs Improvement - } \\
\text { Health Risk }\end{array}$ \\
$\begin{array}{l}\text { Aerobic } \\
\text { Capacity }\end{array}$ & 64 & 43 & 67.2 & 18.8 & 14.0 \\
$\begin{array}{l}\text { Body } \\
\text { Composition }\end{array}$ & 64 & 31 & 48.4 & 17.2 & 34.4 \\
$\begin{array}{l}\text { Abdominal } \\
\text { Strength }\end{array}$ & 64 & 60 & 93.8 & 6.2 & $\mathrm{~N} / \mathrm{A}$ \\
$\begin{array}{l}\text { Trunk } \\
\text { Extension }\end{array}$ & 64 & 37 & 57.8 & 42.2 & $\mathrm{~N} / \mathrm{A}$ \\
$\begin{array}{l}\text { Strength } \\
\begin{array}{l}\text { Upper Body } \\
\text { Strength }\end{array}\end{array}$ & 64 & 27 & 42.2 & 57.8 & $\mathrm{~N} / \mathrm{A}$ \\
\begin{tabular}{l} 
Flexibility \\
\hline
\end{tabular} & 64 & 53 & 82.8 & 17.2 & $\mathrm{~N} / \mathrm{A}$ \\
\hline
\end{tabular}

California Department of Education. (2013). Physical Fitness Testing (PFT). Accessed May 30, 2014 at: http://www.cde.ca.gov/ta/tg/pf/

Only 48.8 percent of students tested in the HFZ; the lowest figure of all the tested schools in San Luis Obispo County. Further, 34.4 percent of the students scored in the Needs Improvement (NI) - Health Risk zone; the highest percentage in the county. "NI Health Risk indicates that if the student continues to track at this level there is a clear potential for future health problem (a more probable risk)" (Human Kinetics, n.d.).

Inferences may be drawn from these results as the percentage ( 29 percent) of time spent (less than 10 hours per week) by South County children on screen time (computer, television, videos, texting) has increased from 2010 levels (Action, 2013, p. 109), which may indicate children in Oceano are spending less time doing physical activities in favor of sedentary behaviors. 


\section{MENTAL HEALTH AND WELLBEING}

Those reporting their mental health as good, very good, or excellent decreased, while the number of mental health patients and the unmet need for mental health care increased (ACTION, 2013).

Incidence of suicide also increased. The number of 2-1-1 calls for assistance, a free program for health and human services information and referrals, increased from 3,376 to 5,196 in 2011 . The highest numbers of calls were for mental health and addiction assistance, which increased from 347 calls to 854 total calls (ACTION, 2013).

\section{HOUSING NEEDS}

The County of San Luis Obispo was given a Regional Housing Needs Assessment (RHNA) Allocation of 4,090. SLOCOG recognizes the importance of creating more housing opportunities for the lower end of the income earning spectrum, and seeks to increase the housing supply and the mix of housing types, tenure and affordability within the region in an equitable manner. For the Unincorporated regions of SLO County, including Cayucos and Oceano, the RHNA is allocated 1,347. Because the Unincorporated Region makes up $43.8 \%$ of the SLO County population, these units are meant to accommodate 151,519 people.

Housing is generally considered affordable if total housing costs do not exceed $30 \%$ of household income. The categories of affordable housing are: extremely low, very low, low and moderate. From 1980-2008, in the SLO County Coastal Zone (Cayucos, Cambria, Los Osos and Avila Beach) 569 housing units were built and received final inspections yet only 3 units for low and very-low income and 7 moderate income units were built in the Coastal Zone, in Cambria and Avila Beach respectively. No affordable 
housing units were built in Cayucos. The County's 2009 Housing Element presents no vacant or underutilized high density sites for very low and low income housing in Cayucos. The Estero Plan supports increasing opportunities for affordable housing by allowing limited residential development in office and commercial areas (Estero Area Plan, 2009).

\section{SUBSTANCE USE}

Alcohol use increased since 2006, but self-reported student substance abuse declined. Over three-quarters of those surveyed in 2013 were concerned about drug, tobacco, and alcohol abuse in their community. The percentage has remained about the same since 2006. The percentage of residents that were very concerned was higher in the South County compared to the North Coast, but the North Coast respondents selected somewhat concerned at a higher percentage (ACTION, 2013).

Table 17 "How concerned are you about drug, tobacco, and alcohol abuse in your community?" Response by region.

\begin{tabular}{l|c|c|c|c|c|c|c|c} 
& \multicolumn{2}{|c|}{ North Coast } & \multicolumn{2}{c|}{ North County } & \multicolumn{2}{c|}{ San Luis Obispo } & \multicolumn{2}{c}{ South County } \\
Response & $\mathbf{2 0 1 0}$ & $\mathbf{2 0 1 3}$ & $\mathbf{2 0 1 0}$ & $\mathbf{2 0 1 3}$ & $\mathbf{2 0 1 0}$ & $\mathbf{2 0 1 3}$ & $\mathbf{2 0 1 0}$ & $\mathbf{2 0 1 3}$ \\
\hline Very Concerned & $32.9 \%$ & $29.2 \%$ & $40.3 \%$ & $41.2 \%$ & $40.0 \%$ & $26.6 \%$ & $37.2 \%$ & $38.4 \%$ \\
Somewhat Concerned & $47.5 \%$ & $46.8 \%$ & $36.9 \%$ & $36.3 \%$ & $34.9 \%$ & $49.1 \%$ & $39.7 \%$ & $36.1 \%$ \\
Not at All Concerned & $19.6 \%$ & $24.0 \%$ & $22.8 \%$ & $22.5 \%$ & $25.2 \%$ & $24.4 \%$ & $23.2 \%$ & $25.5 \%$ \\
\hline Total Respondents & $\mathbf{2 5 5}$ & $\mathbf{2 4 6}$ & $\mathbf{3 1 0}$ & $\mathbf{2 9 4}$ & $\mathbf{2 3 9}$ & $\mathbf{2 8 9}$ & $\mathbf{2 8 5}$ & $\mathbf{2 6 3}$ \\
\hline Source: ACTIONfor Heathy Communities, Telephone Survey, 2010 and 2013.
\end{tabular}

Binge drinking rates were higher in the county than in the state as a whole, with $39 \%$ of residents over 21 years of age reporting that they drank 4 or 5 or more alcoholic beverages on an occasion in the past 30 days (ACTION, 2013). In San Luis Obispo County, $36 \%$ of pregnant women reported drinking at least once in the last month. Binge drinking was more prevalent among respondents in the North Coast region than in the 
South County, and the South county had the largest percentage of "none" responses for 2013 (ACTION, 2013).

Table 18 "Considering all types of alcoholic beverages, in the past 30 days, about how many times did you have (4 if female; 5 if male) or more drinks on an occasion?" Response by region.

\begin{tabular}{l|c|c|c|c|c|c|c|c} 
& \multicolumn{2}{|c|}{ North Coast } & \multicolumn{2}{c|}{ North County } & \multicolumn{2}{c|}{ San Luis Obispo } & \multicolumn{2}{c}{ South County } \\
Response & $\mathbf{2 0 1 0}$ & $\mathbf{2 0 1 3}$ & $\mathbf{2 0 1 0}$ & $\mathbf{2 0 1 3}$ & $\mathbf{2 0 1 0}$ & $\mathbf{2 0 1 3}$ & $\mathbf{2 0 1 0}$ & $\mathbf{2 0 1 3}$ \\
\hline None & $76.8 \%$ & $70.0 \%$ & $76.3 \%$ & $72.4 \%$ & $87.1 \%$ & $71.9 \%$ & $78.2 \%$ & $79.8 \%$ \\
1-2 Times & $13.9 \%$ & $19.2 \%$ & $14.9 \%$ & $18.9 \%$ & $7.3 \%$ & $14.9 \%$ & $12.2 \%$ & $12.9 \%$ \\
3-5 Times & $4.2 \%$ & $5.9 \%$ & $3.7 \%$ & $5.1 \%$ & $4.4 \%$ & $10.6 \%$ & $6.0 \%$ & $5.3 \%$ \\
6 or More Times & $5.2 \%$ & $4.9 \%$ & $5.0 \%$ & $3.6 \%$ & $1.1 \%$ & $2.6 \%$ & $3.6 \%$ & $1.9 \%$ \\
\hline Total Respondents & $\mathbf{2 5 9}$ & $\mathbf{2 5 1}$ & $\mathbf{3 0 9}$ & $\mathbf{2 9 1}$ & $\mathbf{2 4 4}$ & $\mathbf{2 9 2}$ & $\mathbf{2 8 7}$ & $\mathbf{2 6 2}$ \\
\hline
\end{tabular}

Source: ACTON for Heathy Communities, Telephone Survey, 2010 and 2013.

\section{SUBSTANCE USE AMONG CHILDREN AND YOUTH}

The California Healthy Kids Survey is conducted to provide data that would assist schools in (1) preventing youth health-risk behaviors and other barriers to academic achievement; (2) promoting positive youth development, resilience, and well-being; and (3) fostering positive school climates and engagement in learning. It consists of core questions as well as questions incorporated by the subject school, with the primary focus being assessment of student perceptions and experiences, including health-related, nonacademic learning barriers (e.g., substance use, bullying and violence, and poor physical and mental health) (CHKS, 2011).

Of those respondents ACTION respondents with middle school aged children, $56 \%$ reported that alcohol and drug abuse problems were a very serious or somewhat serious problem in 2013, up from 45\% in 2006 and 48\% in 2010 (ACTION, 2013). According to the 2011-12 California Healthy Kids Survey, the number of $11^{\text {th }}$ graders that had consumed at least one drink of alcohol in the past month decreased from $43 \%$ in 2003 - 
2004 to $38 \%$. Use of marijuana remained about the same over the same span of years (CHKS, 2011).

Youth tobacco use declined overall from $20 \%$ in $2005-2006$ to $13 \%$ in $2011-2012$, but the prevalence of smoking among youth in the county was occurring at a higher rate than the state of California as a whole. Tobacco use declined, and more people that smoke reported attempting to quit (a 7\% increase from 2006). The percentage of respondents who smoke were higher in the North Coast region, and the percentage decreased by more from 2010 to 2013 in the South County region than in the North Coast region (ACTION, 2013, CHKS, 2011).

Table 19 Ever Used Cigarettes or Smokeless Tobacco in Lifetime

\begin{tabular}{|c|c|c|c|c|c|c|c|c|c|c|c|c|}
\hline & \multicolumn{4}{|c|}{ Grade 7} & \multicolumn{4}{|c|}{ Grade 9} & \multicolumn{4}{|c|}{ Grade 11} \\
\hline & $05-06$ & $07-08$ & 09-10 & 11-12 & $05-06$ & $07-08$ & $09-10$ & 11-12 & 05-06 & 07-08 & $09-10$ & $11-12$ \\
\hline \multicolumn{13}{|c|}{ A Whole Cigarette } \\
\hline $\begin{array}{l}\text { San Luis } \\
\text { Obispo } \\
\text { County }\end{array}$ & $8 \%$ & $8 \%$ & $7 \%$ & $6 \%$ & $19 \%$ & $23 \%$ & $23 \%$ & $21 \%$ & $32 \%$ & $36 \%$ & $32 \%$ & $27 \%$ \\
\hline California & $6 \%$ & $7 \%$ & $7 \%$ & $7 \%$ & $16 \%$ & $20 \%$ & $20 \%$ & $20 \%$ & $25 \%$ & $29 \%$ & $29 \%$ & $28 \%$ \\
\hline \multicolumn{13}{|c|}{ Smokeless Tobacco } \\
\hline $\begin{array}{l}\text { San Luis } \\
\text { Obispo } \\
\text { County }\end{array}$ & $4 \%$ & $4 \%$ & $4 \%$ & $3 \%$ & $9 \%$ & $9 \%$ & $10 \%$ & $10 \%$ & $14 \%$ & $15 \%$ & $16 \%$ & $13 \%$ \\
\hline California & $3 \%$ & $4 \%$ & $4 \%$ & $4 \%$ & $6 \%$ & $6 \%$ & $8 \%$ & $8 \%$ & $9 \%$ & $9 \%$ & $10 \%$ & $10 \%$ \\
\hline
\end{tabular}

Source: Califomia Healthy Kids Survey, 2005, 2007, 2009, and 2011.

Note: Data presented are the most recent available. 
Table 20 "Do you smoke cigarettes every day, some days, or not at all?" Response by region.

\begin{tabular}{l|c|c|c|c|c|c|c|c} 
& \multicolumn{2}{|c|}{ North Coast } & \multicolumn{2}{c|}{ North County } & \multicolumn{2}{c|}{ San Luis Obispo } & \multicolumn{2}{c}{ South County } \\
Response & $\mathbf{2 0 1 0}$ & $\mathbf{2 0 1 3}$ & $\mathbf{2 0 1 0}$ & $\mathbf{2 0 1 3}$ & $\mathbf{2 0 1 0}$ & $\mathbf{2 0 1 3}$ & $\mathbf{2 0 1 0}$ & $\mathbf{2 0 1 3}$ \\
\hline Every Day & $7.6 \%$ & $7.9 \%$ & $12.3 \%$ & $10.6 \%$ & $6.3 \%$ & $7.4 \%$ & $10.8 \%$ & $7.1 \%$ \\
Some Days & $2.9 \%$ & $2.2 \%$ & $5.5 \%$ & $3.6 \%$ & $2.7 \%$ & $3.3 \%$ & $7.1 \%$ & $1.7 \%$ \\
Not at All & $89.5 \%$ & $89.9 \%$ & $82.2 \%$ & $85.9 \%$ & $91.1 \%$ & $89.3 \%$ & $82.1 \%$ & $91.2 \%$ \\
\hline Total Respondents & $\mathbf{2 5 9}$ & $\mathbf{2 5 1}$ & $\mathbf{3 1 1}$ & $\mathbf{2 9 3}$ & $\mathbf{2 4 4}$ & $\mathbf{2 9 2}$ & $\mathbf{2 8 6}$ & $\mathbf{2 6 3}$ \\
\hline
\end{tabular}

Source: ACTION for Heathy Communifies, Telephone Survey, 2010 and 2013.

In comparison to California State percentages, use of tobacco was reported to be lower at Cayucos Elementary. Zero percent of Cayucos $7^{\text {th }}$ Grade students had ever tried smokeless tobacco or cigarettes. However, a higher percentage of Cayucos students reported drinking alcohol, smoking marijuana, and using inhalants (ACTION, 2013, CHKS, 2011). 
Table 21 Selected Alcohol, Tobacco, and Other Drug Use, With Comparisons to 2007 State CSS

\begin{tabular}{|c|c|c|}
\hline \multirow{3}{*}{ Lifetime and Current ATOD Use } & \multicolumn{2}{|c|}{ 7th Grade $\%$} \\
\hline & \multirow[t]{2}{*}{ District } & \multirow[t]{2}{*}{ CSS } \\
\hline & & \\
\hline \multicolumn{3}{|l|}{ During your life, did you ever... } \\
\hline smoke a cigarette? & 5 & 7 \\
\hline chew tobacco or snuff? & 0 & 4 \\
\hline drink alcohol (glass)? & 41 & 24 \\
\hline use inhalants? & 14 & 11 \\
\hline smoke marijuana? & 32 & 9 \\
\hline \multicolumn{3}{|l|}{ During the past 30 days, did you... } \\
\hline smoke a cigarette? & 0 & 6 \\
\hline chew tobacco or snuff? & 0 & 3 \\
\hline drink alcohol (glass)? & 5 & 15 \\
\hline use inhalants? & 5 & 5 \\
\hline smoke marijuana? & 14 & 7 \\
\hline \multicolumn{3}{|l|}{ Level of Involvement (High Risk Patterns) } \\
\hline \multicolumn{3}{|l|}{ During your life have you ever... } \\
\hline been very drunk or sick after drinking? & 5 & 11 \\
\hline been high from using drugs? & 24 & 8 \\
\hline \multicolumn{3}{|l|}{ During the past 30 days, did you... } \\
\hline drink 5 drinks in a couple of hours? & 0 & 6 \\
\hline
\end{tabular}

Cayucos Elementary, Secondary. California Healthy Kids Survey, 2011-12: Main Report. San Francisco: WestEd Health \& Human Development Program for the California Department of Education.

Use of alcohol, drugs, and tobacco was reported to be about the same for $7^{\text {th }}$ Graders at Lucia Mar Elementary, in comparison to California State percentages, with tobacco use being slightly higher and alcohol use being slightly lower (CHKS, 2011). 
Table 22 Selected Alcohol, Tobacco, and Other Drug Use, With Comparisons to 2007 State CSS and 2007 National YRBS

\begin{tabular}{|c|c|c|c|c|c|c|c|c|}
\hline & \multicolumn{2}{|c|}{7 th Grade $\%$} & \multicolumn{3}{|c|}{ 9th Grade \% } & \multicolumn{3}{|c|}{11 th Grade \% } \\
\hline & District & Css & District & css & YRBS & District & $\operatorname{css}$ & YRBS \\
\hline \multicolumn{9}{|l|}{ Lifetime and Current ATOD Use } \\
\hline \multicolumn{9}{|l|}{ During your hfe did you ever... } \\
\hline smoke a cigarette? (PI) & 9 & 7 & 27 & 20 & $45^{2}$ & 33 & 34 & $55^{2}$ \\
\hline cbew tobacce or smuff? & 5 & 4 & 11 & 6 & $\sim$ & 16 & 10 & $\sim$ \\
\hline drink alcohol (glass)? & 21 & 24 & 47 & 47 & 67 & 62 & 66 & 79 \\
\hline use inbalants? & 11 & 11 & 17 & 14 & 15 & 12 & 15 & 12 \\
\hline smoke marjuana? (PI) & 11 & 9 & 30 & 25 & 29 & 45 & 42 & so \\
\hline \multicolumn{9}{|l|}{ During the past 30 days, did you... } \\
\hline smoke a cigarette? (PI) & 6 & 6 & 14 & 11 & 15 & 16 & 17 & 24 \\
\hline chew tobacco or sauff? & 3 & 3 & 7 & 5 & 6 & 6 & 6 & 6 \\
\hline driak alcohol (glass)? (PI) & 13 & 15 & 26 & 24 & 37 & 39 & 42 & 53 \\
\hline use inhalants? & 5 & 5 & 7 & 7 & $\sim$ & 5 & 3 & $\sim$ \\
\hline smoke marijuana? (PI) & 7 & 7 & 19 & 15 & 16 & 25 & 24 & 21 \\
\hline \multicolumn{9}{|l|}{ Level of Involvement (High Risk Patterns) } \\
\hline \multicolumn{9}{|l|}{ During your lffe have you ever. } \\
\hline been very druak or sick after drinking? & 10 & 11 & 29 & 28 & $\sim$ & 42 & 45 & $\sim$ \\
\hline been high from using drugs? & 10 & 8 & 29 & 22 & $\sim$ & 42 & 37 & $\sim$ \\
\hline \multicolumn{9}{|l|}{ During the part 30 days, did you... } \\
\hline drink 5 drinks in a couple of hours? & 6 & 6 & 18 & 16 & 18 & 28 & 29 & 28 \\
\hline
\end{tabular}

Lucia Mar Unified Secondary. California Healthy Kids Survey, 2009-10: Main Report San Francisco: WestEd Health and Human Development Program for the California Department of Education

\section{FOOD ACCESS AND EATING HABITS}

The percentage of respondents that exercise moderately and eat the daily recommended amount of fruits and vegetables increased, while obesity rates declined from $60 \%$ to $48.1 \%$. The ACTION report indicates that the percentage of children in the county living below the federal poverty level and the number enrolled in the free and reduced school meal program both increased. The percentage of residents who were able to afford enough food, however, increased. The current nutritional guidelines made by the Department of Agriculture recommend getting a minimum of five servings of fruits and vegetables per day. According to the 2013 survey, only $46 \%$ of teens and $48 \%$ of adults in the County meet this standard (ACTION, 2013). 
Table 23 "Yes" response for respondent's self, when asked "On average, do you eat 5 or more servings of fruits and vegetables every day?" By region.

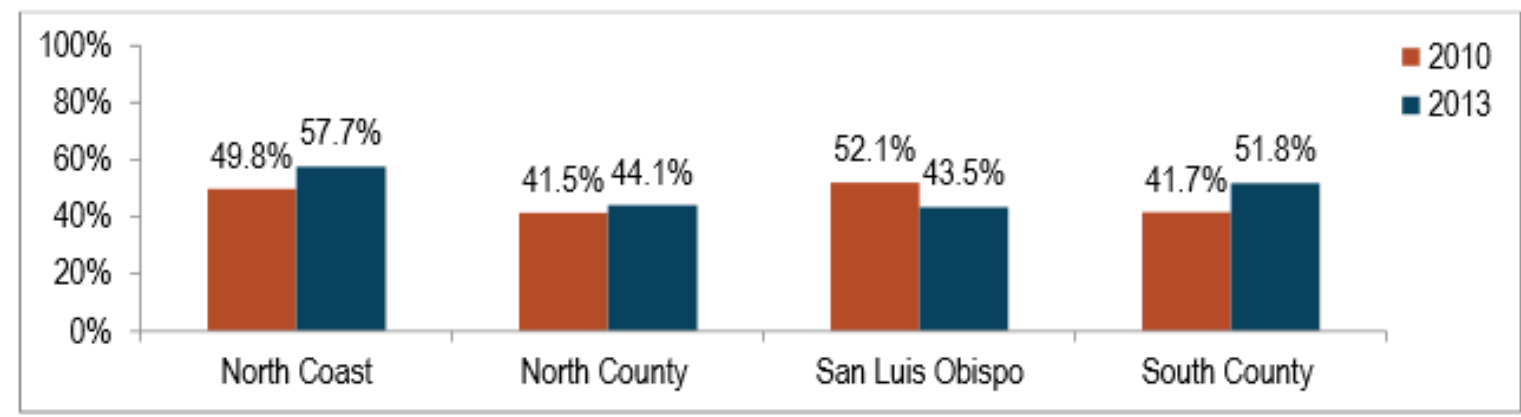

2010 n: North Coast=255, North County=309, San Luis Obispo=235, South County=285; 2013 n: North Coast=251, North County=291, San Luis Obispo=294, South County $=259$

Source: ACTON for Heathy Communifies, Telephone Survey, 2010 and 2013.

Table 24 "Yes" response for respondent's children.

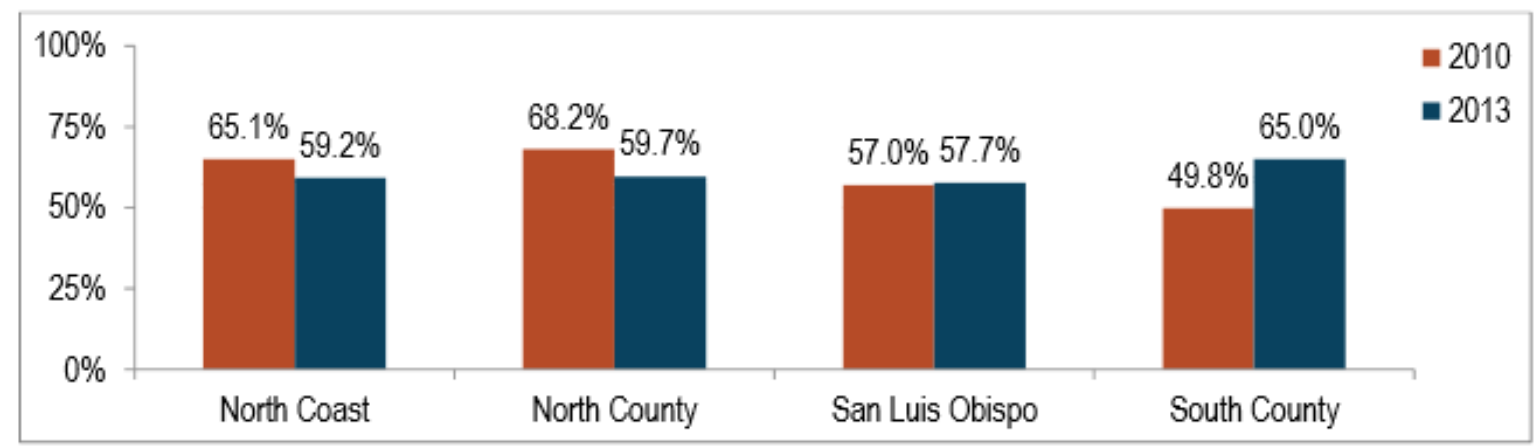

2010 n: North Coast-52; North County=75, San Luis Obispo=46, South County=61; 2013 n: North Coast=53, North County=79, San Luis Obispo=51, South County $=60$

Source: ACTION for Heathy Communifies, Telephone Survey, 2010 and 2013.

\section{Table 25 "Yes" response for respondent's teenagers.}

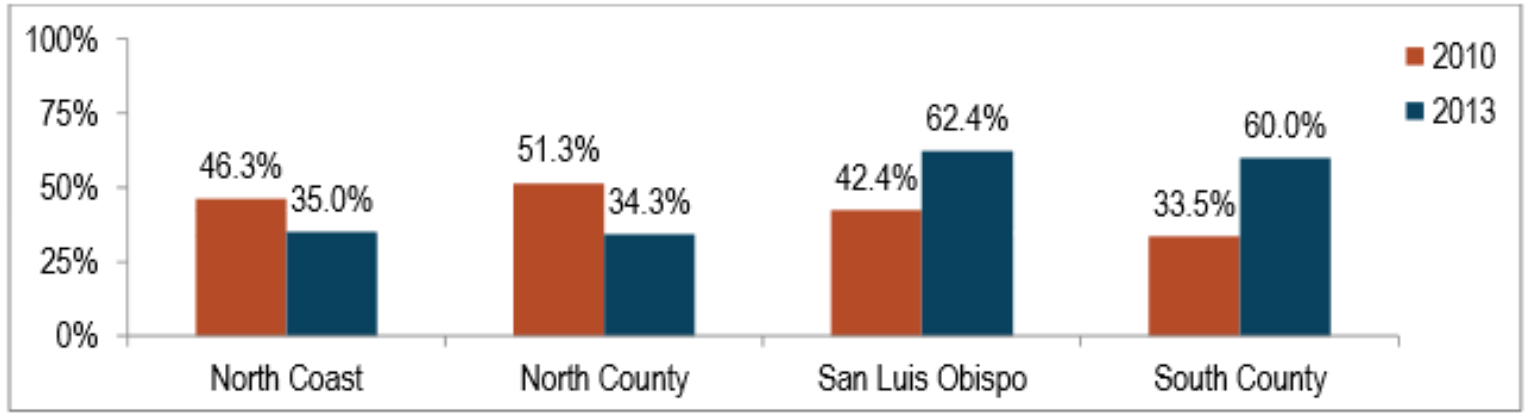

$2010 \mathrm{n}$ : North Coast $=36$, North County $=57$, San Luis Obispo $=40$, South County $=51 ; 2013 \mathrm{n}$ : North Coast $=29$, North County $=63$, San Luis Obispo=30, South County $=41$

Source: ACTION for Healthy Communities, Telephone Survey, 2010 and 2013. 
When asked how many glasses or cans of soda or other sugar sweetened beverages they drink in a day, $73 \%$ responded zero, $13.9 \%$ responded 1 , and $6.2 \%$ responded three. Percentages were higher for children 11 and younger, with $16 \%$ reporting that their child drank one sugar-sweetened beverage, and 9.4\% drank two. The percentages of people who drank one or more sugar-sweetened beverages were higher for the South County region and lower in the North Coast region.

Table 26 Response to "Yesterday, how many glasses or cans of soda, such as Coke, or other sweetened drinks, such as fruit punch or sport drinks, did you drink?"

\begin{tabular}{l|c|c|c|c|c} 
Response & Overall & North Coast & $\begin{array}{c}\text { North } \\
\text { County }\end{array}$ & $\begin{array}{c}\text { San Luis } \\
\text { Obispo }\end{array}$ & $\begin{array}{c}\text { South } \\
\text { County }\end{array}$ \\
\hline Zero & $\mathbf{6 9 . 3 \%}$ & $76.4 \%$ & $66.9 \%$ & $80.2 \%$ & $63.0 \%$ \\
\hline 1 & $\mathbf{1 5 . 9 \%}$ & $10.5 \%$ & $21.1 \%$ & $14.3 \%$ & $12.1 \%$ \\
\hline 2 & $\mathbf{9 . 4 \%}$ & $9.5 \%$ & $8.0 \%$ & $5.5 \%$ & $13.3 \%$ \\
\hline 3 & $\mathbf{2 . 3 \%}$ & $3.6 \%$ & $0.0 \%$ & $0.0 \%$ & $6.1 \%$ \\
\hline 4 & $\mathbf{2 . 1 \%}$ & $0.0 \%$ & $4.0 \%$ & $0.0 \%$ & $2.2 \%$ \\
\hline 5 & $\mathbf{0 . 0 \%}$ & $0.0 \%$ & $0.0 \%$ & $0.0 \%$ & $0.0 \%$ \\
\hline 6 or More & $\mathbf{1 . 1 \%}$ & $0.0 \%$ & $0.0 \%$ & $0.0 \%$ & $3.4 \%$ \\
\hline Total Respondents & $\mathbf{2 4 9}$ & $\mathbf{5 5}$ & $\mathbf{8 1}$ & $\mathbf{5 1}$ & $\mathbf{5 8}$ \\
\hline
\end{tabular}

Source: ACTON for Healthy Communifies, Telephone Survey, 2013.

Table 27 Response to "Yesterday, how many glasses or cans of soda, such as Coke, or other sweetened drinks, such as fruit punch or sport drinks, did your child drink?" (Child 12 to 17).

\begin{tabular}{l|c|c|c|c|c} 
Response & Overall & North Coast & $\begin{array}{c}\text { North } \\
\text { County }\end{array}$ & $\begin{array}{c}\text { San Luis } \\
\text { Obispo }\end{array}$ & $\begin{array}{c}\text { South } \\
\text { County }\end{array}$ \\
\hline 0 Times & $\mathbf{6 8 . 3 \%}$ & $80.6 \%$ & $82.1 \%$ & $61.7 \%$ & $51.8 \%$ \\
\hline 1 Time & $\mathbf{1 2 . 6 \%}$ & $7.1 \%$ & $4.4 \%$ & $20.2 \%$ & $20.4 \%$ \\
\hline 2 Times & $\mathbf{1 1 . 5 \%}$ & $12.3 \%$ & $6.6 \%$ & $5.0 \%$ & $20.4 \%$ \\
\hline 3 Times & $\mathbf{6 . 1 \%}$ & $0.0 \%$ & $6.9 \%$ & $9.0 \%$ & $4.5 \%$ \\
\hline 4 Times & $\mathbf{0 . 8 \%}$ & $0.0 \%$ & $0.0 \%$ & $0.0 \%$ & $2.9 \%$ \\
\hline 5 Times & $\mathbf{0 . 7 \%}$ & $0.0 \%$ & $0.0 \%$ & $4.0 \%$ & $0.0 \%$ \\
\hline Total Respondents & $\mathbf{1 6 7}$ & $\mathbf{2 6}$ & $\mathbf{5 8}$ & $\mathbf{3 1}$ & $\mathbf{4 4}$ \\
\hline
\end{tabular}

Source: ACTION for Healthy Communities, Telephone Survey, 2013. 


\section{ENVIRONMENTAL QUALITY CONCERNS}

In 2013 , respondents were most concerned about water quality (69\%), air pollution (59\%), traffic congestion (58\%), building in open space (57\%), and pesticide use near homes (56\%) (ACTION, 2013). These concerns have been reported as top concerns since 2006. A higher percentage of South County respondents reported concern about air pollution, traffic congestion, and pesticide use than those in the North Coast region. North Coast respondents had the highest response rate for concern over building in open space.

Table 28 "How concerned are you about the following issues in your community?" Response by region.

\begin{tabular}{|c|c|c|c|c|c|c|c|c|}
\hline \multirow[b]{2}{*}{ Response } & \multicolumn{2}{|c|}{ North Coast } & \multicolumn{2}{|c|}{ North County } & \multicolumn{2}{|c|}{ San Luis Obispo } & \multicolumn{2}{|c|}{ South County } \\
\hline & 2010 & 2013 & 2010 & 2013 & 2010 & 2013 & 2010 & 2013 \\
\hline Water Quality & $87.7 \%$ & $74.1 \%$ & $76.0 \%$ & $68.4 \%$ & $68.5 \%$ & $61.4 \%$ & $80.2 \%$ & $72.3 \%$ \\
\hline $\begin{array}{l}\text { Building in } \\
\text { Open space }\end{array}$ & $73.4 \%$ & $63.0 \%$ & $62.3 \%$ & $55.1 \%$ & $69.5 \%$ & $58.6 \%$ & $64.9 \%$ & $56.1 \%$ \\
\hline $\begin{array}{l}\text { Pesticide use } \\
\text { Near Homes }\end{array}$ & $66.6 \%$ & $55.8 \%$ & $53.3 \%$ & $50.5 \%$ & $54.9 \%$ & $52.0 \%$ & $59.9 \%$ & $64.1 \%$ \\
\hline Air Pollution & $56.0 \%$ & $53.9 \%$ & $65.1 \%$ & $60.4 \%$ & $62.5 \%$ & $53.0 \%$ & $64.1 \%$ & $64.1 \%$ \\
\hline $\begin{array}{l}\text { Traffic } \\
\text { Congestion }\end{array}$ & $50.7 \%$ & $39.3 \%$ & $63.5 \%$ & $59.3 \%$ & $70.4 \%$ & $58.8 \%$ & $68.2 \%$ & $65.8 \%$ \\
\hline $\begin{array}{l}\text { Total } \\
\text { respondents }\end{array}$ & $250-259$ & $244-250$ & $307-311$ & 287-294 & $237-244$ & 288-294 & $276-286$ & $258-262$ \\
\hline
\end{tabular}

Source: ACTION for Heathy Communities, Telephone Survey, 2010 and 2013.

The vast majority of survey respondents visited their nearest park, trail, or beach at least once in the last three months. However, $27 \%$ reported that they do not live within walking distance to a park, playground, or open space (CHIS, 2011-2012). Overall, residents would like to see more hiking trails, bike paths, natural areas, and parks in the county. 
Table 29 Response to "What new recreation opportunities would you like to see in your community?"

\begin{tabular}{l|c|c|} 
Response & $\mathbf{2 0 1 0}$ & $\mathbf{2 0 1 3}$ \\
\hline Hiking trails & $53.6 \%$ & $54.5 \%$ \\
\hline Bike paths & $56.6 \%$ & $52.5 \%$ \\
\hline Natural areas & $51.4 \%$ & $47.3 \%$ \\
\hline Parks & $46.8 \%$ & $45.0 \%$ \\
\hline Senior centers & $41.8 \%$ & $36.7 \%$ \\
\hline Playgrounds & $39.9 \%$ & $34.3 \%$ \\
\hline Sports fields & $29.9 \%$ & $28.9 \%$ \\
\hline Gyms & $19.2 \%$ & $20.1 \%$ \\
\hline No new recreation & $7.9 \%$ & $8.0 \%$ \\
opportunities needed & $2.1 \%$ & $1.4 \%$ \\
\hline Swimming pools & $11.1 \%$ & $10.3 \%$ \\
\hline Other & 1,087 & 1,078 \\
\hline Total Respondents & 3,894 & 3,655 \\
\hline Total Responses & &
\end{tabular}

Source: ACTON for Heathy Communifies, Telephone Survey, 2010 and 2013.

Note: This was a multiple response question which enabled respondents to select more than one response.

Note: For additional information on regional breakdouns, please see Appendix $D$.

Long commutes and too much traffic increase stress and affect overall health, as well as contribute to air pollution. Caltrans traffic data shows that $55 \%$ of San Luis Obispo County residents who commute travel less that 20 minutes to work, and $5 \%$ commute over and hour (ACTION, 2013). The increase in vehicle miles traveled (VMT) has outpaced population growth by a 3 to 1 ratio, although this increase has slowed since 2009. 
Table 30 Comparison of Increases in Population, number of vehicles, and Vehicle Miles Traveled (VMT), in San Luis Obispo County.

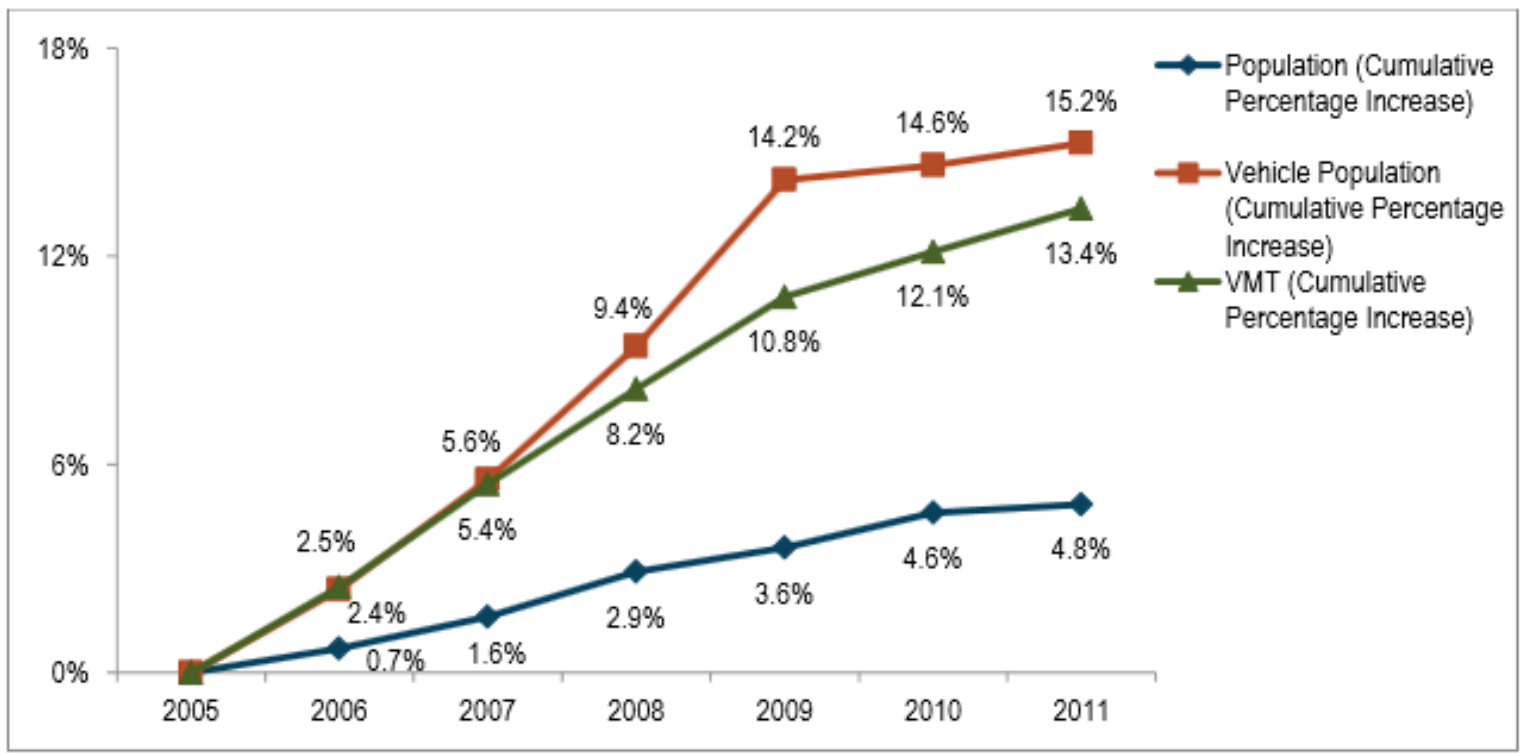

Population Source: Califomia Department of Finance, Demographic Research Unit Vehicle Population and VMT Source: Calformia Air Resources Board's EMFAC 2011-SG database

Note: 2005 was used as a baseline for calculating the cumulative percentage increase. In 2005, the population was 257,567 , the vehicle population was 186,364 , and the VMT was $6,494,086$.

The San Luis Obispo Air Pollution Control Board (APCD) monitors particulate matter and ozone in the air. Long-term exposure to high concentrations of particulate matter and high ozone levels (smog) pose a health danger for the effects to lung and heart problems. Particulate matter is measured at two levels, 2.5 microns or less in diameter (PM2.5) and 10 microns or less (PM10). These size particles can penetrate the lungs and cause harm. There were an estimated 3.1 days in 2012 when the PM2.5 exceeded the national standard, up from 0 days in 2006 (ACTION, 2013). PM10 and PM2.5 levels continue to frequently exceed health standards in the South County with no evidence of improvement. District studies show dust from the Oceano Dunes State Vehicular Recreation Area to be the primary emissions source contributing to this problem (APCD, 2012). The South County Community Monitoring Project was employed to see how much the different neighborhoods in Oceano and on the Nipomo Mesa were affected by 
the dust that blows off the Oceano Dunes. Data gathered from the Oceano area showed elevated particulate concentrations are present during high northwesterly winds at monitors in close proximity to any area of disturbed open sand. These sand areas include the beach as well as Pier Avenue where sand commonly is tracked out of the SVRA by vehicles exiting the park. The project data showed the extent of the plume from these open sand areas to be quite small, with particulate concentrations diminishing quickly downwind. A 40\% drop in PM10 concentration was observed just 0.1 mile downwind of the Pier Avenue monitoring site, while almost no plume presence was detectable at a site less than 0.4 miles downwind from the beach area (APCD, 2013)

In 2012, zero days exceeded the California ozone standards, down from 5 days in 2006.). Monitoring sites throughout the county show that certain areas reach nonattainment levels more often than others. Ozone levels are highest in the Carrizo Plains and Gillis Canyon Road. Coastal areas have always enjoyed relatively low ozone levels, with state or federal standards only rarely exceeded. While there is no evidence of improvement beyond these already low levels, there is no evidence of deterioration, either (APCD, 2012).

According a survey of $5^{\text {th }}$ grade students at Lucia Mar Elementary, $24 \%$ of students responded that a parent or other adult told them they have asthma, and $17 \%$ reported having trouble breathing when not exercising (CHKS, 2010).

The majority of survey respondents reported being "very or somewhat concerned" about water quality. The Beach Report Card measures water quality at 19 different locations on beaches throughout the county. The grades vary from year to year, ranging from $79 \%$ of days receiving a grade $\mathrm{C}$ or better in $2010-2011$ during wet weather, to $100 \%$ of days in dry weather in 2011-2012. 
Table 31 Beach Quality, percentage of Days Receiving “C” or Better.

\begin{tabular}{l|c|c|c} 
Beach Type & $\mathbf{2 0 0 9 - 2 0 1 0}$ & $\mathbf{2 0 1 0 - 2 0 1 1}$ & $\mathbf{2 0 1 1 - 2 0 1 2}$ \\
\hline Summer Dry & $100 \%$ & $95 \%$ & $100 \%$ \\
Winter Dry & $95 \%$ & $94 \%$ & $100 \%$ \\
Wet Weather & $90 \%$ & $79 \%$ & $95 \%$ \\
\hline
\end{tabular}

Source: Beach Report Card, Heal the Bay 2009-2012

Note: Grades refer to the possibility of getting sick from contaminants from swimming at the beach for 1 day. The higher the grade, the lower the chance of getting sick. Beach quality was measured at 19 different locations around San Luis Obispo County.

Water supply continues to be a challenge in the Central Coast region, from securing adequate and reliable sources of water to overuse in agricultural areas. In Cayucos, per connection water use has decreased by $41 \%$ since 2005 . In Oceano, use has increased by $2.2 \%$.

\section{PUBLIC SAFETY}

Almost $80 \%$ of survey respondents in 2013 reported feeling "very Safe" in their communities, $21 \%$ reported feeling "Somewhat Safe" and $0.8 \%$ reported feeling "Not at all Safe." In the North Coast region, the percentage responding "Very Safe" declined slightly to $86.8 \%$ from 2010 (90\%). In the South County, this percentage increased from $73.3 \%$ to $76.2 \%$ from 2010 to 2013 .

Table 32 “How safe would you say you feel in your neighborhood?" Response by region

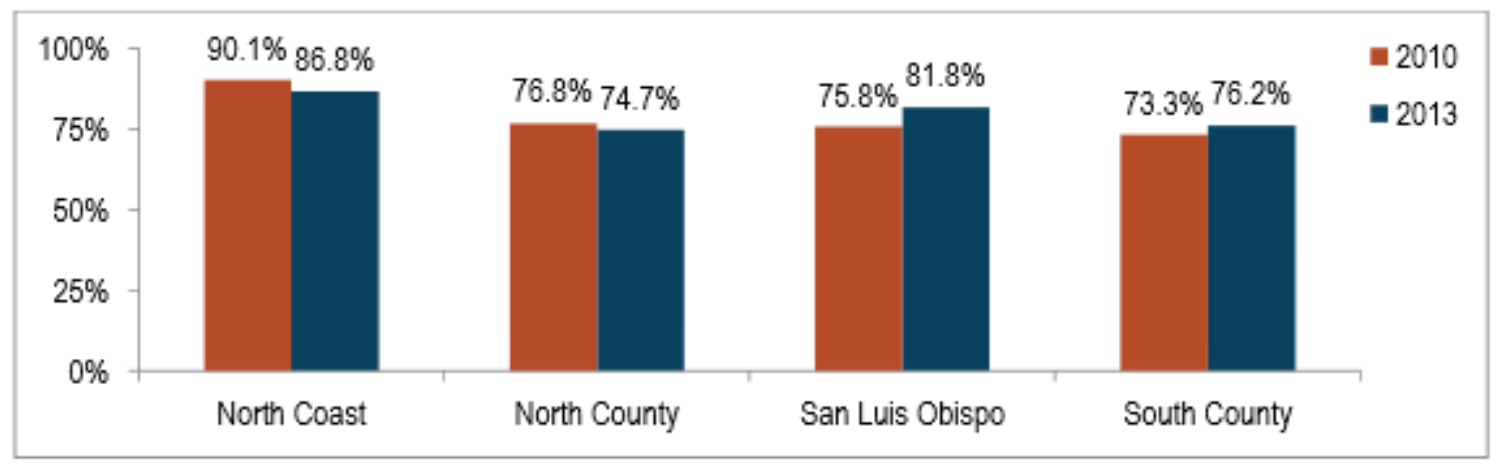

2010 n: North Coast $=259$, North County $=311$, San Luis Obispo=244, South County $=286$; 2013 n: North Coast $=251$, North County $=295$, San Luis Obispo=294, South County $=262$

Source: ACTION for Healthy Communities, Telephone Survey, 2010 and 2013. 
Respondents listed child abuse (77\%), crime (73\%) and teen violence (66\%) as top public safety concerns in 2013. Domestic violence calls and total cases of substantiated child abuse decreased from 2006 to 2012. However, the rate of child abuse cases for the county was higher $(13.9$ per 1,000$)$ than California as a whole at 9.2 per 1,000 . Response percentages declined for all answer choices in all regions from 2010. According to the California Department of Justice, total crime rates declined from 28.9 per 1,000 residents in 2006 to 26.7 per 1000 residents in 2012. Incidents of rape and robbery declined, while aggravated assault increased by $34.9 \%$. Juvenile crime, one of the most salient indicators of community safety, as it is associated with abuse, neglect, substance abuse, mental health problems, gang activity, and family disorganization also decreased in 2012 (Noguera, P., 1995). The juvenile felony and misdemeanor arrest rates decreased from 2006 to 2012 .

In Cayucos, when given the statement "I feel safe at my school", $86 \%$ of $7^{\text {th }}$ Graders chose either "Agree" or "Strongly agree", and 14\% chose "Neither agree nor disagree." Fifth graders responded "Yes, all of the time" at 55\%, "Yes, most of the time" at $27 \%$. In comparison to California State percentages, Cayucos $7^{\text {th }}$ grade students reported a higher incidence of harassment at school, but fewer fights and a lower percentage of fear of being beaten up. 
Table 33 Cayucos Selected School Safety Related Indicators with Comparisons to 2007 State CCS

\begin{tabular}{|c|c|c|}
\hline & \multicolumn{2}{|c|}{ 7th Grade $\%$} \\
\hline & District & CSS \\
\hline \multicolumn{3}{|l|}{ School Safety } \\
\hline \multicolumn{3}{|l|}{ During the past 12 months at school, have you.... } \\
\hline $\begin{array}{l}\text { been harassed because of race/ethnicity, religion, gender, } \\
\text { sexual orientation, or disability? }\end{array}$ & 50 & 31 \\
\hline been in a physical fight? & 10 & 32 \\
\hline been afraid of being beaten up? & 9 & 29 \\
\hline $\begin{array}{l}\text { During the past } 12 \text { months on school property, did you carry any } \\
\text { weapon (gun, knife, or club)? }\end{array}$ & 18 & 10 \\
\hline How safe do you feel when you are at school? Very safe. & 32 & 18 \\
\hline Do you consider yourself a member of a gang? & 14 & 9 \\
\hline \multicolumn{3}{|l|}{ School Protective Factors - High Levels (Resilience } \\
\hline Caring relationships with teacher or other adult & 64 & 31 \\
\hline High expectations from teacher or other adult & 68 & 45 \\
\hline Opportunities for meaningful participation at their school & 18 & 16 \\
\hline Total & 55 & 31 \\
\hline School Connectedness Scale & 55 & 39 \\
\hline
\end{tabular}

In Oceano, $7^{\text {th }}, 9^{\text {th }}$, and $11^{\text {th }}$ Grade students were surveyed. When given the statement "I feel safe at my school", $73 \%$ of $7^{\text {th }}$ Graders chose either "Agree" or "Strongly agree", and $18 \%$ chose "neither agree nor disagree." When asked how safe they feel at school, $29 \%$ of $7^{\text {th }}$ graders answered "very safe" as opposed to $18 \%$ in the state as a whole. 


\section{Table 34 Oceano Selected School Safety Related Indicators with Comparisons to 2007}

State CCS

Table A9.2

Selected School Safety-Related Indicators, Protective Factors, and Connectedness with Comparisons to 2007 State CSS* and 2007 National YRBS

\begin{tabular}{|c|c|c|c|c|c|c|c|c|}
\hline & \multicolumn{2}{|c|}{ 7th Grade \% } & \multicolumn{3}{|c|}{ 9th Grade \% } & \multicolumn{3}{|c|}{11 th Grade \% } \\
\hline & District & css & District & CSS & YRBS & District & css & YRBS \\
\hline \multicolumn{9}{|l|}{ School Safety } \\
\hline \multicolumn{9}{|l|}{ During the past 12 months at school, have you.... } \\
\hline $\begin{array}{l}\text { been harassed because of race/ethnicity, religion, gender, } \\
\text { sexual orientation, or disability? }\end{array}$ & 27 & 31 & 27 & 27 & $\sim$ & 24 & 22 & $\sim$ \\
\hline been in a physical fight? & 22 & 32 & 20 & 25 & 18 & 13 & 23 & 11 \\
\hline been afraid of being beaten up? (PI) & 23 & 29 & 24 & 22 & $\sim$ & 10 & 15 & $\sim$ \\
\hline $\begin{array}{l}\text { During the past } 12 \text { months on school property, did you carry any } \\
\text { weapon (gun, knife, or club)? }\end{array}$ & 10 & 10 & 13 & 13 & $\sim$ & 10 & 13 & $\sim$ \\
\hline How safe do you feel when you are at school? Very safe. (Pi) & 29 & 18 & 29 & 16 & $\sim$ & 31 & 20 & $\sim$ \\
\hline Do you consider yourself a member of a gang? & 7 & 9 & 11 & 8 & $\sim$ & 9 & 8 & $\sim$ \\
\hline \multicolumn{9}{|l|}{$\begin{array}{l}\text { School Protective Factors - High Levels (Resilience } \\
\text { Indicators) }\end{array}$} \\
\hline Caring relationships with teacher or other adult (PD) & 42 & 31 & 35 & 28 & $\sim$ & 43 & 29 & $\sim$ \\
\hline High expectations from teacher or other adult (PI) & 62 & 45 & 46 & 39 & $\sim$ & 53 & 38 & $\sim$ \\
\hline Opportunities for meaningful participation at theur school (PI) & 16 & 16 & 16 & 13 & $\sim$ & 16 & 15 & $\sim$ \\
\hline Total & 42 & 31 & 33 & 27 & $\sim$ & 39 & 28 & $\sim$ \\
\hline School Connectedness Scale (PI) & 68 & 39 & 44 & 34 & $\sim$ & 54 & 31 & $\sim$ \\
\hline
\end{tabular}

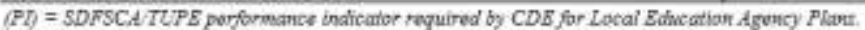

"The California Student Survey includes 9th and 11 th graders in Contimuation Alteruative schools with the data from Comprebensive Traditional high school students.

According to the ACTION for Healthy Communities survey, the top concern reported by

survey respondents in 2013 was the expanding population (14.6\%). This was the top

concern for both the North Coast region and the South County. Also in the top three

were concerns about employment and water. 
Table 35 Response to "In your opinion, what do you think is the one most important issue facing San Luis Obispo County in the next few years?"

\begin{tabular}{|c|c|c|}
\hline 2006 & 2010 & 2013 \\
\hline $\begin{array}{l}\text { 1. Growing too Fast/Uncontrolled } \\
\text { Growth/Overpopulation ( } 41.6 \%)\end{array}$ & 1. Employment/Jobs (21.8\%) & $\begin{array}{l}\text { 1. Growing too Fast/Uncontrolled } \\
\text { Growth/Overpopulation ( } 14.6 \%)\end{array}$ \\
\hline $\begin{array}{l}\text { 2. Housing Costs/Cost of Living } \\
(19.9 \%)\end{array}$ & $\begin{array}{l}\text { 2. Growing too Fast/Uncontrolled } \\
\text { Growth/Overpopulation (13.4\%) }\end{array}$ & 2. Water $(14.3 \%)$ \\
\hline 3. Traffic (11.5\%) & 3. Water $(11.9 \%)$ & 3. Employment/Jobs (11.1\%) \\
\hline 4. Water $(4.5 \%)$ & $\begin{array}{l}\text { 4. Local, State, and National Budget } \\
\qquad(8.3 \%)\end{array}$ & $\begin{array}{l}\text { 4. Housing Costs/Cost of Living } \\
\qquad(9.6 \%)\end{array}$ \\
\hline 5. Roads Need Repair (3.5\%) & $\begin{array}{l}\text { 5. Schools/Overcrowding at Schools } \\
(7.2 \%)\end{array}$ & $\begin{array}{l}\text { 5. Schools/Overcrowding at Schools } \\
\qquad(8.5 \%)\end{array}$ \\
\hline Total Respondents $=427$ & Total Respondents $=921$ & Total Respondents = 936 \\
\hline
\end{tabular}

\section{Existing County Plans Analysis}

To understand the needs for change that better support community health, it is important to first look at what is included in existing policy documents. Cayucos and Oceano are unincorporated areas in San Luis Obispo County and therefore fall under County jurisdiction.

Many of the components of the County General Plan address components of health, even without the inclusion of a health element or health chapter. A 2012 American Planning Association study was used as the basis for the analysis of existing documents (Ricklin, 2012). The study surveyed planners across the nation to find out about the extent to which their current planning documents addressed health. Twenty-two plans were evaluated to determine the extent to which they address public health. Topics included active living, emergency preparedness, environmental exposure, food and nutrition, health and human services, social cohesion, and mental health. The use of this checklist provided a more comprehensive analysis of what is already included in and what is missing from the documents that govern the Cayucos and Oceano communities. 


\section{COUNTY AREA PLANS}

County area plans describe specific land use policies and categories that determine uses, density, and intensity for the specific portions of the county. They specify development standards for public services, circulation, and land use, as well as programs for correcting local problems or conditions.

\section{ESTERO AREA PLAN}

The Estero Plan was adopted in January 2009 to establish a vision for the future of the Estero Planning Area that will guide development over the next 20 years. The goals encourage carefully planned development that respects the area's natural assets, maintains the community's small-town character as a beach community, and balances and promotes both the residential and visitor-serving aspects of the community.

The Estero Area Plan outlines a low-growth, slightly urbanized vision for Cayucos that keeps with its current character, but may also serve to encourage healthy design. The Estero Area Plan outlines the vision for future land use in Cayucos, which includes preventing urban sprawl, encouraging infill development, the creation of a greenbelt surround the town, allowing limited residential development in commercial areas, and phasing development in accordance with available water supply (Estero Area Plan, 2009).

The Estero Area Plan, like the Land Use framework document, includes a goal to foster health and wellbeing, though it does not identify the built environment as a factor in public health or mention chronic disease or health inequity in the vision or introduction. Though the plan is written in clear, non-technical language that makes it accessible to the layperson, matters of public health are not generally identified in this way. Images 
and maps do not identify or consider vulnerable populations or differences in geographies or identify procedure for evaluating or monitoring the health impacts of plans.

Though the plan includes goals and policies that support public health, generally there is no mention of how these may contribute to public health. For example, the plan includes statements of support or policies to maintain and increase public access to the shoreline and recreational opportunities, but does not include a goal to increase active transportation or the number of people who walk and bike to daily activities. There is also no mention of the mental health benefits of natural spaces. The plan does identify programs to improve pedestrian access and safety and to provide traffic calming (PG 429), establishes guidelines for including sidewalks and bike lanes in future development, and establishes a high level of service for park access and design (pg 4-33, 4-34).

The Estero Plan includes policies to protect ground and surface water, including for stormwater runoff, though it is lacking in other areas of environmental exposure protection. Health and human services goals and policies are largely absent from the plan. There are policies included to limit noise to sensitive receptors and incorporate design features to increase safety, though there is no mention of the impact that this may have on crime prevention or promoting active lifestyles.

As in the APA study, the Estero plan is strongest on goals and policies relating to active living, although the explicit link to public health benefit is missing. Environmental exposure is also more strongly represented, although the focus is likely attributable to the influence of CEQA policies. These considerations are helpful to protecting health, but again lack the crucial connection between environmental quality, exposure, and community health. The Estero Plan is very weak in the areas of food and nutrition, 
emergency preparedness, health and human services, and social cohesion and mental health. Some of these topics, however, are better suited to other elements of the County General Plan.

\section{SAN LUIS BAY COASTAL AREA PLAN}

Oceano, along with Pismo Beach, Grover City, Arroyo Grande, Halcyon, and the urban area of Avila Beach, comprise the San Luis Bay Planning Area. The Plan (last revised in August 2009) describes the land use policies for the Coastal Zone portion of the San Luis Bay Planning Area, as well as defines allowable density and intensity and specific development standards meant for addressing issues unique to the individual communities.

The Plan does not contain any explicit promotion of public health related goals or policies in reference to Oceano. In fact, the term "health" is never used in the document within the context of providing benefits for, or the protection of, public health purposes. However, some of the language used throughout the document does have public health supporting implications.

The San Luis Obispo County's General Plan provides recommendations for programs or policies found in the San Luis Bay Coastal Area Plan that have potential public health ramifications. Specifically, one of the Oceano Urban Area Program recommendations is for the County Engineering Department to work in conjunction with property owners and LAFCo in an effort to bring urban street improvements such as curbs, sidewalks and street trees, to residential areas (Ch. 6, p 19). These improvements could provide increased pedestrian mobility and enhance the aesthetic appearance within the neighborhood, which can both act as catalysts for provoking physical activity. 
The Land Use section does provide this potential public health impacting recommendation "a neighborhood park site should be reserved in the easterly portion of the community to better meet resident needs" (Ch. 6, p.14). Though, the recommendation makes no connection between parks or green spaces and the benefits to public and mental health. In Chapter 4: Circulation (2009), the Plan states "the planning area will likely continue to be automobile-based, but alternative components of the circulation system such as transit, bikeways and air traffic will be important components of the area wide circulation system." Recommendations for improved bikeways, "Bike lanes as wide 8 feet, or separated Class I bikeways, are needed on such roadways as [...] along Highway 1 from Pismo Beach through Oceano [...] Class II or III bikeways are recommended on Highway 1 from Oceano onto the Nipomo Mesa" $(C h .4$, p.2) are mentioned for future improvement projects. The potential health and environmental benefits of increasing bike ridership is not mentioned.

\section{OCEANO SPECIFIC PLAN}

The Oceano Specific Plan (2001) was adopted by the San Luis Obispo County Board of Supervisors in 2002, and certified by the California Coastal Commission in 2004. The Specific Plan's purpose is to provide "an overall framework for translating broad community values and expectations into specific strategies for enhancing the community's quality of life" (San Luis Obispo County, 2001, p. 1). The concerns addressed in the Specific Plan were informed by Oceano residents through information collected via surveys, meetings and public workshops. The Specific Plan is meant to be used in conjunction with the San Luis Bay Area Plan.

The Specific Plan places an emphasis on safety, sidewalks, bicycle infrastructure, park, open spaces and recreational facilities, as demonstrated by one of the Specific Plan's 
four defined primary goals, Oceano's future community designs will feature "Improved buildings, public spaces, pedestrian walkways, safe bikeways, more natural areas, parks and high quality landscaping" (p. 13). Indeed, the concept plan for Oceano's downtown is a pedestrian oriented, mixed-use commercial retail development. As detailed in the literature review section of this report, the provision of these built environment features are associated with inhibiting physical activity behaviors, and therefore may yield potential health benefits. There is also implicit acknowledgment that parks, public open spaces and plazas provide intangible beneficiary value by fostering social activity, interaction and community cohesiveness (p. 16), all of which research has shown to be associated with improved mental well-being.

While many of the goals, programs, land use regulations, development standards and design guidelines stated in the Specific Plan would have corresponding positive health impacts, it is generally not described in the document as the overriding motive. Rather, the outlined development strategies are meant to be "used as a promotional tool, to acquaint potential developers with Oceano's economic potential and the expectations of its residents" (p.1). Nevertheless, from a health perspective, the plan does provide new development standards and programs that will serve to help Oceano residents.

\section{OCEANO REVITALIZATION PLAN}

The County of San Luis Obispo, in partnership with the Local Government Commission from the California Department of Transportation, funded by an Environmental Justice Planning Grant, created the Oceano Revitalization Plan (ORP), with work beginning in 2012. The Plan builds off of the 2002 Oceano Specific Plan and seeks to employ actions that will implement policies outlined in the Specific Plan. The ORP lists three objectives: 
- Identifying improvements that will lead to a safer and more walkable downtown and adjacent neighborhood areas,

- Planning for improved mobility, and

- Creating more attractive streetscapes along Highway 1 to enhanced retail activity and jobs

Whereas the Oceano Specific Plan sees improvement of sidewalk infrastructure and connectivity as a necessary step to encourage new development in Oceano, the ORP makes a clearer connection between the health benefits of providing such amenities. For example, "Frequent bicycle racks along the street corridor are another necessity for promoting healthy community living and easily enabling alternative modes of transportation" (San Luis Obispo County, 2012, p. 47).

Public safety is also a primary concern of the plan, as both short- (crosswalk striping, bike lane restriping) and long-term (street medians, roundabouts, lane reductions) improvements, are focused on pedestrian, bicyclist and motorist safety. Improvements in traffic safety and connectivity remove fear barriers and increase opportunities to be physical active.

\section{LOCAL COASTAL PROGRAM}

According to the California Coast Act of 1976, local governments must prepare a land use plan and schedule of implementing actions to carry out the policies of the Coastal Act in all areas designated as a coastal zone. The California Coastal Commission is a state agency with quasi-judicial regulatory oversight over land use and public access in the California coastal zone. San Luis Obispo County consists of an expansive coastal zone which encompasses Cayucos' entire boundary [and part of Oceano]. 
The Coastal Zone Land Use Ordinance (CZLU) is the guiding document of allowable uses in designated coast zones. The purpose of this document is to implement the General Plan and the Coastal Program, and to guide and manage future growth of the county in accordance with those plans. Further, to minimize adverse effects on the public resulting from inappropriate creating, location, use, or design of building sites, buildings, land uses, parking areas, or other forms of land development by providing appropriate standards for development,.

\section{OTHER COUNTY GENERAL PLAN ELEMENTS}

Other goals and policies that apply in Oceano and Cayucos are described in the County General Plan. The General Plan is the blueprint for the future physical, economic and social development of the unincorporated areas of the county, outside cities. It implements California laws that regulate land use planning and development. State law requires that every general plan must contain the following components or "elements": Land Use, Conservation, Noise, Circulation, Open Space, Safety and Housing. In addition, state law allows for the adoption of additional or optional elements of a general plan. The County of San Luis Obispo has adopted seven optional elements: Recreation, Historic and Esthetic, Energy, Off-shore Energy, Economic and Agriculture.

\section{Implications}

Implications and challenges for Cayucos and Oceano have been identified from the research presented in the Existing Conditions Report. Below is a summary of the implications of this information and the challenges presented for each community. This information is incorporated into the design of the outreach phase of the project as well as the goals and programs recommended in the draft plans. 


\section{IMPLICATIONS FOR CAYUCOS}

- Population growth has declined in Cayucos, and vacation homes and rental units account for many of the housing units.

- The population in Cayucos is trending toward older residents, and the median age is quite high at 57.2. This has implications for the prevention of injury, transportation modes, and well as medical care access.

- Cayucos is a bedroom community with very few options for active transportation or transit, which has implications for environmental health and physical activity levels.

- The population in Cayucos is mostly white, well-educated, and almost $100 \%$ English speaking, which will impact community outreach efforts.

- Transit to and from Cayucos is infrequent and time-consuming, which is likely deterring the use of the bus system and increasing the dependence on personal vehicles.

- Cancer and heart disease are the leading causes of death in Cayucos by a large margin. Though these chronic diseases are attributable to a number of factors, increasing exercise and healthy eating habits among community members may have a positive impact on these rates.

- Increased sports programs or after school activities were the number one choice for parents when asked what could increase physical activity for their children. This is important for determining collaborative actions in Cayucos.

- Though most Cayucos students are driven to school, when asked what would encourage active transportation to school, the largest numbers of responses 
were living closer to school, sidewalk or street improvements, and crossing guards, all of which have to do with urban design and pedestrian safety.

- There have been several pedestrian and bicyclist deaths in Cayucos in the last ten years that were caused by collisions with automobiles. Pedestrian and bicycle safety should be a major priority in Cayucos.

- Cayucos Elementary students are in need of physical fitness improvements, and integrating physical activity and healthy eating habits into daily life may help to ameliorate these problems, and help to increase the chances of a healthy adulthood.

- Though the Estero Area Plan supports some aspects that affect community health, specific links between the built environment and health and several indicators are missing.

- North coast residents are very concerned with water quality and availability.

- Housing is not affordable for many income levels in Cayucos, although the low growth rate in town and high costs may render affordable housing infeasible.

\section{IMPLICATIONS FOR OCEANO}

- A large percentage of Oceano's population is comprised of Spanish-only speakers. Added considerations must be used when conducting outreach efforts; documents must be translated and Spanish speaking liaisons should be utilized during community interaction.

- Oceano is a young community, with just 20 percent of the population over the age of 40 . This likely indicates a high percentage of young families with children. 
Community goals should be mindful to include strategies that focus on improving health levels in children.

- A comparatively high percentage of Oceano residents carpool and walk to work. This could be due to the large migrant farm worker population walking to designated locations to carpool to nearby agricultural land. Emphasis should be placed on providing a complete sidewalk network for safe pedestrian travel.

- Cancer and heart disease are the leading causes of death in Cayucos by a large margin. Though these chronic diseases are attributable to a number of factors, increasing exercise and healthy eating habits among community members may have a positive impact on these rates.

- Both the Oceano Specific Plan and Revitalization Plan recognize the need for added park and recreation facilities on the eastern section of Oceano. However, neither plans identified potential areas to develop space for active recreation. Feasible and immediate strategies may be to develop a joint-use agreement to officially allow public access to Oceano Elementary recreation grounds after school hours.

- Oceano 5th graders had some of the poorest aerobic and body composition results in the entire county, as reflected in the 2012-2013 California Physical Fitness Report, putting them at high risk to incur future health problems. Ecological interventions, including those found in the built environment must be prioritized and included in development strategies. 


\section{IMPLICATIONS AND FOR BOTH COMMUNITIES}

- Access to medical care is restricted by increases in cost, higher rates of health insurance, and proximity to medical facilities.

- Only about half of county residents participated in five or more days of physical activity for at least 30 minutes in 2013 , and although this rate is slightly better than previous years, the lack of exercise among many county residents has great implications for health among those individuals.

- Mental health issues are increasing in the county, and there is potential for features in the built environment to contribute to overall mental wellbeing.

- Concern over alcohol and drug abuse remains at similar levels to previous years, although binge drinking rates and youth substance abuse have declined.

- Healthy eating is increasing in the north county, with obesity rates declining and more people consuming enough fruits and vegetables.

- County residents would like to see more hiking trails, bike paths, and natural areas in their communities.

- Most people feel safe in their neighborhoods, and total and juvenile crime rates decreased in the county. 


\section{CAYUCOS FINDINGS}

\section{Introduction}

This chapter contains the findings of the multifaceted study conducted in Cayucos to better understand the characteristics of the community, both in terms of the built environment and local knowledge. A physical inventory was conducted to achieve an understanding of the existing built environment in Cayucos, and ample community outreach provided local knowledge to augment this research.

The physical inventory included a walkability audit and food, parks, and hydration station access assessments. Results of these studies for Cayucos are summarized in this section and displayed in map form. Information is comprised of findings from the following efforts:

- Walkability Study

- Food Access Assessment

- Parks Access Assessment

Community outreach was conducted in several forms in an effort to gather valuable local knowledge and feedback from community members regarding physical activity levels, information about the built environment where they live, work, and play, and perceived barriers to healthful activities and food access. The efforts discussed below include:

- Presentations to Local Government Agencies

- Key Informant Interviews

- Community Group Meetings 
- Cayucos Community Questionnaires

- Public Spaces Questionnaires

- Cayucos Farmers Market: Public Space Improvement Voting

- Cayucos School Outreach

- Plan Draft Review Event

Overall, findings indicate that Cayucos has many characteristics that help to support the health of individuals. However, there are several areas with room for improvement. The Key Findings section combines the most important, relevant, and frequently-encountered findings to present a summary that is useful for the creation of the draft Cayucos Community Health Plan. For more information on the methods for conducting the inventory and outreach, see the Methods section.

\section{Physical Inventory}

In order to better understand the built environment in Cayucos, a physical inventory was conducted to observe and measure features in a systematic way. Though photos of a town and even visits to the areas can speak volumes about the characteristics of that place, finding a way to measure spatial relationships can provide a different view and additional layer of understanding. The physical inventory included a walkability audit and food, parks, and hydration station access assessments. Results and key findings are displayed and described blow for the following inventory efforts:

- Walkability Study

- Food Access Assessment

- Parks Access Assessment 
Through these studies, it becomes clearer that some areas of Cayucos are better served by elements of the built environment that support health, such as comfortable pedestrian travel and short routes to parks. A major finding also includes that there is very little access to healthy food in town. The analysis also could also allow the physical conditions in Cayucos to be compared to those in Oceano or other communities in the county.

\section{WALKABILITY AUDIT RESULTS}

A walkability audit was conducted in Cayucos to provide an objective evaluation of the walking environment, and to identify concerns for pedestrian related to safety, access, comfort, and convenience. Numerous features of the built environment have been associated with physical activity, including residential density, land-use mix, urban sprawl, intersection density, walkability, park availability, and accessibility to physical activity-related resources (Casagrande, 2011). To complete this analysis, an existing spatial analysis tool, the Pedestrian Environment Data Scan (PEDS) was utilized to quantify the qualitative aspects of the Cayucos walking environment, including sidewalks quality, traffic, land use patterns, building accessibility, safety, cleanliness, amenities, the degree of urban enclosure, among other factors. Due to time and resource constraints, the audit was targeted in the downtown area, mostly along Cayucos Drive and Ocean Avenue. Surround streets were not included in the study, although most of the residential areas connect to these major thoroughfares. This section presents the findings from the Walkability Audit study, complete with maps for visualizing problem areas and the most walkable areas of Cayucos by street segment. The detailed results for the audit are available in Appendix A: Physical Inventory.

The maps show that the overall pedestrian and bike-friendliness near the commercial core of the town. To draw more detailed conclusions about the walkability of the 
downtown area, the results were also divided into three categories: ease and comfort of travel, safety, and aesthetics. Each street segment was graded and assigned a color to signify a low or high score. Green signifies the higher scores, yellow signifies scores at a slightly lower grade, orange signifies a low grade, and red signifies the lowest grades.

The overall walkability map (

Figure 3) shows the walkability measurement for each street segment through the downtown core. The top map shows the northwest side of Ocean Avenue, and the bottom map shows the southern end. To a frequent pedestrian or bicyclist visitor to the area, this map may present a finding that is very obvious. Segments 3,7 , and 8 are the most commercialized area of Cayucos, and generally have the most foot traffic. The sidewalks in this area are generally well-kept, and the overall walking and biking experience is pleasant and feels safe. There are many sidewalks, the buildings are accessible from the walkways, and the area is clean and in good condition. The ocean and beach provide a backdrop in this area that encourages visitors, and there are many shops and restaurants to visit. However, even in this area, bike parking is very limited, and sidewalks are sometimes quite narrow or have cracks or obstructions. Ocean Avenue is very wide with single lanes of up to 25 feet, angle parking on both sides of the street, and a center turn lane. The crosswalks are very long, and the view of pedestrians is somewhat obstructed by parked cars. 
Figure 3 - Overall Walkability, Cayucos
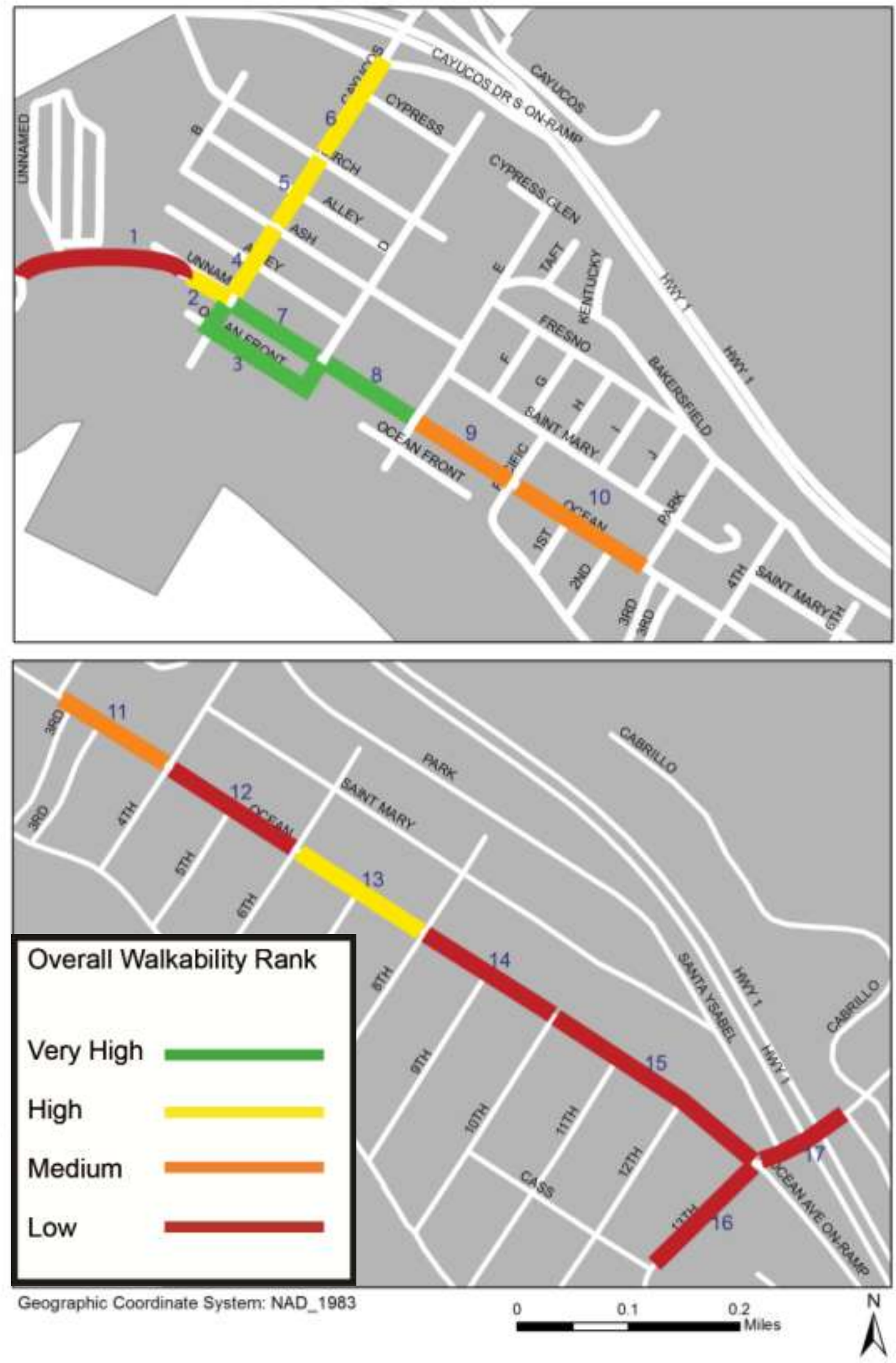
Low ranking street segments (in red and orange) are concentrated at the edges of the commercial core and in areas with more residential uses. Segments 9, 10, and 11 ranked significantly lower in walkability overall compared to Segments 3,7 , and 8 . This area comprises mostly hotels and residential uses, along with a large vacant area. Segment 9, in orange, connects with Pacific Avenue, the street that continues along the beachfront properties and to the beach access points. Segments along 13th Street, which connects Ocean Avenue and Pacific to the neighborhoods to the east of Highway 1 , ranked low consistently.

\section{Ease and Comfort of Travel}

The ease and comfort of travel category (Figure 4) includes only certain categories from the PEDS assessment, including type and number of different uses, the slope of the terrain, sidewalk or walking path conditions, obstructions, and features, bus stops and bus stop amenities, and presence of wayfinding aids. The downtown core scored high in this category, but a few other segments also scored high enough to be shown in green for the presence of a bus stop, completed sidewalks, or fewer path obstructions. For instance, although segments 5 and 9 are very close to, or even considered to be part of the commercial core, they received low scores for ease and comfort of travel. 
Figure 4 - Ease of Travel, Cayucos
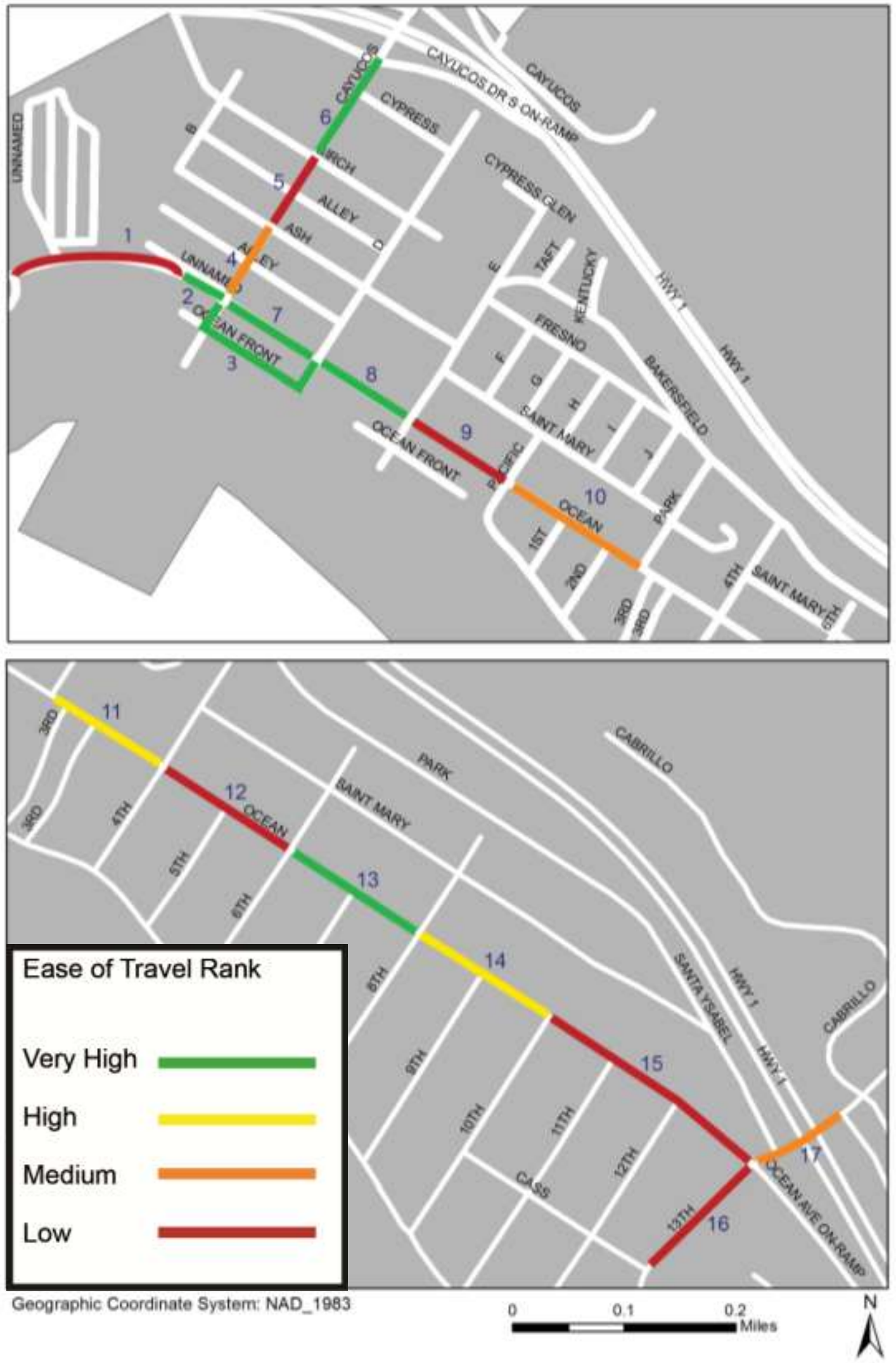


\section{Safety}

The safety category (Figure 5) considers elements such as the number of lanes that a pedestrian must cross, sidewalk completeness, the type of pedestrian facility, number of high volume driveways, crossing aids, and lighting or signage. The safety of the streets therefore refer to safety from traffic, Crime Prevention Through Environmental Design (CPTED) elements, and elements that may increase the likelihood of injury. The segments in the commercial core that ranked highest in walkability overall ranked slightly lower (yellow) for the safety category largely for injury risk and traffic safety issues. The areas on the southern portion of Ocean Avenue maintain the consistent low scores. Cayucos Drive, however, ranked high in this category due in part to the number of crossing aids and other signage. 
Figure 5 - Safety, Cayucos
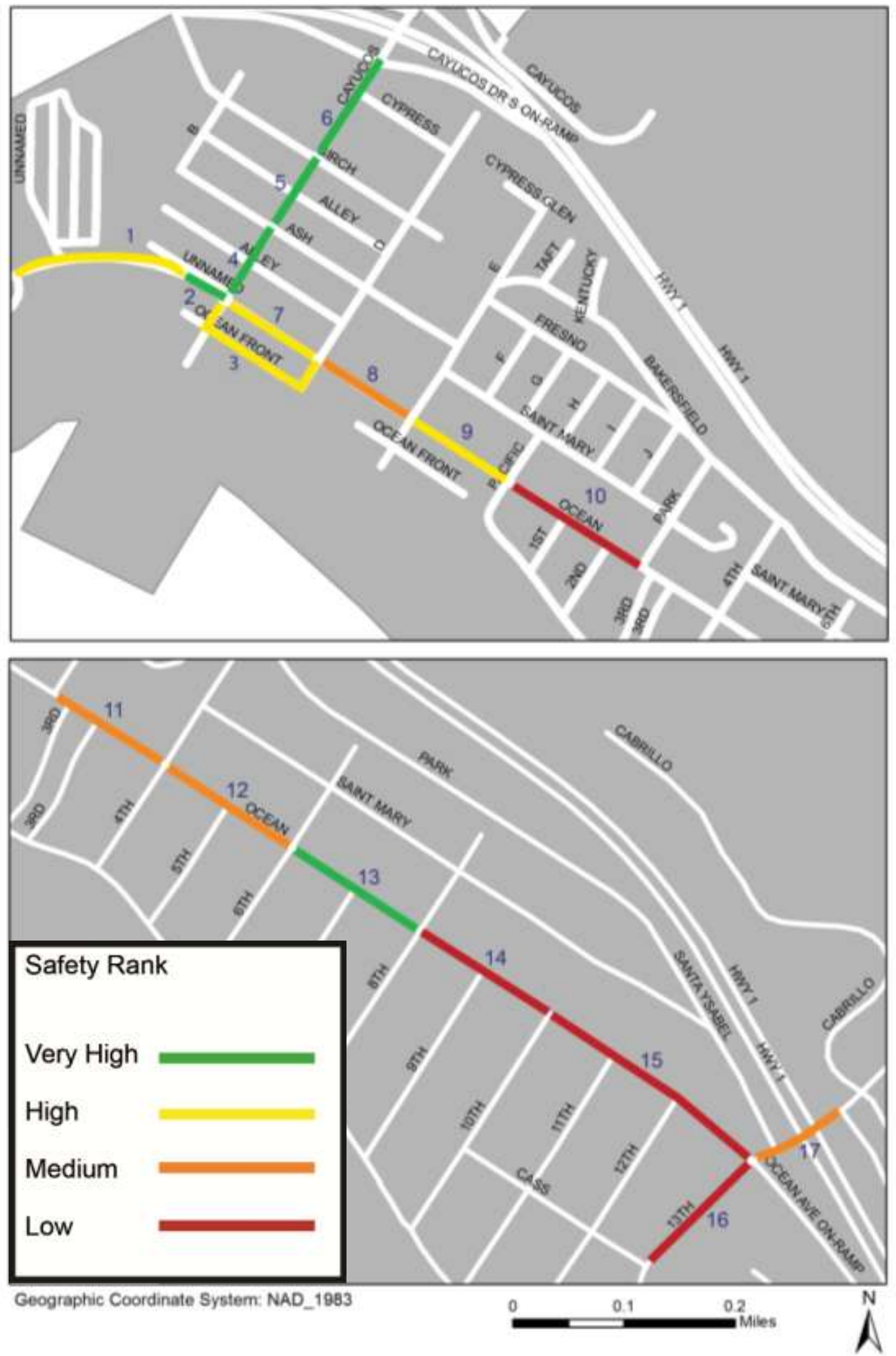


\section{Aesthetics}

The last category attempts to measure the aesthetics of the study area through elements such as the presence of amenities like benches and water fountains, the presence of power lines or trees, cleanliness and maintenance, and degree of enclosure (Figure 6). Though the natural beauty of the town provides high aesthetic value to all areas, it is important to reiterate that the ranking system measures each street segments as compared to the other segments. The core commercial area ranked high in this category in part due to pedestrian amenities, building articulation, and the absence of visible power lines. The area near the Cayucos School on Cayucos Drive and the segment near the Cayucos Market and Paul Andrew Neighborhood Park also ranked high in this category (yellow). The southern end of Ocean Avenue was ranked lower. 
Figure 6 - Aesthetics, Cayucos
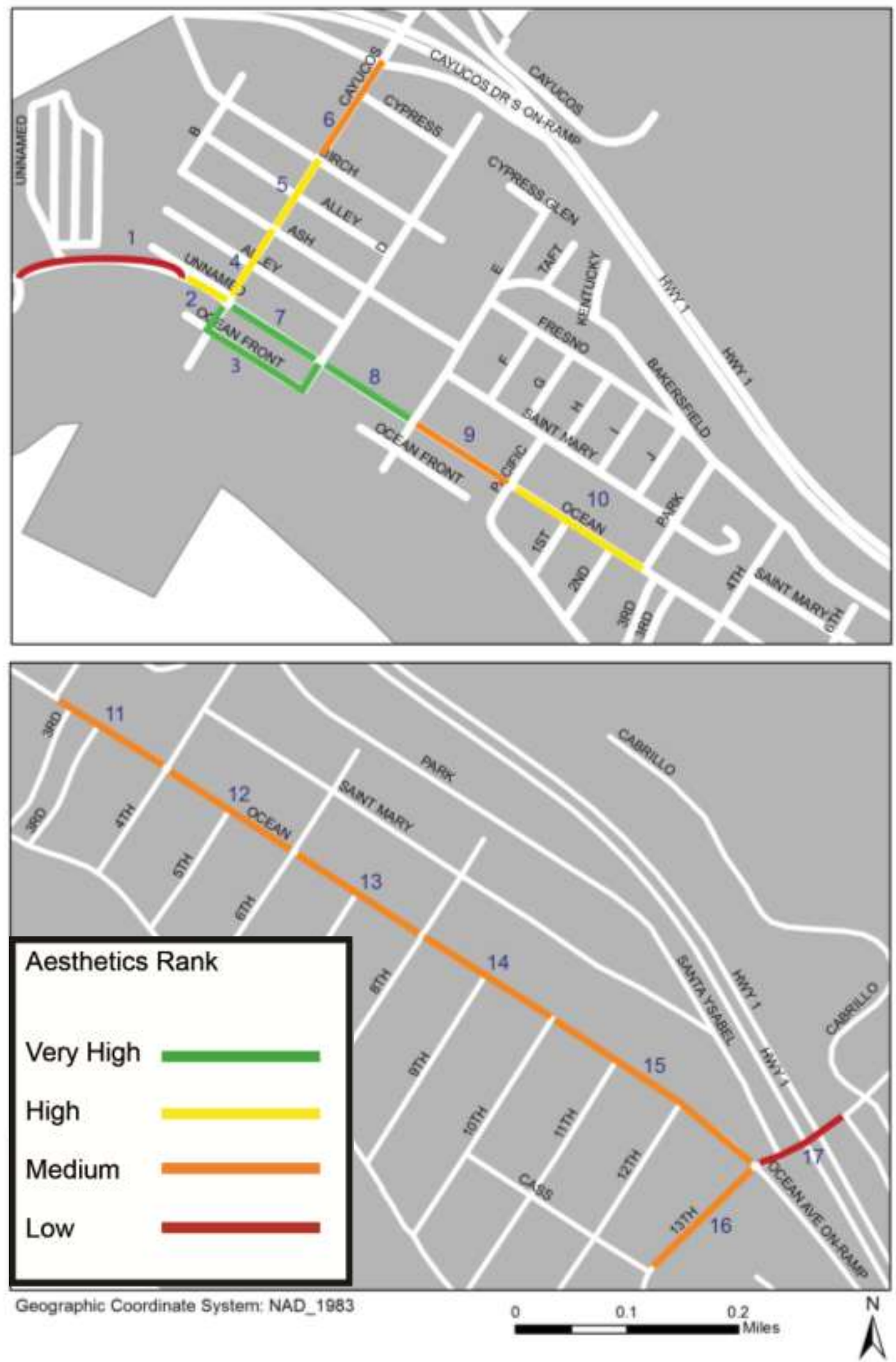
The PEDS tool also includes a subjective assessment, in which the surveyor ranks the street segment on attractiveness for walking and cycling, and safety for walking and cycling. These results are not included because there is some question regarding the accuracy of the data collected. Spreadsheets used to compile and analyze this data are included in Appendix A: Physical Inventory.

\section{Walk Audit Key Findings}

- The overall most walkable street segments are in the core commercial area near the pier.

- Segments south of 8th Street along Ocean Avenue ranked consistently low overall and in the three categories, compared to other street segments.

- Segment 9 connects with Pacific Avenue and to the beach access points, but ranks low in overall walkability.

- Segments along 13th Street, which connects Ocean Avenue and Pacific to the neighborhoods to the east of Highway 1, ranked low consistently.

- Segments 9 and 12 (E Street to Pacific and 4th to 6th) ranked poorly in the Ease and Comfort of travel category, though the segments on either side of these segments ranked higher in that category.

- The segments in the commercial core that ranked highest in walkability overall ranked slightly lower (yellow) for the safety category, largely for injury risk and traffic safety issues.

- Cayucos Drive ranked high in the safety category due in part to the number of crossing aids and other signage. 
- The street segments that offer the most in terms of aesthetics are in the core commercial area.

\section{FOOD ACCESS ASSESSMENT}

The food access assessment was included in the plan in order to analyze the existing availability of food outlets and to help determine need. The assessment was conducted using GIS data collected from San Luis Obispo County and by visits to each of the stores that sell food or beverages. For the analysis of the food retail environment, data was obtained from the local environmental health department to determine the location and type of stores that exist in the study area.

According to the Retail Food Environment Index (RFEI) standards, there are three unhealthy food outlets in Cayucos, and only one small market which sells alcohol but no tobacco (California Center for Public Health Advocacy, 2007). Most stores are similar to convenience markets or gas station shops and only sell alcohol, candy, chips, sodas, tobacco, and similar items. Figure 7 below shows a map that displays 1 -mile and $1 / 2$ mile distances along roads from these stores. 
Figure 7 - Cayucos Store Locations

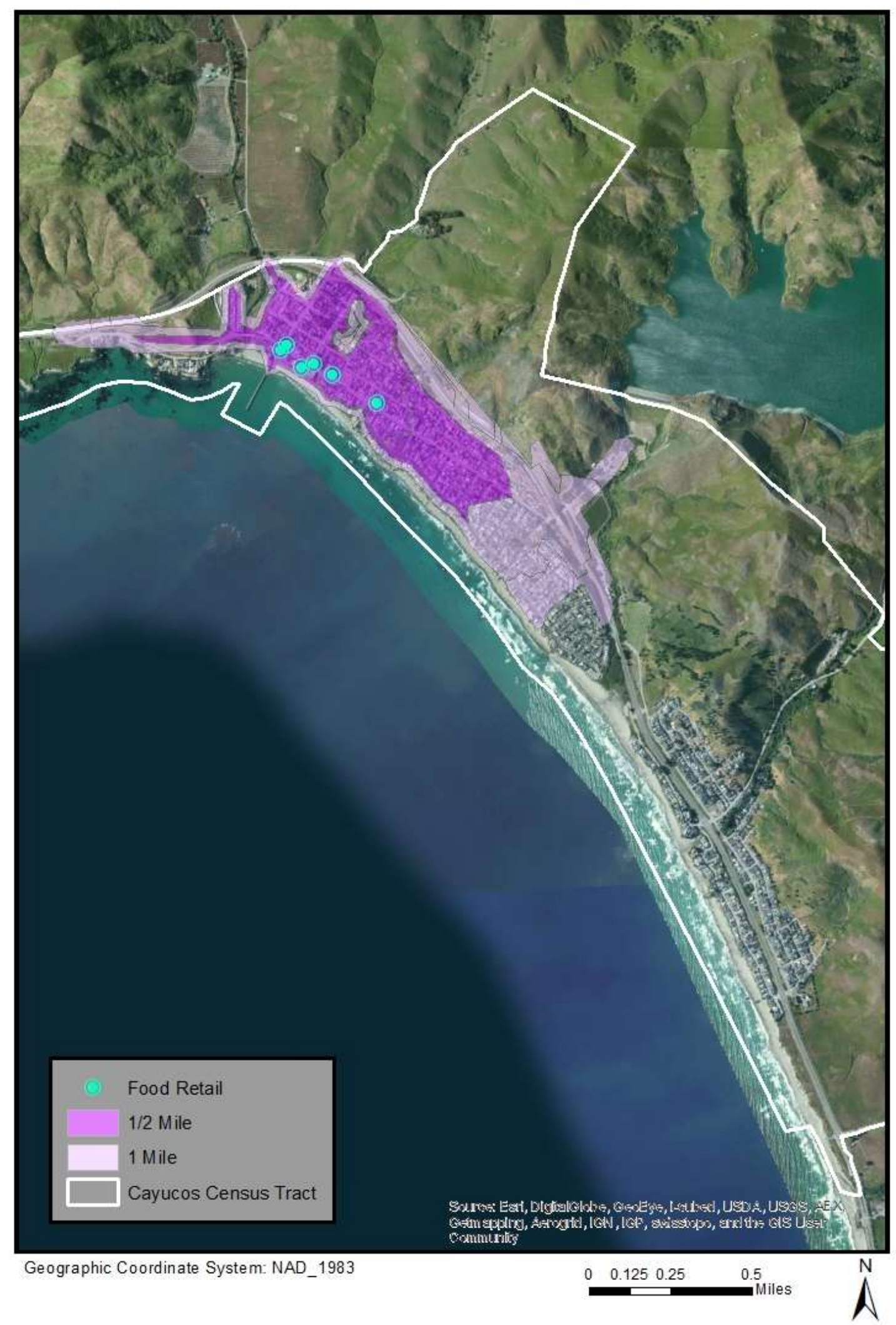


The only store in Cayucos that offers whole grain bread and tortillas, fruits and vegetables, low fat milk, or other healthy items is the Cayucos Supermarket, located on South Ocean Avenue. Figure 8 below shows a map that displays 1 -mile and $1 / 2$ mile distances along roads from the Cayucos Supermarket. Though the store is centrally located, a large portion of residential neighborhoods, especially to the south and across Highway 101 are not within the 1/2-mile or 1 -mile walk or bike distance. This presents an issue of food accessibility and affordability for residents, especially those without access to a personal vehicle such as children and the elderly. 
Figure 8 - Cayucos Healthy Food Access

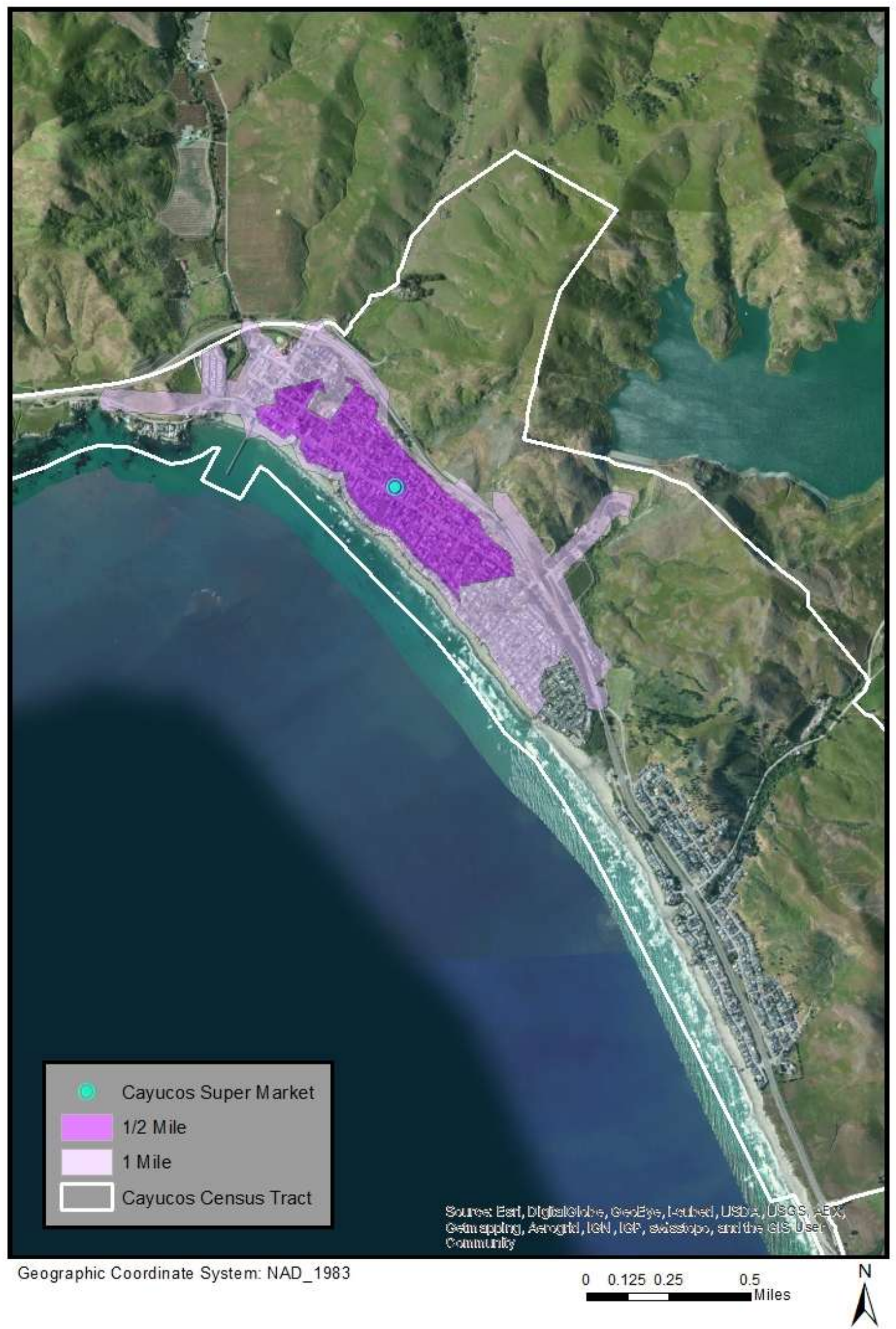


Food Access Assessment Key Findings

- There are three unhealthy food outlets in Cayucos which sell only candy, chips, sodas, tobacco, and similar items.

- The only store with healthy items is the Cayucos Supermarket, located on South Ocean Avenue

- A large portion of residential neighborhoods, especially to the south and across Highway 1 , are not within a $1 / 2$-mile or 1 -mile walk or bike to the grocery store.

\section{PARKS ACCESS ASSESSMENT}

The parks assessment was included to better inform the project as to the community's access to their nearby parks. The parks assessment was conducted using GIS data collected from San Luis Obispo County planning, and field reconnaissance. Both maps show $1 / 4$-mile and $1 / 2$-mile access by way of existing streets. The assessment is meant to convey the accessibility of each facility or access point from the residential areas.

The first map shows parks only, without beach access points (Figure 9). Cayucos has three official parks: Hardie Community Park, Paul Andrew Neighborhood Park, and Norma Rose Park, as well as elementary school playgrounds at Cayucos Elementary School. Hardie Community Park is four acres and features playground equipment, picnic benches, horseshoes, and a lawn area. The tennis courts and community swimming pool are also located at Hardie Park. Paul Andrew Neighborhood Park is a 1-acre park with a playground, picnic tables, and a bike rack. The newest Park, Norma Rose Park, is a 1.5 acre park east of Highway 1. Planned improvements will include a skate park, children's playground, basketball court, rest-room, and picnic areas (San Luis Obispo County Parks, 2002). 
According to National Recreation and Park Association (NRPA) recommended guidelines and the Estero Area Plan, Cayucos needs 27 additional acres of neighborhood and community parks. Cayucos is in particular need of facilities for "active" recreation or active parks, such as ball fields, children's play equipment, and recreation programs (Estero Area Plan, 2008). All of the parks in Cayucos are better suited to passive recreation. As shown in Figure 9, several residential areas are lacking in convenient access to community parks. Though parks are accessible by bike, many residents to the south of downtown do not have convenient pedestrian access to a park. 
Figure 9 - Cayucos Public Park Access

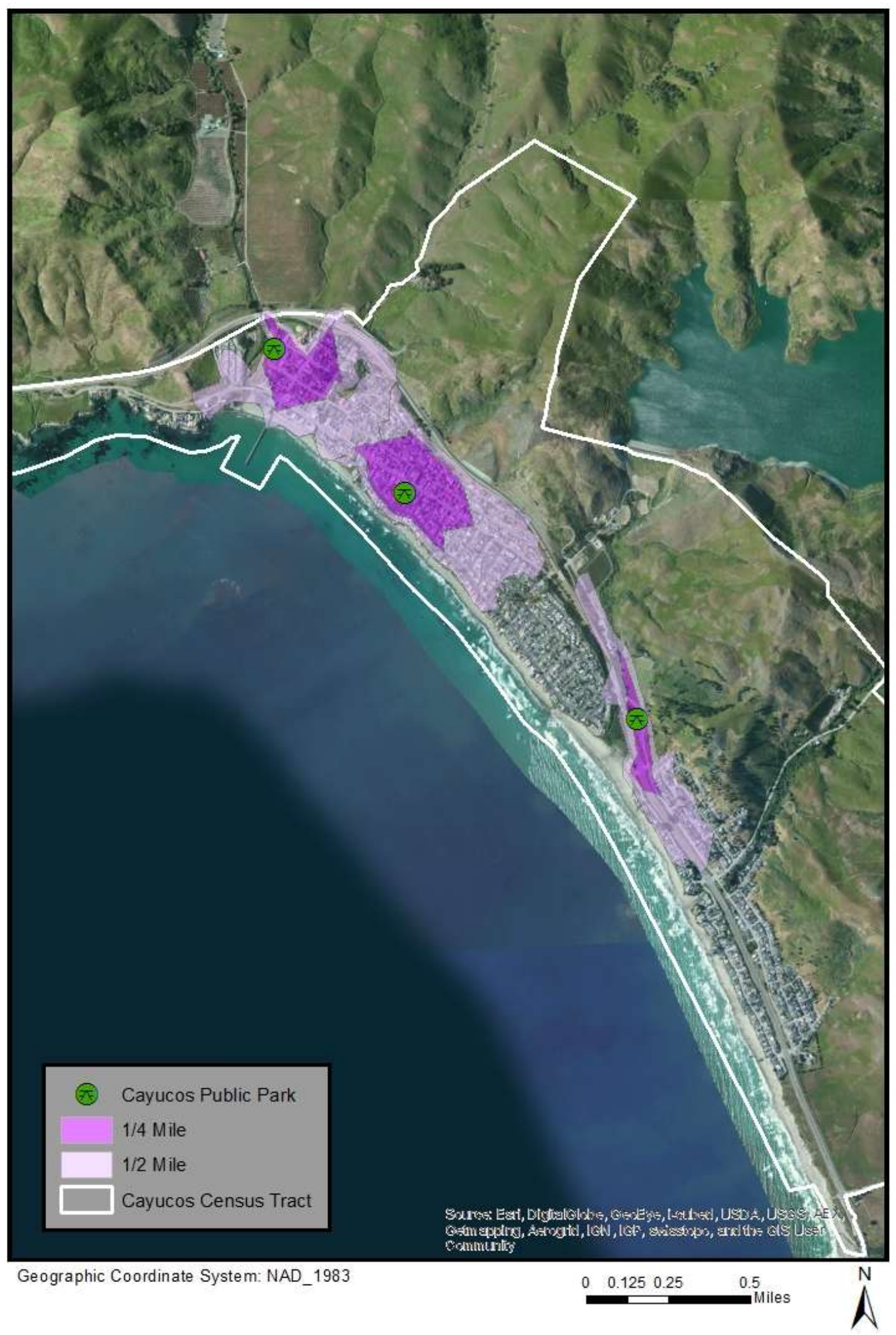


Because many residents of and visitors to Cayucos use the beach for exercise such as walking, running, kayaking, or surfing, and because the beach serves as a community space, the second map identifies the beach access points. The NRPA park guidelines do not factor in access to the beach, which spans the length of the community, includes several access points, and provides a significant recreational opportunity. Though the beach is not an official park, a map was created to include distances along roads to beach access points along with parks Figure 10. With the inclusion of beach access, parks are accessible to most residences in Cayucos. 
Figure 10 - Cayucos Park and Beach Access

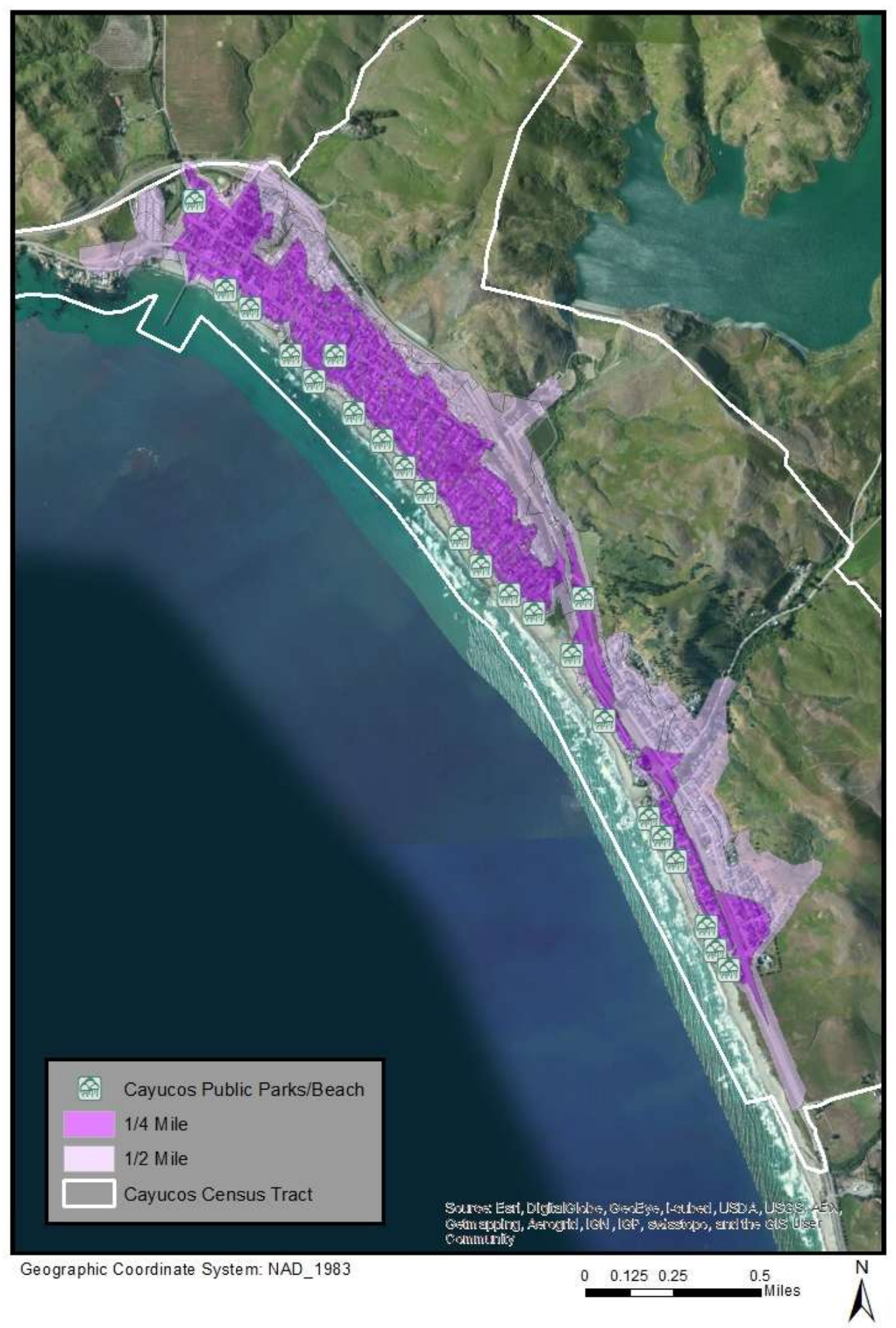


Parks Access Assessment Key Findings

- Especially south of the commercial core, many residents do not have convenient pedestrian access to a park.

- Cayucos needs 27 additional acres of parks, especially active parks, although guidelines do not factor in access to the beach.

- With the inclusion of the several beach access points, parks are accessible by most residences in Cayucos.

\section{Community Outreach}

Background information was used to design and implement an outreach plan in order to create the most accurate, appropriate and relevant Community Health Plan. Community outreach was conducted in several forms in an effort to garner valuable local knowledge and feedback from community members regarding physical activity levels, information about the built environment where they live, work, and play, and perceived barriers to healthful activities and food access. Data is qualitative in nature and questions were developed with the intent of seeking local knowledge. These efforts included public meetings, meetings with key groups, key informant interviews, a community questionnaire, and planning events. The outreach results are described below under several categories:

- Presentations to Local Government Agencies

- Key Informant Interviews

- Community Group Meetings

- Cayucos Community Questionnaires

- Public Spaces Questionnaires 
- Cayucos Farmers Market: Public Space Improvement Voting

- Cayucos School Outreach

- Plan Draft Review Event

The results of the outreach efforts and key findings are detailed below.

\section{PRESENTATIONS TO LOCAL GOVERNMENT AGENCIES}

The purpose presentations to local government agencies were to announce our presence in each community, to state what our intentions would be while working there, to provide the scope and details of our project and ask for their support, as well as to request information and field questions. This was determined to be an important initial step that was necessary prior to the start of any public outreach efforts.

The first presentation to the Cayucos community was December 4, 2013 at the Cayucos Citizens' Advisory Council (CCAC) regular meeting. The CCAC is volunteer organization advising the District 2 County Supervisor Bruce Gibson in matters affecting the community of Cayucos. Two elected representatives and one alternate represent each of the eight precincts. The presentation was a listed agenda item, and the purpose was to introduce the project to the community in a formal way, and to illicit feedback on which other community organizations or individuals to contact for meetings or interviews. The presentation gave a brief history of the relationship between public health and planning, the current chronic disease and obesity public health crisis that involves planning, and the general plan for conducting the project. The CCAC provided input on the idea of the project and some suggestions for outreach.

The second CCAC meeting occurred in June, 2014. The purpose of this presentation was to present the community with findings gathered and a draft of goals, key recommendations and policies for Cayucos. Feedback was welcomed, and important 
changes were incorporated into the document. The presentation included some key findings from existing data and focused on results from community outreach, including the questionnaires, feedback from group discussions, and key informant interview themes.

\section{Local Government Agencies Key Findings}

The CCAC provided input on the idea of the project and some suggestions for outreach:

- Nearly $40 \%$ of the homes in Cayucos are rental units.

- Several community events were mentioned, including the Peddlers' Fair and the Sea Glass Festival.

- Citizens can be found at the Post Office, grocery store, banks, Senior Center, and the school.

- Cayucos is already a healthy place to live.

\section{KEY INFORMANT INTERVIEWS}

The following section discusses and analyzes the results of interviews with representatives from the community. Discussions centered on health issues, community priorities, assets and factors contributing to health, and barriers to improving health in the community. Key informants included government officials with extensive knowledge of Cayucos, active community members, and residents. The same questions were asked of each key informant, though conversations sometimes centered on related topics. Questions and compiled answers are included below.

Question: In your experience, or based on your work with the organization, what would you say are the top 3 or 4 most important assets or factors contributing to health in Cayucos? All interview subjects listed the physical beauty as a factor contributing to 
health, and some elaborated that this helped to get people outside. Many informants listed the sense of community as part of what makes the town a great place to live, specifically through the outcome of events like the Save the Pier concert event and the Fourth of July celebration. One interviewee described Cayucos as having “...a great year round climate, access to ocean sports, strong $\mathrm{K}-8$ school, community minded residents and independent thinkers and doers." Part of the sense of community comes from the involvement in clubs and organizations, though the majority of participants are older, retired residents. One interviewee lamented that she was involved in too many organizations and should learn to say "no", although this was part of what made the community special for her. However, there is also a sense of community at the bars and hangout spots, especially Hoppy's, Schooners, the Tavern, and the Wine Bar. There are a lot of young business owners that also contribute to the town, such as the owners of the Cayucos Hot Sauce company and the owners of Schooners. Young families have also found that Cayucos has a great elementary school, so great that some families want to move to Cayucos so that their children can attend Cayucos Elementary. One interviewee surmised that obesity is less of a problem in Cayucos than elsewhere in the county, and that the higher incomes of residents and gentrified environment may explain some of the reasons for healthfulness in Cayucos.

Question: What would you say are the top 3 or 4 most important health issues in Cayucos? The majority of key informants listed access to healthy, inexpensive food as a large issue, along with the aging population, restricted access to healthcare, and drug or alcohol abuse. Some listed housing affordability as a top concern, and mentioned that there are a lot of illegal or unpermitted secondary units or rentals in town. The lack of bike infrastructure, access to recreational/exercise equipment and facilities, and active transportation came up as issues as well. As one interviewee described, "Pedestrian safety is an issue on South Ocean and along Highway 1, since the community is sort of 
divided by the highway. There are only a couple crosswalks and one underpass." There was also mention of access being restricted to certain facilities, such as the pool, which is not open year-round. Interviewees expressed an interest in exercise classes that are age appropriate, either through a recreation program or a private gym. Alcohol use and abuse was brought up several times. One interviewee said that in Cayucos there is,

...Lots of drinking. People drive drunk a lot. I'm not sure about how many DUls there are, but I'm guessing a lot...The stores in town are mostly selling liquor, and you will always see people in there buying wine, beer, or hard alcohol, sometimes what seems like a lot at a time.

One key informant also described a downside to the tight-knit community nature, especially for those that work and live in town.

Younger people are doing what they can to get by. They are like, 'why move away and do something with your life?' Some get priced out, but remain part of the community by coming to the bars even though they live in Cambria or Morro Bay.

Other problems mentioned included access to grant dollars for community health enhancements, the prevalence of smoking, and the effects of too much greenhouse gas emissions, which is contributing to climate change and will become more of an issue with sea-level rise.

Question: Are the health issues you mentioned priorities for your organization, or are there any programs in your organization that are related to these issues? Though most interviewees represented organizations not directly linked to health advocacy, a few programs and priorities were described. These included transportation for the elderly 
and programs that encourage physical activity. Once interviewee mentioned that, "There are no local programs for drug and alcohol" in Cayucos.

Question: How would you describe the overall health of the Cayucos community? All informants spoke positively of the overall health in Cayucos. The most common answer to this question was that the beach and proximity to the ocean provided ample opportunities for active pursuits, and that the sense of community was helpfulpresumably for mental health through social interaction. However, one informant described the overall health as "Positive, siloed and sometimes insular." This relates to the general sense gathered from several conversations with residents, that identifying problems was sometimes difficult because the community was viewed so positively, and underlying that was an aversion to too much change, which might threaten the positive quality of life in Cayucos. Economic issues were also brought up here, including that there are not a lot of jobs, especially high-paying. The unfinished skate park and bicycle safety were brought up as issues relating to injuries. One informant listed mountain biking, surfing, and kayaking as specific reasons for good overall health, which also relates to the following question.

Question: Would you consider Cayucos a physically active community? This question brought about answers similar to the previous question, and many interviewees listed biking, walking on the beach, surfing, and hiking as evidence that the community is physically active. One informant put it thusly: "Cayucos is fairly active. Some people bike, and a lot walk on the beach in the mornings for exercise. People surf, even some of the older "salty dogs"—not just the younger people." However, barriers to more physical activity were mentioned. The issues with an aging population were brought up, along with barriers to using active transportation, and some potential solutions. 
The bus is really underutilized by most people, probably because it's not convenient...It seems like the only ones using it are Cuesta students...Better biking signs and lighting along the trail and Pacific could help people bike more, especially in the dark. The trail through the cemetery is totally dark, and I won't go that way on my bike alone at night...This might deter people from driving drunk after going to the bars.

Question: Do you think that food is accessible, available, and affordable in the community? Responses to this question were mixed. Some said that food is accessible, but not always affordable. Though there is only one grocery store in Cayucos, there are other options nearby in Cambria and Morro Bay. Some respondents described the prices at the Cayucos Market as "reasonable" while others characterized the prices as less affordable.

[Cayucos is] a vacation town, so things are a lot more expensive. I recently went to get chocolate chips for cookies, and they were $\$ 5.00$ ! Wine is about three times the price it is elsewhere, though beer is about the same price. People commute for work, so they mostly shop on their way home from work in Paso Robles or Morro Bay. In my neighborhood, there a lot of working class people. They go to the Cookie Crock Warehouse in Morro Bay, which has some very cheap, good produce. There is a farmers' market here, but it's held in the morning, I think on Fridays, so it's not really accessible to the working class.

Others had similar sentiments about the grocery store, and some mentioned that it is good "in a pinch" but does not carry all of the options necessary. Overall, food was not difficult to obtain for the interviewees, but it was not thought of as accessible in Cayucos. 
Question: Do you believe there are barriers to enacting policies and creating community support related to active living and healthy eating? This question provoked similar answers from all the key informants regarding the character of the Cayucos community. As one respondent described, in Cayucos there is a "Libertarian point of view much of the time among people that are involved in politics and decision-making, and those that don't have money don't have time to be involved." Another responded that "this is a participative community and not necessarily a "policy" community. We have raised nearly $\$ 500 \mathrm{~K}$ to restore the pier." Others also mentioned other barriers, including that the potential red tape would make policy changes difficult, and one mentioned the difficulty created by the Coastal Commission regulations.

Question: Do you know of any specific "champion" or "champions" for health in the community? This question was meant to aid in further research, but no respondents were able to identify a "champion" for health. However, some respondents offered to help distribute the survey via email, or listed some community groups that should be contacted.

Question: Do you think local government funds should be spent to support health policy actions? Despite the barriers described in a previous question, the majority of interviewees answered "yes" to this question. Specific responses included, "Yes, funds allocated for health should be spent accordingly," and "Yes, there should be acknowledgement of and investment in community health."

Key Informant Interview Key Findings

- The beach and proximity to the ocean provided ample opportunities for active pursuits, including mountain biking, surfing, kayaking, and walking the beach.

- The sense of community is part of what makes the town a great place to live. 
- The majority of participants involved in clubs and organizations are older, retired residents.

- There is also a sense of community at the bars and hangout spots.

- There are a lot of young business owners that also contribute to the town.

- Young families benefit from Cayucos's great elementary school.

- The biggest health problems include the aging population, restricted access to healthcare, drug or alcohol abuse, and smoking.

- There is a lack of bike infrastructure, access to recreational/exercise equipment and facilities, and active transportation.

- The unfinished skate park and bicycle safety were brought up as issues relating to injury.

- Better biking signs and lighting along the trail and Pacific Avenue could help people bike more, especially in the dark.

- Healthy food is not accessible or affordable. People must grocery shop outside of town.

- The farmers' market is held on Friday mornings, which makes it inaccessible.

- The bus is underutilized by most people, and there are few transportation options.

- Pedestrian safety is an issue along South Ocean Avenue and along Highway 1.

- There is a community pool, but it is not open year-round.

- A private gym or recreation program is missing from town. 
- Housing affordability is a concern, and there are unpermitted secondary units and vacation rentals in town.

- There is a lack of jobs, especially high-paying jobs.

- Climate change is a health issue, and will become more of an issue with sealevel rise.

- Governmental red tape and regulations may be barriers to improvements in health.

- Cayucos is not necessarily a "policy" community, and citizens take on issues from the grassroots level.

\section{COMMUNITY GROUP MEETINGS}

In order to efficiently gather feedback from community stakeholders, several community groups were contacted to arrange a meeting to discuss the Community Health Plan. Of those contacted, four groups arranged a meeting: the Cayucos Elementary Parent Teacher Association (PTA), the Lioness Club, Rotary, and the Seniors Club, all of which included a presentation about the project and group discussion. Presentation materials can be found in Appendix C: Outreach Materials.

Questionnaires were distributed to individual group members at each meeting. Some completed the questionnaire prior to the group discussion, others during or after, and some individuals did not submit a questionnaire. In a large group or in smaller groups, three questions were posed for a short discussion. The questions were:

- What are the top three contributors to the health of the Cayucos community?

- In your experience, what are the top 3 most important health issues in Cayucos? 
- What solutions might you propose to increase physical activity, healthy eating, or to address other "root determinants" of health?

The small groups were then asked to share with the larger group. The group discussions produced some feedback on the topic and suggestions for how to make Cayucos a healthier place. Groups listed the clean environment, climate, and the safety of the town as major contributors to health. The "sense of community" and "smallness" were also expressed to be factors. Dog-friendliness and pedestrian safety were also listed as factors contributing to health.

Traffic speeds around the school and running red lights were both brought up as major problems, especially as a hindrance to increase the number of students walking and biking to school. Drugs and alcohol abuse was mentioned multiple times as a major hindrance to health in Cayucos, a response which was also reflected in the questionnaire data and key informant interview responses. Use of heroin, meth, and tobacco use were as specified as problems. One small group specifically mentioned the rise of e-cigarettes and second-hand smoke as a major issue in Cayucos.

Expressed opportunities for solutions included activities for seniors and recreational opportunities that are age-appropriate. Some suggested that the pool become accessible year-round, or that other recreational opportunities become available. Other specific changes mentioned included undergrounding power lines, protecting the night sky from light pollution, and making Ocean Avenue a pedestrian street throughout the commercial district, with parking areas at either end. Overall, groups seemed interested in the topic, but many people were unsure of what should be changed, if anything, in their community, or how changes could be made. This may have been attributed to the short amount of time allotted for each presentation and discussion, or it may parallel the 
idea that preservation of the way of life in Cayucos is very important to many in the community.

Community Group Meetings Key Findings

- Major contributors to health include the clean environment, climate, and beautiful setting.

- Cayucos is a very safe, low crime town with a quick emergency response time.

- The "sense of community" and "smallness" were also expressed to be factors in the overall wellbeing.

- The town is dog-friendly.

- Pedestrian safety was listed as a factor contributing to health.

- Traffic around the school was brought up as a major problem, especially as a hindrance to increase the number of students walking and biking to school.

- Drugs and alcohol abuse was mentioned multiple times as a major hindrance to health in Cayucos. Use of heroin, meth, and tobacco use were as specified as problems.

- One small group specifically mentioned the rise of e-cigarettes and second-hand smoke as a major issue in Cayucos.

- There is a need for activities for seniors and recreational opportunities that are age-appropriate.

- The pool should become accessible year-round, and other recreational opportunities should become available.

- Aesthetic improvements such as undergrounding power lines and protecting the night sky from light pollution are needed. 
- Ocean Avenue could become a pedestrian street throughout the commercial district, with parking areas at either end.

\section{CAYUCOS COMMUNITY QUESTIONNAIRES}

The questionnaire was developed and distributed in an effort to gather quantifiable data to give an indication of community health levels, access to healthy foods, and sentiments regarding the built environment in Cayucos. The Healthy Communities (CRP 470) class at Cal Poly assisted with this portion of outreach. Further details on the methods of data collection for the surveys can be found in the Methodology chapter.

Distribution of the questionnaire began in February, with surveying ending in late March and final collection on May 31. A total of 82 Healthy Communities questionnaires were collected. The data was compiled and calculated using Excel, and more information about the methods may be found in the Methodology section. Responses to the survey questions are summarized below. 
Figure 11 - Question 1: Contributors to Quality of Life, Open-Ended Response, Cayucos

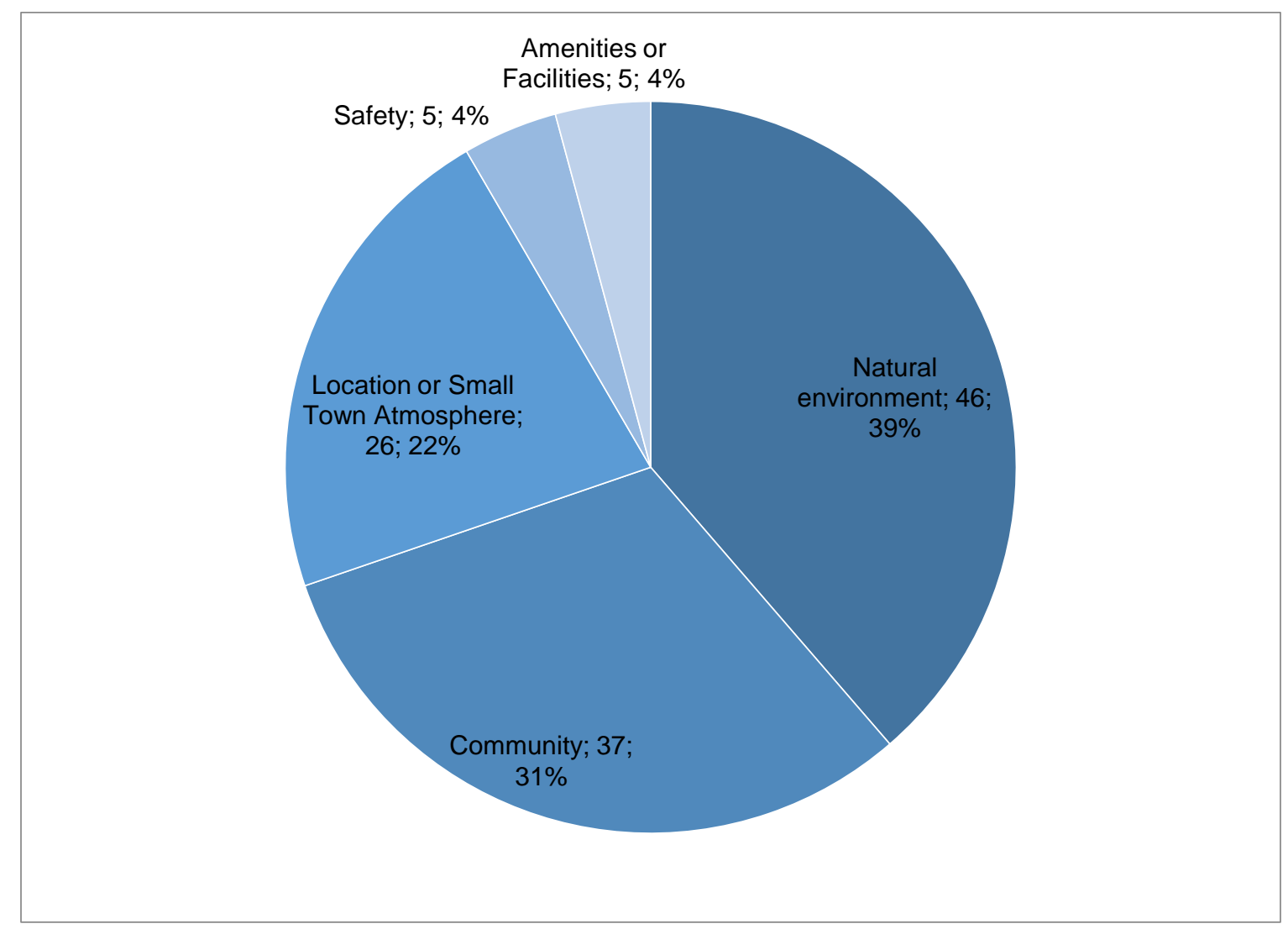

The first question in the questionnaire asked, "Generally speaking, what contributes most to your quality of life in Cayucos?" Responses were input and divided into categories to better assess overall opinions. The category with the greatest number of responses was "natural environment". Some responses in this category included "the weather," "the beach", "the beautiful environment." Responses in the "Community" category were also mentioned very often, in close second to "natural environment." Many respondents simply wrote, "The people" while others mentioned the "tight-knit" community or the many opportunities to become involved in groups or activities. A closely-related category was the "Location or Small-town Atmosphere" which also included a number of responses. Overall, these responses were very broad, but the group of respondents seemed to agree that the quality of life in Cayucos has to do with the physical environment as well as the people. 
Figure 12 - Question 2: Factors that Detract From Health, Open-Ended Response, Cayucos

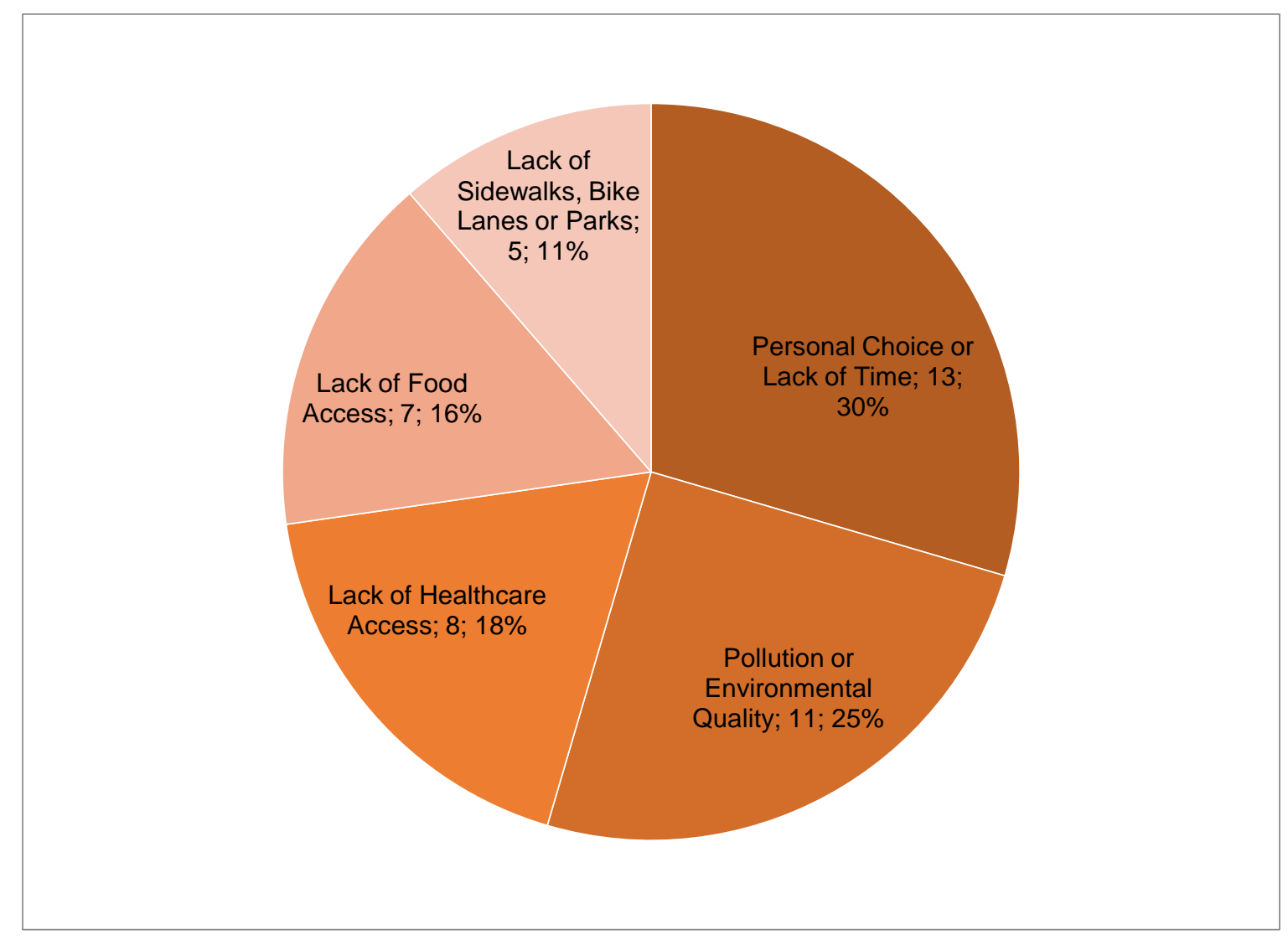

A frequent response to the second question, "What do you think makes it most difficult to be healthy or detracts from overall wellness here?" was "nothing". Of those that did identify an issue or problem, the most frequent responses included some aspect of environmental quality such as "beach debris" or "runoff from streams". Food access and accessible healthcare were also mentioned frequently. "Personal Choice" answers were mentioned by some respondents, which included responses like "ambition to be healthy" and "workload". Other frequent answers centered on the need for sidewalks or bike lanes to be improved. For this question, the "Tourists/Renters" category was mentioned also mentioned a few times, although none mentioned specifically why the presence of tourists were affecting their quality of life. 
Figure 13 - Question 3: Factors for Improving Quality of Life, Cayucos

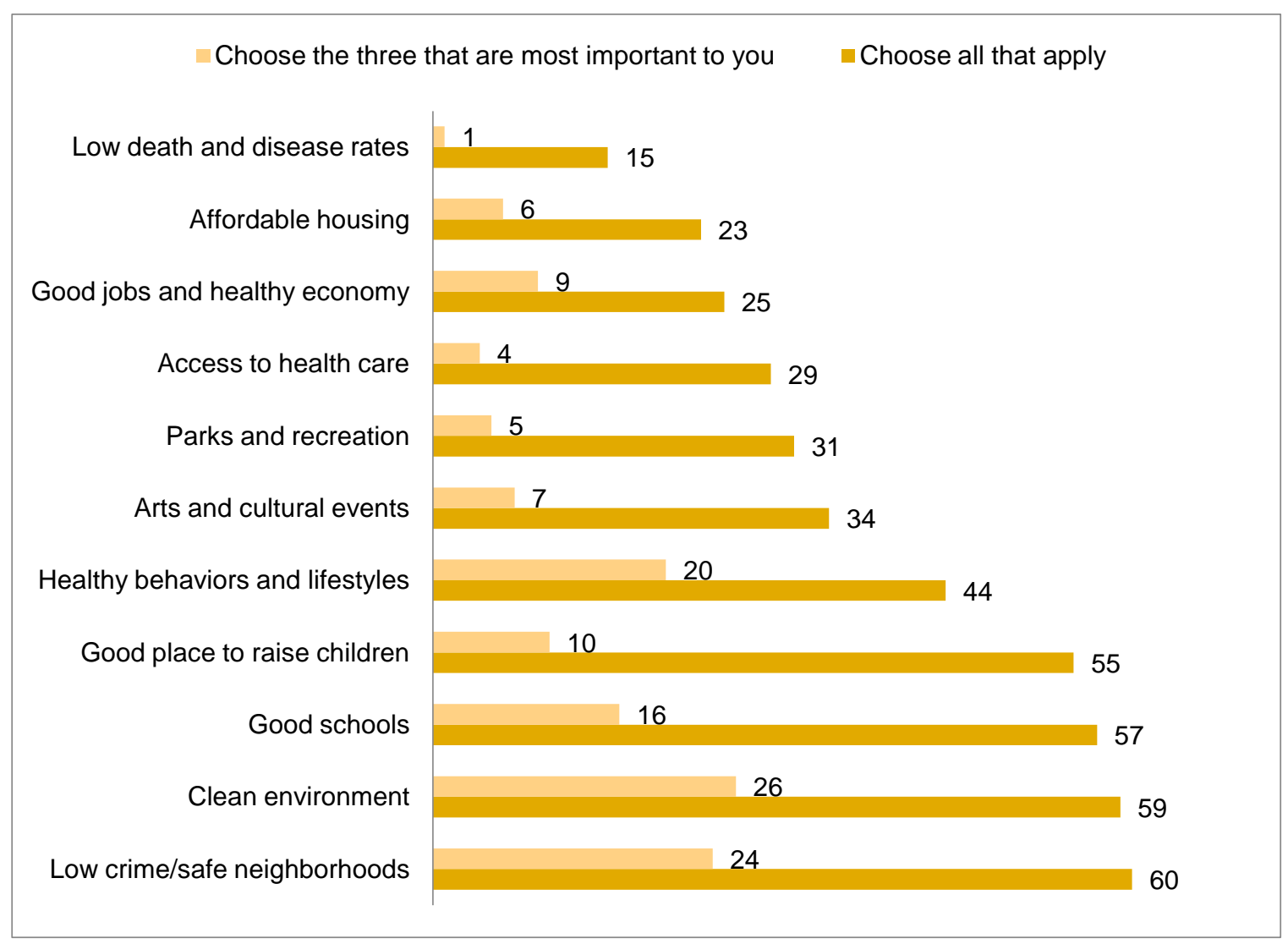

The third question asked, "What do you think are the most important community factors for improving the quality of life in a community?" The options with the highest response rate were good schools, clean environment, low crime and safe neighborhoods, good place to raise children, and healthy behaviors and lifestyles. This was true for both the "check all that apply" data and the "choose the three that are most important to you" option. Many respondents did not circle any answers, but the data for the first part of the question was incorporated into the total. The most important factors among those that did circle options were also clean environment, low crime and safe neighborhoods, and healthy behaviors and lifestyles. 
Figure 14 - Question 4: Greatest Impacts on Community Health, Cayucos

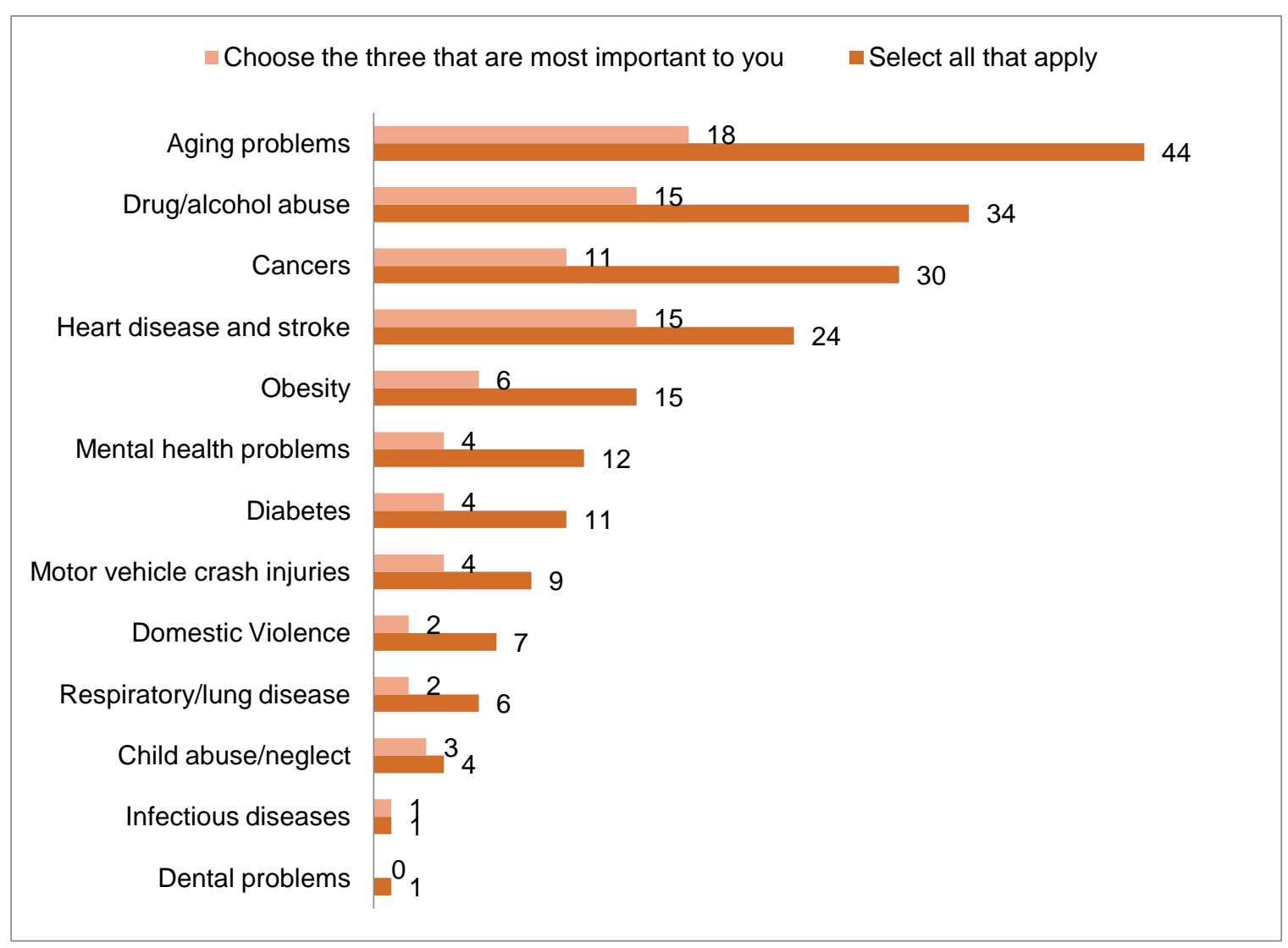

The next question asked about community health in general: "What do you think are the most important problems with the greatest impact on community health?" This question yielded some surprising results, with drug and alcohol abuse ranking at the top of the list along with aging problems, cancers, heart disease and stroke, and obesity. For this question, it was unclear whether respondents were giving answers based on any community impacts, or those in Cayucos specifically. 
Figure 15 - Question 5: Self-Identified Personal Health Rating, Cayucos

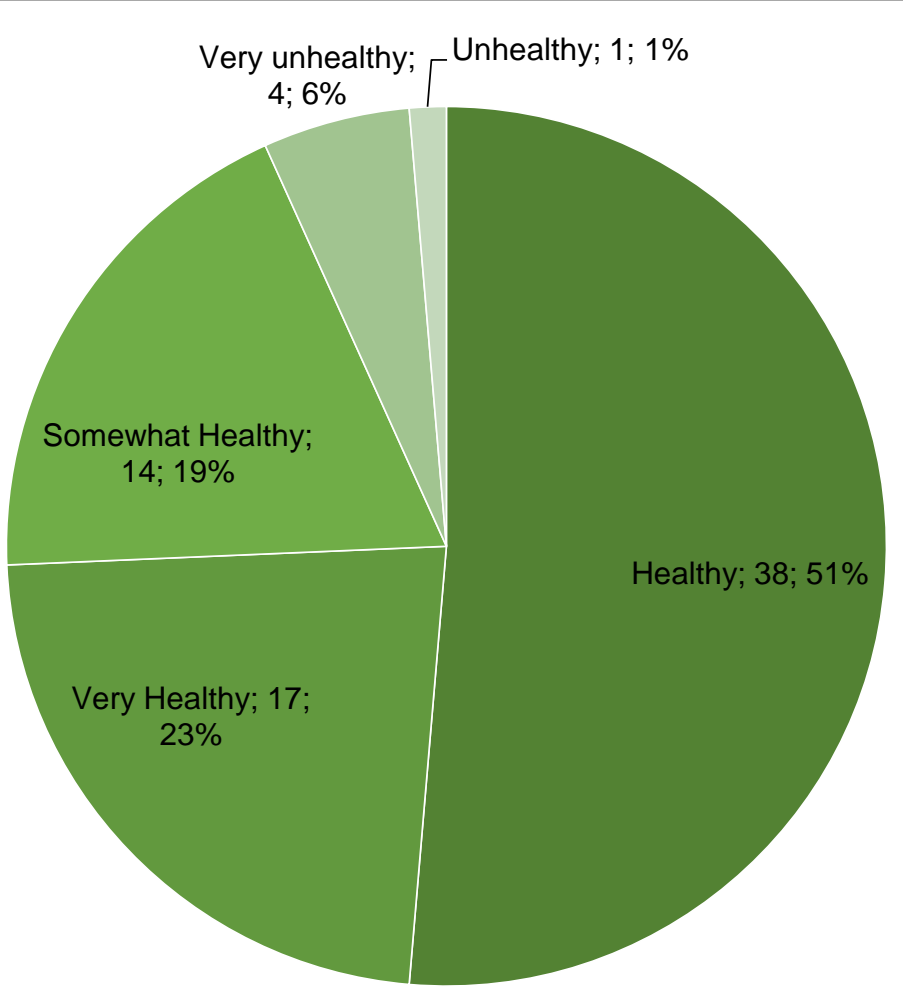

Over three-quarters of respondents rated their personal health as either "healthy" or "very healthy". A small number of respondents said that they were "unhealthy" or "very unhealthy". This finding was also interesting, especially given the aging population and the information presented in the Existing Conditions chapter, which show that a large number of county residents are obese, do not exercise regularly, consume too much sugar, and are diagnosed with chronic diseases that often result from unhealthy habits. However, this data is countywide and does not provide information for Cayucos alone. It could be that Cayucos residents are as healthy as they perceive themselves to be as a result of their lifestyles and perhaps even their location, or this perception of individual health could be skewed. 
Figure 16 - Question 6, Changes that Could Contribute to Health, Open-Ended Response, Cayucos

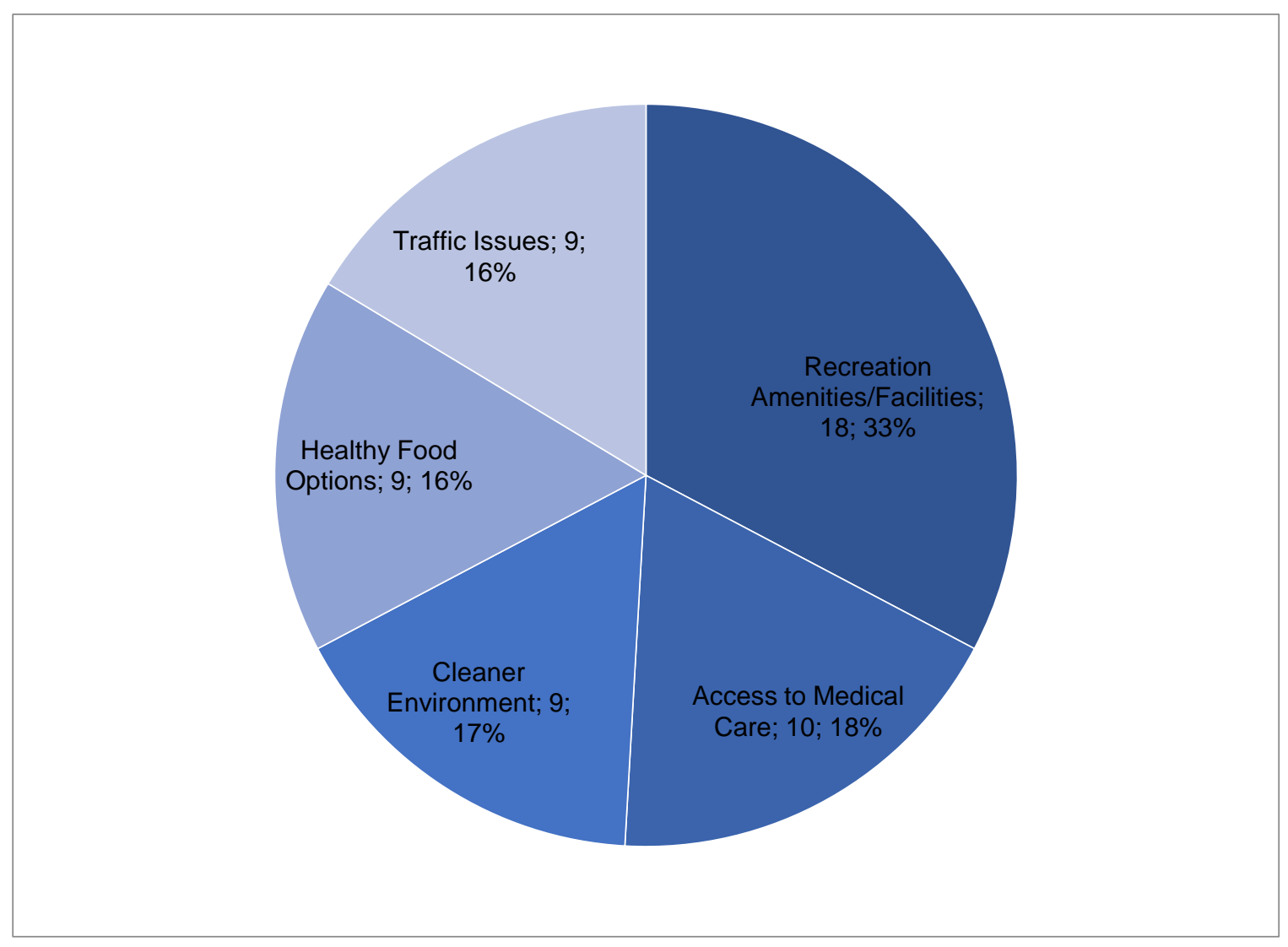

The sixth question asked, "What should change in Cayucos that could contribute to your personal health of the health of the community as a whole?" Like some of the previous questions, this was open-ended and the results were categorized. This question allowed respondents to provide constructive criticisms of their environment, despite the general consensus that Cayucos is already a very healthy place. This question produced a greater spread of results. Some respondents left the space blank or responded "nothing". Of those that responded, the three most frequent responses were those about food access, healthcare access, and pollution or concerns about environmental quality. 
Figure 17 - Question 7: Features that Could Contribute to Health, Cayucos

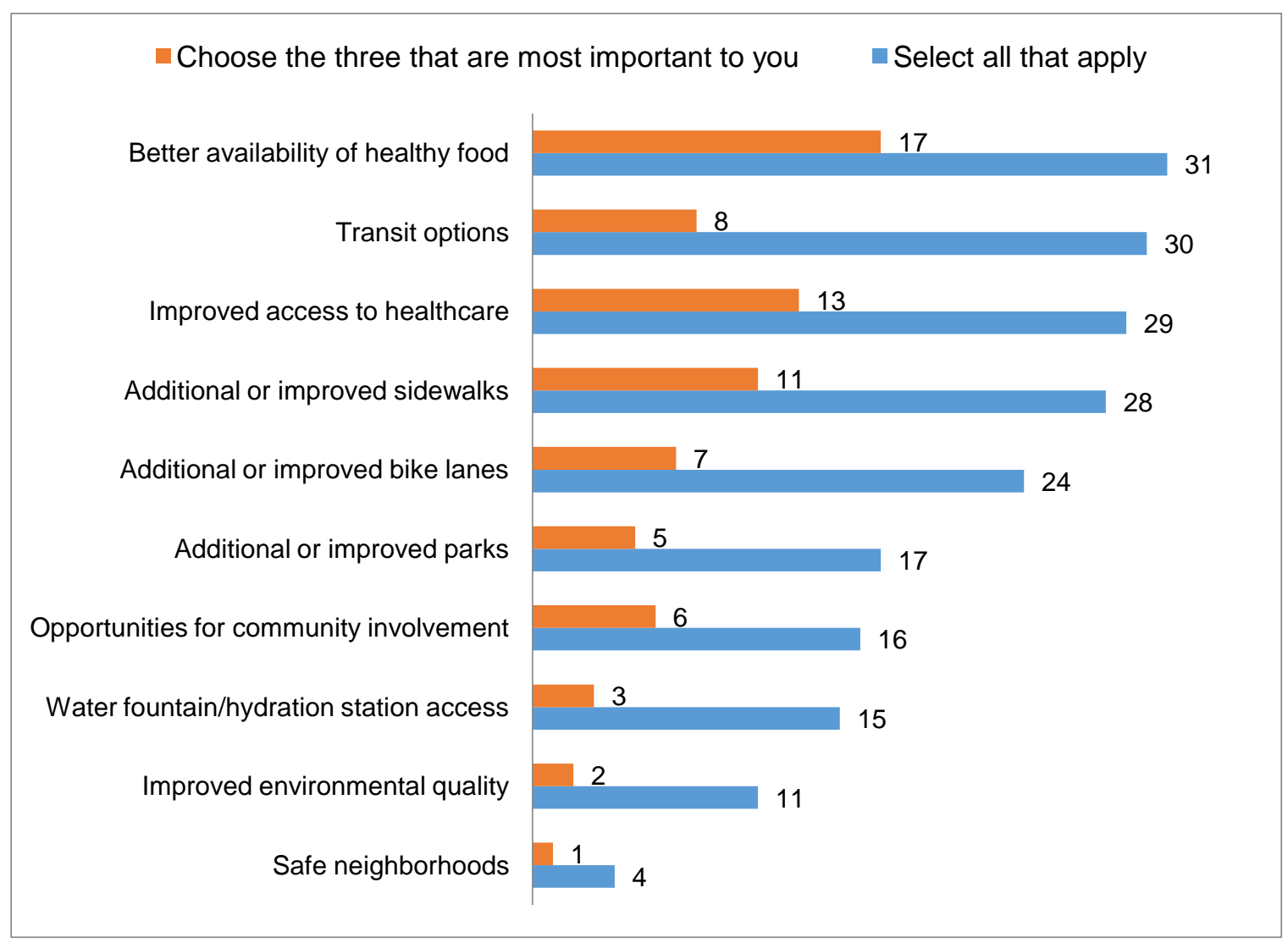

Question seven was similar to question six, but instead of being open-ended, required respondents to check boxes for community features. The question asked, "What community features, if any, could contribute to the health and quality of life in Cayucos?" The answers were also spread across the many options, with a few of the checkbox options being chosen only or two times. It was clear from these responses that safe neighborhoods were not a concern of most respondents, presumably because Cayucos is already considered to be safe. However, sidewalk and bike lane improvements, which may contribute to neighborhood safety, were selected by many of the respondents. Other highly-selected community features included access to healthcare, transit options, and better availability of healthy foods. Although many respondents did not consider Cayucos to have any glaring barriers to health, the community may benefit from many of those built environment improvements which have been shown to impact public health. 
Community Health Questionnaire Key Findings

The questionnaire results provide several indications for health and health-related needs in Cayucos.

- The high importance of natural beauty and the small, involved community were apparent in the results.

- Over three-quarters of respondents rated their personal health as either "healthy" or "very healthy".

- When asked about important factors for a healthy community, the options with the highest response rate were good schools, clean environment, low crime and safe neighborhoods, and good place to raise children.

- The question about the most important problems yielded some interesting results, with drug and alcohol abuse ranking at the top of the list along with aging problems, cancers, heart disease and stroke, and obesity.

- The questionnaires showed that some respondents believe that "nothing" in Cayucos detracts from overall wellness, though many responded that a lack of food access, healthcare access, and pollution or concerns about environmental quality were detracting from health or overall wellness.

- Sidewalk and bike lane improvements, access to healthcare, transit options, and better availability of healthy foods were chosen most often as community features that could contribute to health and quality of life. 


\section{COMMUNITY EVENTS}

\section{Cayucos Farmers Market: Public Space Improvements}

Graduate students in the City and Regional Planning Program at Cal Poly, San Luis Obispo conducted a planning process for the purpose of preserving and improving public space within Cayucos. The project is entitled "Connecting Cayucos: Visions and Actions for Public Space." The proposal includes ideas for parks, streets, and other public spaces. It also considers issues related to parking and economic vitality. This project provided additional public outreach opportunities and community input that helped to inform the Cayucos Community Health Plan.

Outreach included a voting exercise to find out about the desires and needs of community members and visitors, and took place at the Cayucos' Farmers Market on May 23 and May $30^{\text {th }}$. The studio project centered on five main themes as ways of "Connecting Cayucos" through community identity, accessibility, natural resources, health and safety, and economic vitality. These themes were addressed throughout the options for public space improvements illustrated for voting purposes. The top four ideas voted on by the community included:

- Increase public art throughout town (i.e. benches, murals)

- Build a community garden

- Widen sidewalks along Ocean Avenue to increase pedestrian usage, increase outdoor dining, seating, and plantings to distinguish the downtown

- Expand recreation opportunities at Estero Bluffs and Whale Rock Reservoir by expanding connectivity, adding signage, and providing parking areas

Other ideas were expanding Hardy Park, utilizing sustainable street design to clean and slow runoff and storm water, adding an oceanfront multi-use park for special events, car- 
free community spaces, a cross-town community shuttle, extension of bicycle facilities along Ocean Avenue, textured pavement at intersections, and back-in public parking along Ocean Avenue. The results were similar to many of the ideas brought up by the community through the Healthy Community Questionnaire and other forms of engagement. In addition, community members liked the idea of painted crosswalks. Some mentioned that there are mobility issues among the community, and there were concerns that textured intersections could be problematic for seniors , or that removing parking on Ocean Front St could hinder beach access for seniors.

\section{Public Spaces Key Findings}

- Several improvements to public space in Cayucos could also serve as health co-benefits.

- Public art is desired throughout town.

- Sidewalks are desired as places to walk, dine outdoors, and enjoy the environment.

- Connections to the surrounding recreational opportunities are needed.

- Mobility issues are a concern in the community, and new public spaces should incorporate features to maximize access.

\section{$\underline{\text { Cayucos School Outreach }}$}

Activities at Cayucos Elementary were conducted on May 24, 2014, in conjunction with the graduate studio class. Cal Poly students brought materials to engage a group of eight graders through a mapping activity. The mapping exercise involved students selecting cutout images of things that were representative of what they liked to do for physical activity; things that would make them feel safer; and things they "wished" were present in Cayucos. Students were also asked to indicate the travel mode and route they 
took to school. The exercise concluded with each group collectively discussing the features they would most like Cayucos to have. The students mentioned many ideas for improving their environment, but came to a consensus with the following top ideas: street lighting in dark, residential areas, "smoother" roads for bicycling, a paintball or laser tag facility, indoor basketball courts or other indoor recreational opportunities, an expanded Hardy Park that allowed for active recreation and field sports, a new, bigger arcade in town, outdoor seating, and an expanded farmer's market or healthy food outlet.

\section{Cayucos School Key Findings}

- There is a need for street lighting in dark, residential areas, especially for kids to bike and walk.

- Some changes should be made, but the character of Cayucos should remain.

- Some areas need "smoother" roads for bicycling.

- There is a need for facilities for active recreation, including indoor facilities and play fields.

- More outdoor seating is needed in public spaces and at businesses.

- Kids would like to have healthy food options.

\section{$\underline{\text { Plan Draft Review Event }}$}

The last outreach efforts involved returning to the community with draft goals, policies, and implementation measures for review. This process occurred at an event in a community gathering space, the Veteran's Hall. This event was a joint effort conducted for the purposes of this project and Professor Main's Graduate Studio Class, which focused on public spaces in Cayucos. Because the topics overlap extensively, feedback 
was gathered for both planning efforts. The feedback from these efforts further informed the project about specific community concerns, perceptions, wants and needs, and strategies for improving spaces and would like incorporated into their community. The council and the public discussed the feasibility of a community garden, how to bring composting to Cayucos, and about the general state of health in Cayucos. The community feedback was recorded, analyzed and considered in the final draft plan.

\section{Key Findings}

- The community is interested in building a community garden.

- Waste management is of interest.

- Several improvements to public space in Cayucos could also serve as health co-benefits.

\section{Summary of Key Findings}

This section compiles all of the findings and organizes them into themes to guide the interpretation of the wealth of information that will go into the creation of the draft plan. The themes are Participation, Tobacco, Drugs and Alcohol, Pedestrian Activity, Bicycling, Safety Improvements, Healthy Design and Development, Parks and Recreation, Environmental Quality, Healthy Eating, and Access to Healthcare.

\section{Participation}

The first major finding truly resulted from the combination of all efforts detailed in the Findings chapter. Many of the 2,431 citizens of Cayucos are active in a number of community groups, and have been very successful in mobilizing their neighbors and supporters in the greater San Luis Obispo area to achieve desired outcomes for their community. This capacity is sometimes referred to as social capital, and its presence in 
a community is positively correlated with community security, friendship and community, and a civic identify, which studies show improves mental health, cardiovascular health, and faster recovery from illness (Kawachi, Subramanian, and Kim, 2008). In this way, the findings suggest that the community participation levels are a boon to public health, but collaboration will ensure the success of future projects related to the effort.

Key findings on participation:

- The sense of community and volunteerism contributes to making the town a great place to live.

- Cayucos school is great; an asset for children and young families.

- The majority of participants involved in clubs and organizations are older, retired residents.

- There is also a sense of community at the bars and hangout spots.

- The "sense of community" and "smallness" were chosen by participants as factors in overall wellbeing.

- Cayucos is not necessarily a "policy" community, and many community accomplishments begin at the grassroots level.

- There are a lot of young business owners that also contribute to the town.

- When asked about important factors for a healthy community, the options with the highest response rate included good schools, low crime and safe neighborhoods, and good place to raise children.

\section{Tobacco, Drugs, and Alcohol}

The effects of tobacco use, second-hand smoke, and the carcinogenic properties of nicotine continue to be a leading cause of death in California. Electronic cigarettes 
represent a recent issue for tobacco use because of unclear policy throughout the county and the attractiveness of e-cigarettes to youth. Residents in Cayucos are concerned about the rate of smoking and problems with drug and alcohol abuse in their community. Smoking is not currently banned in downtown Cayucos, and smoking is prevalent especially late at night. Concern over alcohol and drug abuse in San Luis Obispo County remains steady, although binge drinking rates and youth substance abuse have declined. There are three unhealthy food outlets in Cayucos, and only one small market which sells alcohol but no tobacco. The proximity of these unhealthy outlets near schools and parks is also of concern.

Key findings on tobacco, drugs, and alcohol

- Drugs and alcohol abuse was mentioned multiple times as a major hindrance to health in Cayucos. Use of heroin, meth, and tobacco use were as specified as problems.

- One small group specifically mentioned the rise of e-cigarettes and second-hand smoke as a major issue in Cayucos.

- Participants listed drug and alcohol abuse as the top ranking at the top of the list of most important problems in Cayucos, along with aging problems, cancers, heart disease and stroke, and obesity.

- Participants included drug or alcohol abuse and smoking at two of the biggest health problems.

Researchers and public health professionals in tobacco cessation and prevention utilize strategies such as reducing tobacco advertising, enforcing penalties for selling alcohols and tobacco to minors, and providing free products and services to those with unhealthy addictions. The department of Behavioral Health provides treatment and recovery 
services for those with drug and alcohol problems. The findings suggest that there is a need to increase awareness of such programs, increase accessibility of County programs, and limit the exposure to such substances.

\section{Pedestrian Activity}

A foundational U.S. Surgeon General's Report on Physical Activity and Health (1996), concluded people of all ages who are generally inactive can improve their health and well-being by becoming even moderately active on a regular basis. Research has found multi-level social ecological factors such as urban aesthetic, perceived safety, accessibility, and opportunity for social interaction to be motivating factors for increased physical activity (Lee \& Moudon, 2004; Brownson, Baker, Housemann, Brennan \& Bacak, 2001).

Though pedestrian activity throughout Cayucos is not as limited as in other areas of the county, there are many areas throughout the commercial core and connecting to residential areas that could benefit from improved pedestrian infrastructure. Though most Cayucos students are driven to school, when asked what would encourage active transportation to school, the largest numbers of responses were living closer to school, sidewalk or street improvements, and crossing guards--all of which have to do with pedestrian safety. Students attending Cayucos Elementary and seniors on the whole were particularly interested in improved walking environments.

\section{Key Findings on Pedestrian Activity}

- Pedestrian safety is an issue for those on the east side of Highway 1 , for people walking and biking downtown on Ocean Avenue, and near the school.

- Participants were supportive of widened sidewalks and increased outdoor seating areas. 
- Pedestrian safety was listed as a major factor contributing to health.

- Traffic around the school was brought up as a major problem, especially as a hindrance to increase the number of students walking and biking to school.

- Pedestrian safety is an issue along South Ocean Avenue and along Highway 1.

- Sidewalk improvements was one of the options chosen most often as a community feature that could contribute to health and quality of life.

Pedestrian-friendly areas allow for low-impact exercise for the elderly, accommodate the incorporation of daily walking to destinations and as a social activity, and accommodate individuals without access to vehicles. Pedestrian activity also invites window-shopping and increased consumer traffic for businesses and increases random encounters with others in the community, which increases neighborly connections, a feeling of belonging, and brings with it improved mental wellbeing. These findings suggest that there is ample room for improvement in pedestrian infrastructure throughout Cayucos.

\section{Bicycling}

Bicycling allows for active transportation at greater distances and speeds than walking, provides connections between residences and transit stops, and is and highly accessible form of transportation for all ages and income levels. Like walking, riding a bike to services and frequent destinations incorporates physical activity into daily life, helping to increase the chances that the rider experiences the countless health benefits of regular exercise.

Key Findings on Bicycling

- Bike lane improvements was one of the options chosen most often as a community feature that could contribute to health and quality of life. 
- There is a lack of bike infrastructure such as bike racks, biking signs, smooth paths and lighting.

- The bike trail along the cemetery needs improvements.

- Street lighting along the bike trail, along Pacific Avenue, and in residential areas could help kids and adults bike more, especially in the dark.

- Complete the path to Morro Bay.

- Bicycle safety was brought up as an issue relating to injury.

- Segments south of $8^{\text {th }}$ Street along Ocean Avenue ranked consistently low overall in terms of walkability and bike-friendliness.

- The Ocean Avenue and Pacific Avenue intersection ranks low in overall walkability.

- Segments along $13^{\text {th }}$ Street, which connects Ocean Avenue and Pacific to the neighborhoods to the east of Highway 1 ranked consistently low in terms of walkability and bike-friendliness.

Cayucos is located along the Pacific Coast Bike trail which follows Highway 1 along the coast. The climate and scenery make Cayucos a great place to bicycle for avid cyclists, casual bikers, and commuters. However, most roads lack a safe amount of lighting, there are few places to park a bicycle, and there have been several bicycle-vehicle collisions in Cayucos. Cayucos Elementary students were also asked to indicate the travel mode and route they took to school; most of them were dropped off by their parents in a car. The students mentioned many ideas for improving their environment, but came to a consensus on a few ideas including street lighting in dark, residential areas and "smoother" roads for bicycling. The findings will help to support accommodation for and encourage use of bicycles. 


\section{Safety Improvements}

In 2008, the Physical Activity Guidelines Advisory Committee reported findings from amalgamated scientific literature on the health benefits of exercise, including that the benefits of activity far outweigh the possibility of adverse outcomes. However, physical activity can expose individuals to risks for injury, due in part to the high priority of accommodation of vehicles and the incomplete adoption of designs and practices for injury prevention in our environments. Seniors are more susceptible to falls, and a large number of injuries are attributable to falls while using footpaths or sidewalks.

\section{Key Findings on Safety Improvements}

- Sidewalk and bike lane improvements were two of the options chosen most often as community features that could contribute to health and quality of life.

- The street segments in the commercial core along Ocean Avenue that ranked highest in walkability overall ranked slightly lower for the safety category, largely for injury risk and traffic safety issues.

- The unfinished skate park and bicycle safety were brought up as issues relating to injury.

- Lack of street lighting was mentioned as a concern.

- Cayucos Drive ranked high in the safety category due in part to the number of crossing aids and other signage.

- Pedestrian safety is an issue for those on the east side of Highway 1, along South Ocean Avenue, and near the school.

- Sidewalk improvements was one of the options chosen most often as a community feature that could contribute to health and quality of life. 
- Cayucos is a very safe, low crime town with a quick emergency response time.

There have been several pedestrian and bicyclist deaths in Cayucos in the last ten years that were caused by collisions with automobiles. The walk audit conducted for this plan showed that there is a discrepancy between overall walkability in town and the safety of the streets. This is due in part to the auto-oriented nature of the streets, obstructions in the walking path, and uneven or incomplete sidewalks. These issues are especially relevant for increasing the number of students walking or biking to school, limiting injuries for those needing to cross Highway 1, and individuals with disabilities or limited mobility. The Department of Transportation has studied numerous tactics to reduce injury-by-vehicle and promote health, which they call safety countermeasures. These include features that call a driver's attention to a pedestrian area, naturally cause slower speeds, and increases in physical space for pedestrians and bicyclists. These measures can increase actual and perceived safety and encourage active use of the built environment. Aside from traffic safety issues, most people feel safe in their neighborhoods.

\section{Healthy Design and Development}

The modern city, built to accommodate the automobile first and foremost, deters physical activity and the use of alternate forms of transportation. The result of this practice is widespread traffic congestion; increased commute time; increased vehicle, pedestrian and biking crashes and injuries; a growing obesity epidemic; a rise in air pollution and respiratory illness; and a growing sense of disconnection between workplaces and homes (CDC, 2009, p.9). Cancer and heart disease are the leading causes of death in Cayucos by a large margin. Though these chronic diseases are attributable to a number of factors, increasing exercise and healthy eating habits among community members may have a positive impact on these rates. 
Key Findings on Healthy Design and Development

- Many residents dislike the abundance tourist activity in town and vacation rental homes, many of which are illegal.

- Affordable housing is lacking in Cayucos.

- The street segments that offer the most in terms of aesthetics are in the core commercial area.

- Some participants supported the idea of a pedestrian street throughout the commercial district, though some are worried about mobility.

- More outdoor seating is needed in public spaces and at businesses.

- Aesthetic improvements such as undergrounding power lines and protecting the night sky from light pollution are needed.

- There is a lack of jobs, especially high-paying jobs.

- There are few transportation options, and the bus is inconvenient.

- The bus is used by younger people, especially to go to the City of San Luis Obispo.

- Sidewalk and bike lane improvements and transit options were two of the options chosen most often as community features that could contribute to health and quality of life.

Cayucos benefits from a highly aesthetically-pleasing natural environment, and a town character that plays off the proximity to the ocean. These characteristics alone serve to encourage active pursuits, and a major result from community outreach efforts showed that this physical beauty is a major contributor to quality of life in Cayucos. However, the small town atmosphere and remote location limit the access to many community needs 
without the use of a private automobile. Transit to and from Cayucos is infrequent and time-consuming, which is likely deterring the use of the bus system and increasing the dependence on personal vehicles. Housing is not affordable for many income levels in Cayucos, although the low growth rate in town and high costs for building along the coast may render affordable housing infeasible in the near future. It will be important to preserve the current character of the town while allowing small increases in density, increase opportunities for aesthetic improvements that attract foot-traffic, and connect neighborhoods to services available in town.

\section{Parks and Recreation}

It has been estimated approximately 400,000 premature deaths occur annually in the United States as a result of the negative health outcomes which stem from obesity due to physical inactivity (Mokdad, Marks, Stroup, \& Gerberding, 2004). Though incorporating physical ability into daily activities can help to "cure" physical inactivity, it has also been proven that living close to parks, trails, and recreation facilities is related to greater use of facilities and more recreational physical activity (Sallis et al., 2011, p. 33).

Key Findings on Parks and Recreation

- There is a need for facilities for active recreation, including indoor facilities, play fields, and a gym or exercise classes.

- There is a need for activities for seniors and recreational opportunities that are age-appropriate.

- Especially south of the commercial core, many residents do not have convenient pedestrian access to a park. 
- With the inclusion of the several beach access points, parks are accessible by most residences in Cayucos.

- The beach and proximity to the ocean provided ample opportunities for active pursuits, including mountain biking, surfing, kayaking, and walking the beach.

- Cayucos needs 27 additional acres of parks, especially active parks.

- There is a community pool, but it is not open year-round.

Parks, hiking areas and additional facilities including the community pool, tennis courts, and school facilities serve the community. Because many residents of and visitors to Cayucos also have access to the beach for exercise such as walking, running, kayaking, or surfing, recreation is accessible by most residents in Cayucos. However, many residents, especially elementary students, expressed a need for parks that are better suited to active recreation, such as team sports. County residents reported wanting more hiking trails, bike paths, and natural areas in their communities. Cayucos Elementary students are also in need of physical fitness improvements, and increased sports programs or after school activities were also the number one choice for parents when asked what could increase physical activity for their children.

\section{Environmental Quality}

Humans are affected by the environmental quality in the places they live, work, and visit. In particular, people are affected by air and water quality. Acute and long term air pollution due to ground level ozone and particulate matter has been shown to have negative impacts on health. Ground level ozone is that main component of smog, and is caused by the emissions of industrial facilities and electric utilities, motor vehicle exhaust, gasoline vapors, and chemical solvents (EPA, 2012). The County of San Luis Obispo often falls into non-attainment status for air quality, meaning that the air quality is 
below state standards. However, measurements near Cayucos usually do not show that air quality is below this state standard.

Stormwater runoff, the water that flows to the storm drains during and after a rain event, contributes to microbial contamination of water supply, especially after rainfall (Gannon and Busse, 1989). There is a strong relationship between large rainfalls and outbreaks of waterborne diseases. Much of the contamination is from non-point source pollution, with major sources including runoff from farms, parking lots, streets, and golf courses. Water-related illnesses can be cause by microbial or chemical contamination from pesticides, metals, nitrates, pharmaceuticals, and organic chemicals. Waterborne illnesses can be caused not only by drinking contaminated water, but also by eating produce irrigated with untreated water, eating seafood caught in contaminated water, and swimming or other recreation in polluted water (Craun,1992). Water pollution affects people locally in Cayucos because of location at the ocean shore, where many residents and visitors enjoy the beach and the waves.

\section{Key Findings on Environmental Quality}

- Physical and environmental beauty is a major factor contributing to health in Cayucos, especially because it adds to the willingness of residents to recreate outside and provides mental health benefits.

- Major contributors to health include the clean environment, climate, and beautiful setting.

- Climate change is a health issue, and will become more of an issue with sealevel rise.

- Governmental red tape and regulations may be barriers to improvements in health. 
- When asked about important factors for a healthy community, the options with the highest response rate were included "clean environment."

- "Pollution or concerns about environmental quality" was one of the frequently noted issues detracting from health or overall wellness.

Just as many community members mentioned the beautiful natural environment as a great asset to their quality of life, pollution and issues of environmental quality were mentioned again and again. North coast residents are very concerned with water quality and availability (ACTION, 2013). Issues in Cayucos range from contaminated runoff pollution to solid waste management. Poor environmental quality affects Cayucos locally, but is an issue with that originates at the regional level.

\section{Healthy Eating}

Though personal diets may be thought of as the responsibility or choice of the individual, the accessibility and affordability of healthy food plays a role in what a community eats. Inadequacies in the local food system impacts communities, especially in terms of public health. The most accessible foods-in convenience stores and fast-food outlets-are high in calories but low in nutritional value. The production of nutrient-rich foods can even threaten regional environmental quality due to the methods used to produce, process, package, and transport the goods. Access to affordable grocery stores and farmers markets increases the likelihood that people will eat healthy food, while those surrounded by convenience and liquor stores are less likely to eat healthy food (Corburn, 2009, p. 80). The food system, good or bad, is impactful to the well-being of communities of all socioeconomic kinds, though the poor are generally more vulnerable to problems of food access (Corburn, 2009). 
Key Findings on Healthy Eating

- There is a lack of healthy food outlets and options in Cayucos, and the food that is in town lacks variety and is expensive.

- The only store with healthy items is the Cayucos Supermarket, located on South Ocean Avenue

- There are three unhealthy food outlets in Cayucos which sell only candy, chips, sodas, tobacco, and similar items.

- Healthy food is not accessible or affordable. People must grocery shop outside of town.

- Kids would like to have healthy food options.

- The farmers' market is held on Friday mornings, which makes it inaccessible to some residents.

- "Lack of food access" was one of the frequently noted issues detracting from health or overall wellness.

- Better availability of healthy foods was one of the options most frequently chosen as a community feature that could contribute to health and quality of life.

Healthy eating is increasing in the north county, with obesity rates declining and more people consuming enough fruits and vegetables. However, only $48 \%$ of adults on the County are consuming the recommended amount of fruits and vegetables. In Cayucos, community members expressed the need for healthy food options, including a health food store, a larger grocery store, healthy, affordable eateries, and access to locallygrown food. Weekly grocery shopping is nearly impossible in Cayucos due to the unavailability of many items, and prices are commensurate with the vacation-town setting, therefore not affordable for residents. According to the Retail Food Environment 
Index (RFEI), there are three unhealthy food outlets in Cayucos, and only one small market which sells alcohol but no tobacco. This presents an issue of food accessibility and affordability for residents, especially those without access to a personal vehicle such as children and the elderly.

\section{Access to Healthcare}

There are many aspects to determining the accessibility of healthcare access and the degree to which access impacts individual health. The location of healthcare facilities in a community, such as hospitals, emergency care facilities, and health clinics influence access. However, factors such as transportation to and from facilities, awareness of facilities and services, availability of insurance, and personal preferences have an impact on the degree to which available healthcare facilities can and will be used.

\section{Key Findings on Health Care Access}

- The population is aging, and there are health concerns associated with aging problems.

- The most important health problems include the aging population and restricted access to healthcare.

- "Lack of healthcare access" was one of the frequently noted issues detracting from health or overall wellness.

- "Access to healthcare" was one of the options most frequently chosen as a community feature that could contribute to health and quality of life.

In San Luis Obispo County, access to medical care is restricted by increases in cost, higher insurance rates, and proximity to medical facilities. When asked what aspects of the Cayucos community detract from overall wellness, one of the most frequent responses was the lack of healthcare access. Though the vast majority of residents 
described their personal health as "healthy" or "very healthy", many were concerned about aging problems and chronic diseases. The high median age and high percentage of seniors residents in town, coupled with the lack of healthcare facilities in town and limited transit, presents a healthcare access problem for Cayucos residents. Findings suggest that there is a need to increase access to healthcare for the wellbeing of the community. 


\section{OCEANO FINDINGS}

\section{Introduction}

This chapter provides a summary of the findings collected from the parks and food vendor inventory and access assessments, as well as the findings from the outreach activities, including presentations to local advisory bodies, key informant interviews, community survey results, feedback from public events and plan draft review meetings conducted in Oceano.

A physical inventory was conducted to achieve an understanding of the existing built environments and included food, parks, and hydration station access assessment. Results of these studies for Oceano are summarized in this section and displayed in map form.

Community outreach efforts provided valuable feedback and local knowledge from community members regarding physical activity levels, information about the built environment where they live, work, and play, and perceived barriers to healthful activities and food access. For more detailed information on the methods used for conducting the inventory and outreach, see the Methodology section.

\section{Physical Inventory}

In order to better understand the built environment in Oceano, a physical inventory was conducted to observe and measure features in a systematic way. The physical inventory included a walkability audit and food, parks, and hydration station access assessments. Results and key findings are displayed and described below. 


\section{WALKABILITY AUDIT RESULTS}

As noted in both the Methodology chapter and in this chapter's introduction, a walking audit was not deemed necessary due to the fact similar sidewalk inventories had already been previously conducted and of which the data was accessible in the Oceano Specific Plan, the Oceano Revitalization Plan, and most recently (2013) with the Safe Routes to School (SRTS) Infrastructure Survey.

The existing sidewalk inventory map (see Figure 18) taken from the Oceano Revitalization Plan was utilized for this project due to its recent completion, simplicity to read and illustrative appeal. The map provides an aerial view of the town with the Oceano Community Service District boundaries marked in yellow. Streets that feature sidewalks on both sides of the street are in blue. Streets that offer only one sidewalk are noted in green. Finally, streets that possess no sidewalks are indicated in red.

\section{Figure 18 - Oceano Existing Sidewalk Inventory Map}

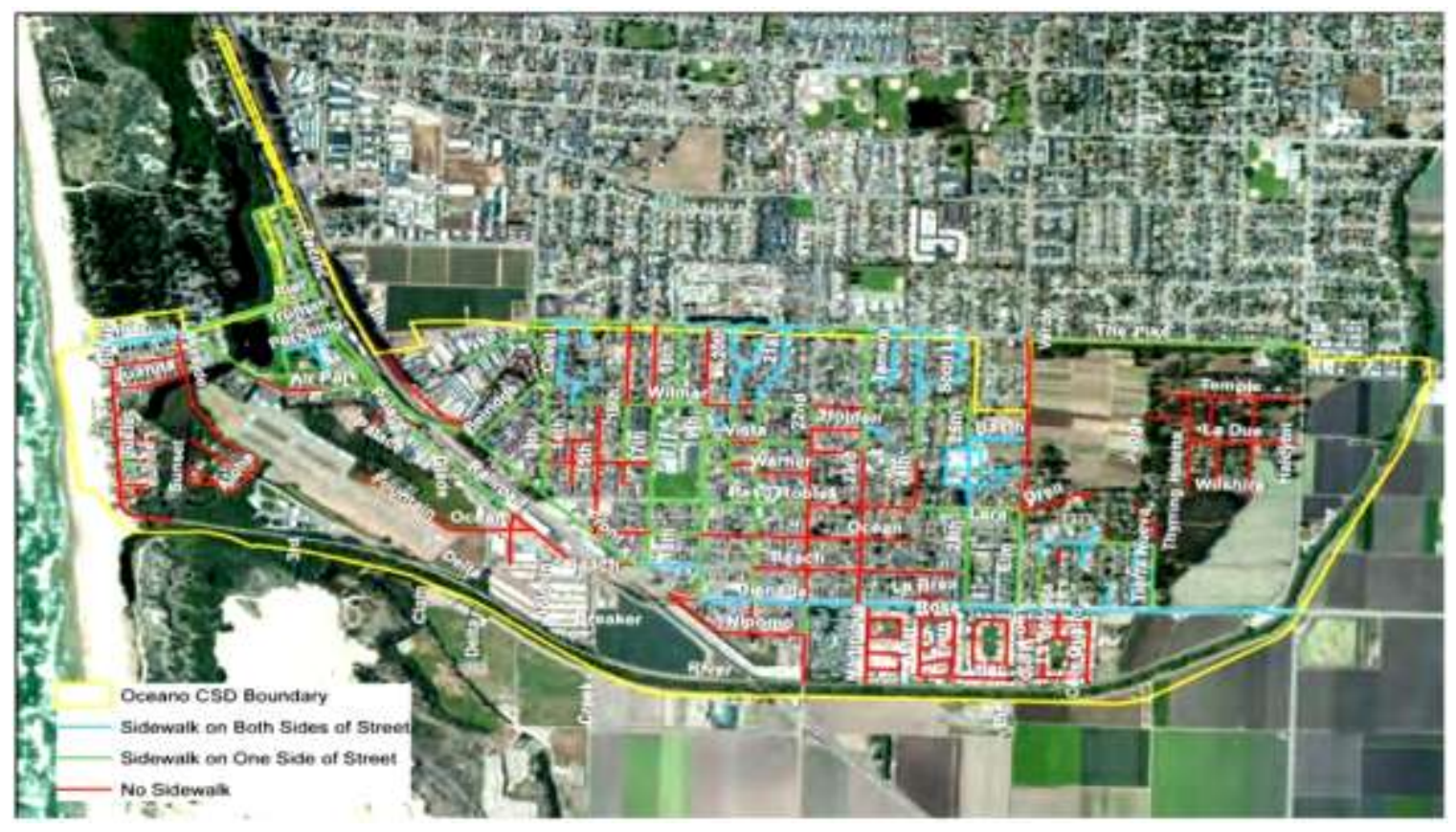




\section{Within Residential Areas}

The existing sidewalk inventory map clearly illustrates a severely disconnected pedestrian network. Using Oceano Elementary as a center-point (found between Wilmar Road and Paso Robles Street running east to west; and 17th and 19th streets running north to south), the residential areas in closest proximity to the elementary school are without intuitive sidewalk connectivity to either adjacent neighborhood streets, the commercial downtown, or to the school. Much of the southwest section of Oceano lacks sidewalks entirely, forcing pedestrians to walk near the edge of the road and around cars parked on the street shoulders. Only portions of Cienaga Street/Highway 1 and a few small neighborhood residential streets running along the north border of Oceano have complete sidewalks. Sidewalks in the remaining sections of Oceano are intermittently placed, non-existent or poorly maintained.

The Oceano Specific Plan (2002) indicates many of the residential streets lack adequate gutter and curb systems which are necessary for storm water control (p. 20 \& 41). Heavy rain can create flooding in these areas that can linger and create additional encumbrances to pedestrian accessibility.

\section{Within the Commercial Retail Core}

A number of the main streets along Highway 1, near the commercial and retail core, intersect with the highway at skewed angles which create inordinately long pedestrian crossing points and poor sight lines for motorists. Lack of pedestrian amenities such as street lights, bike racks and benches, along Highway 1 and residential streets reduce walkability and are deterrents to pedestrian activity. As with many of the central residential blocks in Oceano, the commercial retail core is prone to flooding that can act

as an added hindrance to foot traffic in the area (Oceano Specific Plan, 2002, p. 17).The 
need for improved sidewalk infrastructure in Oceano has been identified and espoused as a primary need in numerous planning documents on the area.

\section{Pedestrian Connectivity to the Beach and County Park}

While being in relatively close proximity to both the beach and Oceano County Park, for most of Oceano, walking to either of these destinations can be very problematic, as the lack of designated access paths and prospect of having to cross Highway 1 serve as dissuasive factors. The Specific Plan provides an illustrative description of the inordinate effort needed to access the beach by foot:

Getting to the beach on foot from the Downtown is daunting. The long way is up over the railroad bridge to Pier Avenue along a heavily traveled route. The short cut eventually gets you to the dike along Arroyo Grande Creek down to the beach in front of Strand. This way is the preferred approach for the community, but has several impediments. The traveler must cross Highway 1 , cross the railroad tracks, walk along undefined road edges through an industrial packing plant, and navigate several turns before making it to the dike on the Arroyo Grande Creek. (SLO County, 2002, p.35)

The Oceano Revitalization Plan identifies trail connections to the beach as a priority for Oceano residents (SLO County, 2013, p.52). Presently, no such implementation projects have been initiated as of yet.

Findings

- Oceano's sidewalk infrastructure network is incomplete, unattractive and discontiguously patterned, resulting in an unfriendly walking environment that disconnects pedestrians from key destination points within the town. Oceano's 
SES profile and the status of its pedestrian network comport with research findings which indicate "Access to recreation facilities, quality and safety of pedestrian facilities, and aesthetics are poorer in areas with mostly low-income and racial or ethnic minority populations" (Sallis et al., 2011, p. 33; Bridging the Gap, 2012, p. 1).

- A lack of clearly marked, safe, accessible paths to the beach and County Park is a hindrance to a large portion (west of Highway 1) of Oceano residents. This finding coincides with research that indicates low-income, ethnic minority communities have less access to recreation facilities, and poorer quality and safety of pedestrian infrastructure (Sallis et al., 2011, p. 33)

\section{PARKS AND HYDRATION STATION ACCESS ASSESSMENT}

The parks and hydration station assessment was included to better inform the project as to the community's access to their nearby parks and public drinking water sources. For the purposes of this assessment, parks were defined as areas that were being utilized by the public for active recreation. The parks assessment was conducted using GIS data collected from San Luis Obispo County planning, and field reconnaissance. Both maps show the location of the parks and $1 / 4$-mile and $1 / 2$-mile access by existing streets. The assessment is meant to convey the accessibility of each facility or access point from the residential areas.

The first map (see Figure 19, page 186) shows existing park and recreation spaces in Oceano. A total of 25.58 (not including Oceano Elementary facilities) acres of land is dedicated to recreation space in the community, which account for 3.78 percent of the total land use in Oceano (County of San Luis Obispo, 2002, p. 3). Oceano Memorial Park (County Park) is the community's largest recreation area, located east of Highway 1, north of the airport. It features large open areas (grass) that allow for active 
recreation, park benches, barbeque pit, a basketball court and restroom facilities. Across the street, west of the park is an additional, long and narrow strip of green space that runs parallel to the lagoon.

The large recreation field located at Oceano Elementary is utilized by the community as an unofficial space for recreation, sports and physical activities, featuring a large grassy field, a baseball backstop, soccer goals, basketball courts and playground structures. As such, the school grounds were included in the assessment. Its central location in the community core makes it accessible to a larger portion of the community, as illustrated on the maps on page 187 (Figure 20 - Existing Park and Outdoor Recreation Space Proximity Map with Proposed Space).

The dark purple overlay on the map indicates the community area served within a quarter-mile of the park or recreation area via the existing street network. The lighter purple overlay indicates the community area served within a half-mile. The proximity map indicates the residential areas on the western side of Oceano are adequately served by County Park, though the potential to serve a larger part of the community is hindered by the barrier Highway 1 creates and the lack of a safe, clearly marked access path to the park. Conversely, the centralized location of Oceano Elementary allows access to a much larger portion of Oceano residents. However, the current sidewalk network infrastructure issues specified in the previous walkability findings section impact access to the school facilities and its use.

The second map (see Figure 20, p. 157) a proposed recreation facility on the eastern section of Oceano, and features the same quarter mile and half-mile distance overlay indicators as the previous map. The parcel of land (APN: 062-074-012) is found between 25th, Basin, and S. Elm Street, and is owned by the City of Arroyo Grande, yet it's in the Oceano's Community Service District boundaries. The land use is designated as Public 
Facility. Arrangements would need to be made between the county, Oceano and Arroyo Grande, for the land to be purchased or to create a shared-use agreement. The map illustrates the potential added area a park or green space access the proposed area would provide.

Separate hydration station access maps were not created. This was deemed unnecessary due to the fact public drinking fountains are traditionally found at parks and open space areas. As such, the parks assessment maps sufficiently illustrate the potential distance in access area in the community should drinking fountains be installed at County Park and the proposed location, where they currently don't exist.

\section{Findings}

- Research has indicated people who live within walking distance (one-quarter mile) of a park are 25 percent more likely to meet the recommended minimum weekly exercise requirements (Saelens, Sallis, \& Frank, 2003). A large portion of the community live within one-quarter mile of Oceano Elementary. However, without a formal joint-use agreement with the Lucia Mar School District which would provide accountability and outline responsibilities for maintenance and regulation, over use of the facilities on the school grounds may lead to a tragedy of the commons scenario.

- Research has indicated active living behaviors in Latino populations are greatly influenced by access to park and recreation facilities (Lovasi et al, 2009). This notion is supported by feedback garnered in the community survey in which the lack of recreation facilities (i.e. "there are no parks...no recreation centers...gym") was mentioned in responses most frequently as to what makes it most difficult to be healthy or detracts from overall wellness 
- With Oceano's lack of financial resources, it must make better use of the facilities it presently has. A safe, clearly marked access path that would better link residents east of Highway 1 to County Park is a priority.

Figure 19 - Existing Park and Outdoor Recreation Space Proximity Map

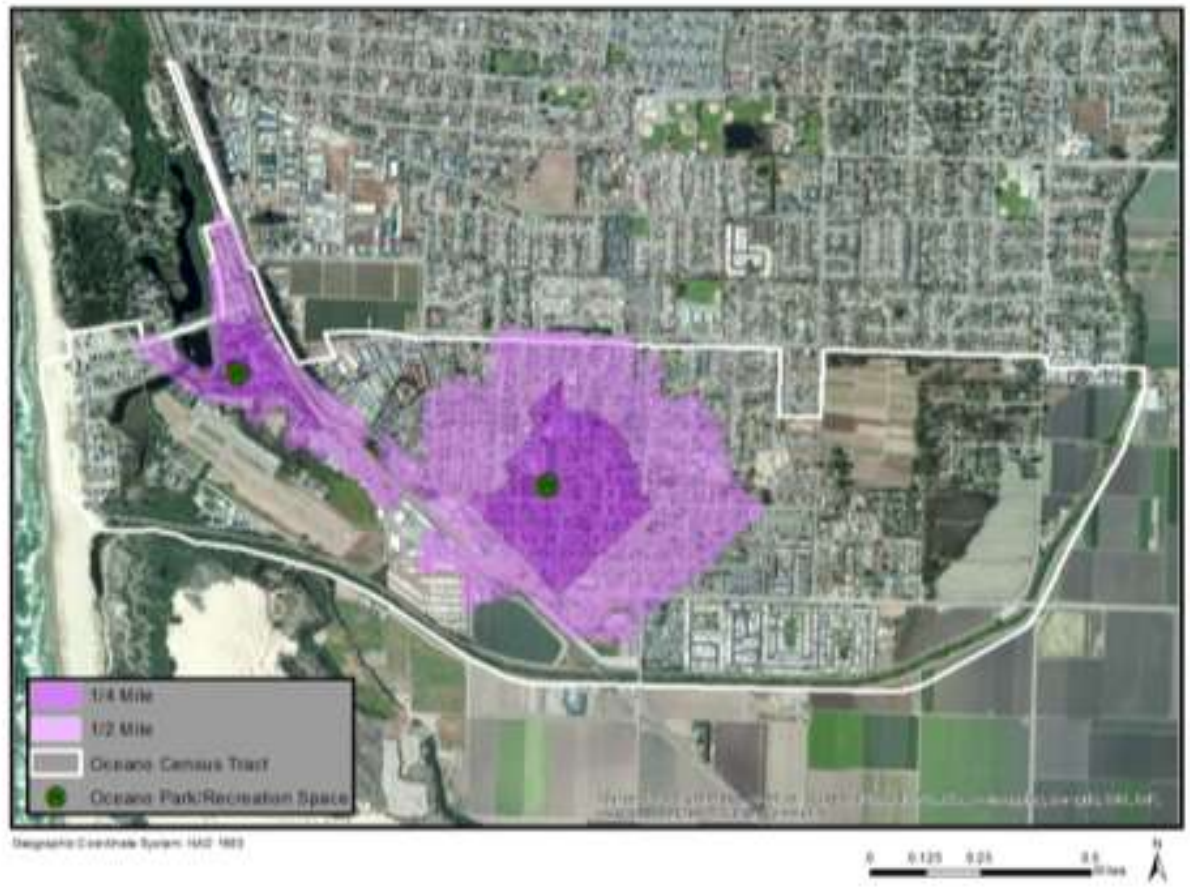


Figure 20 - Existing Park and Outdoor Recreation Space Proximity Map with Proposed Space

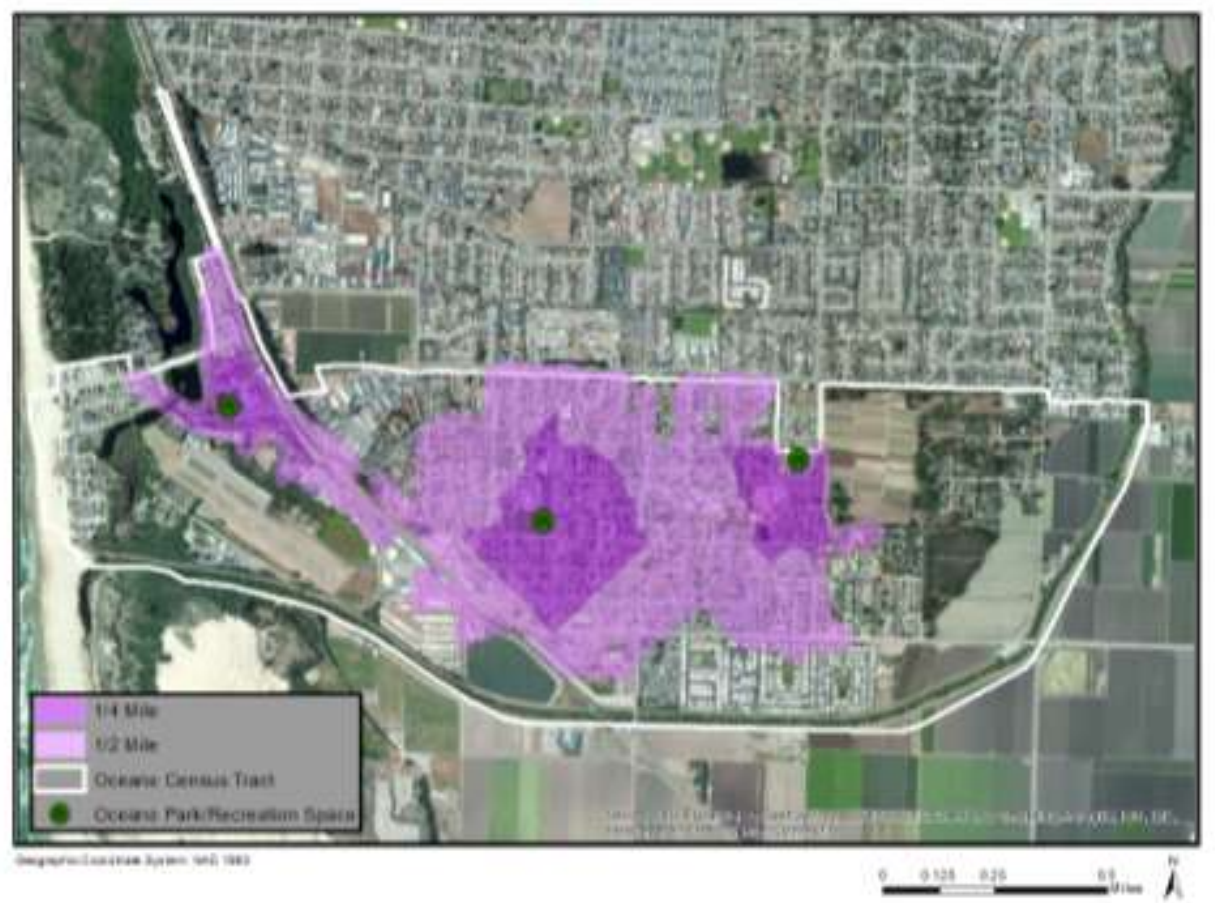

\section{FOOD ACCESS ASSESSMENT}

The food access assessment was included in the plan in order to analyze the existing availability of food outlets and to help determine need. The assessment was conducted using GIS data collected from San Luis Obispo County and by visits to each of the stores that sell food or beverages. For the analysis of the food retail environment, data was obtained from the local environmental health department to determine the location and type of stores that exist in the study area.

According to the Retail Food Environment Index (RFEI) standards, there are five unhealthy food outlets in Oceano (California Center for Public Health Advocacy, 2007). These stores were primarily convenience markets or gas station shops, selling primarily alcohol, candy, chips, sodas, tobacco, and similar items. Central Market, La Tapatía Market and Deli, and Johnson's market offer a better variety of healthy food items, such 
as whole grain bread and tortillas, fruits and vegetables, and reduced fat milk. A fruit and vegetable stand near Tierra Nueva Lane and Highway 1 on the southeast side of Oceano offers an abundance of fresh produce and unprocessed items.

Figure 21 on page 189 shows half-mile to 1-mile accessibility distances based on the street/road network to the healthy food vendors in the community. These vendors are dispersed evenly throughout Oceano, placing most of the community within a half-mile of a healthy and nutritious food source. These areas are denoted by the dark purple overlay on the map. Areas of the community that are within 1-mile of these vendors are denoted in the light purple overlay.

Figure 22 on page 190 shows the locations of the unhealthy food vendors in the community. The map uses the same color overlay scheme with distance areas within a half-mile in dark purple; light purple for areas within 1-mile of a vendor.

\section{Findings}

- Healthy food sources are accessible within the community

- The unhealthy food stores are clustered together, reducing access to these vendors. However, the majority of these vendors are located less than a halfmile from the elementary school, which may promote poor food buying choices for neighborhood children

- There are currently no fast food vendors in Oceano

- There are no large chain supermarkets in Oceano

- Currently, only one food vendor accepts WIC, which may limit the ability to buy healthy food options for some residents 
- Community survey respondents mentioned the wide selection of fresh produce at certain markets in Oceano, but also preferred the larger overall selection of foods and affordable prices at Vons, located in Grover Beach, just over a mile from the most northern border of Oceano.

Figure 21 - Oceano Healthy Foods Vendor Proximity Map

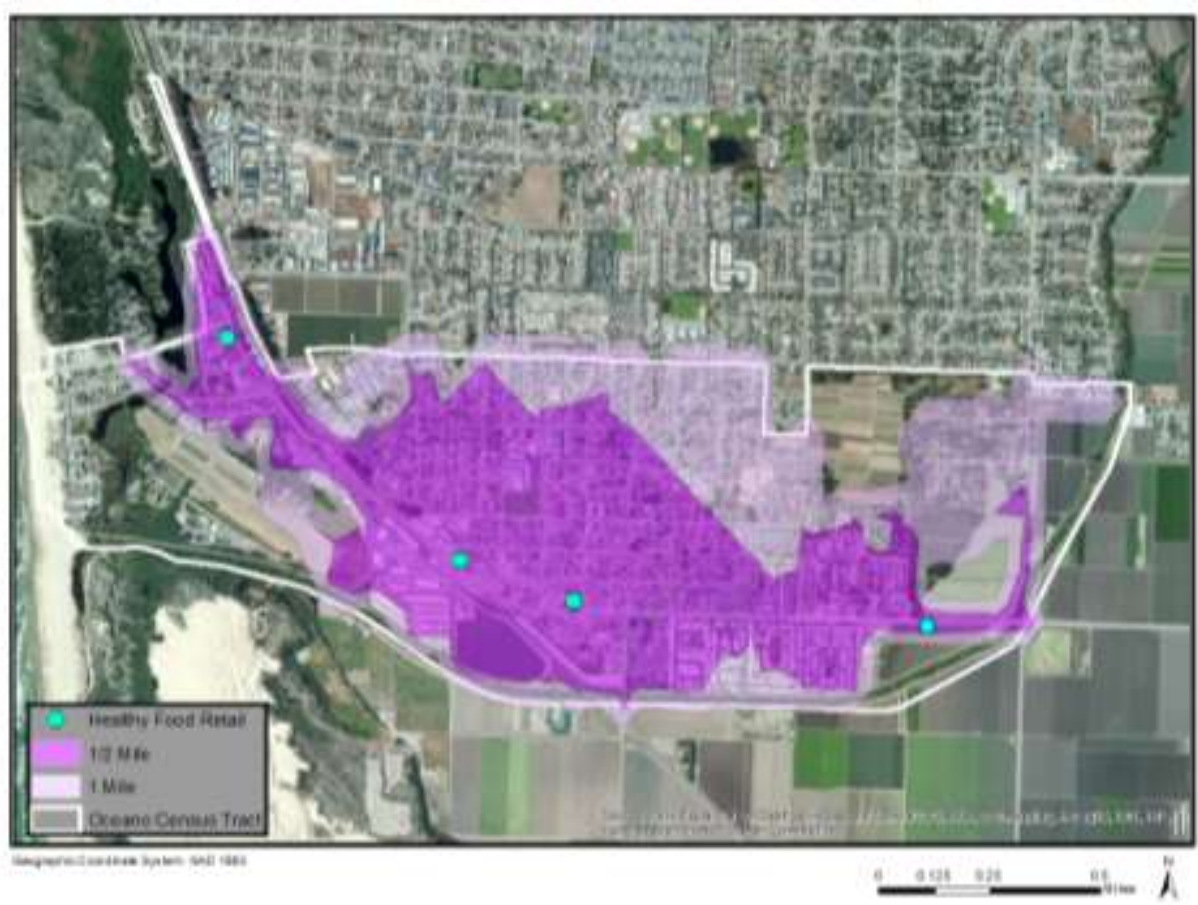


Figure 22 - Unhealthy Food Vendor Proximity Map

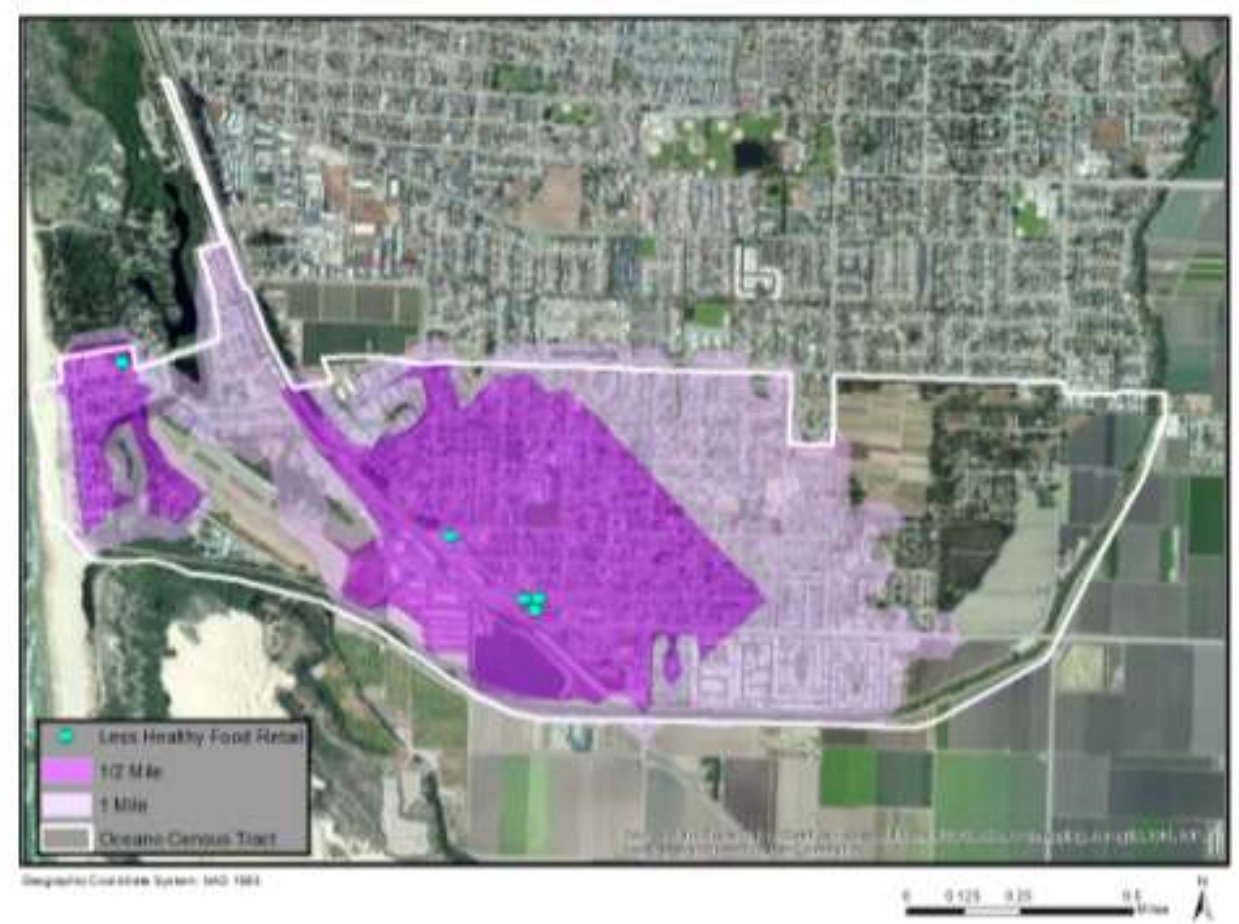

\section{Community Outreach}

In order to create the most accurate, appropriate and relevant Oceano Community Health Plan, community outreach was conducted in an effort to elicit public participation and garner valuable feedback from community members regarding topics such as physical activity levels; preferred exercise activities; perspective of the built environment in which they live, work and play; and perceived hindrances and desires in their community. The outreach efforts were comprised of the following:

\section{LOCAL GOVERNMENT AGENCY PRESENTATIONS}

Presentations were conducted on Jan 22, 2014, before the CSD, and on Jan. 27, 2014, before the OAC. The presentations served to announce my presence in the community and state what my intentions would be while working there, as well as to provide the scope and details of the project and ask for their support. In addition, the presentations 
informed the project by providing a platform to engage with politically active community members that have in-depth knowledge of both historical and contemporary issues in Oceano.

The board members of the CSD and members of the OAC both provided feedback at the end of the presentations, suggesting locations within the community to conduct surveys, mentioned sidewalk infrastructure and street lighting as primary needs, and were mostly supportive of the project's overall intention and stated goals. However, a few board members of the CSD were specifically critical of the scope of the project's subject matter believing issues such as drug abuse, needle-share programs and homelessness were not being addressed. It was explained to the board that these concerns, while legitimate community issues, were beyond the scope of the project's research investigation; that being the role of the built environment and its impact on public health. Both agencies agreed that they would be interested in having me return to present the project's findings and provide a copy of the final document once completed.

\section{Findings}

- The role of the built environment on public health is a new concept for some local officials. More effort needs to be made by the public health and planning departments to better inform government agencies of the connection and its importance

- Some advisory council members felt the time, energy and resources used by the County Health Department would be better spent trying to help assist the homeless and drug addicts in the community

- Sidewalk infrastructure and street lights were mentioned as a primary needs for the community 


\section{KEY INFORMANT INTERVIEWS}

The following section discusses and analyzes the results of interviews and group meetings with representatives from the community. Discussions centered on health issues, community priorities, assets and factors contributing to health, and barriers to improving health in the community. Key informants included employees of local government, community service groups and family resource centers, whom have extensive knowledge of Oceano and its residents. The same questions were asked of each key informant, though conversations sometimes centered on related topics. Questions and compiled answers are included below.

Question: In your experience, or based on your work with the organization, what would you say are the top 3 or 4 most important health issues in Oceano? Answers to this question were varied, but childhood obesity was identified by all interviewees as an issue within the community. The lack of sidewalks, streetlights, concerns over safety, lack of recreation destinations (i.e. parks and open space), and scarcity of healthy food options were all mentioned as hindrances to physical activity. One interviewee said the following:

Obesity is definitely a problem for both adults and children. My own experience; my own son; teenagers and what they eat-they don't eat healthy. There is nothing in the community available to them—nothing locally to benefit them.

Additionally, cultural barriers and lack of nutrition education were specifically mentioned as barriers that must be addressed; one informant provided the following related anecdote: 
We have a literacy hour where parents bring in their toddlers. The mothers were talking about how the doctors were telling them they need to ease off of feeding them because they (the children) were becoming overweight $[\ldots]$ they need education. The mothers couldn't believe it. In a Mexican household, feeding you is loving you.

Question: Are the health issues you mentioned priorities for your organization, or are there any programs in your organization that are related to these issues? Two of the interviewees who work for a family resource center both said they network with health organizations such as Dignity Health, which offer exercise and healthcare classes. Another interviewee, who works for a youth organization within the community, said they do focus on healthy eating habits, providing a workshop twice a week in which they do physical activities and discuss healthy eating choices. The same individual mentioned the lack of free public recreation facilities in the community, noting the cost to utilize the Oceano Community Center as prohibitive. The dearth of available options that would interest teenagers was also mentioned as problematic. Arrangements with gym facilities outside of the area are typically made, but these are not available to the groups on a regular basis. "We have worked with Grover Beach CrossFit in the past. We also go to the gym in Pismo Beach to workout, because the gym available for us to use here (Oceano) costs us money."

Question: How would you describe the overall health of the Oceano/Cayucos community? Follow up: Are there any health issues that seem to be impacting particular groups (children, teenagers, elderly, etc.)? Are there certain neighborhoods or geographic areas that have unmet needs related to active living? Childhood obesity was again identified as a primary concern by the key informants. The homeless in Oceano, specifically those found near the train tracks, were suspected as groups that may have 
issues related to drug abuse. The informants who had intimate experience dealing with individuals and community groups felt the health issues in Oceano were generally the same for everyone, being that Oceano's physical dimensions are so small. One interviewee elaborated on the health issues of the specific groups they worked with, "a lot of our moms are dealing with diabetes—but definitely both (children and adults)," they added "We have young, 30-40 year old people having heart issues too." Another mentioned "A community pool would be great. A lot of these kids don't' know how to swim," an irony being that Oceano is located in such close proximity to the ocean.

\section{Question: Would you consider Oceano a physically active community?}

Follow up: Can you tell me more about how the built environment in Oceano may be preventing people from being more active? Two of the informants (whom were interviewed together) gave a definitive "no" when asked this question, stating "I think a lot of it has to do with the environment-with gangs and drug users," continuing "another thing is when it gets dark, it really gets dark." These statements echoed a lot of the sentiments received from community feedback. This corresponds with research that perceptions of safety (i.e. the lack of) and lack of built environment amenities such as street lamps can alter active living behaviors. A different informant found it difficult to provide a definitive answer to the question, stating "You do see people walking and jogging, but it's unclear if they are from here or not. Kids are on the street playing because we don't' have sidewalks." All the interviewees agreed that physical activity levels would increase if there were more opportunities and facilities that would allow for it, and mentioned the elementary school as the unofficial park that's most accessible for the community to use-_kids jump the fence [at the school] to use the soccer field." When asked to specifically name what may be hindering (physical, cultural, psychological barriers) residents from being more active, one informant responded "Sidewalks. There are no sidewalks for safety [...] no places to ride bikes in safe areas; 
the roads are narrow. No activities," The built environment was the common denominator, but other reasons were forwarded as well. "Nutrition and physical activity are not really strong parts of Hispanic culture-it's a new concept [the expectation is] go to school and do your homework."

Question: Do you think that food is accessible, available, and affordable in the community? Food accessibility and availability within Oceano was not identified as an issue by the informants. However, affordability was mentioned as a problem for some community members. "I have a family that said they were spending all their money at Central Market $[\ldots]$ they have affordable fresh produce, but many of their other items are two to three times more expensive."

Many low-income families were said to be going outside of Oceano to Santa Maria to find better value. One informant lamented "The markets have reasonable prices on some items, but I see older people walk all the way to Vons to more for their money." The topic of nutrition education was brought up as a barrier to healthy eating choices. Decisions regarding food choices may be influenced by simple availability rather than nutritional quality. "We do a food distribution each month where we hand out nutritious foods, but I don't know how many of our families know the importance of eating the right types of fruits and vegetable [fresh vs. canned]."

Question: Do you believe there are barriers to enacting policies and creating community support related to active living and healthy eating? This question provoked responses that provided very different perspectives. One informant noted political apathy as a major factor in not getting community support for policies that would benefit the community, stating 
There is no community involvement. You go to the board meetings and there isn't any community members getting involved. I don't think the public know they have the opportunity to speak; they don't want to stir things up-people just want to live in peace.

Others described feeling like bystanders, powerless to create change, watching the needs of others (neighboring communities) be attended to. "We feel like we're being bypassed, whereas Arroyo Grande or Grover Beach get more attention offered to them."

Question: Do you know of any specific "champion" or "champions" for health in the community? Only the Promotores Collaborative was mentioned specifically. The Promotores are community health workers that serve low-income, underserved populations that have less access to health care resources and facilities. They work independently, with local non-profit agencies, county or state governments to educate communities on prevention, health and wellness.

Question: Do you think local government funds should be spent to support health policy actions? Without providing specific policy actions they wish to see supported, the informants all affirmed the notion that local government funding should be used to support policies that will improve health outcomes in the community.

\section{Findings}

- The presence of gangs and illicit activity has decreased the perception of safety and security in Oceano, which in turn influences the desire for some community members to do physical activities such as walking or jogging

- Stray dogs were brought up as another contributing factor to negative safety perceptions 
- Cultural and traditional values may be barriers to learning and modifying health behaviors for certain segments of the community

- The need for parks and free public recreation spaces was identified as a need

- The Oceano Community Center is too expensive for many families to use with regularity

- The community needs nutrition and preventative health education

\section{COMMUNITY EVENTS}

\section{Oceano Elementary Event}

On February 21, 2014, a survey and mapping exercise was conducted with Mr. Jim Dececco's 6th grade class at Oceano Elementary. A mapping exercise that involved students selecting cutout images of things that were representative of what they liked to do for physical activity; things that would make them feel safer; and things they "wished" Oceano had. Students were also asked to indicate the travel mode and route they took to school and back, in addition to any other destinations they frequently visited in the community.

The exercise concluded with each group collectively discussing the features they would most like Oceano to have. Skate and water parks, football field, basketball courts, and trees were among the most commonly mentioned.

A brief six-question survey was conducted prior to the mapping exercise, and inquired about the students' physical activity behaviors, eating habits, and "wishes" regarding recreation facilities. The six questions and accompanying survey results are found in Table 36, Oceano Survey Results. 


\section{Table 36 Oceano Survey Results}

\begin{tabular}{|c|c|c|c|}
\hline Q1 & Answer choices & Total & $\%$ \\
\hline \multirow{12}{*}{$\begin{array}{l}\text { What types of activities do you do for } \\
\text { physical activity while not in school? }\end{array}$} & Playing sports & 19 & 0.86 \\
\hline & Going for a walk & 11 & 0.50 \\
\hline & Running & 8 & 0.36 \\
\hline & Riding a bike & 7 & 0.32 \\
\hline & Skateboarding & 6 & 0.27 \\
\hline & Dancing & 5 & 0.23 \\
\hline & Swimming & 4 & 0.18 \\
\hline & Hiking & 4 & 0.18 \\
\hline & Jump rope & 3 & 0.14 \\
\hline & Kickball & 3 & 0.14 \\
\hline & Dodgeball & 2 & 0.09 \\
\hline & Other & 0 & \\
\hline Q2 & Answer choices & & $\%$ \\
\hline \multirow{8}{*}{$\begin{array}{l}\text { Where in Oceano do you go to be } \\
\text { physically active? }\end{array}$} & In your front or backyard & 10 & 0.45 \\
\hline & At your school & 9 & 0.41 \\
\hline & Somewhere outside of Oceano & 6 & 0.27 \\
\hline & Boys \& Girls Club & 5 & 0.23 \\
\hline & On the street or road & 3 & 0.14 \\
\hline & Oceano Community Center & 3 & 0.14 \\
\hline & The beach & 3 & 0.14 \\
\hline & Other & 0 & \\
\hline Q3 & Answer choices & & $\%$ \\
\hline \multirow{12}{*}{$\begin{array}{l}\text { Which one of the following things } \\
\text { would you like to see in Oceano? }\end{array}$} & More playgrounds & 11 & 0.50 \\
\hline & Outdoor basketball courts & 10 & 0.45 \\
\hline & Football field & 9 & 0.41 \\
\hline & Better sidewalks & 7 & 0.32 \\
\hline & A skate park & 6 & 0.27 \\
\hline & Water fountains & 6 & 0.27 \\
\hline & Soccer field & 5 & 0.23 \\
\hline & Park and recreation areas & 5 & 0.23 \\
\hline & More bike racks & 4 & 0.18 \\
\hline & More benches & 4 & 0.18 \\
\hline & Healthier places to eat & 1 & 0.04 \\
\hline & Other & 0 & \\
\hline Q4 & Answer choices & Total & $\%$ \\
\hline \multirow{6}{*}{$\begin{array}{l}\text { What is preventing you from being } \\
\text { more physically active? }\end{array}$} & There isn't much to do outdoors in Oceano. & 9 & 0.41 \\
\hline & It's hard to walk in some places because & 6 & 0.27 \\
\hline & I don't feel safe in some neighborhoods & 6 & 0.27 \\
\hline & I don't feel there are things preventing me & 5 & 0.23 \\
\hline & There are a lot of stray animals (example: & 2 & 0.09 \\
\hline & Other & 0 & \\
\hline Q5 & Answer choices & \multicolumn{2}{|c|}{$\%$} \\
\hline \multirow{3}{*}{$\begin{array}{l}\text { Do you feel Oceano is a place that } \\
\text { allows you to be physically active? }\end{array}$} & Yes & \multicolumn{2}{|c|}{0.36} \\
\hline & No & \multicolumn{2}{|c|}{0.23} \\
\hline & I don't know & \multicolumn{2}{|c|}{0.32} \\
\hline Q6 & Answer choices & Total & $\%$ \\
\hline \multirow{6}{*}{$\begin{array}{l}\text { When you're not eating at home, where } \\
\text { do you go to buy food? }\end{array}$} & Vons & 9 & 0.41 \\
\hline & A market & 5 & 0.23 \\
\hline & The convenience store & 4 & 0.18 \\
\hline & Other & 3 & 0.14 \\
\hline & A taquería & 1 & 0.05 \\
\hline & ${ }^{*}$ three did not respond & & \\
\hline
\end{tabular}




\section{Findings}

- Sixth graders expressed a strong desire/need to be physically active outside of school

- Children are walking, but need further pedestrian infrastructure to promote activity and safety

- Areas around 17th and 19th Streets were identified as places that felt unsafe

- They want park and recreation facilities such as basketball courts, skate parks and bike trails

- Safety concerns, lack of sidewalks and general view that there is nothing to do in Oceano impacts their decisions to be physically active or not

- 41 percent (9 students) of the respondents said they go to Vons to buy food

- Survey responses (41 percent; 9 students) suggest the perception that "there isn't much to do outdoors in Oceano" is preventing students from being more physically active

\section{Day of the Child Event}

On April 27, 2014, an information booth was reserved for the Day of the Child event held at the Oceano Community Center in Oceano. This annual event is well-attended by community members, with approximately 300-400 at this year's event. My participation at the event was primarily for informational purposes, providing visitors a looped PowerPoint visual that described the Oceano Elementary event, as well as large printed graphic displays which provided selected results from the community questionnaire.

However, a large scroll of blank paper was provided at the table and visitors were asked to list features they would like to see in Oceano. More than 60 suggestions were collected, with answers ranging from improved sidewalks, parks and recreation areas, 
and street lamps. Outside of built environment features, a desire for particular facilities and land use developments such as health care clinics and a commercial center were regularly mentioned. Non-physical features such as an increase in police presence, security and overall safety were commonly listed by respondents. These answers corresponded with community feedback received from the other outreach efforts mentioned in this chapter.

\section{Findings}

- Safety and security concerns came up prominently among responses; requests for more patrols, less gangs and vandalism were suggested

- The need for street lights, additional parks, after school activities for children, sidewalks, and medical centers were commonly mentioned by booth visitors

- Family and social service groups have a strong influence in the Hispanic/Latino community in Oceano

- Hispanic/Latino parents in Oceano are strongly motivated by efforts which seek to improve the lives of their children

\section{OCEANO COMMUNITY QUESTIONNAIRE}

Distribution of the questionnaire began in February on through late March. Surveys were conducted in-person throughout the community, at locations frequently visited by residents, such as Central Market and La Tapatía Market \& Deli. However, a large number of the surveys were conducted in-person via door-to-door knocking by Oceano Promotores volunteers. A total of 124 questionnaires were collected. 
Figure 23 - Survey Question: Contributors to quality of life in Oceano

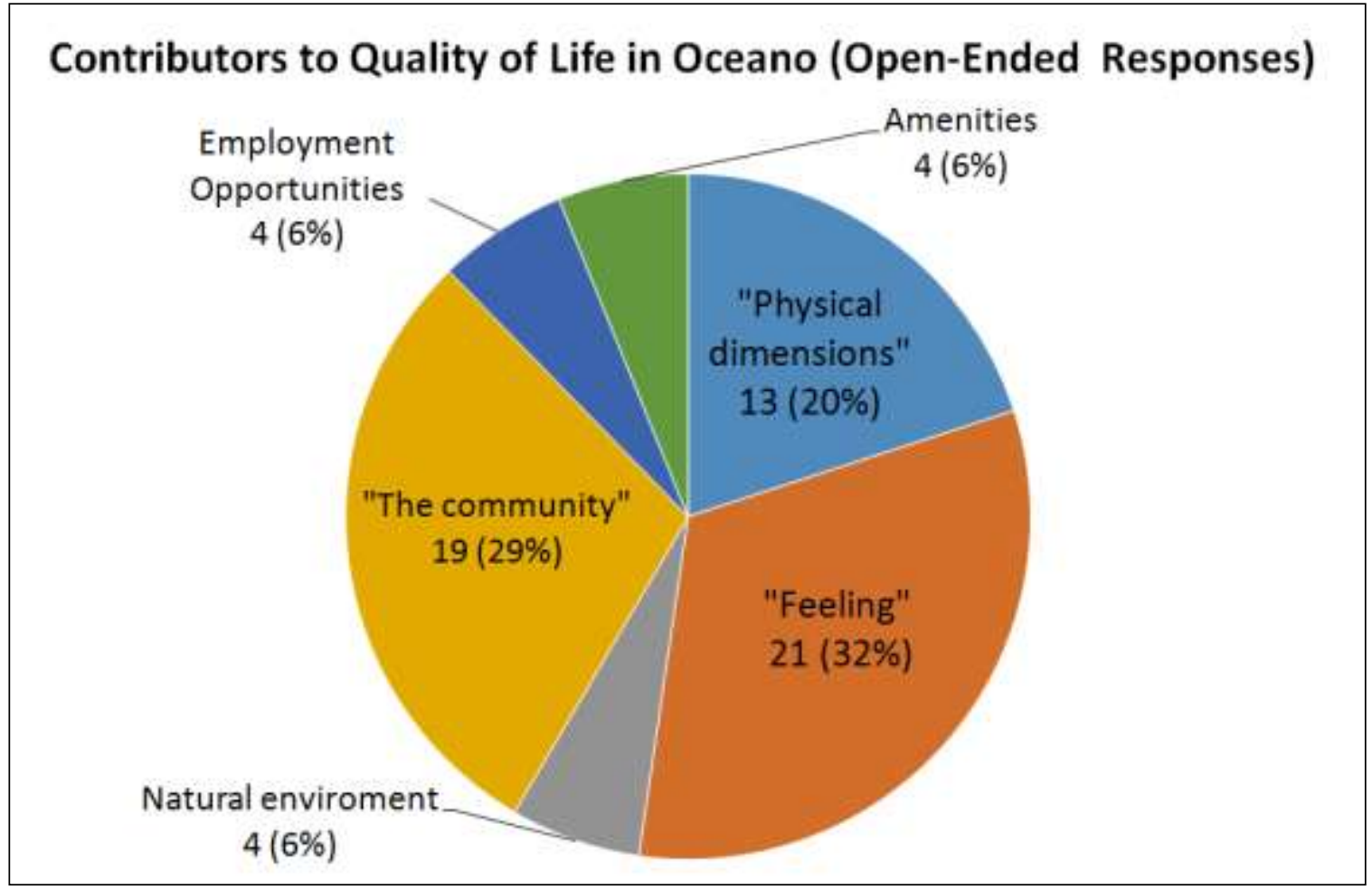

Survey respondents were asked (see Figure 23), "Generally speaking, what contributes most to your quality of life in Cayucos?" However, the phrasing of this question does not translate well to Spanish, so the question was rephrased to "What do you like most about Oceano?" Responses were input and divided into categories to better assess overall opinions. The category totaling the greatest number of responses were answers relating to "feeling" such as feeling safe or being in an inviting environment. The category totaling the second highest number of responses was "the community." Examples of answers placed under this category were "my neighbors"; "the people"; and "social life." The third most responded to category was "physical dimensions." Answers that were placed under this category described Oceano as a "small town" or "small community." 
Figure 24 - Survey Question: Factors that detract from health and wellness in Oceano

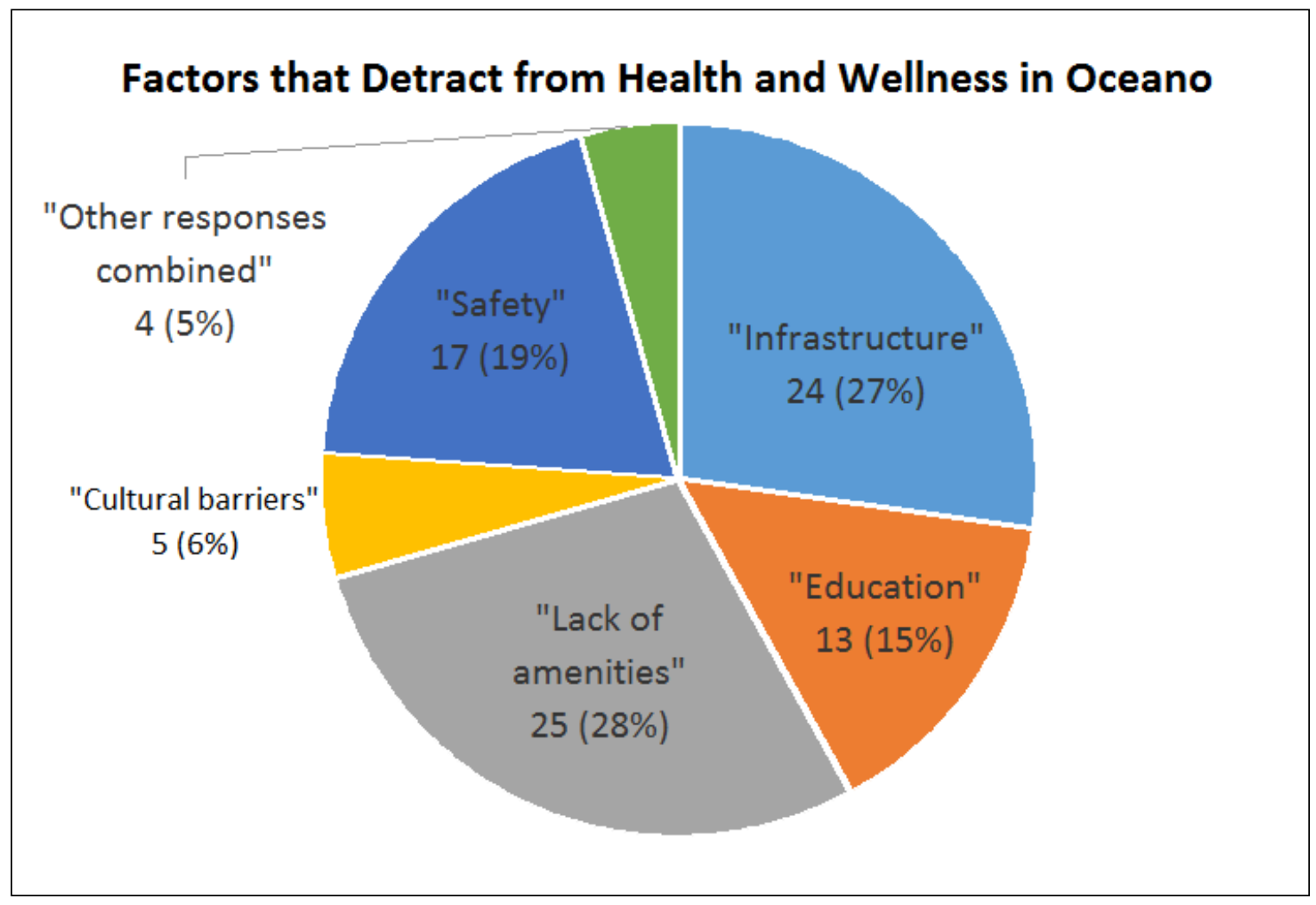

Survey respondents were asked (see Figure 24), "What do you think makes it most difficult to be healthy or detracts from overall wellness here?" Answers such as "there are no parks," "no places to play," and "no recreation centers" were categorized under "Lack of amenities" and yielded the most responses to the question. "Infrastructure" was the second most categorized response with answers such as "no sidewalks," "no bike lanes," "no places to exercise," and "no parks" being the most commonly written types of answers to the question. In order, the categories "Safety" and "Education" followed after, resulting in 19 percent and 15 percent of the total responses from those that attempted to answer the question. Clearly, the community has voiced its opinion that features of the built environment in the form of land use and infrastructure is hindering their ability to be healthy. 
Figure 25 - Survey Question: Perceptions of Personal Health

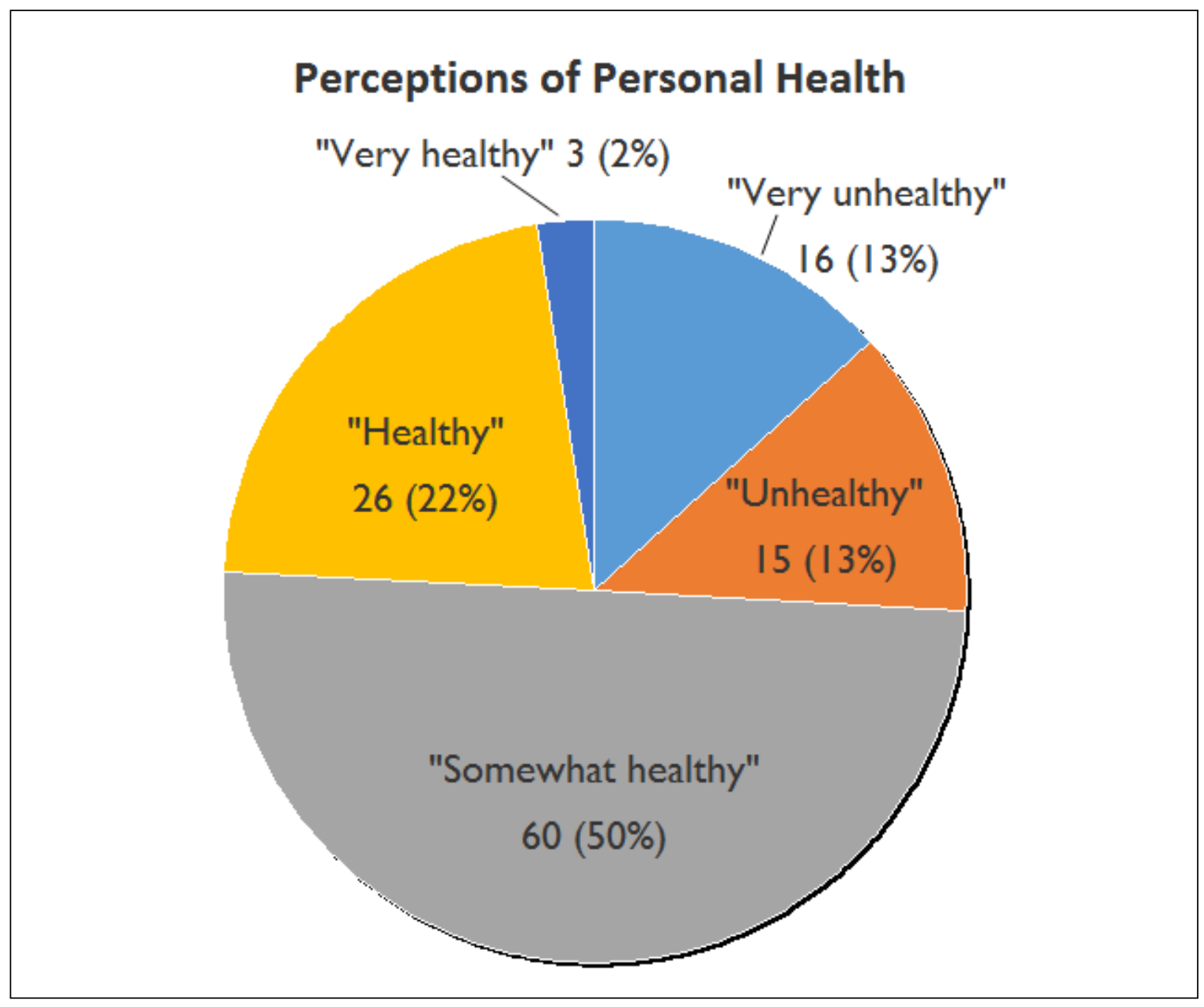

Survey respondents were asked (see Figure 25), "How would you rate your own personal health?" The respondents were asked to choose from the following descriptors: "Very unhealthy”; "Unhealthy”; “Somewhat healthy”; "Healthy”; "Very healthy." Half (50 percent) of all respondents which answered the question (120 total responses) viewed themselves as "Somewhat healthy." Interestingly, one-quarter (25 percent) of respondents had negative perspectives of their own health, describing themselves as either "Unhealthy" (12 percent) or "Very unhealthy" (13 percent). Further, more people described their personal health as "Very unhealthy" (16 responses) than those that perceived themselves to be "Very healthy" (3 responses). 
Figure 26 - Features that would Improve Personal Health

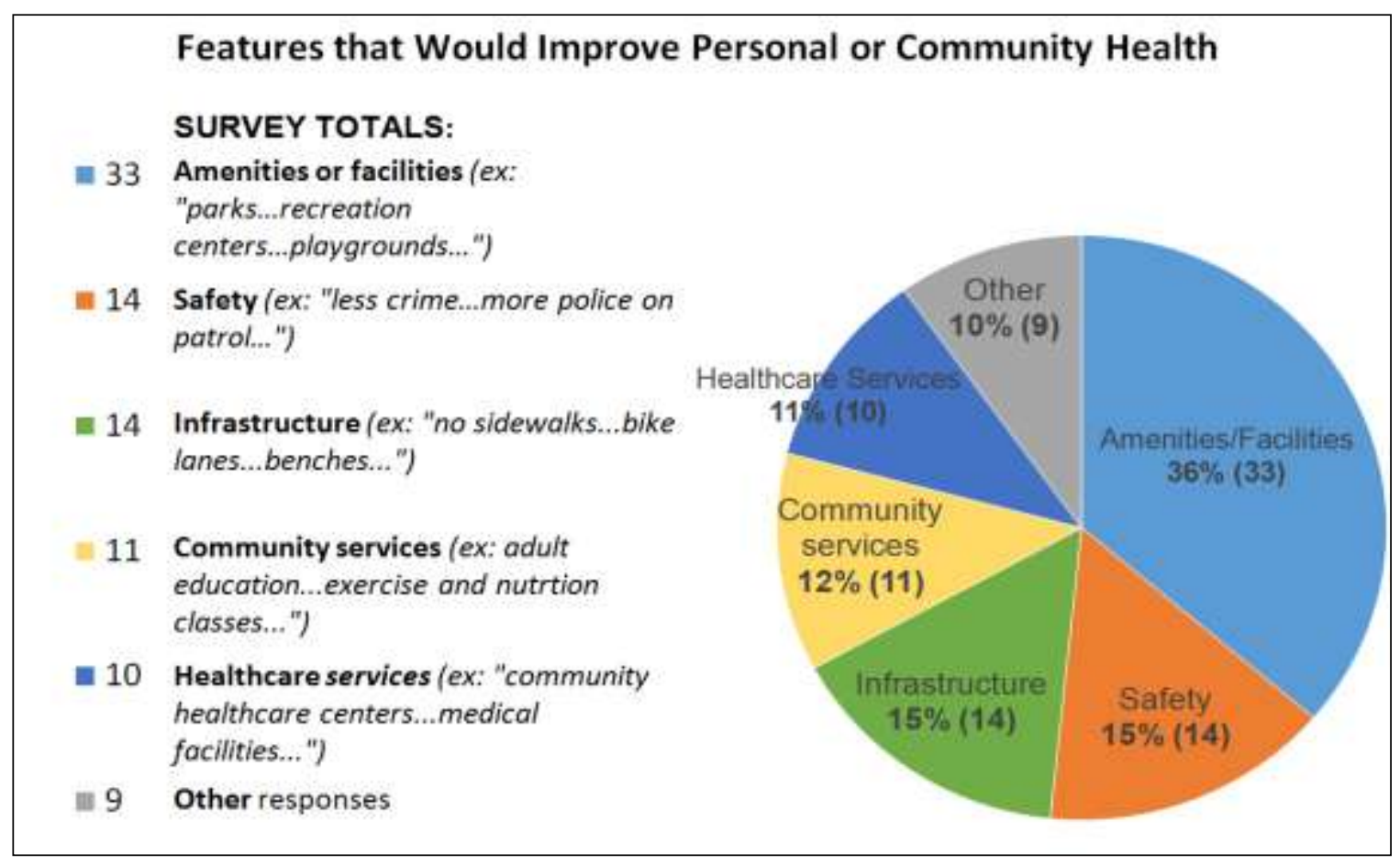

Survey respondents were given an open-ended response question which asked (see Figure 26) "What should change in Oceano that could contribute to your personal health or the health of the community as a whole?" The opinions were grouped into categories to better assess overall opinions. For this question, the categories were "Amenities"; "Safety"; "Infrastructure”; "Community services"; "Healthcare services”; and unrelated answers that were grouped into "Others." The majority (36 percent) of respondents gave answers such as "parks, "recreation centers," "playgrounds," and other answers which could categorized as added recreation or facility features. The next highest response rates (15 percent) were answers that were placed into the categories relating to "Safety" and "Infrastructure." 
Figure 27 - Prioritized Community Features Most Important to Oceano

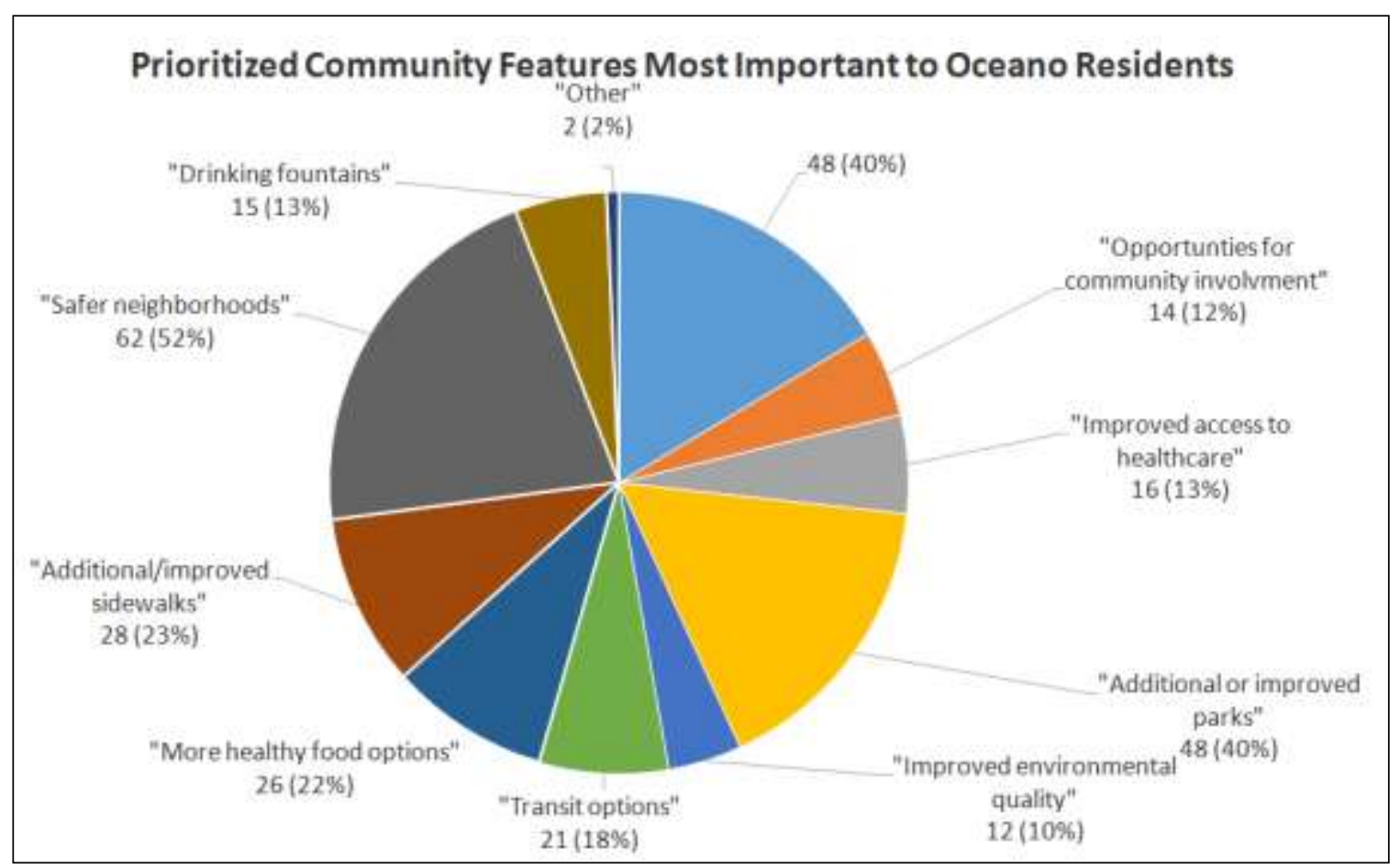

Survey respondents were asked (see Figure 27), "What community features, if any, could contribute to the health and quality of life in Oceano?" They were asked first to checkmark all that applied, and then were asked to prioritize three answer choices they felt were most important. The pie chart represents the prioritized answer choices.

\section{Findings}

- Notions regarding safety (i.e. "factors that would improve quality of life...features that could contribute to quality of life... what makes it most difficult to be healthy...") were a common theme receiving high response rates throughout the questionnaire

- The lack of surety of personal health with such a large number of respondents may indicate individuals in the community may be maintaining unhealthy lifestyles, putting themselves at risk for immediate or long term health risks. An increase in health and nutrition education could benefit community members by 
informing them of the dangers of unhealthy lifestyle behaviors, and educating them on the benefit of healthy and active living.

- Answers categorized generically as feeling, community and physical dimension ranked as the top three responses to what respondents liked most about Oceano

- Amenities and facilities (i.e. parks, recreation, playgrounds, et cetera) were mentioned most frequently as the thing that could contribute to their own personal health or the health of the community as a whole

- Lack of amenities and facilities (i.e. "there are no parks...no recreation centers...gym") were mentioned in responses the most frequently as to what makes it most difficult to be healthy or detracts from overall wellness

\section{Summary of Key Findings}

Several common themes, voiced by the community, developed as information was collected from the outreach efforts. The following is a summary of key findings stemming from those themes which helped shape the goals, objectives, policies and actions later outlined in this project.

\section{Obesity and Physical Activity}

The health benefits of regular physical activity, even at moderate levels, are wellestablished; weight management, mental and physical well-being, and resistance to many chronic and preventable diseases stem from active lifestyle. Obesity risks are correlated to sedentary lifestyle behaviors, which are influenced by a multitude of socioecological factors, including planning decisions that can impact an individual's (or community's) ability to live a healthy and active lifestyle. 
- Obesity was identified as a major health concern by the community, though the concerns were primarily directed towards children versus adults

- Cultural and educational barriers were said to be hindrances that needed to be first addressed in order to elicit behavioral changes

- The rates of screen time (computer, television, videos, texting, et cetera) for South County Area (of which Oceano belongs to) children has increased to more than 10 hours per week (Action, 2013, p. 109)

During interviews with key informants who work closely with families in the community, it was said the notion of maintaining healthy diet and physical activity for long term health benefits was not a primary concern for first generation Latino community members, and therefore those values are not known or passed on to those belonging to the younger generation. The community survey provided insight into residents' perceptions of their own personal health levels. Half of the all respondents viewed themselves as "somewhat healthy." Perhaps even more revealing was that a quarter of respondents deemed their personal health as "unhealthy" to "very unhealthy." Beyond incorporating planning decisions and urban design that will affect the built environment, a strong health education component must be part of any comprehensive strategy meant to create positive health outcomes in Oceano. One possible planning and design solution would be to create a partnership that would allow use of a facility for free, regularly scheduled health awareness and education classes (Dannenberg et al., 2011, p. 140).

\section{$\underline{\text { Healthy Food Access and Affordability }}$}

Access to fresh produce and nutritious food sources is vital to helping maintain a healthy diet which can help reduce the risk of obesity and diet-related diseases. Declining physical activity rates and increases in obesity rates in the U.S. have been accompanied by the increased availability of less nutritious foods, such as prepackaged, highly 
process, high sugar and fat dense foods, which are typically found in small convenient store and gas station markets (Raimi + Associates \& Transportation and Land Use Collaborative of Southern California [TLUCSC], 2005, p. iv).

- Healthy food vendors are well dispersed throughout the Oceano community

- Affordability, rather than accessibility was identified as a greater issue among residents

- Studies have indicated that large chain supermarkets are inequitably distributed, with fewer types of these stores per capita in lower income communities when compared to higher income communities (Raimi + Associates \& TLUCSC, 2005, p. iv)

- A study conducted in Atlanta suggests fewer healthy food sources are within walking distance in low-income communities than higher-income communities (Glanz, Sallis, Saelens, \& Frank, 2007)

- Many residents go outside of town to access the large chain supermarkets that offer a wider variety of food options and affordable prices than what is found in the smaller markets in Oceano

Lack of food access and healthy food options were not regularly mentioned by the community. This is likely due to the availability of food outlets (three markets and various produce stands) that serve fresh fruits and vegetables in the community. However, affordability was stated to be an issue by key informants. The produce available at the markets in town were said to be affordable, but many other food items (not specified) were said to be overpriced, which leads to people traveling out of Oceano to larger chain supermarkets in Santa Maria and Grover Beach. Research findings indicate the availability of large chain supermarkets in low-income Hispanic neighborhoods is less 
than that which is found in predominantly White or Black neighborhoods (Powell et al., 2007, p. 190).

A large chain supermarket is not likely feasible for a community like Oceano. However, community design that provides safe and easy pedestrian, bike and transit options to healthy food sources, as well as land use decisions which allow opportunities for increasing healthy food vendors, resulting in a competitive pricing environment which can benefit a community's overall nutritional health.

\section{Community Design, Land Use and the Built Environment}

Growing research has demonstrated a strong correlation between the built environment and its effect on public health. In contrast to less-dense, sprawled out communities, community design that provides a mix of compact residential, retail and commercial development, which places an emphasis on walking and bicycling to perform routine daily tasks are associated with raised physical activity levels, decreasing the likelihood of being obese (Lopez, 2004, p. 1577-1578). The designated use, layout, and design of a community's physical structures and environment affect active living behaviors, which influences health outcomes (Aboleta, 2004)

- Oceano children desire an increase in the availability of accessible park and recreation facilities

- Oceano's current sidewalk network is insufficient, incomplete and poorly maintained, placing pedestrians at risk in residential and commercial areas

- Residents believe improved or additional bicycle lanes could improve quality of life in Oceano.

- Mixed use developments that offer a mix of neighborhood accessible retail, restaurants, grocery stores, civic use, open spaces and employment 
opportunities have been shown to be catalysts for active living behaviors and improved health outcomes (Raimi + Associates \& TLUCSC, 2005, p. iv)

Survey results indicate the community prioritizes improved bicycle and sidewalk infrastructure as a need. The need for additional park and recreation facilities were also mentioned consistently in survey responses and dialogue with community members. Though the Oceano Community Center (OCC) serves the area as an indoor recreation facility, it was mentioned by interviewees, survey respondents and anecdotally in conversation as being cost prohibitive to use for events. Additionally, some residents felt the OCC lacked diverse activity options (offering only a basketball court) and didn't do enough to reach out to the community in terms of providing activities or classes.

Opportunities should be explored to see if partnerships could be created between the Lucia Mar School District (in charge of running the OCC) and local public and private health entities to provide free, regularly scheduled health education and cessation classes at the facility. Of primary concern is the lack of available medical health care facilities in Oceano. The San Luis Obispo Planning and Building Department planners along with the Oceano Advisory Council can partner to develop creative ordinances and permitting that can help recruit medical care providers into the community.

\section{Perceptions of Safety and Security}

Multiple research findings have indicated feelings related to personal safety and security were behavioral motivators which help determine whether community residents will be physically active (Minnesota Department of Health, 2012, p. 23). The perceived threat of violence or crime in certain neighborhoods and overall communities can impact decisions to walk for leisure, exercise or even necessity, such as those who walk to work or to a transit stop to travel to work (Jackson \& Sinclair, 2012, p. 134). 
- Oceano sixth graders identified specific areas in Oceano where they didn't feel safe and avoided

- Gangs were mentioned by both Oceano children and adults as a community issue

- The desire for street illumination at night was mentioned prevalently during outreach activities

- Research has indicated crime rates are influenced by building design and land uses (Baer \& Rattray, 2007, p. 4)

- Crime Prevention Through Environmental Design (CPTED) principles can help create a safer environment

Street lights were identified regularly as a need, as the lack of illumination in residential areas in Oceano provoked feelings of fear and safety (lack of) at sundown. Illuminating dark residential and commercial areas are one of the CPTED strategies that can help deter criminal behavior through environmental design. Its strategies are based on the ability to influence decisions that precede criminal acts. For example, pedestrian scaledlighting, large commercial and residential windows and low landscaping features provide clear sightlines for casual surveillance of on the streets, providing a less inconspicuous environment and opportunity for criminal behavior. CPTED principles should be incorporated into design guidelines for Oceano, or at the very least, policies should encourage the use of these principles in future development proposals. Two primary barriers to health care access are not having health insurance coverage and not have a usual source of care. 


\section{Access to Health Care}

The health of a population is influenced by a number of factors, including social, economic and environmental circumstances. The availability and proximity of health care facilities, as well as overall quality of service also act as barriers to health care services, in addition the degree of acculturation, English proficiency, and immigration status all impact access to care (Tienda \& Mitchell, 2006, p. 410). Recent immigrants are more likely to be unfamiliar and confused with U.S. health care system, which can interfere with receiving appropriate and timely care (Wells, Golding, Hough, Burnam, and Karno, 1989). The inability to speak and understand English proficiently can reduce the ability to understand essential health care information and instruction by a provider, as well as

preventative health care and awareness information in a predominantly English speaking country (Tienda \& Mitchell, 2006, p. 412). Finally, legal residency status affects eligibility for Medicare or Medicaid insurance.

- According to the 2008-2012 American Community Survey 5-Year estimates, 76.8 percent of Oceano's population are not U.S. citizens

- 28.7 percent of the total civilian non-institutionalized population uninsured; 38.5 percent of Hispanic or Latino residents are uninsured

- $\quad 32.6$ percent of the population speak Spanish; 14.1 percent speak English less than "very well"

- With the Oceano Community Health Center on Cienga Street closing its doors, the community is now without any primary or ambulatory health care facility within its borders 
- "Two key barriers to health care access are not having health insurance coverage and not having a usual source of care" (Tienda \& Mitchell, 2006, p. 412) 


\section{NEXT STEPS}

This project culminates with two separate Draft Community Health Plans, one each for the communities of Oceano and Cayucos in San Luis Obispo County. In order for the plan to reach the project goal to improve community health, raise awareness of the links between the built environment and health, and introduce the conceptual ideas behind the future adoption of a Countywide Health element, the following additional steps may be taken:

- Present the Plan to the County Health Commission.

- Present each plan to the perspective Citizen Advisory Councils. This will help to bring attention to the information provided and raise awareness about key local issues.

- Review goals, policies, and action programs to ensure their feasibility and to gauge community support. Plan elements that are not feasible in the foreseeable future or contrary to community support should be eliminated.

- Disseminate the plan to other organizations, agencies and individuals to build community support around the plan. Make the plan publicly available online on the HEALSLO website.

- Engage in an effort to implement parts of the plans. Engage with the communities of Oceano and Cayucos to prioritize and determine the feasibility of Action Programs listed in the plan, seek funding for projects, and work with the Healthy Communities Workgroup, the Health Commission, Cal Poly, and citizen groups to implement a positive physical change to the built environment or guiding policy change to raise awareness and build excitement about the nexus between planning and public health. 


\section{REFERENCES}

Aboelata, M. J. (2004). The Built Environment and Health: 11 Profiles of Neighborhood Transformation. Prevention Institute. Retrieved from http://www.preventioninstitute.org/index.php?option=com_jlibrary\&view=article\&i $\mathrm{d}=114 \&$ Itemid $=127$

ACTION for Healthy Communities. 2013. Community Foundation San Luis Obispo. Accessed November 14, 2013 at http://www.sloccf.org/community_needs.php.

American Institute of Stress. (2011). Effects of Stress. Retrieved from http://www.stress.org/topic-effects.htm

Air Pollution Control District, San Luis Obispo County (APCD). (2012). 2012-2017 Strategic Plan Update. Retrieved from http://www.slocleanair.org/images/cms/upload/files/B-1.pdf.

Annual Air Quality Report. (2012). San Luis Obispo Air Pollution Control Board (APCD). Accessed at: http://www.slocleanair.org/images/cms/upload/files/2012aqrtFINAL.pdf.

Binder, S. Injuries among older adults: the challenge of optimizing safety and minimizing unintended consequences. Injury Prevention 2002; 8 (Suppl IV): iv2iv4.Accessed April 27, 2014 at http://injuryprevention.bmj.com.ezproxy.lib.calpoly.edu/content/8/suppl_4/iv2.full. $\mathrm{pdf}+\mathrm{html}$

Bell ML, M. A. Ozone and short-term mortality in 95 us urban communities, 1987-2000. (2010). JAMA 292, 2372-2378. 
Bridging the Gap Research. (2012). Income disparities in street features that encourage walking. BTG Research Brief. 1-4. Retrieved from http://www.bridgingthegapresearch.org/_asset/02fpi3/btg_street_walkability_FIN AL_03-09-12.pdf

Brownson, R. C., Baker, E. A., Housemann, R. A., Brennan, L. K., \& Bacak, S. J. (2001). Environmental and Policy Determinants of Physical Activity in the United States. American Journal of Public Health. 91 (12),1995-2003.doi:

10.2105/AJPH.91.12.1995

California Department of Education. (2013). Physical Fitness Testing (PFT). Accessed April 29, 2014 at: http://www.cde.ca.gov/ta/tg/pf/

California Conference of Local Health Officers and County Health Executives Associates of California (2013). Chronic disease prevention framework. 3-4. Retrieved from http://www.cdph.ca.gov/programs/cclho/Documents/ChronicDiseaseReportFINAL .pdf

California Department of Education. (2013). Physical Fitness Testing (PFT). Accessed April 29, 2014 at: http://www.cde.ca.gov/ta/tg/pf/

California Highway Patrol. (2014). Statewide Integrated Traffic Records System Records Request, May 29, 2014.

Cao, X., Handy, S.L., \& Mokhtarian, P.L. (2006). The influences of built environment and residential self-selection on pedestrian behavior: evidence from Austin, TX. Transportation. (33), 1-20. Retrieved from http://escholarship.org/uc/item/4jn1w8qn\#page-2

Casagrande, S., et. Al. (2011). Association of Walkability With Obesity in Baltimore City, Maryland. December; 2011 101(Suppl 1): S318-S324 
Cayucos Elementary, Elementary. California Healthy Kids Survey, 2009-10: Main Report. (2010). San Francisco: WestEd Health and Human Development Program for the California Department of Education.

Cayucos Elementary, Secondary. California Healthy Kids Survey, 2011-12: Main Report. (2012). San Francisco: WestEd Health \& Human Development Program for the California Department of Education

Centers for Disease Control and Prevention, National Center for Injury Prevention and Control. 2013. Injuries and Violence are Leading Causes of Death: Key Data \& Statistics. Accessed February 20, 2014 at http://www.cdc.gov/injury/overview/data.html.

Centers for Disease Control and Prevention. Motor Vehicle Traffic-Related Pedestrian Deaths - United States, 2001-2010. MMWR 2013; 62: 277-282. Accessed February 22, 2014 at http://www.cdc.gov/mmwr/pdf/wk/mm6215.pdf.

Centers for Disease Control and Prevention. (n.d.). Behavioral Risk Factor Surveillance System, Sortable Risk Factors and Health Indicator: California 2011http://wwwn.cdc.gov/sortablestats/

Clark RM, Rizzo GS, Belknap JA, Cochranes C. (1999). Water quality and the replacement and repair of drinking water infrastructure: the Washington, DC case study. J Water SRT - Aqua 48(3):106-114.

Community Foundation San Luis Obispo. Accessed November 14, 2013 at: http://www.sloccf.org/community_needs.php.

County Health Status Profiles. (2011). California Department of Health Services and California Conference of Local Health Officers, 2003-2011. Accessed February 
24,2014 at

http://www.cdph.ca.gov/data/statistics/Pages/DeathProfilesbyZIPCode.aspx.

Corburn, J. (2009). Toward the Healthy City: People, Places, and the Politics of Urban Planning. Cambridge, Mass.: MIT Press.

County of San Luis Obispo. (date). County of San Luis Obispo General Plan. Retrieved from http://www.slocounty.ca.gov/planning/General_Plan_Ordinances_and_Element s.htm

County of San Luis Obispo, Estero Area Plan. (2009). Retrieved from http://www.slocounty.ca.gov/Assets/PL/Area+Plans/Estero+Area+Plan.pdf

County of San Luis Obispo, San Luis Bay Coastal Area Plan. (1988). Retrieved from http://www.slocounty.ca.gov/Assets/PL/Area+Plans/San+Luis+Bay+Coastal+Are a+Plan.pdf

County of San Luis Obispo, Oceano Specific Plan (2002). Retrieved from http://www.slocounty.ca.gov/Assets/PL/Specific+Plans/Oceano+Specific+Plan.pd f

County of San Luis Obispo, Oceano Revitalization Plan (2013). Retrieved from http://www.slocounty.ca.gov/Assets/PL/Draft+Plans/OceanoRevit.pdf

Craun GF. (1992). Waterborne disease outbreaks in the United States of America: Causes and prevention. Word Health Statistics Quarterly 45:192-99.

Crimmins, E. M., Hayward, M. D., \& Seeman, T. E. (2004). Race/ethnicity, socioeconomic status, and health. Critical perspectives on racial and ethnic differences in health in late life, 310-352. Retrieved from http://www.ncbi.nlm.nih.gov/books/NBK25526/ 
Curriero FC, Patz JA, Rose JB, Lele SD. (2001). The association between extreme precipitation and waterborne disease outbreaks in the United States, 1948-1994. Am J Public Health 91:1194-1199.

Dannenberg, A. L., Frumkin, H., \& Jackson, R. J. (2011). Making healthy places: Designing and building for health, well-being, and sustainability. Washington, DC: Island Press.

Downey, L. (2007). US metropolitan-area variation in environmental inequality outcomes. Urban Studies. 44(5-6), 953-977. DOI: 10.1080/00420980701256013

Feng, J., Glass, T. A., Curriero, F. C., Stewart, W. F., \& Schwartz, B. S. (2010). The built environment and obesity: A systemic review of the epidemiologic evidence. Health \& Place. 16 (2), 175-190. DOI: 10.1016/j.healthplace.2009.09.008

Furst, Tony. 2012. Memorandum Promoting the Implementation of Proven Safety Countermeasures. January 12, 2012. US Department of Transportation, Federal Highway Administration. Accessed February 21, 2014 at http://safety.fhwa.dot.gov/provencountermeasures/pc_memo.htm)

Gannon JJ, Busse MK. (1989). E. coli and enterococci levels in urban stormwater, river water and chlorinated treatment plant effluent. Water Res 23:1167-1176.

Glanz, K., Sallis, J. F., Saelens, B. E., \& Frank, L. D. (2007). Nutrition environment measures survey in stores (NEM-S): development and evaluation. American Journal of Preventative Medicine. (32) 4, 282-289. Retrieved from http://www.ncbi.nlm.nih.gov/pubmed/17383559

Godbey, G., (2009). Outdoor recreation, health, and wellness: Understanding and enhancing the relationship. Resources For the Future. 9 (21), Retrieved from http://www.rff.org/documents/RFF-DP-09-21.pdf 
Goodman, A. B., Blanck, H. M., Sherry, B., Park, S., Nebeling, L., Yaroch, A. L. (2007). Behaviors and attitudes associated with low drinking water intake among U.S. adults, food attitudes and behaviors survey, 2007. Preventing Chronic Disease Public Health Research, Practice, and Policy. 10, 1-10. Retrieved from http://www.cdc.gov/pcd/issues/2013/pdf/12_0248.pdf

Gordon-Larsen,P.,Nelson, M. C., Page, P.,\&Popkin, B. M.(2006). Inequality in the built environment underlies key health disparities in physical activity and obesity.Pediatrics.117(2), 417-424. DOI: 10.1542/peds.2005-0058

Gullone, E. 2000. The biophilia hypothesis and life in the 21st century: Increasing mental health or increasing pathology? Journal of Happiness Studies 1, 293-321.

Halonen, J. I. et al. (2010). Ozone and cause-specific cardiorespiratory morbidity and mortality. J Epidemiol Community Health 64, 814-820.

Hess, P. M., Moudon, A. V., Snyder, M. C., \&Stanilov, K. (1999). Site design and pedestrian travel. Transportation Research Record. 1674, 9-19. Retrieved from http://faculty.washington.edu/moudon/writing\%20docs/sitedesign.pdf

Hodgson, K. (2012, June 18). Food Access: The Missing Sustainability Planning Topic? [Weblog entry]. Retrieved from: http://blogs.planning.org/sustainability/2012/06/18/food-access-the-missingsustainability-planning-topic/

Hodgson, K., (2009). Where food planning and health intersect. Journal of the American Planning Association, August/September 9-13.

Humpel, N., Owen, N., Leslie, E. (2002). Environmental factors associated with adults' participation in physical activity: a review. American Journal of Preventative 
Medicine. (22), 188-199. Retrieved from

http://www.ncbi.nlm.nih.gov/pubmed/11897464

Johns Hopkins Center for a Livable Future, (2010). Food distribution and transport, background reading. Retrieved from: http://www.jhsph.edu/research/centers-andinstitutes/teaching-the-food-system/curriculum/distribution_and_transport.html

Kawachi, I., Subramanian, S., and Kim, D. (2008). Social capital and health. New York: Springer.

Kushner, N. (2013). Quenching community thirst: Planning for more access to drinking water in public places. American Planning Association. 1-23. Retrieved from: https://www.planning.org/research/publichealth/pdf/wateraccessreport.pdf

Lee, C., Moudon, A. V. (2004). Physical activity and environment research in the health field: implications for urban and transportation planning practice and research. Journal of Planning Literature. (19), 147-181. Retrieved from http://hmcrc.srph.tamhsc.edu/Literature/PhysicalActivity/PAEnvironmentResearc h.pdf

Lerner, J. (2010, April 28). How urban planning can improve public health. Pacific Standard. Retrieved from http://www.psmag.com/navigation/health-andbehavior/how-urban-planning-can-improve-public-health-11408/

Levin RB, Epstein PR, Ford TE, Harrington W, Olson E, \& Reichard, EG. (2002). US Drinking water challenges in the twenty-first century. Environmental Health Perspectives 110(S 1):43-52.

Litman, T. A. (2014). Economic Value of Walkability. Victoria Transport Policy Institute. Retrieved from http://www.vtpi.org/walkability.pdf 
Lopez, R., (2004). Urban sprawl and risk for being overweight or obese. American Journal of Public Health. (94) 9, 1574-1579. Retrieved from http://www.ncbi.nlm.nih.gov/pmc/articles/PMC1448496/

Lovasi, G. S., Hutson, M. A., Guerra, M., \& Neckerman, K. M. (2009). Built environment and obesity in disadvantaged populations. Epidemiologic Reviews. 31, 7-20. DOI: 10.1093/epirev/mxp005

Lucia Mar Unified Elementary. California Healthy Kids Survey, 2009-10: Main Report. (2010). San Francisco: WestEd Health and Human Development Program for the California Department of Education.

Maller, C., Townsend, M., Pryor, A., Brown, P., \& St Leger, L. (2005). Healthy nature healthy people: 'contact with nature' as an upstream health promotion intervention for populations. Health Promotion International. 21 (1), 45-54. doi: doi:10.1093/heapro/dai032

Maller, C., Townsend, M., St Leger, L., Henderson-Wilson, C., Pryor, A., Prosser, P., \& Moore, M. (2009). Healthy parks, healthy people: The health benefits of contact with nature in a park context. The George Wright Forum.26 (2), 51-83. Retrieved from http://www.georgewright.org/262maller.pdf

Mass, J., Verheij, R. A., Spreeuwenberg, P., \& de Vries, S. (2006). Green space, urbanity, and health: how strong is the relation? Journal of Epidemiology \& Community Health. 60, 587-592. doi: 10.1136/jech.2005.043125

Mokdad, A. H., Marks, J. S., Stroup, D. F., \&Gerberding, J. L. (2004). Actual causes of death in the United States, 2000. Journal of the American Medical Association, 291 (10), 1238-1245. Retrieved from www.csdp.org/research/1238.pdf 
Moore, L. V., Diez Roux, A.V. (2006) Associations of neighborhood characteristics with the location and type of food stores. Am J Public Health. 96(2), 325-331. doi: 10.2105/AJPH.2004.058040

National Center for Chronic Disease Prevention and Health Promotion (2013). A practitioner's guide for advancing health equity: Community strategies for preventing chronic disease. Retrieved from http://www.cdc.gov/nccdphp/dch/pdf/HealthEquityGuide.pdf

New York City (NYC) Global Partners. (2011). Best Practice: Demonstrating Air Quality and Climate Change Impacts on Public Health. Accessed June 2, 2014 at http://www.nyc.gov/html/unccp/gprb/downloads/pdf/Toronto_Environment_AirQu ality.pdf.

Noguera, P. (1995). Reducing and Preventing Youth Violence: An Analysis of Causes and an Assessment of Successful Programs, Harvard Education Review.

Northridge, M. E., \& Freeman, L. (2011). Urban planning and health equity. Journal of Urban Health, Vol. 88 (3), 582-597. DOI: 10.1007/s11524-011-9558-5

Payment P, Richardson L, Siemiatycki J, Dewar R, Edwardes M, \& Franco E. (1991). A randomized trial to evaluate the risk of gastrointestinal disease due to consumption of drinking water meeting current microbial standards. American Journal of Public Health 81:703-708.

Physical Activity Guidelines Advisory Committee. (2008). Physical activity guidelines advisory committee report, 2008. Washington, DC: US Department of Health and Human Services, 2008, E22-E35. Retrieved from http://www.health.gov/paguidelines/report/pdf/committeereport.pdf 
Peters, A., Dockery, D. W., Muller, J. E. \& Mittleman, M. A. (2001). Increased Particulate Air Pollution and the Triggering of Myocardial Infarction. Circulation 103, 28102815.

Pothukuchi, K., and Kaufman, J. (1999). Placing food issues on the community agenda: The role of municipal institutes in food system planning. Agriculture and Human Values 16:213-24.

Pothukuchi, K. , \& Kaufman, J. (2000). The food system - a stranger to the planning field. Journal of the American Planning Association, 66(2), 113-124.

_ 2000. The food system. Progressive Planning. 2004. Special issue: food and planning. No. 158 (Winter).

Powell, L. M., Slater, S., Mirtcheva, D., Bao, Y., \&Chaloupka, F.J. (2007) Food store availability and neighborhood characteristics in the United States. Prev Med. 44(3), 189-195. Retrieved from http://www.healthydurham.org/docs/file/committees/obesity_chronic_care/Grocst ore.pdf

Ricklin, A., et al. 2012. Healthy Planning: an evaluation of comprehensive and sustainability plans addressing public health. Chicago: American Planning Association. Retrieved from http://www.planning.org/research/publichealth/pdf/evaluationreport.pdf.

Roszak, T., M.E. Gomes, and A.D. Kanner, eds. 1995. Ecopsychology: Restoring the Earth, Healing the Mind. San Francisco: Sierra Club Books.

Saelens, B. E., Handy, S. L. (2008). Built environment correlates of walking: a review. Med Sci Sports Exerc. 2008; (11), 550-566. DOI: 10.1249/MSS.0b013e31817c67a4. 
Saelens, B. E., Sallis, J.F., \& Frank, L.D. (2003). Environmental correlates of walking and cycling: findings from the transportation, urban design, and planning literatures. Annals of Behavioral Medicine.(25), 80-91.

Safe Routes to School Infrastructure Inventory. (2013). Retrieved from https://library.slocog.org/PDFS/Rideshare/SRTS_InfrastructureMaps/SRTS\%20I nfrastructure\%20Inventory\%20Results\%20by\%20School\%20\%20Tier\%201/Tier\%201\%20-

\%20Barriers,\%20Obesity,\%20TIMS,\%20Speed\%20and\%20Vehicle\%20Count\% 20Data/SRTSII_Tier_1_ObesityData.pdf

Sallis, J. F., Millstein, R. A., \& Carlson, J. A. (2011). Community design for physical activity. In A. L. Dannenberg, H. Frumkin, \& R. J. Jackson (Eds.), Making healthy places: Designing and building for health, well-being, and sustainability (pp. 3349). Washington, DC: Island Press.

San Luis Obispo Air Pollution Control Board (APCD). (2012). Annual Air Quality Report. Accessed at: http://www.slocleanair.org/images/cms/upload/files/2012aqrtFINAL.pdf.

San Luis Obispo Air Pollution Control Board (APCD). (2013) South County Community Monitoring Project. Accessed at http://slocleanair.org/images/cms/upload/files/Final\%20Report.pdf.

San Luis Obispo County Parks, Parks Projects. (2002). Retrieved from http://www.slocountyparks.com/information/parkprojects.htm

Sherer, P. M., (2006). The benefits of parks: Why America needs more city parks and open space. San Francisco: The Trust for Public Land. 
Space Matters: Planning, designing, building and maintaining for community wellbeing. New Zealand Injury Prevention Strategy. Accessed on April 26, 2014 at: http://nzips.govt.nz/documents/public_and_play_spaces\%20for\%20pdf\%20V5(2) .pdf.

Stokols, D. (1992). Establishing and maintaining healthy environments: Toward a social ecology of health promotion. American Psychologist, 47(1), 6-22.

Sullivan, W. C., \& Chang, C. (2011). Mental health and the built environment. In A. L. Dannenberg, H. Frumkin, \& R. J. Jackson (Eds.), Making healthy places: Designing and building for health, well-being, and sustainability (pp. 106-116). Washington, DC: Island Press.

Tienda, M., \& Mitchell, F. (Eds.). (2006). Hispanics and the Future of America. National Academies Press. Retrieved from http://books.google.com/books?hl=en\&lr=\&id=uCm_5E8Dx6AC\&oi=fnd\&pg=PA1 $\& d q=$ Hispanics + and + the + Future + of + America.\&ots=SxnuQDkShQ\&sig=wySmy5 T8dZF0mIQzPlb9ipbrO5E\#v=onepage\&q=Hispanics\%20and\%20the\%20Future $\% 20$ of\%20America. $\& \mathrm{f}=$ false

Transportation Research Board, Institute of Medicine of the National Academies. Committee on Physical Activity, Health, Transportation, and Land Use. (2005). Does the built environment influence physical activity: Examining the evidence. (TRB Special Report 282). Retrieved from http://onlinepubs.trb.org/onlinepubs/sr/sr282.pdf

U.S. Census Bureau. (2012). ACS 2012 5-year, Cayucos, CA CDP. Retrieved January 25, 2014, from http://censusreporter.org/profiles/16000US0612132-cayucos-ca/. 
U.S. Census Bureau. (2012). ACS 2012 5-year, Oceano, CA CDP. Retrieved January 25, 2014, http://censusreporter.org/profiles/16000US0653294-oceano-ca/.

United States Environmental Protection Agency (EPA). (1994). Long Island Sound Study. Summary of the Comprehensive Conservation and Management Plan. Stamford, CT: US EPA. Report EPA-842-S-94-001.

United States Environmental Protection Agency (EPA). 2012. Six common air pollutants. Accessed February 22, 2014 at ttp://www.epa.gov/airquality/particlepollution/health.html.

United States Environmental Protection Agency (EPA). (2012). Stormwater Management Best Practices. Accessed June 2, 2014 at http://www.epa.gov/oaintrnt/stormwater/best_practices.htm.

United States Environmental Protection Agency (EPA). (2014). Ways to Reduce Air Pollution. Accessed June 2, 2014 at http://www.epa.gov/air/caa/peg/reduce.html

U.S. Department of Health and Human Services. (1996). Physical Activity and Health: A Report of the Surgeon General. Atlanta, GA: U.S. Department of Health and Human Services, Centers for Disease Control and Prevention, National Center for Chronic Disease Prevention and Health Promotion, 1-300. Retrieved from http://www.cdc.gov/nccdphp/sgr/pdf/sgrfull.pdf

Vasey, D. (1992). An ecological history of agriculture : 10,000 B.C.-A.D. 10,000. Ames: lowa State University Press.

Wells, K. B., Golding, J. M., Hough, R. L., Burnam, M. A., \& Karno, M. (1989). Acculturation and the probability of use of health services by Mexican Americans. Health Services Research, 24(2), 237. Retrieved from file://C:/Users/Phillip/Downloads/hsresearch00084-0100.pdf 


\section{APPENDIX A: PHYSICAL INVENTORY}

\section{A. Physical Inventory}
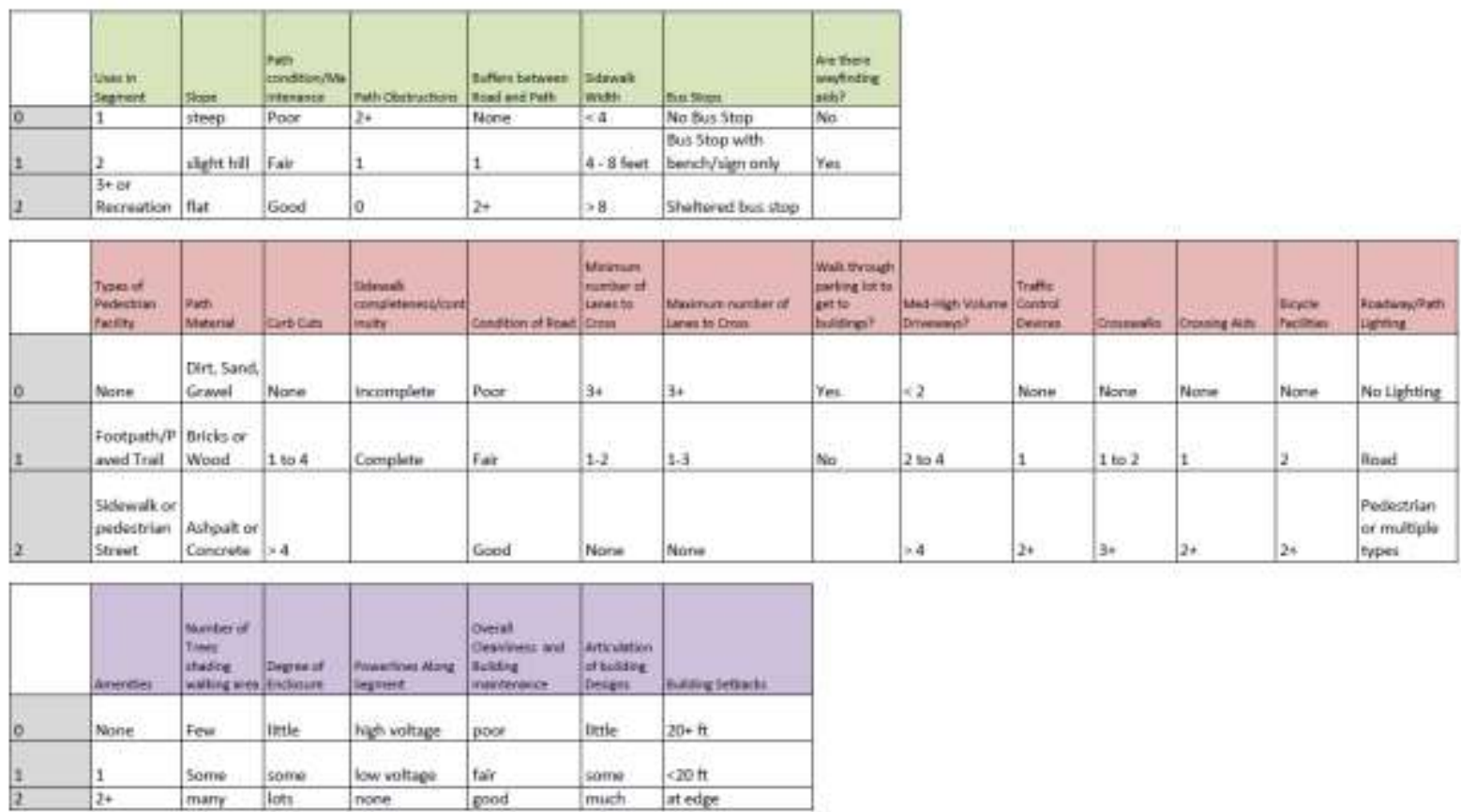
APPENDIX B: CASE STUDY ANALYSIS

\section{B. Case Study Analysis}

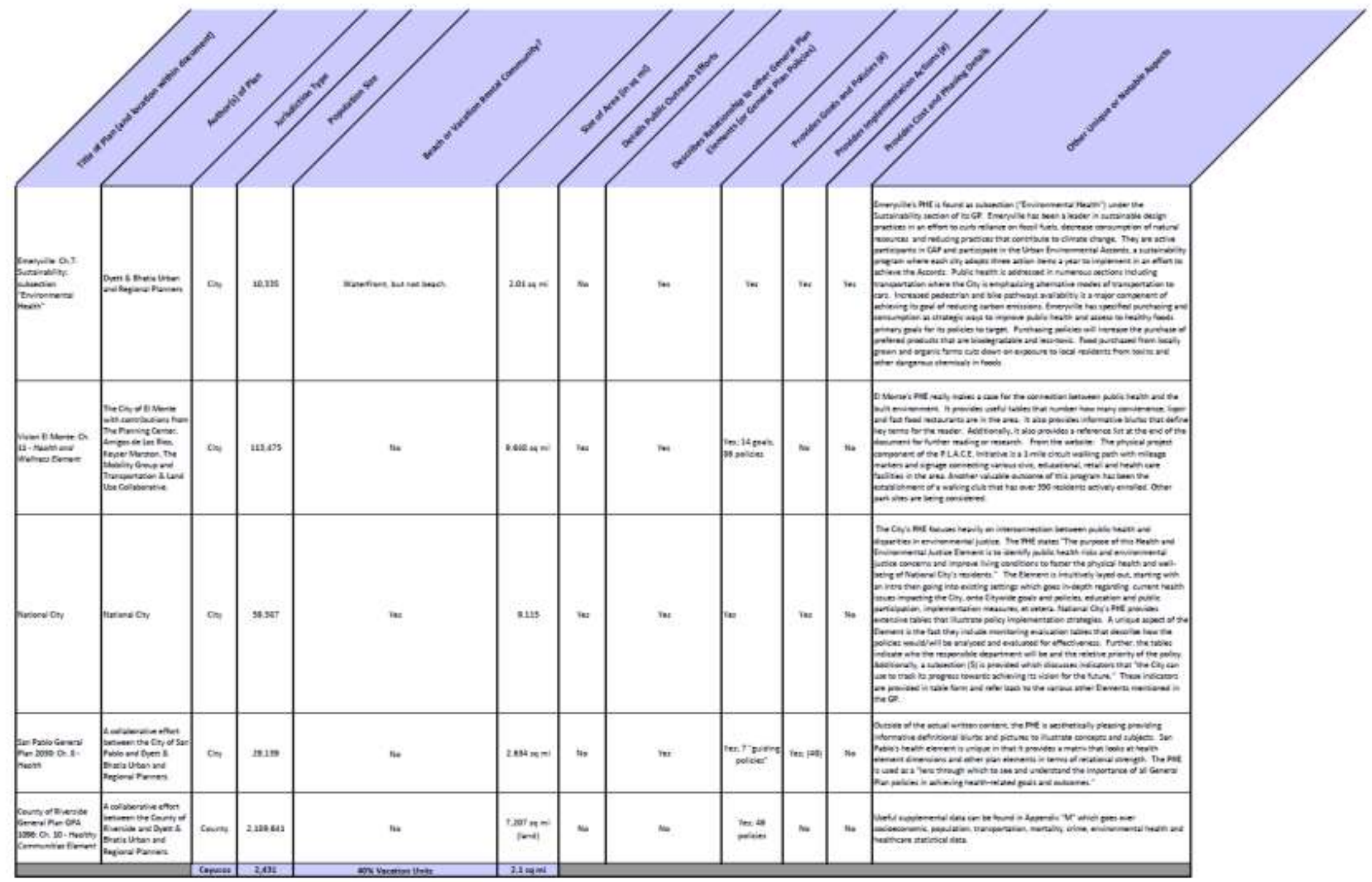


APPENDIX C: OUTREACH MATERIALS

\section{Outreach Materials}

\section{Cayucos Healthy Community Questionnaire}

Date

Location

This survey is being offered to residents of Cayucos to find out more about the health-related needs of residents. This survey is voluntary and anonymous. You may choose to stop answering questions at any time.

1. Generally speaking, what contributes most to your quality of life in Cayucos?

2. What do you think makes it most difficult to be healthy or detracts from overall wellness here?

3. What do you think are the most important factors for improving the quality of life in a community? Check $(\boldsymbol{V})$ all that apply AND circle three you consider the most important.

Good place to raise children

_ Low crime / safe neighborhoods

_ Good schools

_ Access to health care (e.g., family doctor)

Parks and recreation

Clean environment
_ Affordable housing

_ Arts and cultural events

_ Good jobs and healthy economy

Healthy behaviors and lifestyles

_ Low death and disease rates

Other

4. What do you think are the most important problems with the greatest impact on community health in Cayucos? Check $(\mathbb{})$ all that apply AND circle the three you consider the most important.

__ Aging problems (arthritis, hearing/vision loss)

Cancers

_ Child abuse / neglect

_ Dental problems

Diabetes

_ Obesity

__ Domestic Violence
Heart disease and stroke

Infectious Diseases (e.g., hepatitis, TB)

Mental health problems

_ Motor vehicle crash injuries

Respiratory / lung disease

Drug/alcohol abuse

Other

5. How would you rate your own personal health? Choose one.
- Very unhealthy
- Somewhat healthy
- Very healthy
- Unhealthy
- Healthy

6. What should change in Cayucos that could contribute to your personal health or the health of the community as a whole?

7. What community features, if any, could contribute to the health and quality of life in Cayucos? Check $(\boldsymbol{V})$ all that apply AND circle the three you consider the most important.

_ Additional or improved bike lanes

_ Opportunities for community involvement

_ Improved access to healthcare

_ Additional or improved parks

_ Improved environmental quality

_ Transit options

8. Do you have any other comments or suggestions?
Better availability of healthy food Additional or improved sidewalks Safer neighborhoods

_ Water fountains/hydration station access Other 


\section{APPENDIX C: OUTREACH MATERIALS}

\section{Cayucos Healthy Community Questionnaire}

Demographic Information (participants may want to fill this out themselves)

Sex: $\quad M_{-} F_{-}$

How would you describe your ethnicity?

Age:
- $18-29$
- $50-59$
- $30-39$
- $60-69$
- $40-49$
- $70-79$

- 80 and older

- Decline to state

What is your total annual household income? (Select one.)

- Less than $\$ 14,999$

- Between $\$ 15,000-\$ 44,999$

- Between $\$ 45,000-\$ 74,999$

- More than $\$ 75,000$

How many people (including yourself) are in your household? 


\section{APPENDIX C: OUTREACH MATERIALS}

Cayucos Community Health Plan ISan Luis Obispo County Public Health I Health Promotion Division | 4/15/2014

\section{Cayucos Community Health Plan}

Thank you for the opportunity to meet with the Lioness Club about community health in Cayucos! We are very interested in learning the opinions of active community members.

\section{What is this project about?}

- One of the Health Agency goals is to improve the state of "social and root determinants" of health. These are factors that influence health but have less to do with genetics and more to do with the environment in which we live.

- The built environment affects health through providing opportunities for:
- physical activity
- social interaction
- access to healthy food
- minimizing the risk of injury

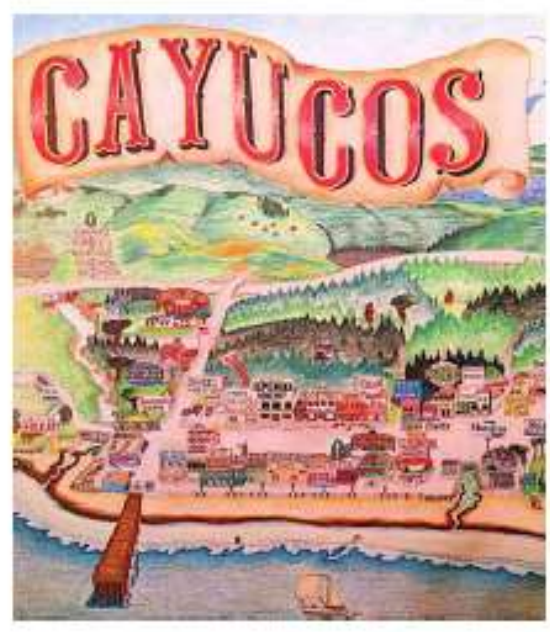

- Today the leading causes of death are chronic, preventable conditions.

- A physical environment that promotes health is an integral part of making our communities healthier. Elements of a healthy community include:
- healthy food access
- safe neighborhoods
- sustainable and safe transportation
- parks, recreation, and community facilities
o healthy economy
- environmental health
- medical access

\section{Who is doing the work?}

- Jennifer Franich, City and Regional Planning Master's student at Cal Poly, with the help of other students and public health staff.

- This project is a collaborative effort between San Luis Obispo Health Agency, HEAL-SLO, and Cal Poly, San Luis Obispo.

Why am I at the Lionesses?

- The document will seek to address health in planning at the small community level.

- A very important part of this effort is community outreach, and we are seeking input from community groups.

Thank you for taking the time to answer questions and discuss these topics. The information you have provided will be used to develop options for helping to make Cayucos a healthier place. 


\section{APPENDIX C: OUTREACH MATERIALS}

Cayucos Community Health Plan |San Luis Obispo County Public Health | Health Promotion Division | 4/8/2014

\section{Cayucos Community Health Plan}

Thank you for the opportunity to meet with the PTA about community health in Cayucos! We are very interested in learning the opinions of families and educators in the community.

What is this project about?

- One of the Health Agency goals is to improve the state of "social and root determinants" of health. These are factors that influence health but have less to do with genetics and more to do with the environment in which we live.

- The built environment affects health through providing opportunities for:

- physical activity

- social interaction

- access to healthy food

- minimizing the risk of injury

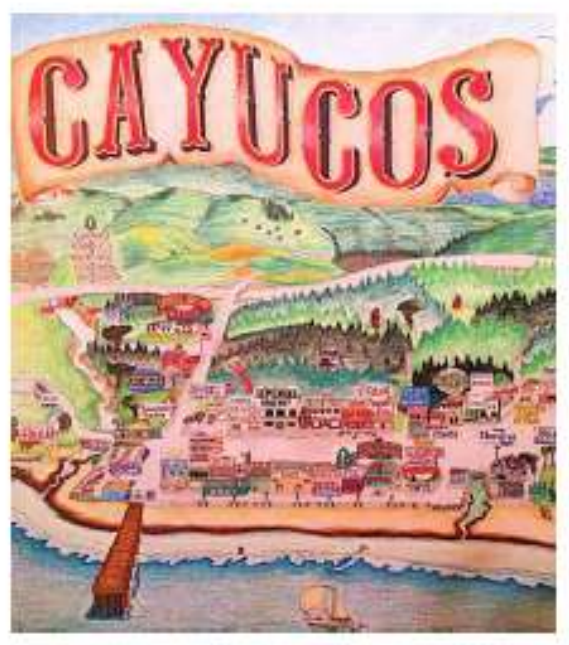

- Today the leading causes of death are chronic, preventable conditions.

- A physical environment that promotes health is an integral part of making our communities healthier. Elements of a healthy community include:

- healthy food access

- safe neighborhoods

- sustainable and safe transportation

- parks, recreation, and community facilities

- healthy economy

- environmental health

- medical access

Who is doing the work?

- Jennifer Franich, City and Regional Planning Master's student at Cal Poly, with the help of other students and public health staff.

- This project is a collaborative effort between San Luis Obispo Health Agency, HEAL-SLO, and Cal Poly, San Luis Obispo.

\section{Why am I at the PTA?}

- The document will seek to address health in planning at the small community level.

- A very important part of this effort is community outreach, and we are seeking input from community groups.

Thank you for taking the time to answer questions and discuss these topics. The information you have provided will be used to develop options for helping to make Cayucos a healthier place. 


\section{APPENDIX C: OUTREACH MATERIALS}

\section{Cayucos Community Health Plan}

Thank you for the opportunity to meet with the Rotary Club about community health in Cayucos! We are very interested in learning the opinions of active community members.

What is this proiect about?

- One of the Health Agency goals is to improve the state of "social and root determinants" of health. These are factors that influence health but have less to do with genetics and more to do with the environment in which we live.

- The built environment affects health through providing opportunities for:

- physical activity

- social interaction

- access to healthy food

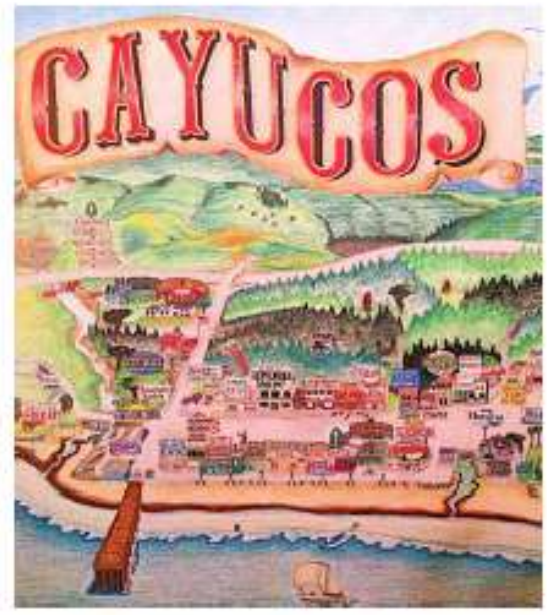

- minimizing the risk of injury

- Today the leading causes of death are chronic, preventable conditions.

- A physical environment that promotes health is an integral part of making our communities healthier. Elements of a healthy community include:

- healthy food access

- safe neighborhoods

- sustainable and safe transportation

- parks, recreation, and community facilities

- healthy economy

- environmental health

- medical access

Who is doing the work?

- Jennifer Franich, City and Regional Planning Master's student at Cal Poly, with the help of other students and public health staff.

- This project is a collaborative effort between San Luis Obispo Health Agency, HEAL-SLO, and Cal Poly, San Luis Obispo.

\section{Why am I at Rotary?}

- The document will seek to address health in planning at the small community level.

- A very important part of this effort is community outreach, and we are seeking input from community groups.

Thank you for taking the time to answer questions and discuss these topics. The information you have provided will be used to develop options for helping to make Cayucos a healthier place. 


\section{APPENDIX C: OUTREACH MATERIALS}

\section{Key Informant Interview Questions}

Name
Organization
Date Completed

Title/Position

Topics: Main health concerns, biggest barriers to preventing or addressing health issues, vulnerable populations (children, seniors), existing programs and services, ideas for new programs, services, and partnerships.

\section{Introduction}

I'm [name] from the Public Health Department and Cal Poly City and Regional Planning. We are working on a project to [strengthen community involvement to improve health access in our town/county]. An important first step in our effort is to better understand health needs in [Oceano/Cayucos]. To do that, we are conducting interviews with key community leaders.

The themes that emerge from the interviews will be used to inform the final community health plan. While we will use the themes from the interviews, the interviews themselves will be strictly confidential. If you agree, we would list the names of all the people we interview.

Your knowledge would be very valuable and we hope you could make yourself available for in interview. The interview will only take 25-30 minutes. Could we schedule a time to time to meet?

\section{Questions:}

1. In your experience, or based on your work with the organization, what would you say are the top 3 or 4 most important health issues in [Cayucos/Oceano]

Probe: Do you think obesity is a problem? Childhood obesity?

2. Are the health issues you mentioned priorities for your organization, or are there any programs in your organization that are related to these issues?

3. How would you describe the overall health of the Oceano/Cayucos community?

Probe: Are there any health issues that seem to be impacting particular groups (children, teenagers, elderly, etc.)? Are there certain neighborhoods or geographic areas that have unmet needs related to active living?

4. Would you consider Oceano/Cayucos a physically active (walking, jogging, biking, swimming, etc.) community?

If Yes:

a) What types of physical activity do you see people participating in?

b) Are there specific concentration points for physical activity (i.e. community center, outdoor basketball/tennis courts, etc.)?

If $\mathrm{No}$ : 


\section{APPENDIX C: OUTREACH MATERIALS}

a) What do you believe is hindering (physical, political, cultural barriers)

Oceano/Cayucos residents from being more active?

Examples:

- Absence or inaccessibility of walkways, trails, bike paths.

- Absence or inaccessibility of recreation centers and/or playgrounds.

- Lack of organized sports activities

5. Do you think that food is accessible, available, and affordable in the community?

Probe:

a) Explain how it is or is not.

b) Are there differences among different groups in the community?

c) Are there certain neighborhoods or geographic areas that have unmet needs related to healthy eating?

6. Do you believe there are barriers to enacting policies and creating community support related to active living and healthy eating?

If Yes:

a) Who do they represent? (and how representative are they?)

b) Why do you think they oppose active living policies?

c) Do you think this individual/group is knowledgeable about active living issues?

d) In your view, is this individual/group trustworthy?

7. Do you know of any specific "champion" or "champions" for health in the community? Probe:

a) Who do they represent?

b) What is their interest in supporting active living policies?

c) Do you think this individual/group is knowledgeable about active living issues?

d) In your view, is this individual/group trustworthy?

8. Do you think local government funds should be spent to support health policy actions?

Do you have any other comments that you would like to add?

THANK YOU for taking the time to participate in this interview. 


\section{APPENDIX C: OUTREACH MATERIALS}

Cayucos Questionnaire Packet |CRP 470 | Healthy Communities

$2 / 14 / 2014$

\section{Cayucos Community Health Plan}

Thank you for agreeing to help gather information about community health in Cayucos! Contact info: Jennifer's Number: 253-906-3122, Kelly's Number: 310-633-3008

Questionnaire Locations Map

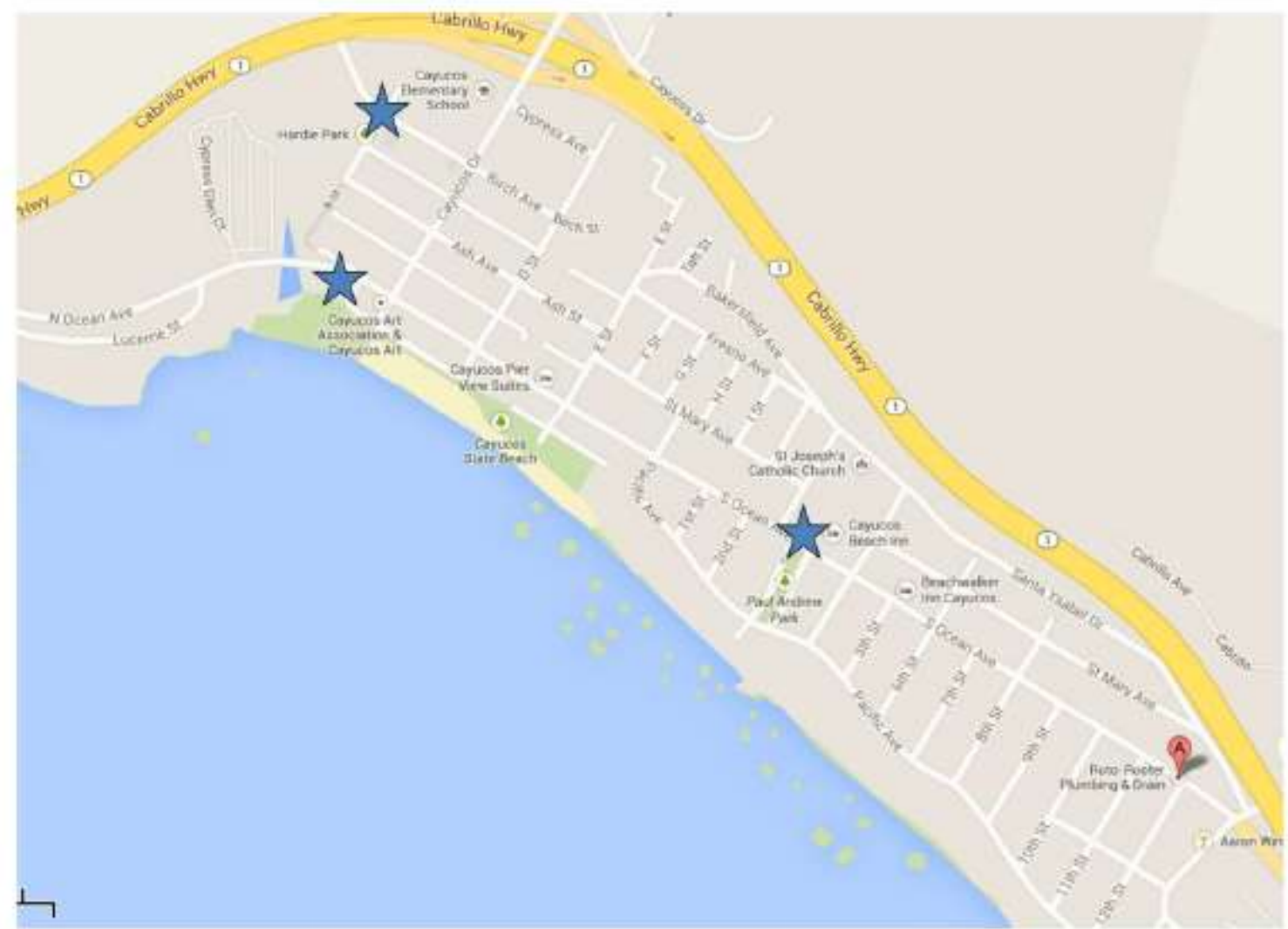

\section{Project Info (for your reference, in case someone you talk to has questions)}

- A collaborative effort between San Luis Obispo Health Agency, Health Promotion, and Cal Poly.

- A professional project that satisfies the culminating experience requirement for a Masters student.

- The built environment affects health through providing opportunities for physical activity, social interaction, and access to healthy food, and minimizing the risk for injury.

- Many jurisdictions in California have conducted similar efforts, though none have attempted it with a community as small as Cayucos, or with an unincorporated community.

- These efforts use the existing framework of the general plan, and as such this project will incorporate characteristics of a health element.

- Another similar project is being conducted simultaneously in Oceano. 


\section{APPENDIX C: OUTREACH MATERIALS}

Cayucos Questionnaire Packet |CRP 470 | Healthy Communities $2 / 14 / 2014$

\section{SCRIPT FOR QUESTIONNAIRE}

STEP 1 -Greeting

Good afternoon! Do you have a few minutes to answer some questions about your community?

STEP 2 - Introduce Yourself

We are Cal Poly Students, and we are collecting questionnaires to find out what people think about the quality of life and health in Cayucos.

STEP 3 - Filtering

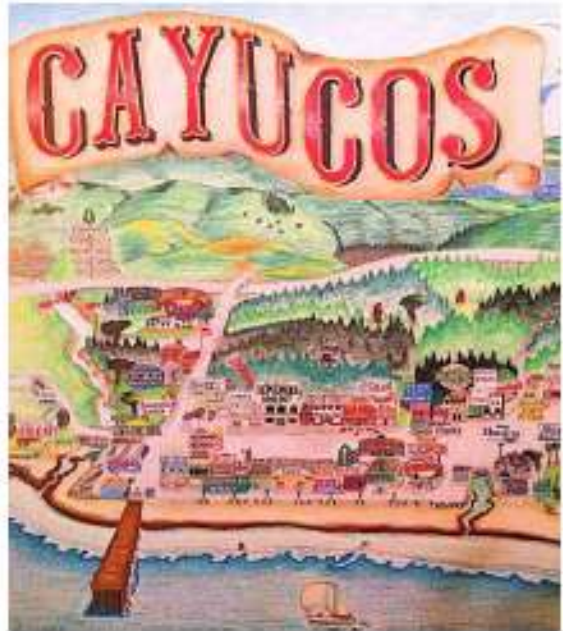

Are you 18 or older? (If no, let them know that while you value their input, we can't legally include them in the questionnaire pool.) Do you live in Cayucos, or are you visiting? (If they are visiting, we don't want to include the results. but if they live, work, or have family in town, we are interested in that.)

STEP 4 - Disclaimer

This survey should take only 2-3 minutes. The answers will be kept anonymous, and you can stop at any time or choose not to answer any question.

STEP 5 - Ask questionnaire questions.

Note all responses, and include notes if they happen to give you more information than you are directly asking for. It might be very helpful information!

STEP 8 - Thank participants.

Thank you for taking the time to talk to me. The information you have provided will be used to develop options for helping to make Cayucos a healthier place. 
APPENDIX C: OUTREACH MATERIALS

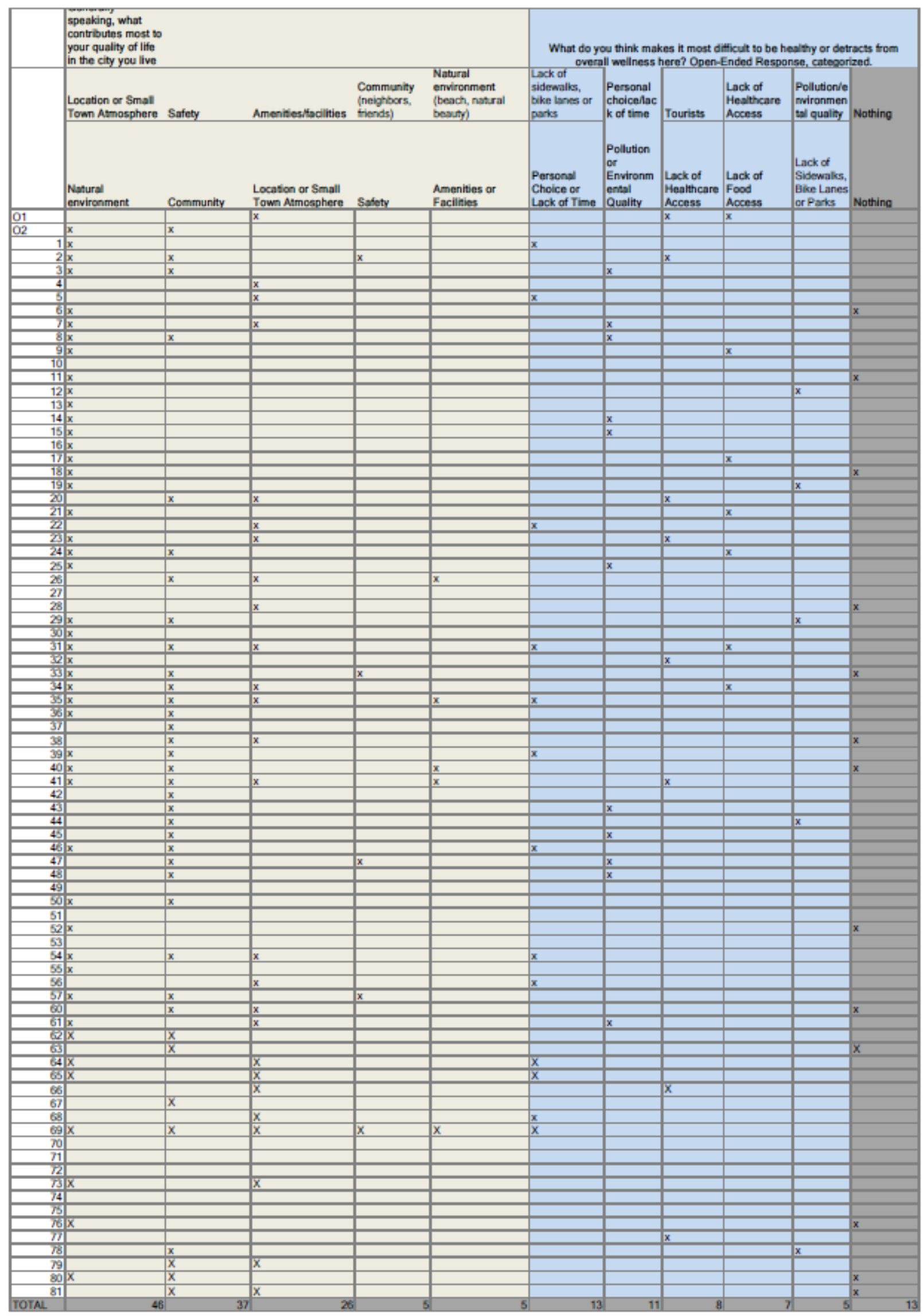


APPENDIX C: OUTREACH MATERIALS

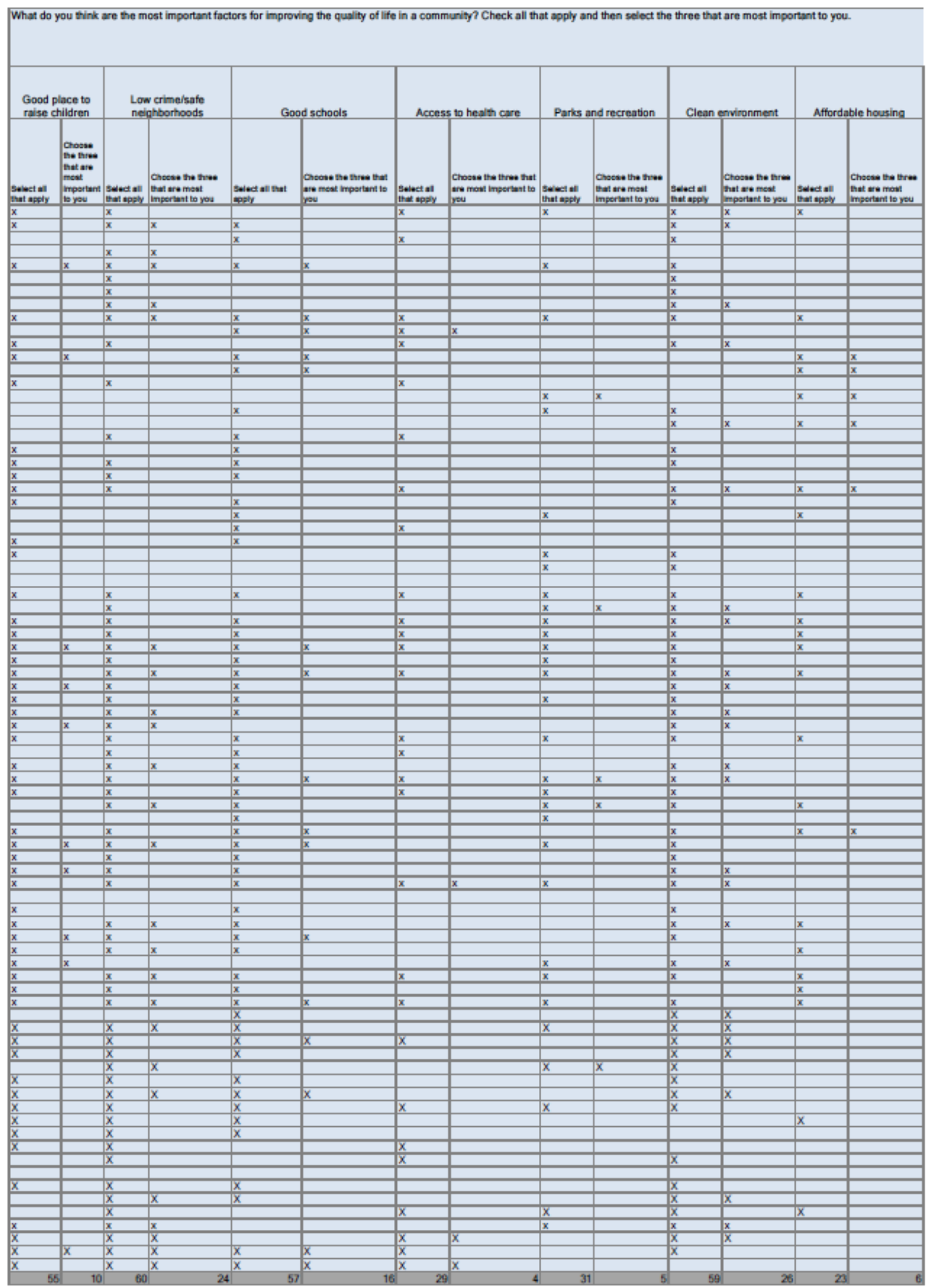


APPENDIX C: OUTREACH MATERIALS

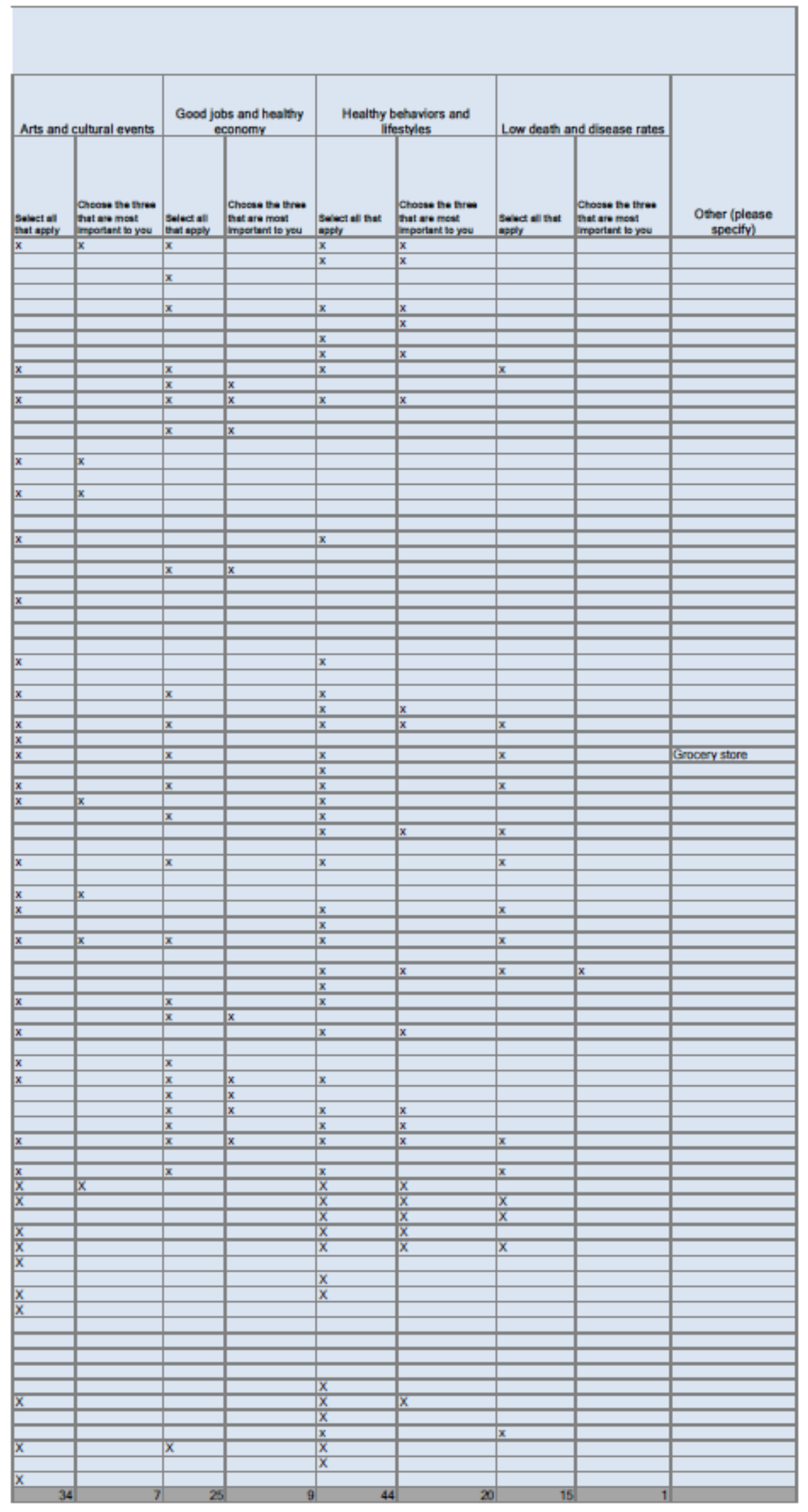


APPENDIX C: OUTREACH MATERIALS

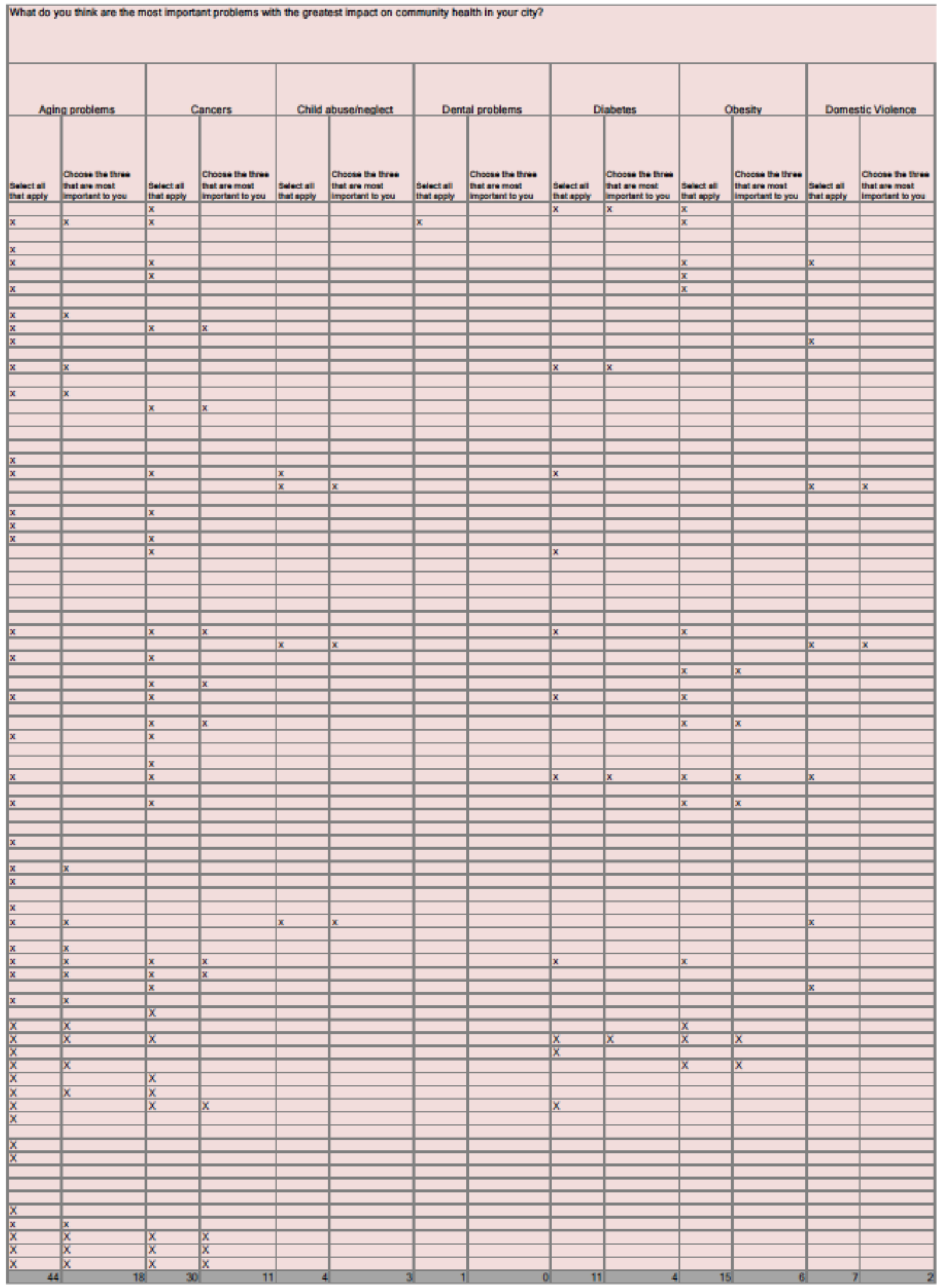


APPENDIX C: OUTREACH MATERIALS

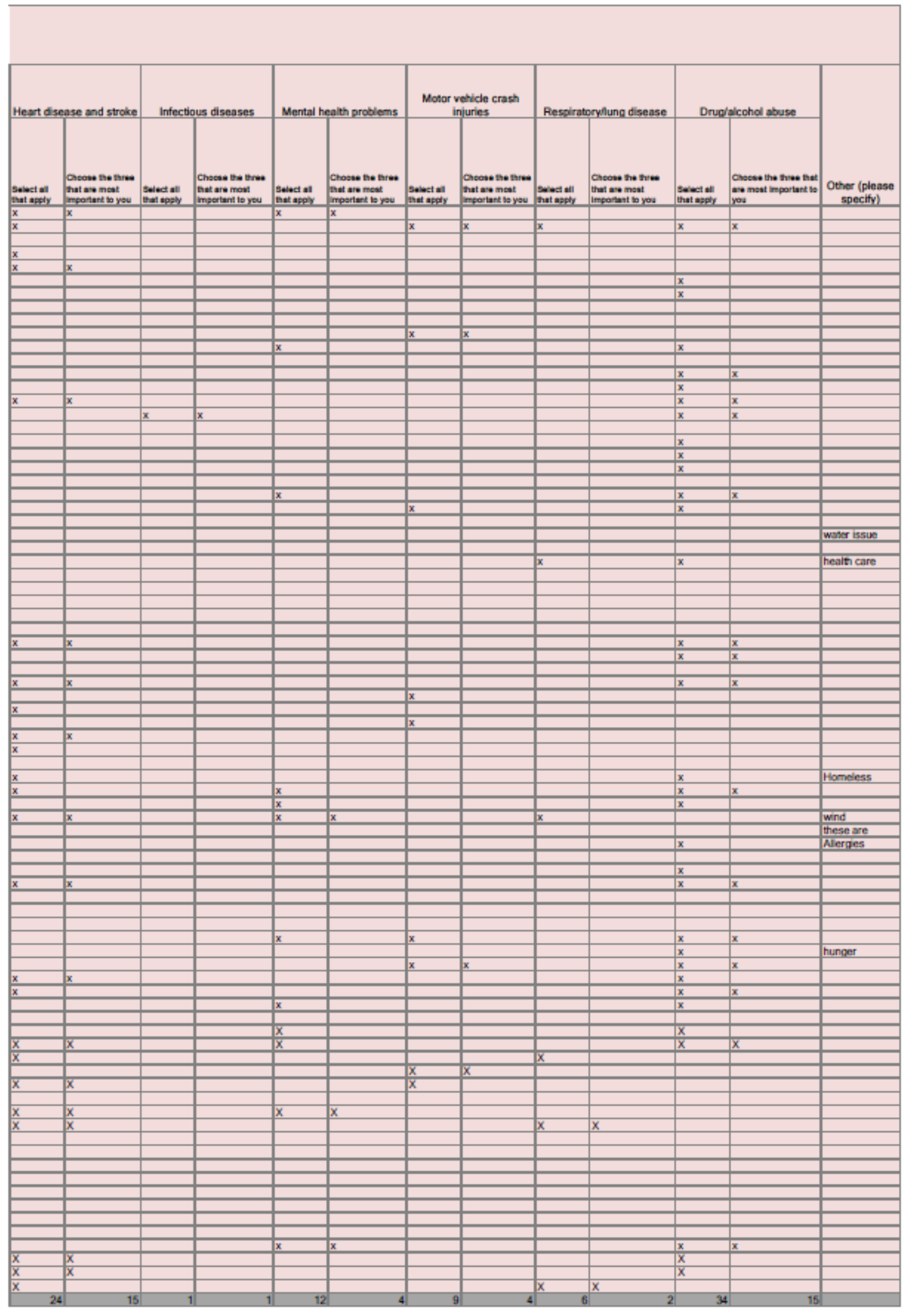


APPENDIX C: OUTREACH MATERIALS

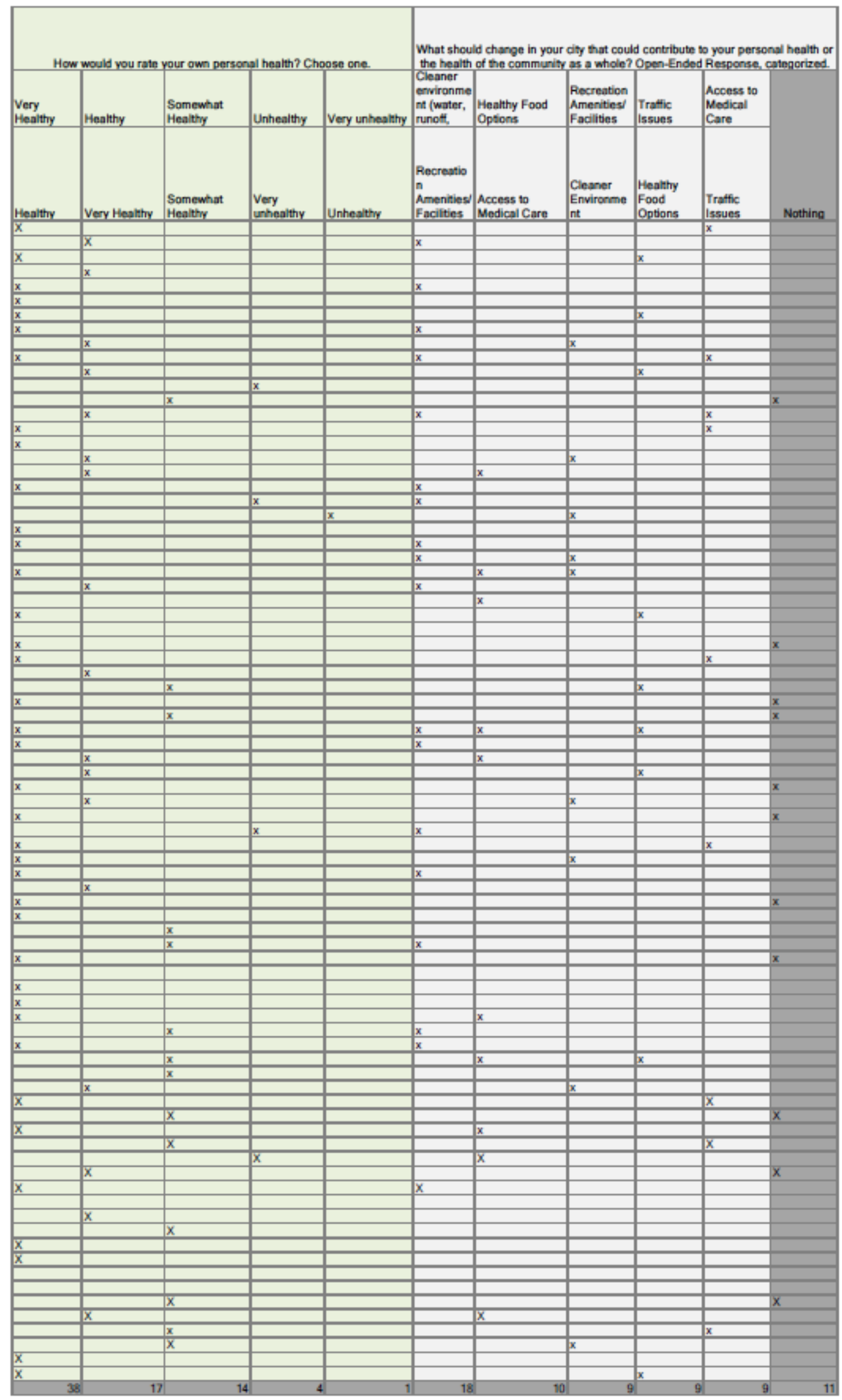


APPENDIX C: OUTREACH MATERIALS

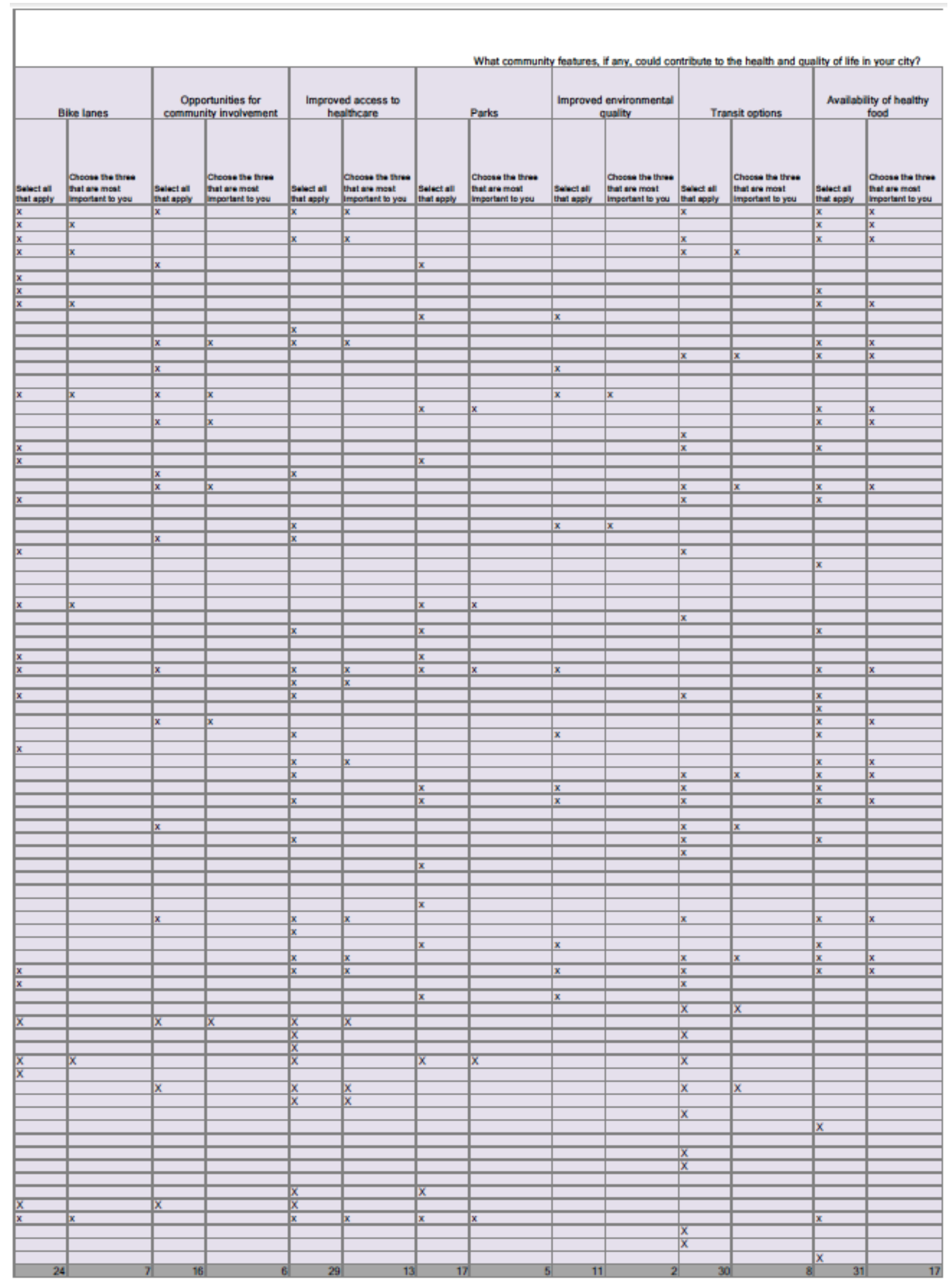


APPENDIX C: OUTREACH MATERIALS

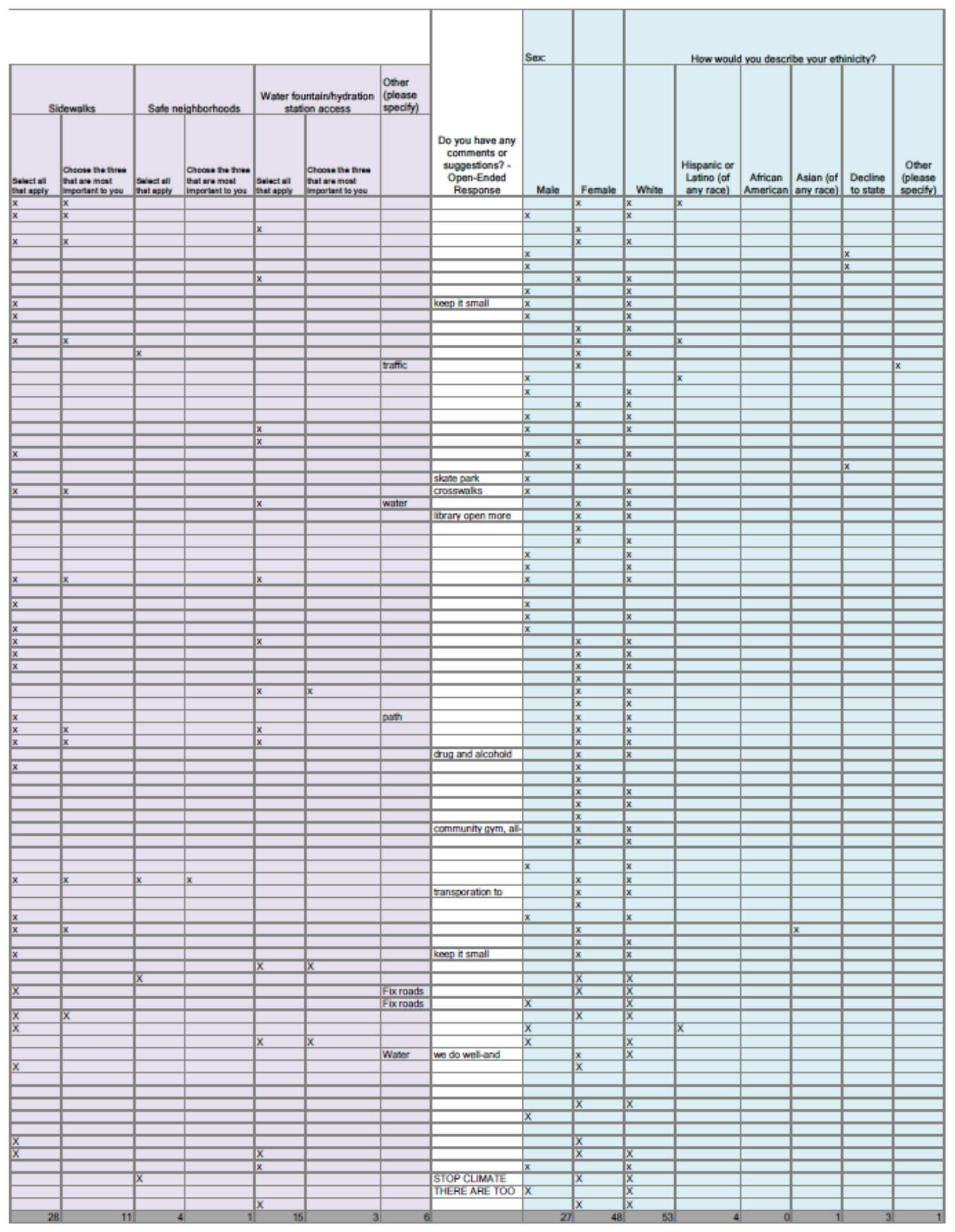


APPENDIX C: OUTREACH MATERIALS

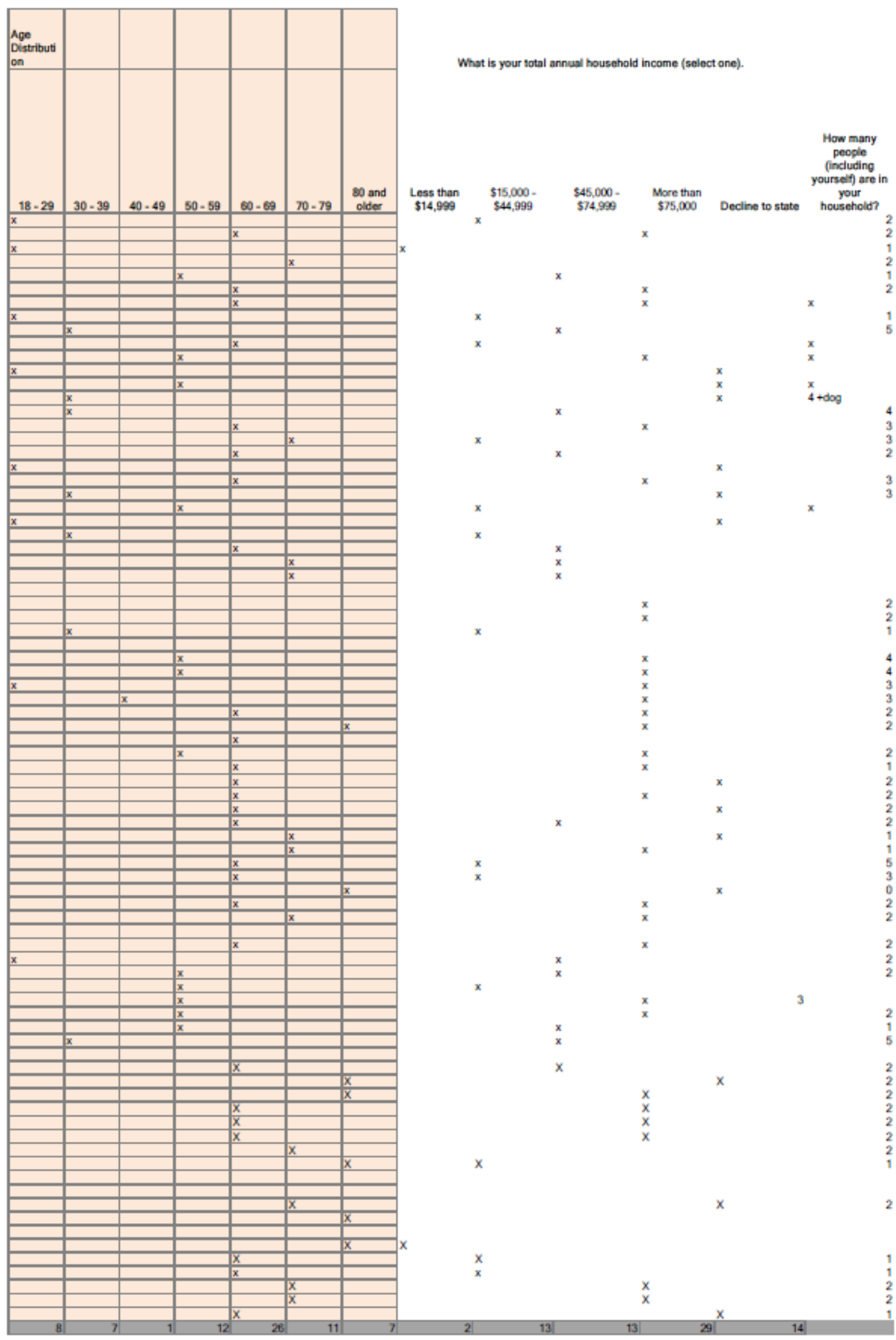



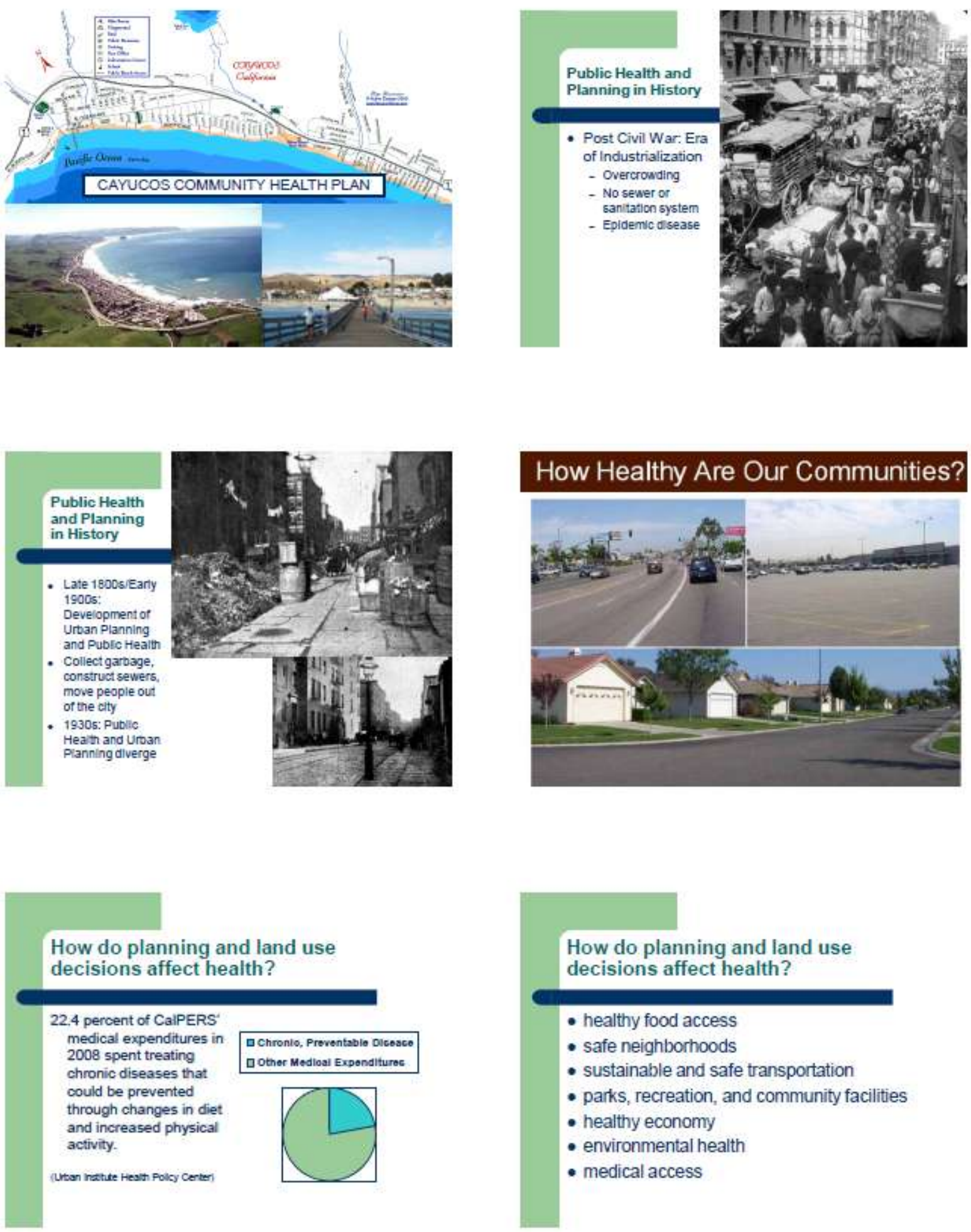

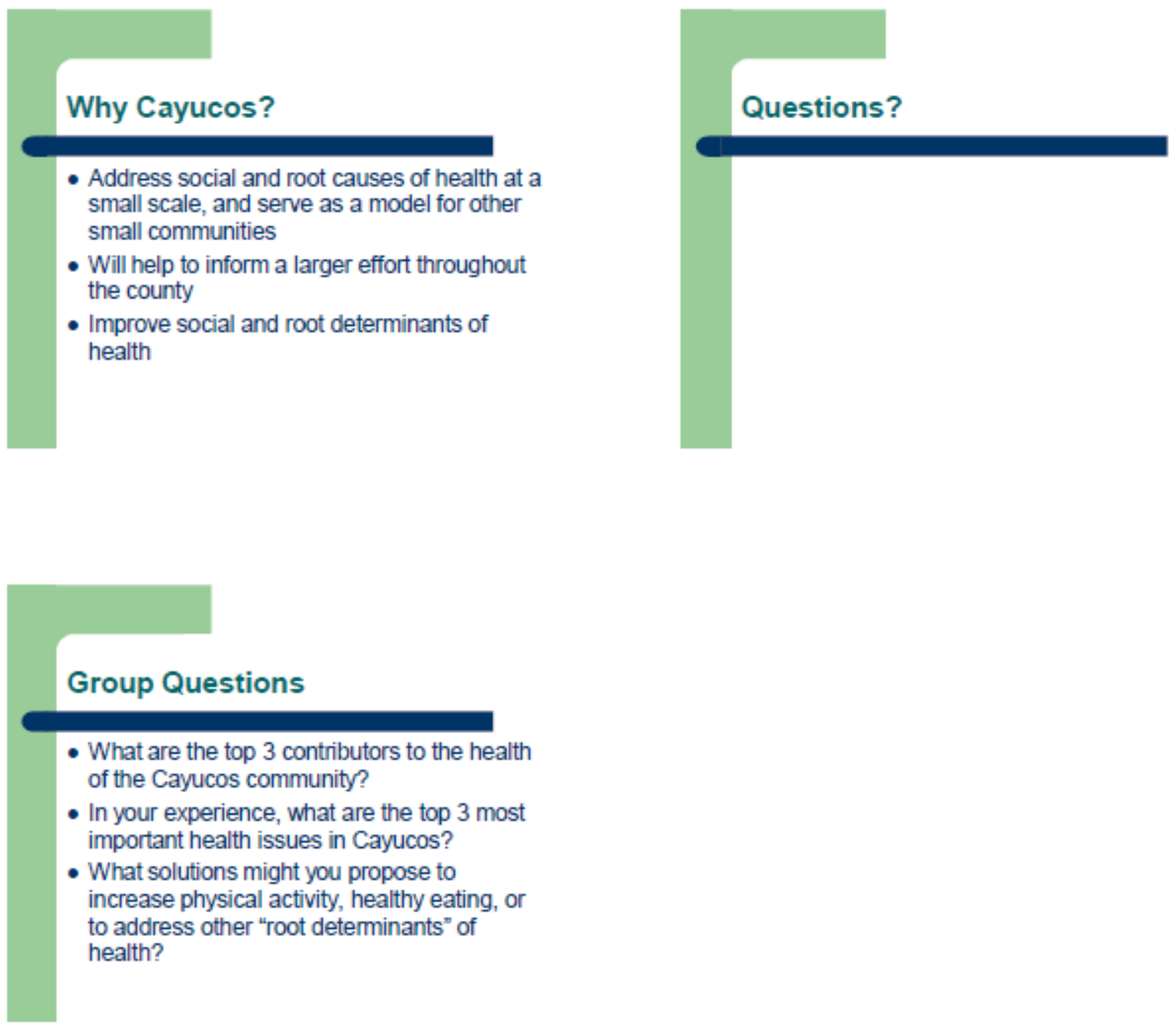
D. Cayucos Community Health Plan 


\section{4}

\section{CAYUCOS COMMUNITY HEALTH PLAN}

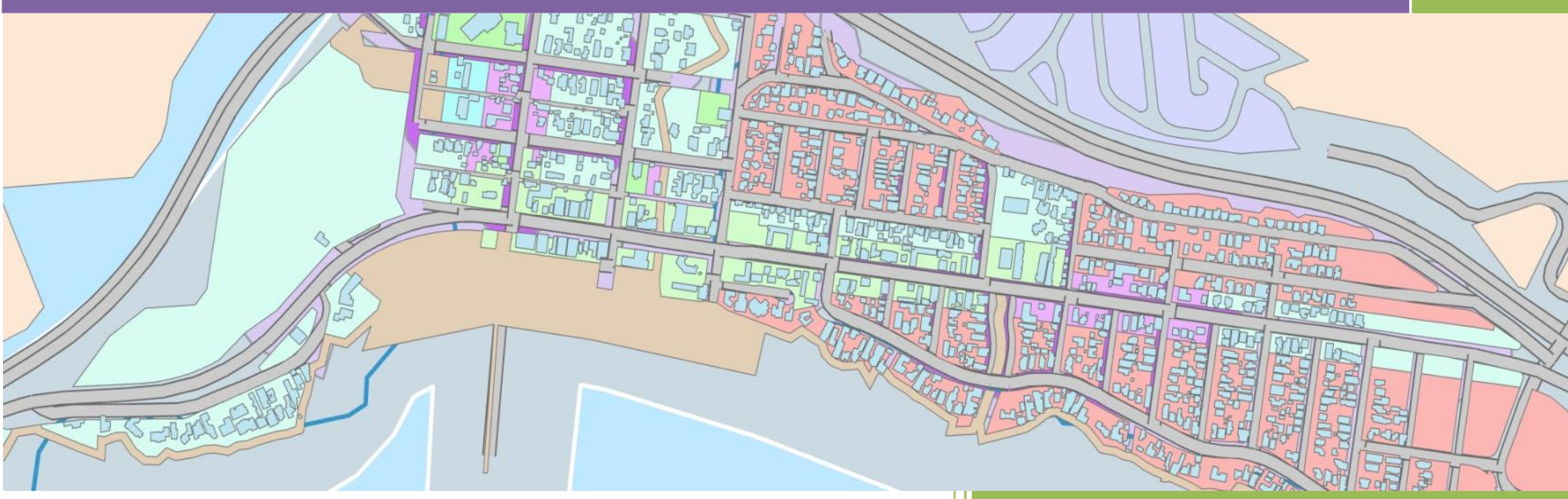

San Luis Obispo County Health Agency Health Promotion DRAFT | June 2014 


\section{ACKNOWLEDGMENTS}

This plan was designed and authored by Jennifer Franich, Masters Student in City and Regional Planning at Cal Poly, in partial fulfillment of a Master of City and Regional Planning degree at California Polytechnic State University, San Luis Obispo. She also served as the graduate planning intern at the Health Promotion Division of the San Luis Obispo County Health Agency. Phillip Brennan, also a graduate intern, assisted with the crafting of the plan. The project with developed under the direction of Professor Kelly D. Main, PhD. Professor Kelly Main chaired the professional project committee, which also included Kathleen Karle, Director of Health Promotion at the San Luis Obispo County Health Agency, and Chuck Stevenson, lecturer at Cal Poly in City and Regional Planning and former Planning Director for the County of San Luis Obispo.

Development of the Cayucos Community Health Plan involved many individuals, including Cayucos Citizen Advisory Council Members, Health Agency representatives, and faculty and students at Cal Poly. All of these efforts are greatly appreciated.

\section{Healthy Communities Workgroup}

Karen Aydelott

Ellen Carroll

Geoffrey Chiapella

Kenta Ishii

Kathleen Karle

Kelly D. Main

Sachi Oshima

Jim Patterson

Chuck Stevenson

Stephanie Teaford

Janice Fong Wolf

\section{Partners}

HEAL SLO

SLO County Health Commission SLO County Health Department SLO County Planning and Building 


\section{TABLE OF CONTENTS}

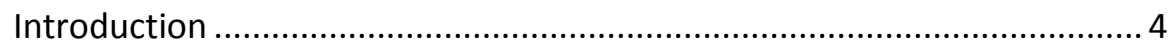

Community Health Goals ................................................................... 7

Health and the Built Environment: A Historical Perspective ....................... 8

Relationship to Other Planning Documents .......................................... 10

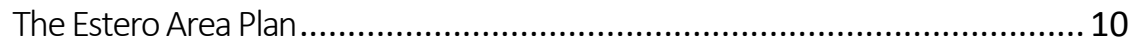

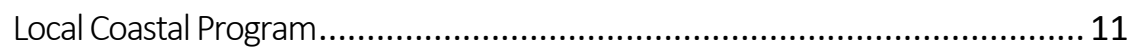

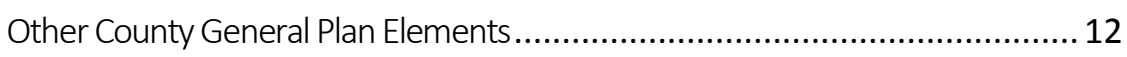

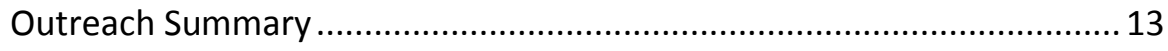

Health \& Wellness Context ................................................................... 14

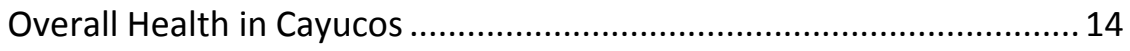

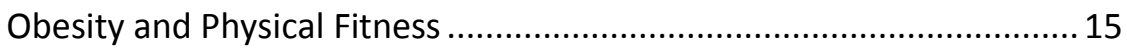

Parks, Recreation, and Open Spaces.................................................. 16

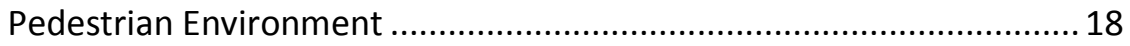

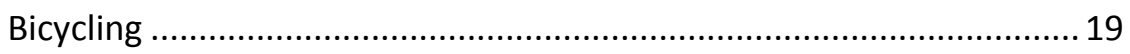

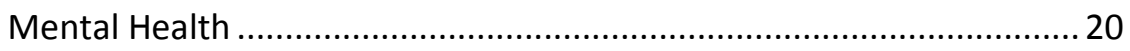

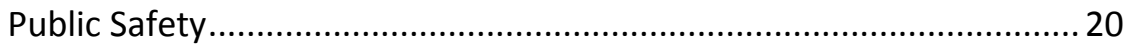

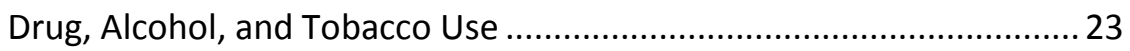

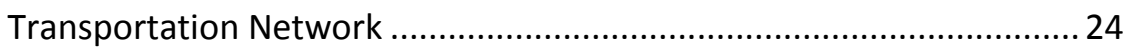

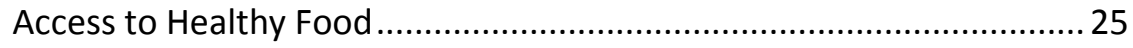

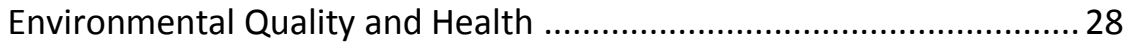

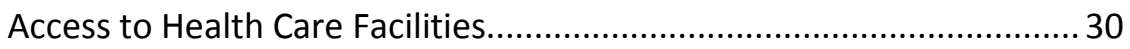

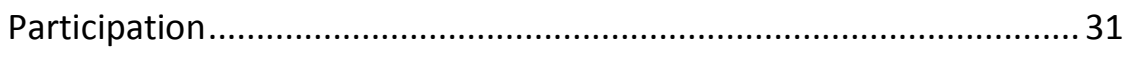

Goals, Policies, and Action Programs..................................................... 32

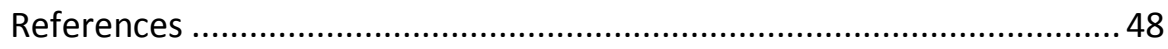


With these assertions, many jurisdictions in California have created Health Elements to include as optional elements into their existing general plans. The Cayucos Community Health Plan makes use of this framework to address health in planning as applicable at the small community level.

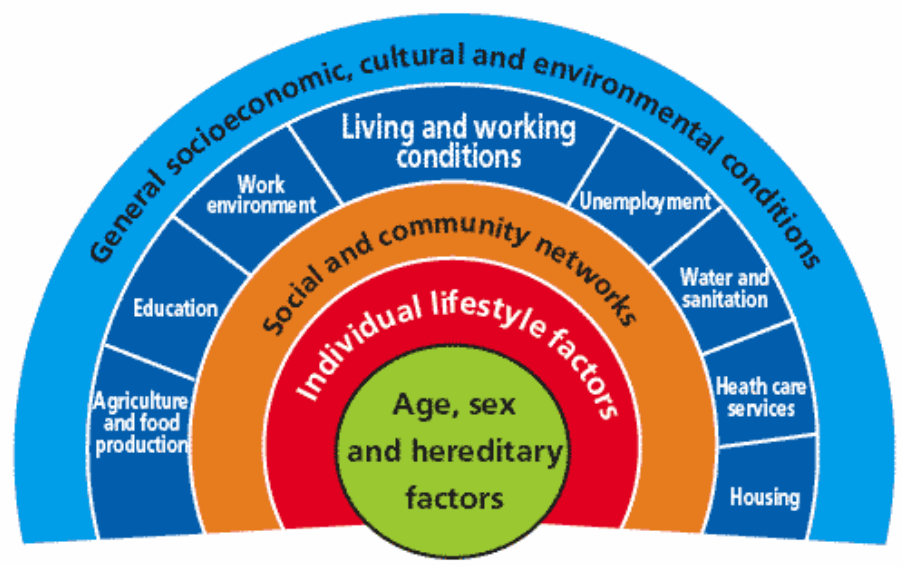

The Ecological Model

Factors such as genetics, age, and existing health conditions and access to healthcare, account for approximately 30 percent of health outcomes on an individual basis (Institute of Medicine, 2005). The determinants that make up the remaining 70 percent of health outcomes include services and infrastructures other than health care, such as recreational opportunities, education, transportation, housing conditions, access to food, employment, environmental quality, and social, economic, and political factors (Human Impact Partners 2011 , p. 10). This demonstrates the importance of taking a holistic, community-based approach to improving public health and working with community partners to make public health and wellness priorities for the community. 
Cayucos is an active community in many ways: first in terms of the mobility of the population, including commuters and vacationers, secondly in the literal sense, as the abundant sunshine and natural features encourage active pursuits of all kinds, and thirdly in terms of community participation, which drives the bulk of the improvements, conveys a sense of community pride, and produces explicit examples of how the people care for their hometown. This active community exudes spirit, and may be a primary reason for the attractiveness of this beach town for visitor throughput the county and California. This plan strives to reinforce the many positive attributes already present and forge a future that supports the improved health of Cayucos residents. 


\section{COMMUNITY HEALTH GOALS}

The Cayucos Community Health Plan centers on feasible changes, policy actions, and the exploration of possible new avenues to promote community involvement, partnerships within the county, the healthy habits, physical activity, ease of access to nutritious foods and health care, improved safety, and a clean, beautiful environment. The goals that guide this plan are a result of the careful study of community healthy conditions in the area, the self-identified needs in the community, and best practices for achieving the optimum health-promotive environment.

GOAL 1: Strengthened partnerships between the Health Agency, the County Planning Department, and the Cayucos community in policy implementation and programming.

GOAL 2: A low rate of smoking, drug and alcohol abuse among Cayucos residents and visitors.

GOAL 3: A built environment that promotes increased walking for recreation and transportation for all age groups and abilities as a means of addressing root determinants of health.

GOAL 4: An environment that encourages physical activity and social interaction through a reduced risk of injury and a safe multimodal transportation system.

GOAL 5: A built environment that accommodates bicycles as a means of active transportation and recreational opportunity.

GOAL 6: An aesthetically pleasing and inviting environment that is designed to accommodate residents and visitors of all ages and abilities.

GOAL 7: A local parks and recreation system that accommodates residents, local employees, and visitors of all ages, interests, and abilities to promote mental and physical health and wellbeing throughout Cayucos.

GOAL 8: A standard of environmental quality that encourages active pursuits, prevents exposure to toxic or infectious substances, and minimizes local greenhouse gas emissions.

GOAL 9: Accessible, affordable food for all Cayucos residents.

GOAL 10: Convenient access to a wide range of healthcare facilities in Cayucos and nearby for all ages and income levels. 


\section{HEALTH AND THE BUILT ENVIRONMENT: A Historical Perspective}

The origin of modern city planning can be traced to the urban reform movement near the end of the nineteenth century, which arose from the need to mitigate the health issues caused by rampant industrialization, urbanization and population increase. Major cities were a breeding ground for infectious diseases such as yellow fever, cholera, typhoid and tuberculosis. Further, toxic air pollution and run-off from nearby industrial sites, ventilation and lack of clean water sources made living in a city a health risk. Over the course of the following decades, the two fields continued to work jointly to tackle the incredulous health issues in dense, putrid, and harmful urban neighborhoods. However, by the first quarter of the twentieth century, the two fields began to diverge. Advancements in research and technology led to the understanding of diseases being biological in nature instead of environmental (Drummond, 2013). Meanwhile, the organization of built environments was left to urban planners. By the middle of the last century, the two fields became their own specialized professions; each working independently of one another and with its own respective interests.

Today, a growing number of planning professionals and researchers are working to reintegrate public health and planning and contextualize land use decisions as a community health issue. The public health and community planning disciplines intersect in the interest of improving safety, nutrition, environmental quality, physical exercise, and the spread of disease. Health departments and planning professionals throughout the world have realized that without changes to particular physical determinants of health, behavioral changes cannot be influenced and risk factors contributing to chronic disease can neither be addressed or controlled (CCLHO and CHEAC, 2013). Health professionals have begun 
collaborating with planners in an effort to bring forth changes to the built environment to positively influence public health.

Research has shown what has long been perceived as common sense: there is a strong correlation between the built environment and public health. "The designated use, layout, and design of a community's physical structures including its housing, businesses, transportation systems, and recreational resources affect patterns of living (behaviors) that, in turn, influence health" (Aboelata, 2004). The decisions communities make and the planners that create plans for them to control land use, vehicle circulation, zoning and street design are all elements that affect individual propensity for healthy diets and physical activity. The Cayucos Community Health Plan will serve to strengthen policies that acknowledge the connection between health and the built environment. It will guide programming, funding, and future development toward a more healthconscious environment. 


\section{RELATIONSHIP TO OTHER PLANNING DOCUMENTS}

The Cayucos Community Health Plan helps to address health where it is not fully addressed elsewhere in the General Plan. San Luis Obispo County area plans describe specific land use policies and categories that determine uses, density, and intensity for the specific portions of the county. They specify development standards for public services, circulation, and land use, as well as programs for correcting local problems or conditions.

\section{The Estero Area Plan}

The Estero Area Plan provides the land use policies for the area of the north county that includes Cayucos. The Estero Plan was adopted in January 2009 to establish a vision for the future of the Estero Planning Area that will guide development over the next 20 years. The goals encourage carefully planned development that respects the area's natural assets, maintains the community's small-town character as a beach community, and balances and promotes both the residential and visitorserving aspects of the community. The Estero Area Plan outlines a lowgrowth, slightly urbanized vision for Cayucos that keeps with its current character, but may also serve to encourage healthy design. The Estero Area Plan outlines the vision for future land use in Cayucos, which includes preventing urban sprawl, encouraging infill development, the creation of a greenbelt surround the town, allowing limited residential development in commercial areas, and phasing development in accordance with available water supply (County of San Luis Obispo, 2009).

The Estero Area Plan includes a goal to foster health and wellbeing, though it lacks how to address many aspects of community health, and does not identify the built environment as a factor in public health or mention chronic disease. There is also no established procedure for evaluating or monitoring the health impacts of plans. 
The Estero Area Plan includes goals and policies that support public health, though generally there is no mention of how these may contribute to physical activity levels, mental health, access to health services, healthier eating. The Estero Area Plan is strongest on goals and policies relating to active living, although the explicit link to public health benefit is missing. The plan identifies programs to improve pedestrian access and safety and to provide traffic calming (pg. 4-29), establishes guidelines for including sidewalks and bike lanes in future development, and establishes a high level of service for park access and design (pg. 4-33, 4-34). Environmental exposure is also more strongly represented, although the focus is likely attributable to the influence of CEQA policies. The plan includes policies to protect ground and surface water, including for stormwater runoff, though it is lacking in other areas of environmental exposure protection. There are policies included to limit noise to sensitive receptors and incorporate design features to increase safety, though there is no mention of the impact that this may have on crime prevention or promoting active lifestyles. These considerations are helpful to protecting health, but again lack the crucial connection between environmental quality, exposure, and community health.

\section{Local Coastal Program}

According to the California Coast Act of 1976, local governments must prepare a land use plan and schedule of implementing actions to carry out the policies of the Coastal Act in all areas designated as a coastal zone. The California Coastal Commission is a state agency with quasi-judicial regulatory oversight over land use and public access in the California coastal zone. San Luis Obispo County consists of an expansive coastal zone which encompasses Cayucos' entire boundary (County of San Luis Obispo, 1988).

The Coastal Zone Land Use Ordinance (CZLU) is the guiding document of allowable uses in designated coast zones. The purpose of this document is to implement the General Plan and the Coastal Program, and to guide and manage future growth of the county in accordance with those plans. Further, to minimize adverse effects on the public resulting from 
inappropriate creating, location, use, or design of building sites, buildings, land uses, parking areas, or other forms of land development by providing appropriate standards for development. These development standards apply to a large portion of the land in Cayucos due to the community's location along the coast. When applicable, additional permitting from the Coastal Commission often adds another layer of development regulation to many projects in Cayucos.

\section{Other County General Plan Elements}

Other goals and policies that apply in Cayucos are described in the San Luis Obispo County General Plan. The General Plan is the blueprint for the future physical, economic and social development of the unincorporated areas of the county, outside cities. It implements California laws that regulate land use planning and development. State law requires that every general plan must contain the following components or elements: Land Use, Conservation, Noise, Circulation, Open Space, Safety and Housing. In addition, state law allows for the adoption of additional or optional elements of a general plan. The County of San Luis Obispo has adopted seven optional elements: Recreation, Historic and Esthetic, Energy, Off-shore Energy, Economic and Agriculture (County of San Luis Obispo, 2014). The goals, policies, and programs described herein were developed and tailored specifically for Cayucos, but may lend indications of the types of policy language that would be appropriate to include in a Countywide Health Element. Because health outcomes are determined by a number of factors, extraneous of policies to guide development and land use, this plan should be considered in conjunction with existing and future planning documents. 


\section{OUTREACH SUMMARY}

Several efforts were made to connect with the community prior to and throughout development of this document. The goal of the outreach effort was to garner valuable perspective and feedback from community members regarding physical activity levels, information about the built environment where they live, work, and play, and perceived barriers to healthful activities and food access. Efforts included key informant interviews with representatives from the community, a widely-distributed questionnaire, meetings with active community groups, a planning activity with students at Cayucos Elementary, visits to community events such as the Farmers' Market and Seaglass Festival, and presentations to the Cayucos Citizens' Advisory Council. Outreach results aided in constructing goals, policies, and programs that will meet the specific needs of the Cayucos community. Results are included in the following section, Health and Wellness context, and contributed to creating a more complete picture of community health in Cayucos.
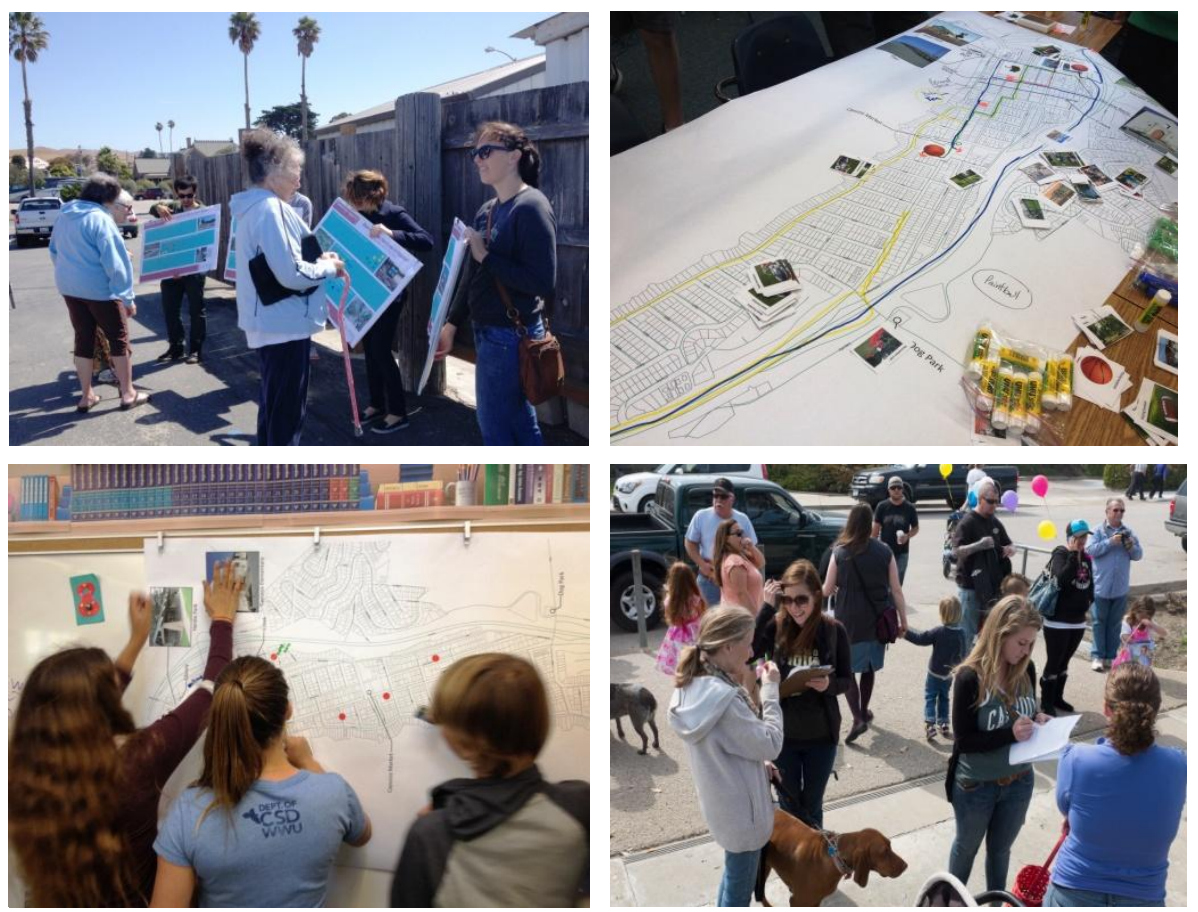

Community Outreach in Cayucos 


\section{HEALTH \& WELLNESS CONTEXT}

The Health \& Wellness Context section describes health concepts that relate to city planning, the built environment and public health. Background information is provided regarding existing conditions and issues found in Cayucos that relate back to those concepts, helping to inform and provide rationale behind the goals, objectives and policies later outlined in this document.

Cayucos's status as an unincorporated, censusdesignated place meant certain communitylevel health data was not available. In these cases, regional county-level data taken from the ACTION for Healthy Communities Project (2013) was utilized, with "North Coast" area data being representative of Cayucos, along with the communities of Baywood, Cambria, Harmony, Los Osos, Morro Bay, and San Simeon. Additionally, project studies involving specific segments of Cayucos's population were utilized, and provided some relevant data findings that helped to inform this plan. This section also includes some general information about the known relationships between health and the built environment. Key findings from community outreach and physical assessments of the built environment are also included here to provide context for the specific issues in Cayucos.

\section{Overall Health in Cayucos}

Cayucos is a town of about 2,500 residents, and a somewhat affluent, well-educated, and mostly white community. In 2013, per capita income averaged $\$ 42,000$ per year, compared to about $\$ 30,000$ per capita in California overall. Educational attainment in Cayucos is also high, with $94.5 \%$ having attained a high school diploma, and $40.5 \%$ holding a bachelor degree, compared to $30.5 \%$ in California. The population in Cayucos is trending toward older residents, and the median age is quite high at 57.2 (U.S. Census Bureau, 2012). These demographics have implications for the prevention of injury, transportation modes, and well as medical care access.

According to those that live in Cayucos, the town is a healthy place to live. Almost $3 / 4$ of questionnaire respondents indicated that they are "very healthy" or "healthy." Cancer and heart disease are the leading causes of death in Cayucos but a large margin. During a three-year (2008-2010) recorded span, the leading causes of death in Cayucos were cancer and diseases of the heart (CDHS, 2003-2011). These health conditions commonly stem from obesity, poor nutrition, and sedentary lifestyles. Cayucos is also an aging community, with a median age of about 1.5 times that in San Luis Obispo County, and $65 \%$ of residents are over fifty years of age. Only $10 \%$ of the population is under 18 (U.S. Census Bureau, 2012). Though these chronic diseases are attributable to a number of factors, increasing exercise and healthy eating habits among community members may have a positive impact on these rates. 
Number of Deaths in Cayucos

\begin{tabular}{|c|c|c|c|c|}
\hline & 2008 & 2009 & 2010 & Total \\
\hline Cancer & 10 & 6 & 8 & 24 \\
\hline Diseases of the Heart & 11 & 7 & 5 & 23 \\
\hline $\begin{array}{l}\text { Chronic Lower } \\
\text { Respiratory Disease }\end{array}$ & 1 & 2 & 3 & 6 \\
\hline Injury & 1 & 1 & 3 & 5 \\
\hline Stroke & 2 & 0 & 2 & 4 \\
\hline Suicide & 0 & 3 & 1 & 4 \\
\hline $\begin{array}{l}\text { Essential Hypertension } \\
\text { \& Hypertensive Renal } \\
\text { Disease }\end{array}$ & 2 & 0 & 1 & 3 \\
\hline Alzheimer's Disease & 1 & 1 & 0 & 2 \\
\hline Diabetes & 0 & 1 & 1 & 2 \\
\hline $\begin{array}{l}\text { Chronic Liver Disease } \\
\text { and Cirrhosis }\end{array}$ & 0 & 0 & 2 & 2 \\
\hline $\begin{array}{l}\text { Influenza and } \\
\text { Pneumonia }\end{array}$ & 0 & 1 & 0 & 1 \\
\hline $\begin{array}{l}\text { Nephritis, Nephrotic } \\
\text { Syndrome and } \\
\text { Nephrosis }\end{array}$ & 0 & 0 & 0 & 0 \\
\hline Other & 6 & 4 & 2 & 12 \\
\hline Total & 34 & 26 & 28 & 88 \\
\hline
\end{tabular}

(County Health Status Profiles, California Department of Health Services and California Conference of Local Health Officers, 2003-2011).

Population growth has declined in Cayucos, and vacation homes and rental units account for many of the housing units. Cayucos currently has 2,354 total housing units and 1,040 vacant housing units, making up $44 \%$ of the total housing units. Much of the vacancy rate can be explained in the 893 seasonal, vacation use homes or second homes. As a town of many vacationers and as a small bedroom community, high-paying jobs and affordable housing are both lacking in Cayucos. Seventyfour percent of owner-occupied units are valued at 500,000 or more, and $22 \%$ are over one million, which is more than double the county rate of $7 \%$.

\section{Obesity and Physical Fitness}

Lack of physical activity and obesity is associated with an increased risk of many chronic diseases, including the leading causes of death listed above (Feng, Glass, Curriero, Stewart, \& Schwartz, 2010). It has been estimated approximately 400,000 premature deaths occur annually in the United States as a result of the negative health outcomes which stem from obesity due to physical inactivity (Mokdad, Marks, Stroup, \& Gerberding, 2004). A body mass index (BMI) of 30 kilograms/meter or more is considered obese, and overweight is considered to be a BMI of $25 \mathrm{~kg} / \mathrm{m}$ or more. According to the California Health Interview Survey (CHIS), in 2011-2012 48\% of adults in San Luis Obispo County were overweight or obese, which although a high rate, was lower than the State of California as a whole (60\%).

According to the 2013 ACTION for Healthy Communities Report, released by the Community Foundation, just over half $(53 \%)$ of San Luis Obispo County resident respondents participated in five or more days of physical activity for at least 30 minutes in 2013. When asked if their employer tries to help employees with healthier eating and physical activity, including weight reduction programs, subsidizing health club memberships, or providing stress management classes, $41.4 \%$ responded yes, a figure which declined since 2006 (ACTION, 2013). This not only indicates that lack of physical activity is an issue in the county, but that it is becoming a larger issue 
with time. Numerous features of the built environment have been associated with physical activity, including residential density, land-use mix, urban sprawl, intersection density, walkability, park availability, and accessibility to physical activity-related resources (Casagrande, 2011).

Cayucos Elementary students are also in need of physical fitness improvements. According to the California Department of Education, aerobic capacity is perhaps the most important indicator of physical fitness and assesses the capacity of the cardio respiratory system by measuring endurance. According to student fitness testing results, $17 \%$ of 5 th Graders tested at Cayucos Elementary during the 20122013 school year were classified in the "needs improvement health risk" category for body composition. In the aerobic capacity area, 39\% were classified as "needs improvement" (ACTION, 2013). Of 34 Cayucos $7^{\text {th }}$ Graders, 21\% were classified in the "needs improvement health risk" category for body composition, and $6 \%$ were classified as "needs improvement" under aerobic capacity (CDE, 2013).

This is a matter of concern because habitual inactivity early in life can establish life-long high risk behaviors. These findings indicate that among children and adults in Cayucos, an increase in physical fitness is necessary as a means of preventing illness. When asked what would help their children to exercise more, $43 \%$ of county survey respondents listed activities at school and after-school, $30.4 \%$ listed a park or playground closer to home, and $25.6 \%$ said safer streets for children to walk to destinations (ACTION 2013).
The following sections, Parks, Recreation and Opens Spaces; Pedestrian Environment, and Biking, detail results connecting Cayucos with opportunities for physical activity.

\section{Parks, Recreation, and Open Spaces}

Though incorporating physical ability into daily activities can help to "cure" physical inactivity, it has also been proven that living close to parks, trails, and recreation facilities is related to greater use of facilities and more recreational physical activity (Sallis et al., 2011, p. 33). Overall, residents would like to see more hiking trails, bike paths, natural areas, and parks in the county. Convenient, accessible parks and recreation facilities in directly correlated to the amount that individuals exercise. Additional facilities or improved access can increase the proportion of residents who exercise three times per week by $25 \%$.

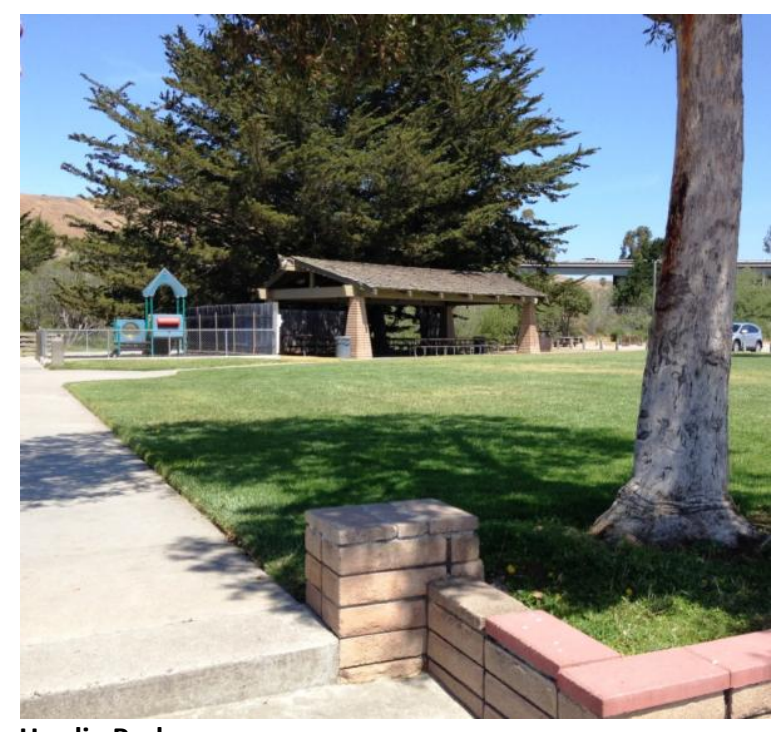

Hardie Park 
Parks, hiking areas and additional facilities including the community pool, tennis courts, and school facilities serve the community. Cayucos has three official parks, Hardie Community Park, Paul Andrew Neighborhood Park, and Norma Rose Park, as well as elementary school playgrounds at Cayucos Elementary School. The Cayucos Public Park Access map shows $1 / 4$-mile and $1 / 2$-mile access to these parks via existing streets. Hardie Community Park is 4 acres and features playground equipment, picnic benches, horseshoes, and a lawn area. The tennis courts and community swimming pool are also located at Hardie Park. Paul Andrew Neighborhood Park is a 1-acre park with a playground, picnic tables, and a bike rack. The newest park, Norma Rose Park, is a 1.5 acre park east of Highway 1 . Improvements to come include a skate park, children's playground, basketball court, restroom, and picnic areas (San Luis Obispo County Parks, 2002). According to National Recreation and Park Association (NRPA) recommended guidelines, and the Estero Area Plan, Cayucos needs 27 additional acres of neighborhood and community parks.

In particular, Cayucos needs more opportunities for "active" recreation, such as ball fields, children's play equipment, and recreation programs (Estero Area Plan, 2008). Many Cayucos residents, especially elementary students, expressed a need for parks that are better suited for team sports. Some community members also indicated that there is a need for activities for seniors.
Cayucos Public Park Access

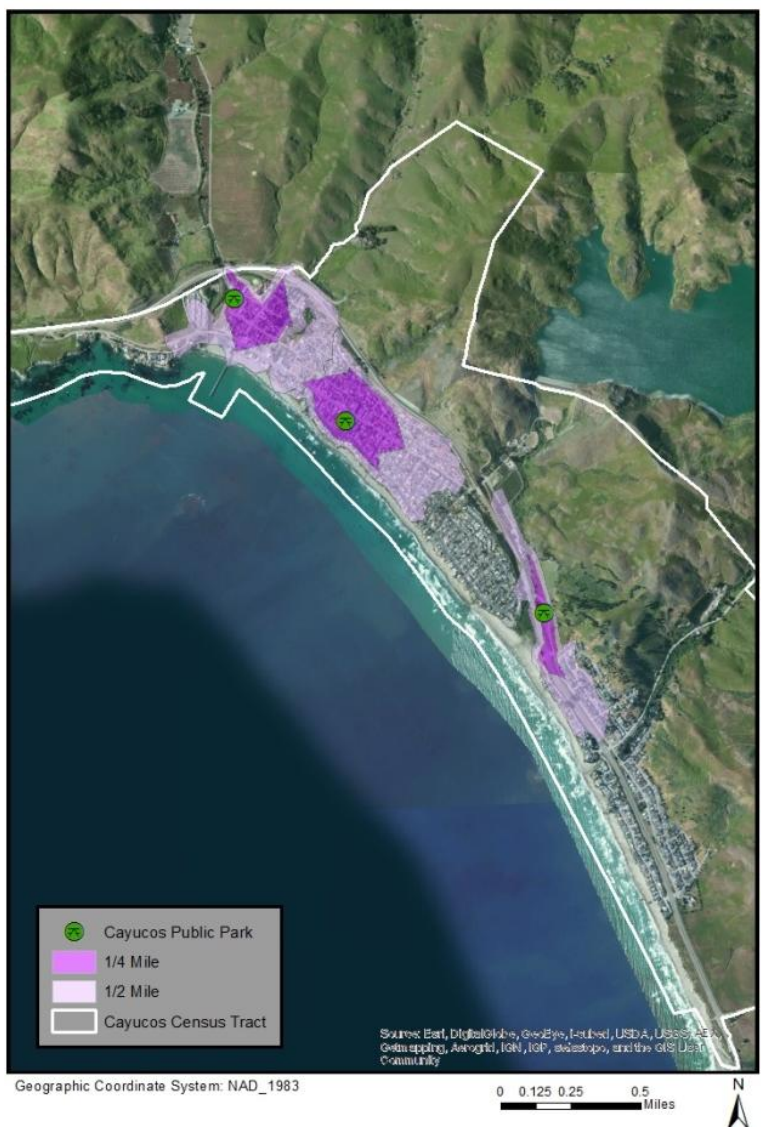

The first map shows parks only, without the beach access points. The maps show that especially south of the commercial core, many residents do not have convenient pedestrian access to a park.

Because many residents of and visitors to Cayucos use the beach for exercise such as walking, running, kayaking, or surfing, and because the beach serves as a community space, the second map identifies the beach access points. The Cayucos Public Park and Beach Access map also shows $1 / 4$-mile and $1 / 2-$ mile access by existing streets. With the inclusion of beach access, parks are accessible by most residences in Cayucos. 
Cayucos Public Park and Beach Access

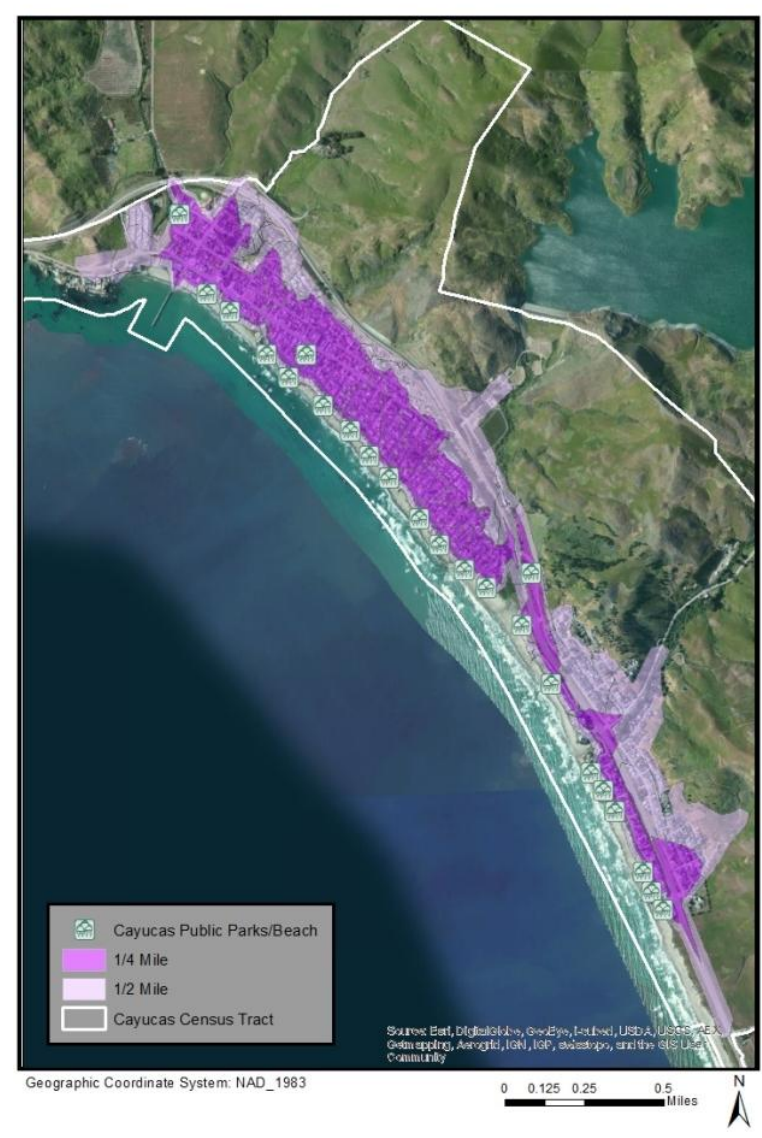

Pedestrian Environment

A foundational U.S. Surgeon General's Report on Physical Activity and Health (1996), concluded people of all ages who are generally inactive can improve their health and well-being by becoming even moderately active on a regular basis. Research has found multi-level social ecological factors such as urban aesthetic, perceived safety, accessibility, and opportunity for social interaction to be motivating factors for increased physical activity (Lee \& Moudon, 2004; Brownson, Baker, Housemann, Brennan \& Bacak, 2001; Cao, Handy, \& Mokhtarian, 2006). Pedestrian-friendly areas allow for low-impact exercise for the elderly, accommodate the incorporation of daily walking to destinations and as a social activity, and accommodate individuals without access to vehicles. Pedestrian activity also invites windowshopping and increased consumer traffic for businesses and increases random encounters with others in the community, which increases neighborly connections, a feeling of belonging, and brings with it improved mental wellbeing (Litman, 2014; Saelens and Handy, 2008). Outreach participants were supportive of widened sidewalks and increased outdoor seating areas, and pedestrian safety was listed as a major factor contributing to health. "Sidewalk improvements" was also one of the options chosen most often as a community feature that could contribute to health and quality of life.

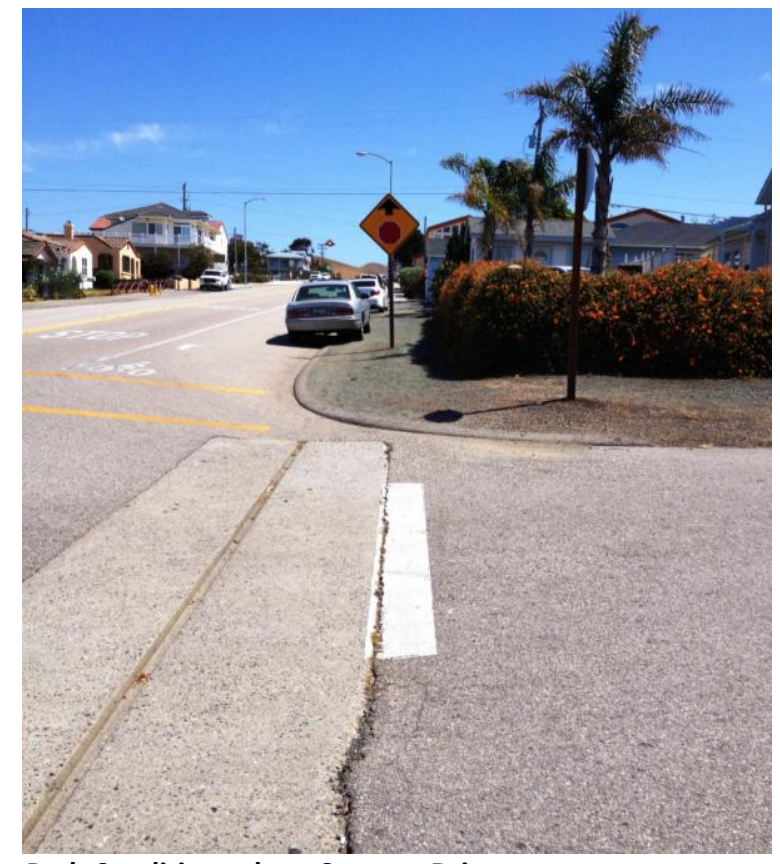

Path Conditions along Cayucos Drive

A walkability audit was conducted in Cayucos to provide an objective evaluation of the walking environment, and to identify pedestrian 
concerns related to safety, access, comfort, and convenience. Though pedestrian activity throughout Cayucos is not as limited as in other areas of the county, there are many areas throughout the commercial core and connecting to residential areas that could benefit from improved pedestrian infrastructure. In Cayucos, the overall most pedestrian and bike-friendly area is along the northern section of Ocean Avenue, near the commercial core of the town, as indicated on the walk audit results map.

\section{Overall Walkability}
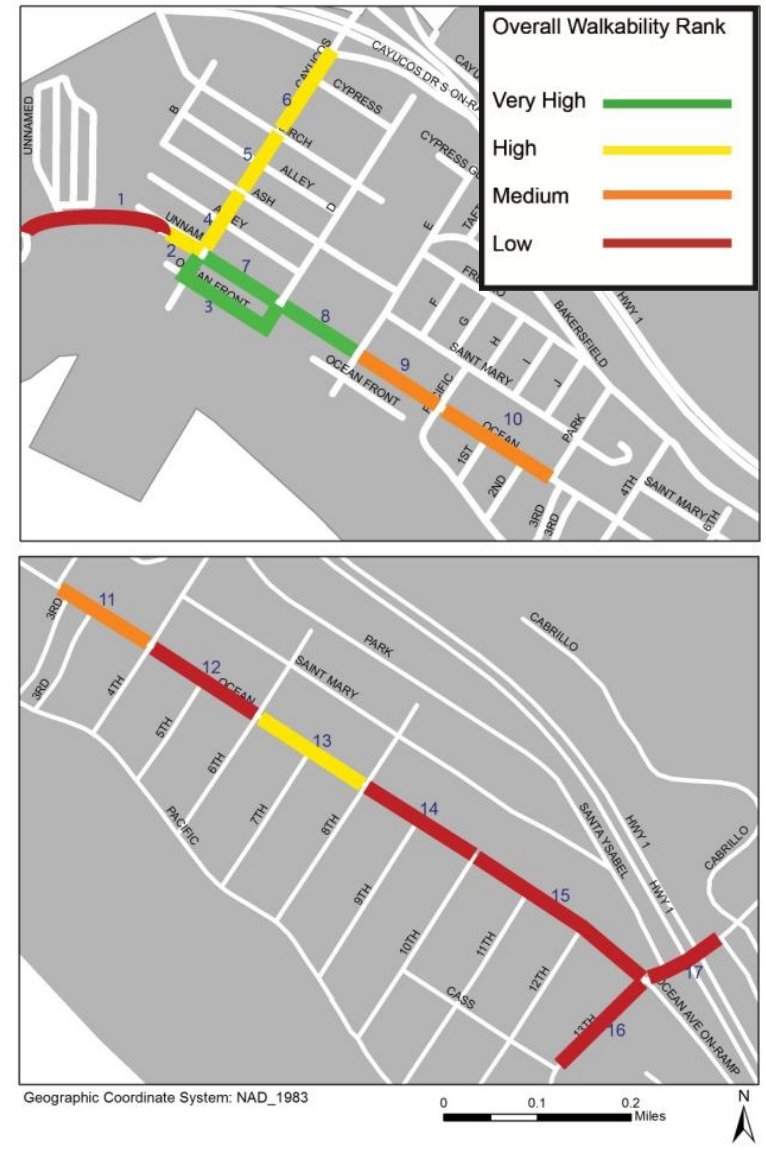

Students attending Cayucos Elementary and seniors on the whole were particularly interested in improved walking environments. Pedestrian safety is an issue for those on the east side of Highway 1, for people walking and biking downtown on Ocean Avenue, and near the school. These findings suggest that there is ample room for improvement in pedestrian infrastructure throughout Cayucos.

\section{Bicycling}

Bicycling allows for active transportation at greater distances and speeds than walking, provides connections between residences and transit stops, and is and highly accessible form of transportation for all ages and income levels. Like walking, riding a bike to services and frequent destinations incorporates physical activity into daily life, helping to increase the chances that the rider experiences the countless health benefits of regular exercise. Bike lane improvements was one of the options chosen most often as a community feature that could contribute to health and quality of life.

Cayucos is located along the Pacific Coast Bike Trail which follows Highway 1 along the coast. The climate and scenery make Cayucos a great place to bicycle for avid cyclists, casual bikers, and commuters. However, most roads lack a safe amount of lighting, there are few places to park a bicycle, and there have been several bicycle-vehicle collisions in Cayucos. Results from outreach include that street lighting along the bike trail, along Pacific Avenue, and in residential areas could help kids and adults bike more, especially in the dark. Bicycle safety was also brought up as an issue relating to injury.

There is a lack of bike infrastructure in Cayucos, such as bike racks, biking signs, smooth paths and lighting. Many residents supported the plans to complete the path to Morro Bay, and 
said that the bike trail along the cemetery needs improvements.

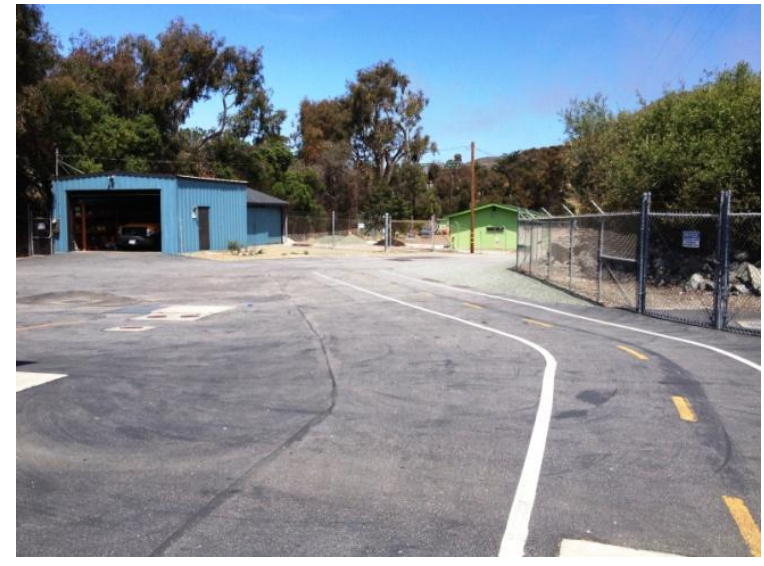

Colin C. Reilly Bike Path

The walk audit showed that segments along $13^{\text {th }}$ Street, which connects Ocean Avenue and Pacific Avenue to the neighborhoods to the east of Highway 1 ranked consistently low in terms of walkability and bike-friendliness.

\section{Mental Health}

According to the American Institute of Stress (2011), an increasing number of Americans are citing personal health and their family's health as a source of stress. Godbey (2009) states an "estimated 75 percent of all visits to primary care physicians are for stress-related complaints and disorders" (p. 3). Countywide, those reporting their mental health as good, very good, or excellent decreased, while the number of mental health patients and the unmet need for mental health care increased (ACTION, 2013). Incidence of suicide also increased. The number of 2-1-1 calls for assistance, a free program for health and human services information and referrals, increased from 3,376 to 5,196 in 2011 . The highest numbers of calls were for mental health and addiction assistance, which increased from 347 calls to 854. Though it is not clear that Cayucos specifically is troubled by mental health problems, these conclusions suggest that mental health is an increasing issue throughout the county.

Research studies have indicated being in contact, or in the very least, in sight of natural environments has beneficial effects on our mental health (Maller, Townsend, St Leger, Henderson-Wilson,Pryor, Prosser, \& Moore, 2009, Gullone, 2000.). Further, Maller et al. (2005) argue that "Empirical, theoretical and anecdotal evidence demonstrates contact with nature positively impacts blood pressure, cholesterol, outlook on life and stressreduction" (p. 49). The provision of open spaces, green spaces and parks, i.e., the built environment, contribute to overall well-being through increased levels of physical activity, relaxation, recreation and social engagement (Maller et al., 2009, p. 54) and is beneficial across all age groups (Mass, Verheij, Spreeuwenberg, \& de Vries, 2006, p. 590). Efforts to improve health through the design of the built environment are one aspect of creating a community that supports mental health and wellbeing.

\section{Public Safety}

Public safety and perceptions of public safety contribute to the use or avoidance of public spaces. Almost $80 \%$ of SLO County ACTION survey respondents in 2013 reported feeling "very safe" in their communities, 21\% reported feeling "Somewhat Safe" and only $0.8 \%$ 
reported feeling "Not at all Safe." According to the Healthy Community Questionnaire results, Cayucos specifically is a very safe, low crime town with a quick emergency response time.

Juvenile crime, one of the most salient indicators of community safety, as it is associated with abuse, neglect, substance abuse, mental health problems, gang activity, and family disorganization also decreased in 2012 (Noguera, P., 1995). The juvenile felony and misdemeanor arrest rates decreased from 2006 to 2012. In Cayucos, when given the statement "I feel safe at my school", $86 \%$ of $7^{\text {th }}$ Graders chose either "Agree" or "Strongly agree", and $14 \%$ chose "Neither agree nor disagree." Fifth graders responded "Yes, all of the time" at 55\%, "Yes, most of the time" at $27 \%$. In sum, Cayucos is rightly assumed to be a safe community, and it is likely that feelings about safety or security are not a major health factor. Elements of the built environment may help to continue the trend of low crime rates, especially through Crime Prevention through Environmental Design (CPTED) techniques, such as lighting and natural surveillance (Newman, 1972, Crowe, 1991).

Safety in the built environment also includes safety from injury. In 2008, the Physical Activity Guidelines Advisory Committee reported findings from amalgamated scientific literature on the health benefits of exercise, including that the benefits of activity far outweigh the possibility of adverse outcomes (USDHHS, 2008). However, physical activity can expose individuals to risks for injury, due in part to the high priority of accommodation of vehicles and the incomplete adoption of designs and practices for injury prevention in our environments. In Cayucos, the unfinished skate park and bicycle safety were brought up as issues relating to injury. Lack of street lighting was mentioned as a concern.

Seniors are more susceptible to falls, and a large number of injuries are attributable to falls while using footpaths or sidewalks (Binder, 2002). Uneven surfaces are a major cause, along with slippery surfaces, steepness, and stairs that are hard to see or too high. Obstructions such as pavement signs, poorly sited street furniture, protruding grates or manhole covers, and litter and other debris, create tripping hazards.

Walkability: Safety Category
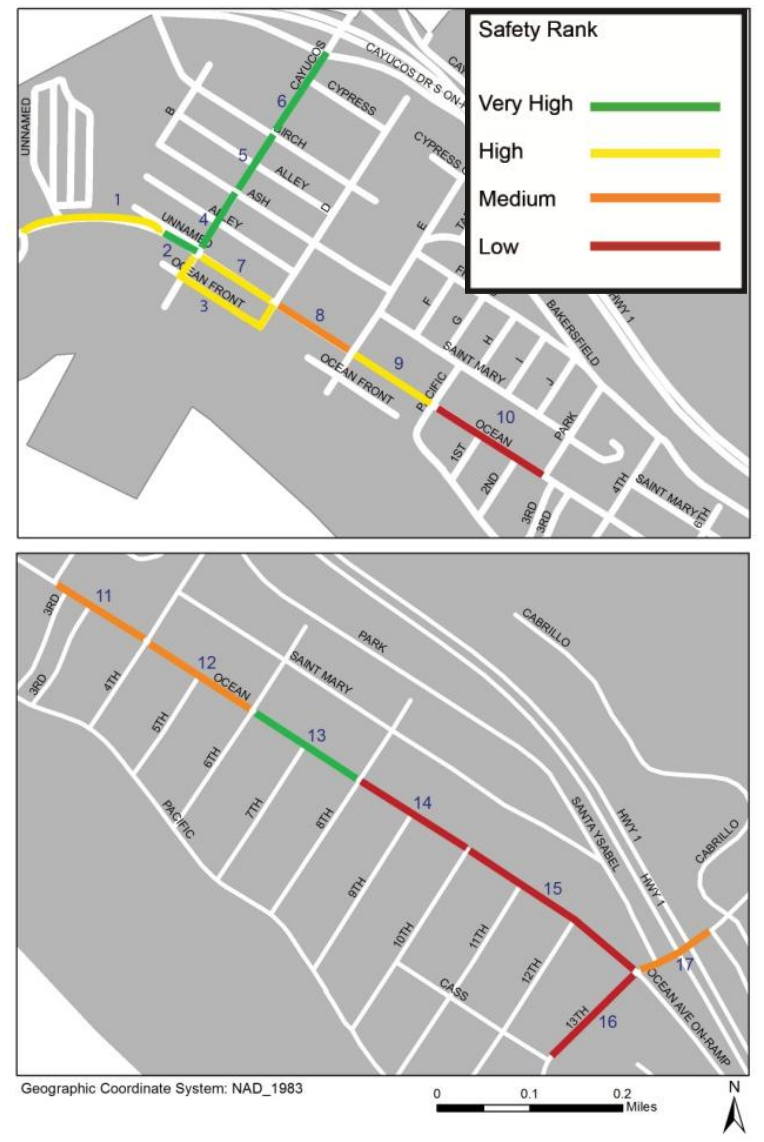

Cayucos Drive ranked high in the safety category due in part to the number of crossing aids and other signage. The street segments in 
the commercial core along Ocean Avenue that ranked highest in walkability overall ranked slightly lower for the safety category, largely for injury risk and traffic safety issues. According to the California Highway Patrol, there were nine pedestrian-vehicle collisions resulting in injuries in Cayucos since 2004, and two of these collisions resulted in death. There were eight bicycle/vehicles collisions since 2004, and of these seven resulted in injuries (CHP, 2014).

Pedestrian safety is an issue for those on the east side of Highway 1 , along South Ocean Avenue, and near the school. There have been several pedestrian and bicyclist deaths in Cayucos in the last ten years that were caused by collisions with automobiles. The walk audit conducted for this plan showed that there is a discrepancy between overall walkability in town and the safety of the streets. This is due in part to the auto-oriented nature of the streets, obstructions in the walking path, and uneven or incomplete sidewalks. In Cayucos, sidewalk and bike lane improvements were two of the options chosen most often as community features that could contribute to health and quality of life.

These issues are especially relevant for increasing the number of students walking or biking to school, limiting injuries for those needing to cross Highway 1 , and individuals with disabilities or limited mobility.

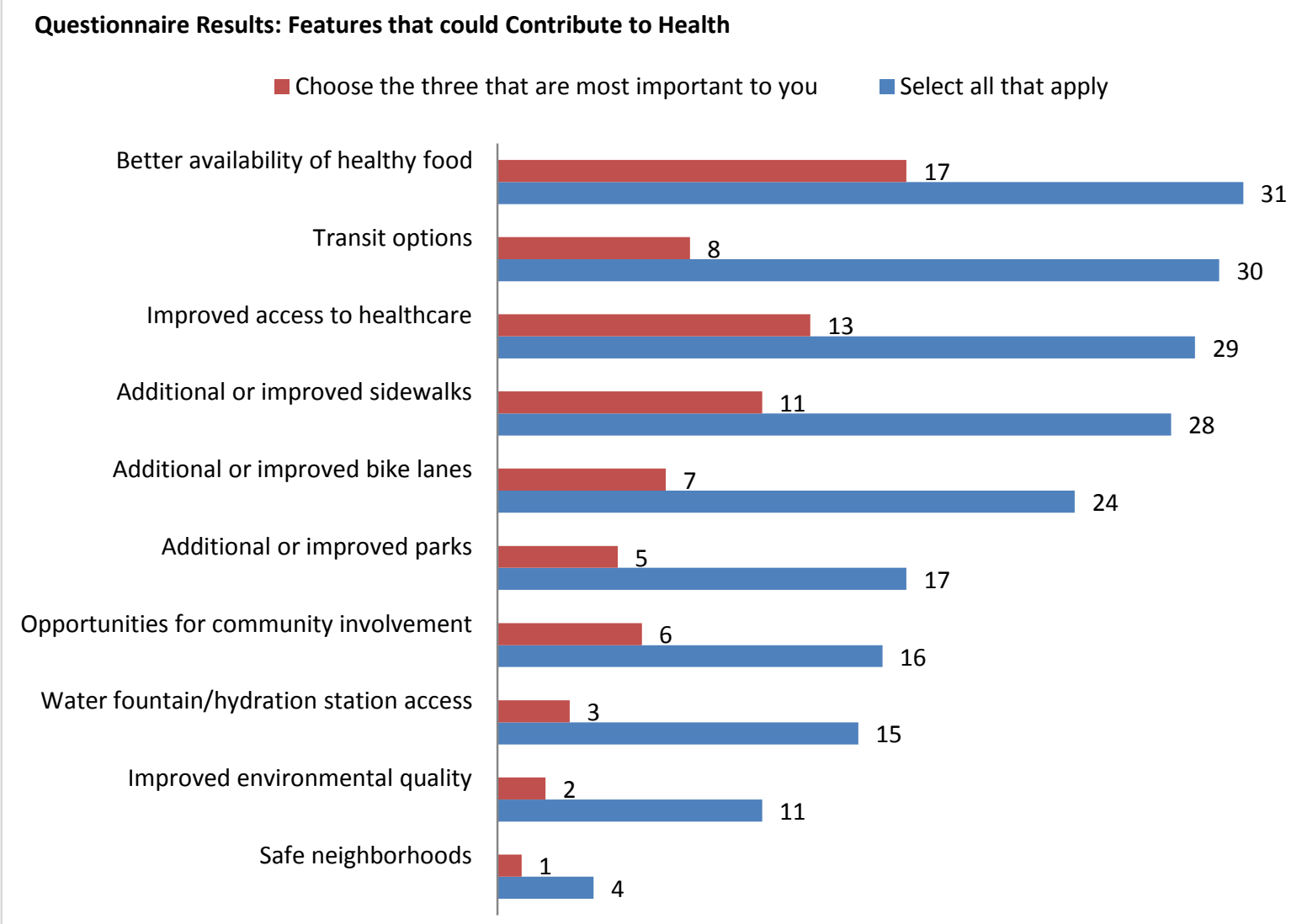


The Department of Transportation has studied numerous tactics to reduce injury-by-vehicle and promote health, which they call safety countermeasures (Furst, 2012). These include features that call a driver's attention to a pedestrian area, naturally cause slower speeds, and increases in physical space for pedestrians and bicyclists. These measures can increase actual and perceived safety and encourage active use of the built environment. Aside from traffic safety issues, most people in Cayucos feel safe in their neighborhoods. Design standards that maximize visibility, utilize natural surveillance and access control techniques, and spaces that are well-maintained can help to support crime-free use of the built environment in the future.

\section{Drug, Alcohol, and Tobacco Use}

The effects of tobacco use, second-hand smoke, and the carcinogenic properties of nicotine continue to be a leading cause of death in California. Electronic cigarettes represent a recent issue for tobacco use because of unclear policy throughout the county and the attractiveness of e-cigarettes to youth. Outreach participants listed drug and alcohol abuse as the top ranking at the top of the list of most important problems in Cayucos, along with aging problems, cancers, heart disease and stroke, and obesity.

Tobacco use declined among adults in the county, and more people that smoke reported attempting to quit (a 7\% increase from 2006) (ACTION, 2013). Residents in Cayucos are concerned about the rate of smoking and problems with drug and alcohol abuse in their community. Smoking is not currently banned in downtown Cayucos, and smoking is prevalent especially late at night. One group of outreach participants specifically mentioned the rise of ecigarettes and second-hand smoke as a major issue in Cayucos. The percentage of respondents who smoke were higher in the North Coast region compared to other areas in the county. Though the numbers have only slight differences, it appears that use of tobacco and alcohol and drug abuse is a problem in Cayucos, akin to or perhaps slightly more than other areas of the county.

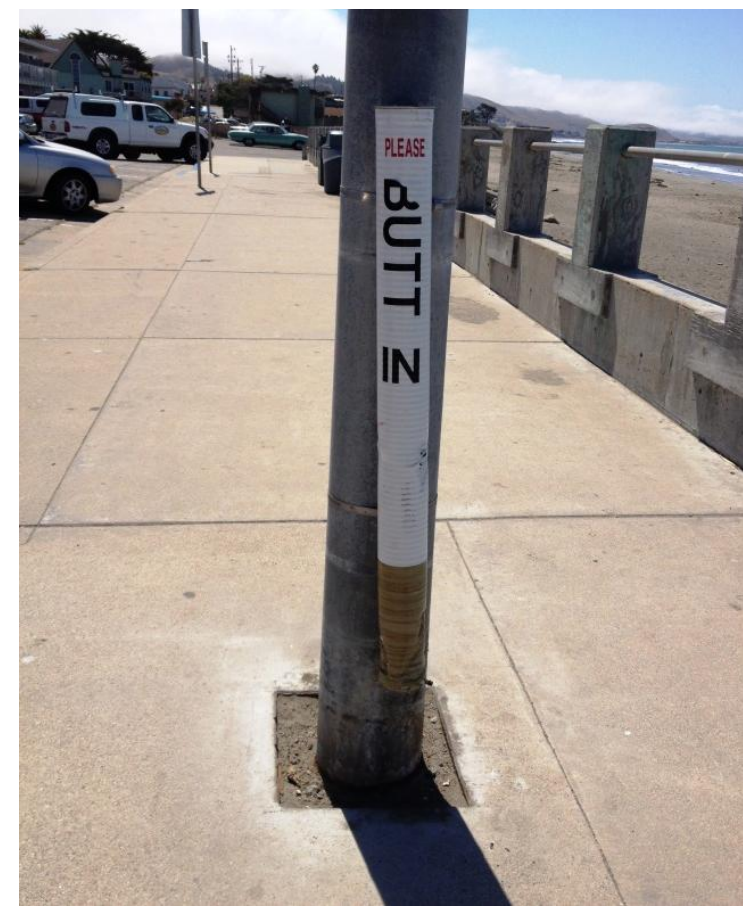

Cigarette Disposal along Ocean Front Avenue

Youth tobacco use declined overall from $20 \%$ in 2005-2006 to $13 \%$ in 2011-2012, but the prevalence of smoking among youth in the county was occurring at a higher rate than the State of California as a whole (ACTION 2013). There are three tobacco retailers in Cayucos, and four retailers that sell alcohol. The proximity of these stores near schools and parks 
is also of concern. In comparison to California State percentages, use of tobacco was reported to be lower at Cayucos Elementary. Zero percent of Cayucos $7^{\text {th }}$ Grade students had ever tried smokeless tobacco or cigarettes. However, a higher percentage of Cayucos students reported drinking alcohol, smoking marijuana, and using inhalants.

Concern over alcohol and drug abuse in San Luis Obispo County remains steady, although binge drinking rates and youth substance abuse have declined over the last decade. Of SLO County ACTION survey respondents with middle school aged children, 56\% reported that alcohol and drug abuse problems were a very serious or somewhat serious problem in 2013, up from 45\% in 2006 and 48\% in 2010 (ACTION, 2013). Drugs and alcohol abuse was mentioned multiple times as a major hindrance to health in Cayucos. Use of heroin, meth, and tobacco use were as specified as problems.

According to the 2011-12 California Healthy Kids Survey, the number of $11^{\text {th }}$ graders that had consumed at least one drink of alcohol in the past month decreased from $43 \%$ in 2003 2004 to $38 \%$. Use of marijuana remained about the same over the same span of years.

Concern over alcohol and drug abuse remains at similar levels to previous years, although binge drinking rates and youth substance abuse have declined. Alcohol use among adults increased since 2006, but self-reported student substance abuse declined. Binge drinking rates were higher in the county than in the state as a whole, with $39 \%$ of residents over 21 years of age reporting that they drank 4 or 5 or more alcoholic beverages on an occasion in the past
30 days. Binge drinking was more prevalent among respondents in the North Coast region than some other regions of the county (ACTION, 2013).

Researchers and public health professionals in tobacco cessation and prevention utilize strategies such as reducing tobacco advertising, enforcing penalties for selling alcohols and tobacco to minors, and providing free products and services to those with unhealthy addictions. The Department of Behavioral Health provides treatment and recovery services for those with drug and alcohol problems. The findings suggest that there is a need to increase awareness of such programs, increase accessibility of county programs, and limit the exposure to such substances.

\section{Transportation Network}

Long commutes and too much traffic increase stress and affect overall health in individuals by impacting physical activity rates and obesity, as well as contribute to air pollution. The modern city, built to accommodate the automobile first and foremost, deters physical activity and the use of alternate forms of transportation. The result of this practice is widespread traffic congestion; increased commute time; increased vehicle, pedestrian and biking crashes and injuries; a growing obesity epidemic; a rise in air pollution and respiratory illness; and a growing sense of disconnection between workplaces and homes (CDC, 2009, p.9; Lopez, 2004). 


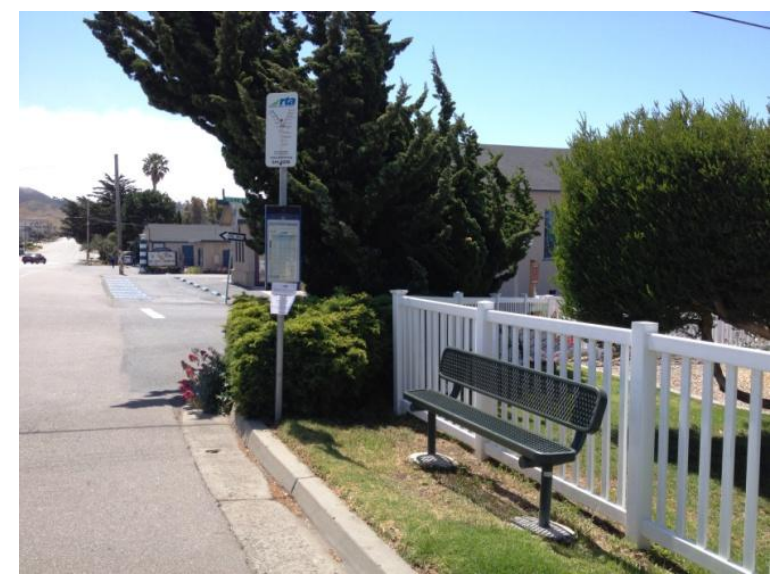

Bus Stop on South Ocean Avenue

Cayucos's small town atmosphere and remote location limit the access to many community needs without the use of a private automobile. Transit to and from Cayucos is infrequent and time-consuming, which is likely deterring the use of the bus system and increasing the dependence on personal vehicles. Caltrans traffic data shows that mean travel time to work in Cayucos is similar to the figure for county residents at 18.2 minutes, and about 10 minutes less than the mean travel time for California as a whole. Mode of transportation to work was also comparable to that of other county workers with $75 \%$ driving alone. Fourteen percent carpooled, as opposed to $11 \%$ countywide (ACTION, 2013). Access to transit is a critical component of a healthy transportation system, though adequate and convenient access is difficult to achieve in a small town.

During an outreach activity, Cayucos Elementary students were asked to indicate the travel mode and route they took to school; most of them were dropped off by their parents in a car. The students mentioned many ideas for improving their environment, but came to a consensus on a few ideas including street lighting in dark, residential areas and "smoother" roads for bicycling. In San Luis Obispo County, the most common way to get to school was also by car, followed by taking the school bus. About a quarter of elementary school children in the North Coast and City of San Luis Obispo regions walk to school, and 13\% of those in the North Coast region bike. Walking was even more prevalent in the North Coast region for Middle or Junior High School children at $38.1 \%$. When county residents were asked specifically about what would encourage active transportation to school, the largest numbers of responses were living closer to school, sidewalk or street improvements, and crossing guards. Sidewalk and bike lane improvements and transit options were two of the options chosen by Cayucos residents most often as community features that could contribute to health and quality of life.

Communities that encourage multiple transportation modes through a well-connected transit, bicycle, and pedestrian network can decrease overall vehicle miles traveled (VMT), which has been shown to decrease traffic speeds, volumes, and traffic-related injuries.

\section{Access to Healthy Food}

Though personal diets may be thought of as the responsibility or choice of the individual, the accessibility and affordability of healthy food plays a role in what a community eats. Inadequacies in the local food system impacts communities, especially in terms of public health (Hodgson, 2009). The most accessible foods-in convenience stores and fast-food outlets-are high in calories but low in 
nutritional value. The production of nutrientrich foods can even threaten regional environmental quality due to the methods used to produce, process, package, and transport the goods (Johns Hopkins Center for a Livable Future, 2010). Access to affordable grocery stores and farmers markets increases the likelihood that people will eat healthy food, while those surrounded by convenience and liquor stores are less likely to eat healthy food (Corburn, 2009, p. 80; Moore and Diez Roux, 2006). The food system, good or bad, is impactful to the well-being of communities of all socioeconomic kinds, though the poor are generally more vulnerable to problems of food access (Corburn, 2009).

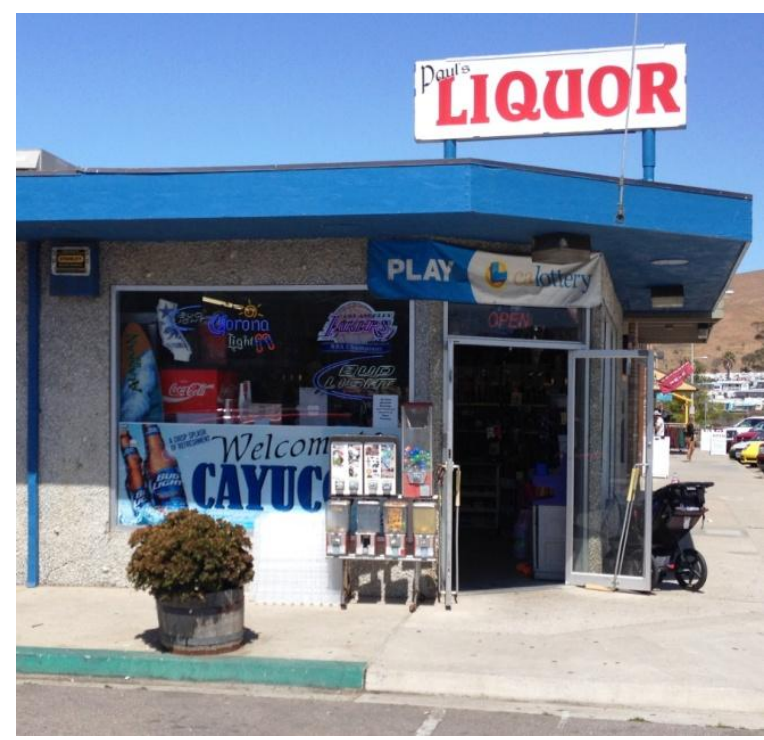

Liquor Store on Ocean Avenue

The percentage of ACTION survey respondents in the county that exercise moderately and eat the daily recommended amount of fruits and vegetables has increased, while obesity rates declined from $60 \%$ to $48.1 \%$.

The percentage of residents who were able to afford enough food, however, increased in the county. The current nutritional guidelines made by the Department of Agriculture recommend getting a minimum of five servings of fruits and vegetables per day. According to the 2013 survey, only $46 \%$ of teens and $48 \%$ of adults in the county meet this standard. When asked how many glasses or cans of soda or other sugar sweetened beverages they drink in a day, $73 \%$ of teens responded zero, $13.9 \%$ responded 1 , and $6.2 \%$ responded three. Percentages were higher for children 11 and younger, with 16\% reporting that their child drank one sugarsweetened beverage, and $9.4 \%$ drank two. The percentages of people who drank one or more sugar-sweetened beverages were lower in the North Coast region (ACTION, 2013). These results show that county residents are consuming too much unhealthy food and not enough fruits and vegetables.

The food access assessment in Cayucos analyzed the existing availability of food outlets and to help determine need. The assessment was conducted using GIS data collected from San Luis Obispo County and by visits to each of the stores that sell food or beverages. There are three unhealthy food outlets in Cayucos which sell only candy, chips, sodas, tobacco, and similar items.

The only store in Cayucos that offers whole grain bread and tortillas, fruits and vegetables, low fat milk, or other healthy items is the Cayucos Supermarket, located on South Ocean Avenue. A parks access map below displays 1mile and $1 / 2$ mile distances along roads from the Cayucos Supermarket. 
Cayucos Healthy Food Access

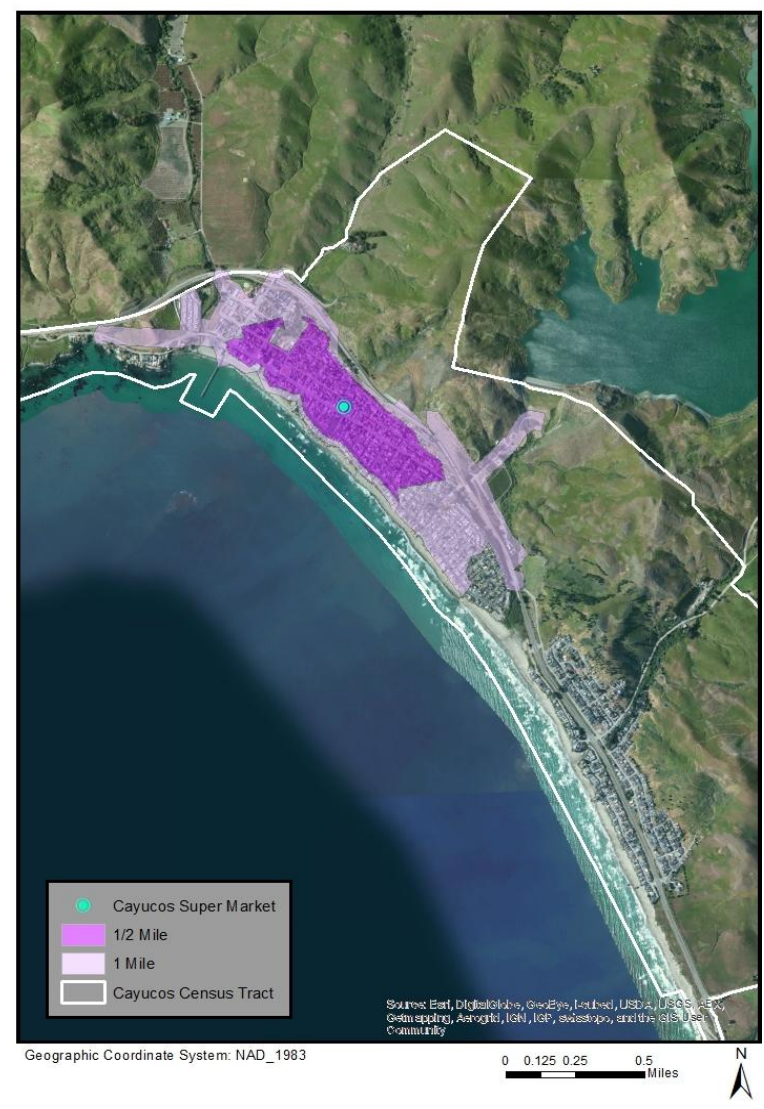

A large portion of residential neighborhoods, especially to the south and across Highway 101 are not within the $1 / 2$-mile or 1 -mile walk or bike to the grocery store.

Healthy eating is increasing in the north county, with obesity rates declining and more people consuming enough fruits and vegetables. However, only $48 \%$ of adults in the county are consuming the recommended amount of fruits and vegetables. In Cayucos, community members expressed the need for healthy food options, including a health food store, a larger grocery store, healthy, affordable eateries, and access to locally-grown food.
Cayucos Food Retail Excluding Super Market

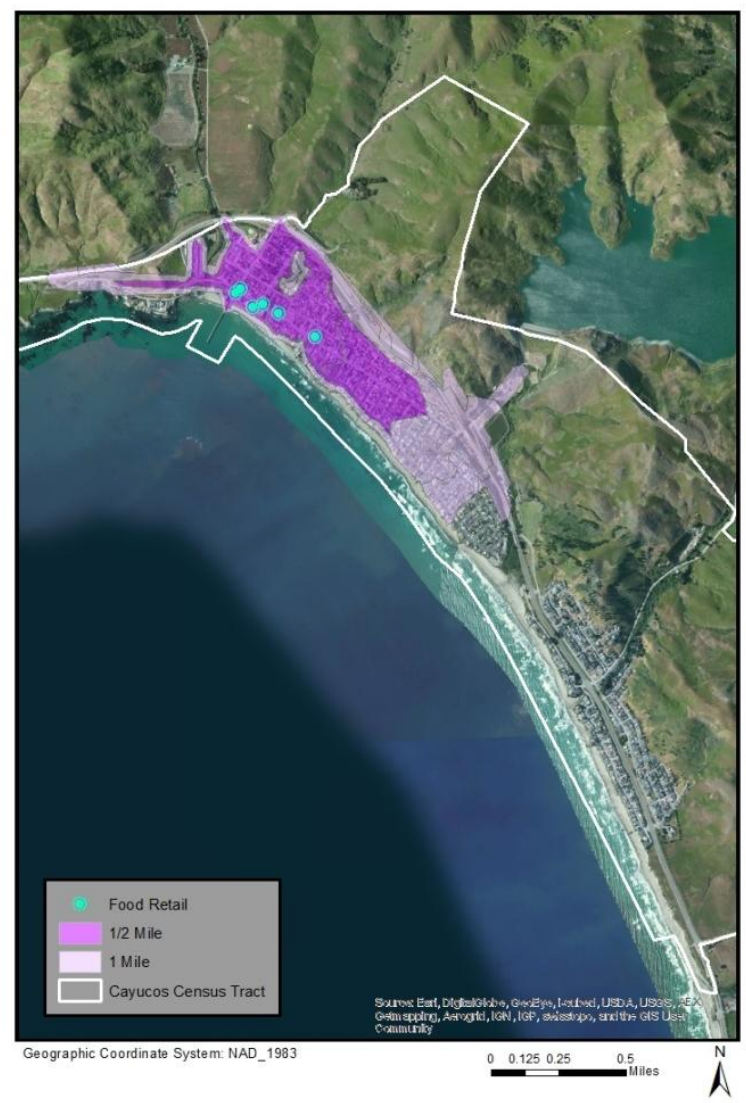

Weekly grocery shopping is nearly impossible in Cayucos due to the unavailability of many items, and prices are commensurate with the vacation-town setting, therefore not affordable for residents.

"Lack of food access" was one of the frequently noted issues detracting from health or overall wellness. Better availability of healthy foods was one of the options most frequently chosen as a community feature that could contribute to health and quality of life. Other key outreach findings included that even kids would like to have healthy food options, and that the farmers' market on Friday mornings, inaccessible to some residents that work or go to school during that time. 
According to the Retail Food Environment Index (RFEI), there are three unhealthy food outlets in Cayucos, and only one small market which sells alcohol but no tobacco (Truong, Fernandes, An, Shier, and Sturm, 2010). This presents an issue of food accessibility and affordability for residents, especially those without access to a personal vehicle such as children and the elderly.

\section{Environmental Quality and Health}

Although many community members mentioned the beautiful natural environment as a great asset to their quality of life, pollution and issues of environmental quality were mentioned again and again. "Pollution or concerns about environmental quality" was one of the frequently noted issues detracting from health or overall wellness.

\section{Factors that Detract From Health, Open-Ended Response}

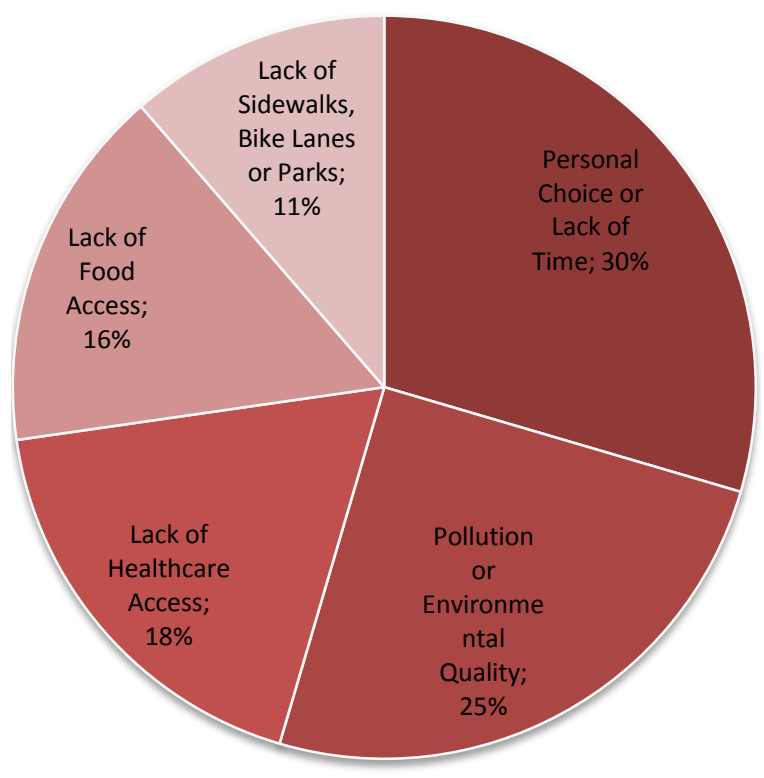

Humans are affected by the environmental quality in the places they live, work, and visit. In particular, people are affected by air and water quality. In 2013, ACTION survey respondents throughout the county were most concerned about water quality (69\%), air pollution (59\%), traffic congestion (58\%), building in open space (57\%), and pesticide use near homes (56\%) (ACTION, 2013). These concerns have been reported as top concerns since 2006 .

Acute and long term air pollution due to ground level ozone and particulate matter has been shown to have negative impacts on health (bell, 2010). Ground level ozone is that main component of smog, and is caused by the emissions of industrial facilities and electric utilities, motor vehicle exhaust, gasoline vapors, and chemical solvents (EPA, 2012). The San Luis Obispo Air Pollution Control Board (APCD) monitors particulate matter and ozone in the air. Long-term exposure to high concentrations of particulate matter and high ozone levels (smog) pose a health danger for the effects to lung and heart problems. Particulate matter is measured at two levels, 2.5 microns or less in diameter (PM2.5) and 10 microns or less (PM10). These size particles can penetrate the lungs and cause harm. Monitoring sites throughout the county show that certain areas reach non-attainment levels more often than others. The County of San Luis Obispo often falls into non-attainment status for air quality, meaning that the air quality is below state standards. In 2012, zero days exceeded the California ozone standards, down from 5 days in 2006 (APCD, 2012). Ozone levels are highest in the Carrizo Plains and Gillis Canyon Road. There were an estimated 3.1 days in 2012 when the PM2.5 exceeded the national standard, up from 
0 days in 2006 (ACTION, 2013). However, measurements near Cayucos usually do not show that air quality is below this state standard.

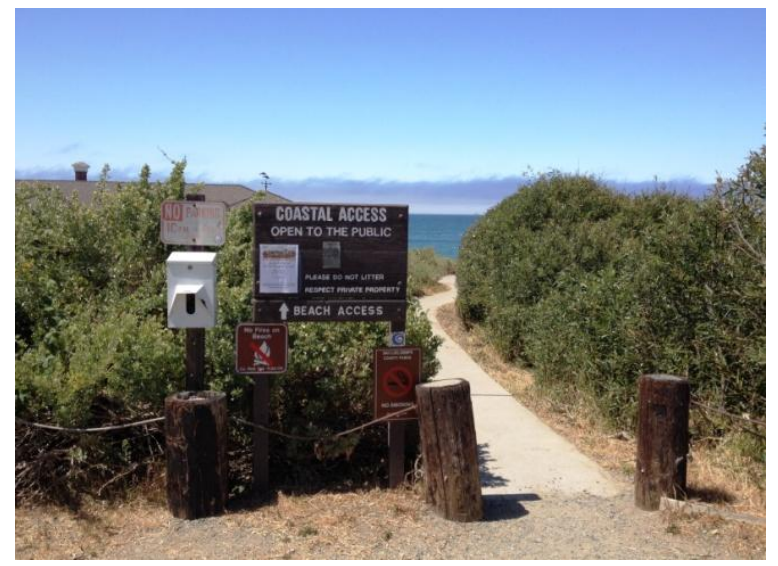

Coastal Access Point

The majority of ACTION survey respondents reported being "very or somewhat concerned" about water quality. Stormwater runoff, the water that flows to the storm drains during and after a rain event, contributes to microbial contamination of water supply, especially after rainfall (Gannon and Busse, 1989). There is a strong relationship between large rainfalls and outbreaks of waterborne diseases. Much of the contamination is from non-point source pollution, with major sources including runoff from farms, parking lots, streets, and golf courses.

Water-related illnesses can be cause by microbial or chemical contamination from pesticides, metals, nitrates, pharmaceuticals, and organic chemicals (Curriero, Patz, Rose, and Lele 2001). Waterborne illnesses can be caused not only by drinking contaminated water, but also by eating produce irrigated with untreated water, eating seafood caught in contaminated water, and swimming or other recreation in polluted water (Craun, 1992). The Beach Report Card measures water quality at 19 different locations on beaches throughout the county. The grades vary from year to year, ranging from $79 \%$ of days receiving a grade $\mathrm{C}$ or better in 2010-2011 during wet weather, to $100 \%$ of days in dry weather in 2011-2012 (Heal the Bay, 2014). Water pollution affects people locally in Cayucos because of location at the ocean shore, where many residents and visitors enjoy the beach and the waves.

North coast residents are very concerned with water quality and availability (ACTION, 2013). Water supply also continues to be a challenge in the Central Coast region, from securing adequate and reliable sources of water to overuse in agricultural areas. In Cayucos, per connection water use has decreased by $41 \%$ since 2005. Some outreach participants in Cayucos also mentioned climate change as a health issue.

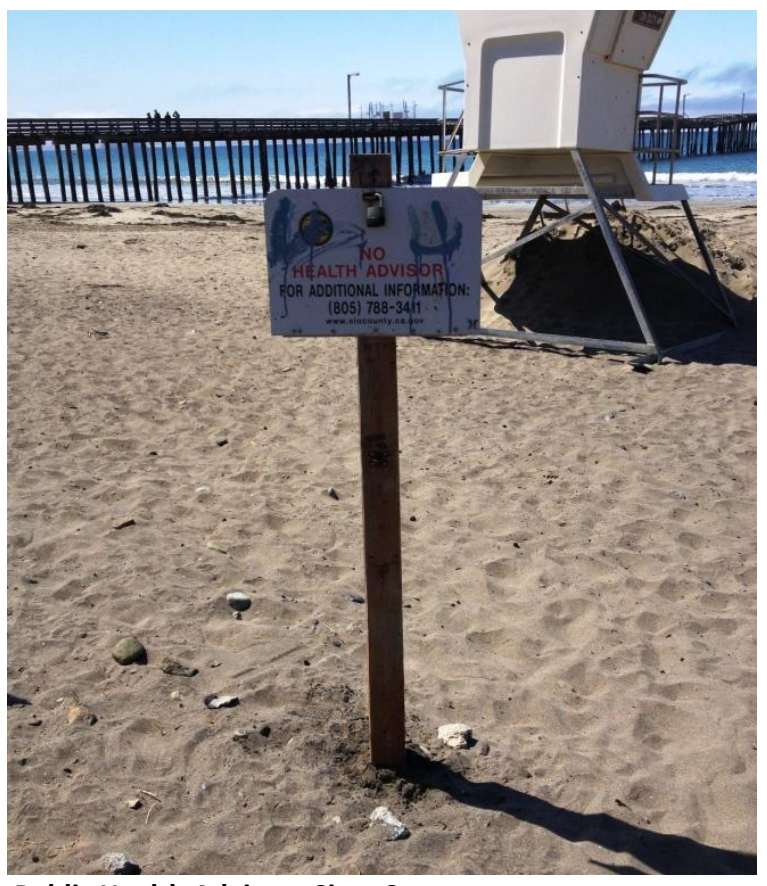

Public Health Advisory Sign, Cayucos 
Issues in Cayucos range from contaminated runoff pollution to solid waste management. Poor environmental quality affects Cayucos locally, but is an issue with that originates at the regional level. Physical and environmental beauty is a major factor contributing to health in Cayucos, especially because it adds to the willingness of residents to recreate outside and provides mental health benefits. When asked about important factors for a healthy community, the options with the highest response rate were included "clean environment."

\section{Access to Health Care Facilities}

There are many aspects to determining the accessibility of healthcare access and the degree to which access impacts individual health. The location of healthcare facilities in a community, such as hospitals, emergency care facilities, and health clinics influence access. However, factors such as transportation to and from facilities, awareness of facilities and services, availability of insurance, and personal preferences have an impact on the degree to which available healthcare facilities can and will be used.

The percentage of county residents with health insurance and those with a regular source of healthcare decreased since 2010 (ACTION, 2013). The percentage of people with an inability to receive medical care due to cost increased, and $73.4 \%$ of those without insurance do not have it because they cannot afford it or it is too expensive. In the North Coast region $85 \%$ of residents have health insurance, and $35.4 \%$ of them have insurance through a state or federal program such as Medicare or Medi-Cal. In San Luis Obispo County, access to medical care is restricted by increases in cost, higher insurance rates, and proximity to medical facilities. When asked what aspects of the Cayucos community detract from overall wellness, one of the most frequent responses was the lack of healthcare access. Though the vast majority of residents described their personal health as "healthy" or "very healthy", many were concerned about aging problems and chronic diseases.

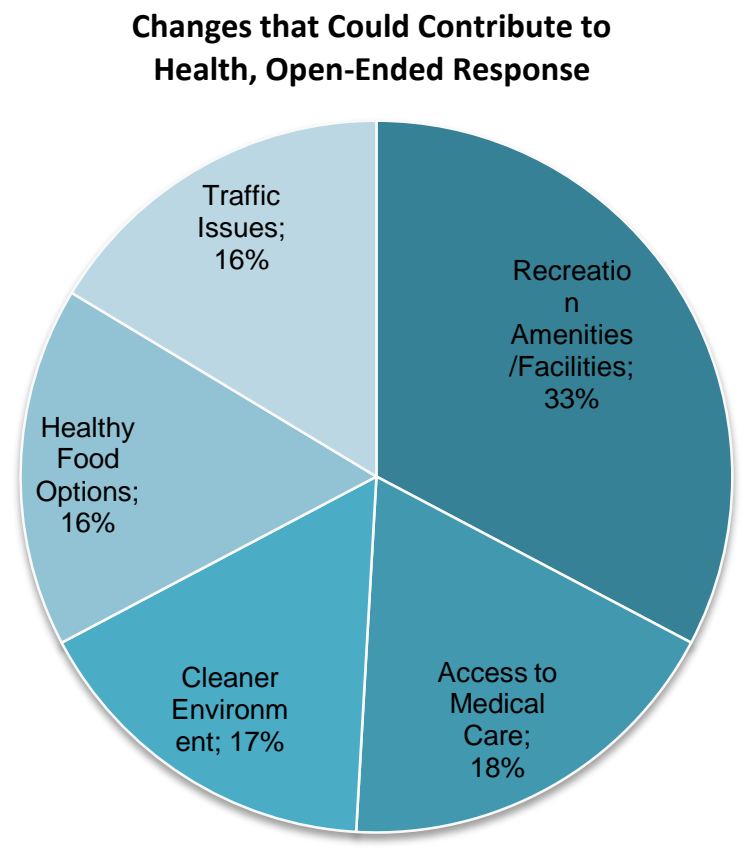

The high median age and high percentage of seniors residents in town, coupled with the lack of healthcare facilities in town and limited transit, presents a healthcare access problem for Cayucos residents. "Access to healthcare" was one of the options most frequently chosen as a community feature that could contribute to health and quality of life. 


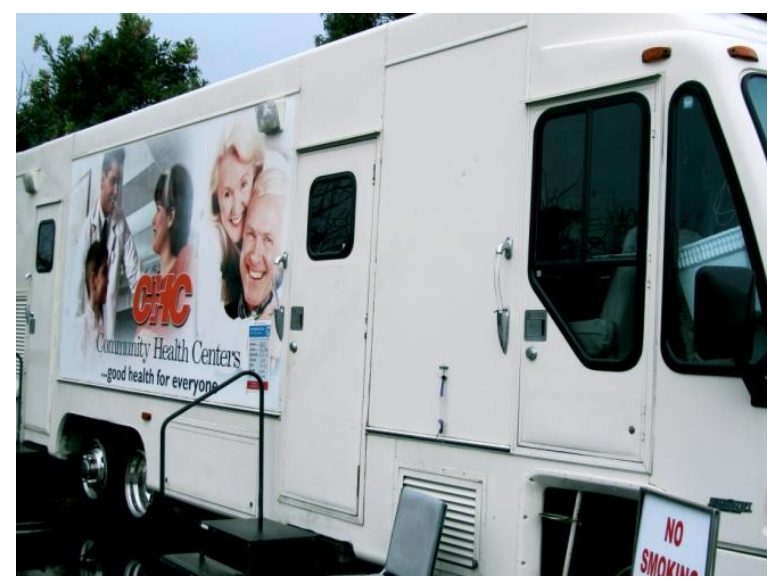

Mobile Clinic

Findings suggest that there is a need to increase access to healthcare for the wellbeing of the community.

\section{Participation}

Many of the 2,431 citizens of Cayucos are active in a number of community groups, and have been very successful in mobilizing their neighbors and supporters in the greater San Luis Obispo area to achieve desired outcomes for their community. According to the majority of questionnaire respondents, the sense of community and volunteerism contributes to making the town a great place to live. Though the majority of participants involved in clubs and organizations are older, retired residents, there is also a sense of community at the bars and hangout spots, and a lot of young business owners also contribute to the town. This capacity is sometimes referred to as social capital, and its presence in a community is positively correlated with community security, friendship and community, and a civic identify, which studies show improves mental health, cardiovascular health, and faster recovery from illness (Kawachi, Subramanian, and Kim, 2008).

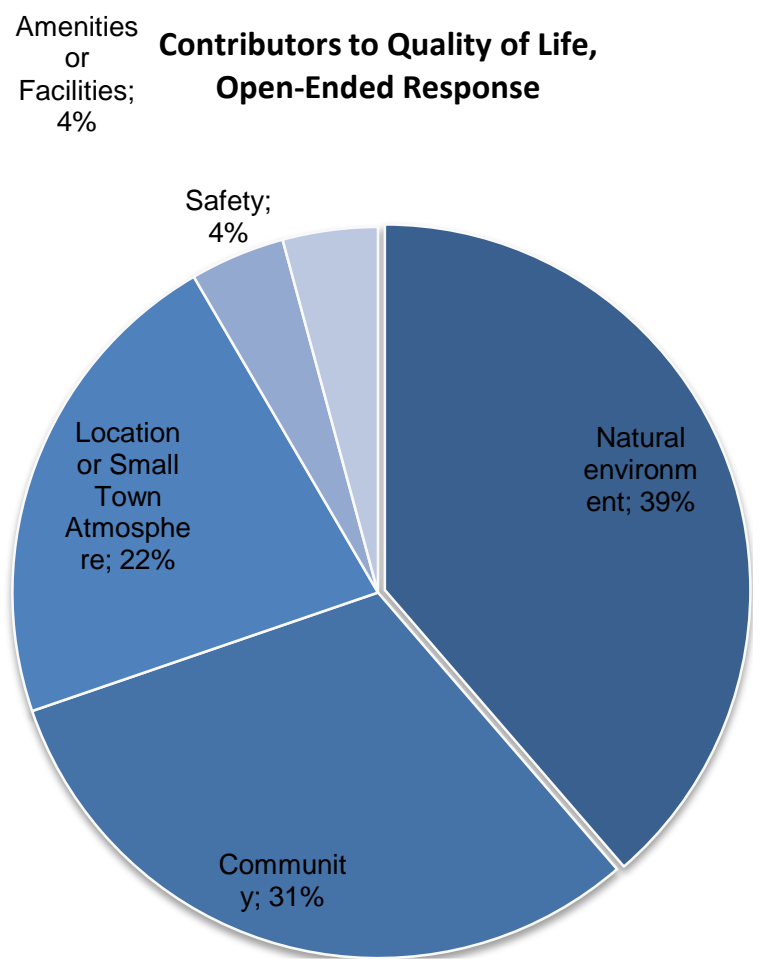

When asked about important factors for a healthy community, the options with the highest response rate included good schools, low crime and safe neighborhoods, and good place to raise children. The "sense of community" and "smallness" were chosen by participants as factors in overall wellbeing.

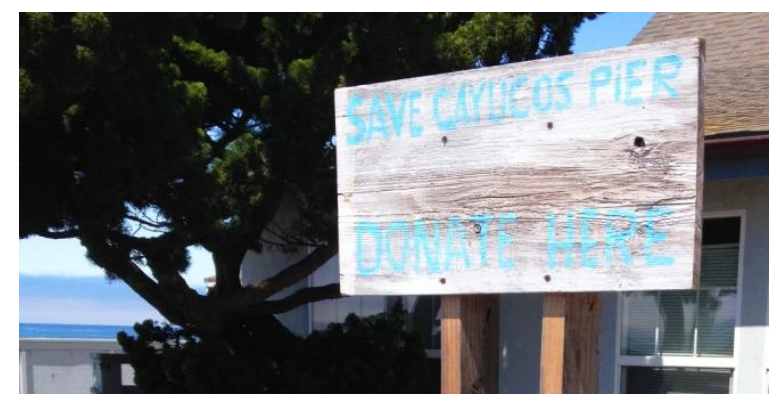

Save the Pier Fund Sign

In this way, the findings suggest that the community participation levels are a boon to public health, but collaboration will ensure the success of future projects related to the effort. 


\section{GOALS, POLICIES, AND ACTION PROGRAMS}

This section identifies community health goals, policies, and programs that emerged from community participation, analysis of existing conditions in Cayucos, and best planning practices. These ideas are meant to be integrated into the existing General Plan, incorporated into a future health element, adopted as an appendix to the Estero Area Plan, or adopted by community groups. The goals and policies herein should be used in conjunction with existing elements of the San Luis Obispo County General Plan in order to achieve a holistic approach to community health.

\section{CCHP GOAL 1: Strengthened partnerships between the Health Agency, the County Planning Department, and the Cayucos community in policy implementation and programming.}

Citizens in Cayucos are highly effective in grassroots mobilization for achieving community improvements and exhibit a high degree of social capital. Collaboration with public health experts, integrating processes to address public health, and applying community design methods to ensure that the public has a say in the outcomes of planning documents are aspects crucial to the success of these planning efforts. The following goals, policies, and implementing programs strive to maintain this level of involvement and expand the reaches to include collaboration with local government, including the Health Agency, throughout all segments of the Cayucos community. 


\section{POLICIES}

P. 1.1 Plan review. Seek input from public health specialists when updating General Plan Elements or other plans to ensure that physical activity, nutrition, and other health determinants are addressed.

P. 1.2 Increased Participation. Invite and encourage young families, youth, businesses, and organizations to become participants in the planning and policy-making process through diverse communication methods.

P. 1.3 Education. Raise awareness about the importance of healthy behaviors and physical fitness to overall well-being.

\section{ACTION PROGRAMS}

A. 1.1 Establish a quarterly health update from the County Health Department to the Cayucos Citizen Advisory Council to inform the community on health issues and public health priorities.

A. 1.2 Integrate public education initiatives into existing Health Promotion activities such as Public Health Week to define and promote links between the built environment and health outcomes.

A. 1.3 Refer community and development permit applications that could potentially impact health conditions and outcomes (physical activity, nutrition, or environment) to the Healthy Communities Workgroup for review.

A. 1.4 Route all discretionary project permit applications to the County Health Commission for review.

A. 1.5 Periodically assess the health of Cayucos residents and make this information available to the public. 


\section{CCHP GOAL 2: A low rate of smoking, drug and alcohol abuse among Cayucos residents and visitors.}

Residents in Cayucos are concerned about the rate of smoking and problems with drug and alcohol abuse in their community. Researchers and public health professionals in tobacco cessation and prevention utilize strategies such as reducing tobacco advertising, enforcing penalties for selling alcohol and tobacco to minors, and providing free products and services to those with unhealthy addictions. The department of Behavior Health provides treatment and recovery services for those with drug and alcohol problems. These policies and programs aim to increase awareness of such programs, increase accessibility of County programs, and limit the exposure to such substances.

\section{POLICIES}

P. 2.1 Reduce public smoking. Encourage smoke-free parks, public spaces, and eating areas to reduce the visibility of smoking and exposure to second-hand smoke.

P. 2.2 Electronic Cigarettes. Include e-cigarettes in policies that prevent the advertising, sale, or use of tobacco.

\section{ACTION PROGRAMS}

A. 2.1 Reduce alcohol and tobacco advertising. Increase enforcement of existing tobacco and alcohol retail laws, such as the Lee Law. Provide incentives to retailers to reduce advertisements and displays that encourage the purchase of tobacco and alcohol, especially those that target minors.

A. 2.2 Liquor Stores. Limit the number of liquor stores in Cayucos and establish a minimum distance from schools and other destinations. 
A. 2.3 Education and substance abuse assistance. Establish areas within town where notifications will be posted or where information is available about county-sponsored tobacco cessation classes, substance abuse education, and addiction assistance programs. Explore the feasibility and need for local programming in the north coast region.

\section{CCHP GOAL 3: A built environment that promotes increased walking for recreation and transportation for all age groups and abilities as a means of addressing root determinants of health.}

Though pedestrian activity throughout Cayucos is not as limited as in other areas of the county, there are many areas throughout the commercial core and connecting to residential areas that could benefit from improved pedestrian infrastructure. Students attending Cayucos Elementary and seniors on the whole were particularly interested in improved walking environments. Pedestrian-friendly areas allow for lowimpact exercise, incorporates exercise into daily activities, accommodate individuals without access to vehicles, increases neighborly connections and improved mental wellbeing.

\section{POLICIES}

P. 3.1 Neighborhood Retail Centers. Encourage nodes of neighborhood services within walking distance (one-quarter mile) of all residences.

P. 3.2 Beach access. Include e-cigarettes in policies that prevent the advertising, sale, or use of tobacco. Protect beach access points as a unique opportunity for active recreation and pleasant pedestrian route to downtown.

P. 3.3 Landscape Improvements. Make streets and other public spaces more appealing to pedestrians by increasing vegetation where 
appropriate, planting street trees, improving landscaping, adding seating areas, and removing barriers in the walking path.

P. 3.4 Expand pedestrian areas. Identify opportunities to maximize the use of streets as space for the community to walk and socialize. Explore opportunities to reclaim portions of streets such as excess parking areas, to develop parklets, public spaces, and additional sidewalk areas.

P. 3.5 New development. When new development occurs, integrate the site design into the surrounding pedestrian network to accommodate future users. Advocate against design proposals that block access, create barriers, or create safety hazards for pedestrians.

\section{ACTION PROGRAMS}

A. 3.1 Focus on maintenance and improvement of existing areas.

A. 3.2 Work with the SLO County Health Agency Injury Prevention Division to audit the walking environment for Cayucos seniors, and encourage the improvement of problematic areas.

A. 3.3 Improve pedestrian-scale lighting along Pacific Avenue and Ocean Avenue. Designs should incorporate strategies to limit light pollution while maximizing safety for bicyclists and pedestrians.

A. 3.4 Incorporate universal design or Americans with Disabilities Act (ADA) requirements, especially in high-volume pedestrian areas, near seniors' facilities, and downtown.

A. 3.5 Pursue expansion of sidewalks downtown to increase opportunities for outdoor dining and spontaneous community interaction. 


\section{CCHP GOAL 4: An environment that encourages physical activity and social interaction through a reduced risk of injury and a safe multimodal transportation system.}

Cayucos is located along the Pacific Coast Bike Trail which follows Highway 1 along the coast. The climate and scenery make Cayucos a great place to bicycle for avid cyclists, casual bikers, and commuters. However, most roads lack a safe amount of lighting, there are few places to park a bicycle, and there have been several bicycle-vehicle collisions in Cayucos. Bicycling allows for active transportation at greater distances and speeds than walking, provides connections between residences and transit stops, and is and highly accessible form of transportation for all ages and income levels. Like walking, riding a bike to services and frequent destinations incorporates physical activity into daily life, helping to increase the chances that the rider experiences the countless health benefits of regular exercise. The goals and policies below, along with goals to increase safety, will help to support accommodation for and encourage use of bicycles.

\section{POLICIES}

P. 4.1 Expand bicycle infrastructure. Improve bike lane visibility, install bicycle racks or other forms of bike parking, additional signage, and wayfinding aids for cyclists.

P. 4.2 Eliminate barriers. Identify and eliminate barriers to bicycling including such as damaged, incomplete, blocked, or rough bike paths, excessive vehicle speeds, and insufficient lighting.

P. 4.3 Prioritize Bicycle Parking. Provide incentives for the development of adequate bicycle parking and support facilities in existing and new businesses and in new development projects, where appropriate. 
P. 4.4 Seek grant funding for the installation of public bicycle parking throughout downtown and at major destinations throughout Cayucos.

P. 4.5 Improve Bicycle Network. Create a network of clearly visible bicycle lanes, signed bicycle routes, and bicycle priority streets.

\section{ACTION PROGRAMS}

A. 4.1 Education and bicycle promotion. Work with SLO County Injury Prevention, the Safe Routes to School effort, the school district, and community groups to encourage bicycle safety for bicyclists and motorists and promotional events such as bicycle rodeos, bicycle clinics, and helmet distribution events.

A. 4.2 State and Regional Partnerships. Work with CalTrans, SLOCOG, and RTA to increase bicycle access to transit options and improve safety for cyclists along Highway 1.

A. 4.3 Install pedestrian-scale lighting along the bike path extending from Norma Rose Park to 13th Street. Install additional signage to notify and encourage potential users of the bike path location.

\section{CCHP GOAL 5: A built environment that accommodates bicycles as a means of active transportation and recreational opportunity.}

The walk audit conducted for this plan showed that there is a discrepancy between overall walkability in town and the safety of the streets. This is due in part to the auto-oriented nature of the streets, obstructions in the walking path, and uneven or incomplete sidewalks. These issues are especially relevant for increasing the number of students walking or biking 
to school, limiting injuries for those needing to cross Highway 1, and individuals with disabilities or limited mobility.

Safety countermeasures, those features that call a driver's attention to a pedestrian area, naturally cause slower speeds, and increases in physical space for pedestrians and bicyclists. These measures can increase actual and perceived safety and encourage active use of the built environment.

\section{POLICIES}

P. 5.1 Increase Transit. Work with RTA to improve transit stops throughout town to include benches, shelters, and bicycle parking. Consider key destinations, including health care providers, schools, parks and grocery stores, when designing routes

P. 5.2 Highway 101 pedestrian improvements. Work with CalTrans to improve safety and accessibility for pedestrians crossing Highway 1 , including a reduced speed zone, pedestrian signage, and higher visibility crosswalks. Work with CalTrans and the community in order to prevent pedestrian crossings at unimproved locations.

P. 5.3 Traffic Calming. Implement traffic calming strategies in areas around schools and parks.

\section{ACTION PROGRAMS}

A. 5.1 Work collaboratively with the school district, SLOCOG, and the PTA to identify and address school access and safety issues through the Safe Routes to School Program.

A. 5.2 Reduce traffic speeds where appropriate around high-volume pedestrian areas, parks, residential neighborhoods, and public spaces. 
A. 5.3 Explore the feasibility of narrowing Ocean Avenue to naturally slow traffic and allow for wider, safer sidewalks and bike lanes.

A. 5.4 Increase the visibility of crosswalks, school zones, and high-volume pedestrian areas through the addition of varying textures and colors of crosswalks, pedestrian and crossing signs, and physical improvements such as crossing islands, raised crosswalks, curb extensions, reduced radii at intersections, perpendicular curb ramps and other measures known to improve pedestrian safety.

\section{CCHP GOAL 6: An aesthetically pleasing and inviting environment that is designed to accommodate residents and visitors of all ages and abilities.}

Cayucos benefits from a highly aesthetically-pleasing natural environment, and a town character that plays off the proximity to the ocean, and ample resources for active pursuits. However, the small town atmosphere and remote location limit the access to many community needs without the use of a private automobile, encourages tourism and vacation rental housing units, and drives up housing costs. The following goal, policies, and implementing programs aim to preserve the current character of the town, preserve a permanent population, and connect neighborhoods to services available in town.

\section{POLICIES}

P. 6.1 Street Closures. Allow street closures for events such as farmers' markets, arts and craft fairs, and bicycle and pedestrian events on a promotional basis. Explore the feasibility of creating a permanent pedestrian street.

P. 6.2 Design Guidelines. Preserve the unique character and atmosphere of Cayucos as new development occurs by working with the 
community to incorporate design guidelines into existing County Planning documents.

P. 6.3 Vacation Rentals. Enforce use restrictions in residential areas to reduce the incidence of unpermitted vacation rentals in order to avoid frequent vacancies of housing units, reestablish personal connections within neighborhoods, and lessen the risk for nuisances.

P. 6.4 Recreation. Encourage private development of recreational facilities such as fitness centers, climbing gyms, outdoor sporting facilities, and equipment rental that complement and supplement the public recreational system.

\section{ACTION PROGRAMS}

A. 6.1 Reduce physical barriers as consistent with universal design principles or the Americans with Disabilities Act to accommodate less mobile individuals.

A. 6.2 Explore ways on increasing public art, especially in areas lacking aesthetic quality.

\section{CCHP GOAL 7: A local parks and recreation system that accommodates residents, local employees, and visitors of all ages, interests, and abilities to promote mental and physical health and wellbeing throughout Cayucos.}

Cayucos residents of and visitors have access to parks, nearby trails, a community pool, tennis courts, and use the beach for exercise such as walking, running, kayaking, or surfing. However, many residents, especially elementary students, expressed a need for parks that are better 
suited to active recreation, such as team sports. This finding is also consistent with language from the Estero Area Plan (2008). The following goal, policies, and implementing programs seek to diversify the parks and recreation system to accommodate all users.

\section{POLICIES}

P. 7.1 Adopt policies that recognize that parks, open spaces, and beach access is a critical strategy to improve health benefits in the town, particularly as related to obesity, diabetes, and mental health.

P. 7.2 Park design. Design new facilities and update existing facilities to provide natural surveillance, minimize injury risks, have adequate, pedestrian scale lighting, and signs that include hours of operation.

P. 7.3 Complete plan and secure funding in full for separated path extending from Cayucos to Morro Bay.

P. 7.4 Recreation activities. Support and encourage year-round sports and recreation activities, such as team sports, fitness classes, clubs for hiking, biking, surfing, and other similar activities.

P. 7.5 Joint use agreements. Collaborate with the school district to establish or update a joint use agreement for community-wide access to school recreational facilities such as sports fields.

\section{ACTION PROGRAMS}

A. 7.1 Consider extending community pool hours to accommodate users year-round.

A. 7.2 Improve signage along bicycle routes and at community gateways to better direct residents and visitors to parks and community facilities. 
A. 7.3 Inclement weather recreation. Explore the possibility of indoor recreational facilities such as basketball or squash courts.

A. 7.4 Support community programs to increase awareness and use of hiking opportunities in the area.

A. 7.5 Explore the feasibility of expanding Hardy Park to include a large field to accommodate team sports

A. 7.6 Explore community interest in an outdoor exercise circuit in existing parks. The course should be clearly marked with signage and include instructions for use.

\section{CCHP GOAL 8: A standard of environmental quality that encourages active pursuits, prevents exposure to toxic or infectious substances, and minimizes local greenhouse gas emissions.}

Although many community members mentioned the beautiful natural environment as a great asset to their quality of life, pollution and issues of environmental quality were also mentioned again and again. Issues in Cayucos range from contaminated runoff pollution to solid waste management. Poor environmental quality affects Cayucos locally, but is an issue with that originates at the regional level. The goal, policies, and programs below seek to bring attention to environmental quality issues, institute local programs for a cleaner environment that supports health, and serve as a model for San Luis Obispo County and the greater central coast region.

\section{POLICIES}

P. 8.1 Non-point source pollution management. Support programs and efforts to protect the ecological integrity of the watershed. 
P. 8.2 Runoff Education. Educate the public about the links between specific sources of non point-source water pollution, environmental, quality, and health risks.

P. 8.3 Waste reform. Implement a recycling and composting program to include commercial uses, residents, and visitors with the goal of reducing per capita solid waste disposal to landfill by $20 \%$

P. 8.4 Runoff Management. Encourage the use of runoff management techniques, such as green streets and bioswales, to slow and clean stormwater.

\section{ACTION PROGRAMS}

A. 8.1 Increase the number trees for their many environmental benefits, including natural carbon sequestration

A. 8.2 Work with community groups to maintain and improve awareness about the need to clean up after pets, emphasizing the harmful effects to water quality. Increase the availability of clean up bags in areas with many pedestrians.

A. 8.3 Incorporate sustainable and watershed-friendly landscaping in all new development.

A. 8.4 Notify the public of hazards such as dangerous water quality or injury hazards through public education, notification systems, and public signage.

A. 8.5 Encourage the use of compost, and require where appropriate community farming and neighborhood gardening that eliminates or reduces the use pesticides, herbicides, and chemical fertilizers.

A. 8.6 Increase participation in commercial and residential food waste collection through a composting program. 
A. 8.7 Reduce waste by improving participation in recycling programs, encouraging recycling downtown, and instituting a green waste or composting program.

\section{CCHP GOAL 9: Accessible, affordable food for all residents.}

In Cayucos, community members expressed the need for healthy food options, including a health food store, a larger grocery store, healthy, affordable eateries, and access to locally-grown food. Weekly grocery shopping is nearly impossible in Cayucos due to the unavailability of many items, and prices are commensurate with the vacation-town setting, and therefore not affordable for residents. This presents an issue of food accessibility and affordability for residents, especially those without access to a personal vehicle such as children and the elderly. The measures below seek to address the Cayucos's specific issues with healthy food availability, and many provide other health co-benefits.

\section{POLICIES}

P. 9.1 Incentives for food retailers. Support financing, zoning, tax incentives, or other programs that encourage new and existing food retailers and institutions to increase healthy food options.

P. 9.2 Encourage and, when feasible, facilitate opportunities for Community-Supported Agriculture within the community.

P. 9.3 Encourage and facilitate existing and new public or private shuttle systems to transport seniors and others in need to nearby grocery stores and other sources of healthy food. 
P. 9.4 Encourage the development of healthy food establishments downtown and in neighborhood commercial areas throughout Cayucos.

P. 9.5 Require new development to provide and maintain drinking water fountains or hydration stations where appropriate.

\section{ACTION PROGRAMS}

A. 9.1 Facilitate careful maintenance of existing water fountains, recognizing the need for fresh water to be publicly available to support community health.

A. 9.2 Work with community groups to facilitate the development of convenient and accessible community gardens where residents can plant and grow fruit and vegetables within each neighborhood.

A. 9.3 Pursue grants and other funding sources for the development of community gardens to benefit mental and physical health.

A. 9.4 Encourage the development of edible school yards as an educational resource, or in combination with community garden establishment and maintenance.

A. 9.5 Encourage the development of underutilized land in parks and vacant lots into productive space for growing fruits and vegetables.

A. 9.6 Consider an additional farmers market day and time, or change the day and time of the current seasonal farmers market to better accommodate members of the community that work and attend school.

A. 9.7 Adopt healthy food guidelines, and provide incentives for retail stores and restaurants that provide healthy options. 


\section{CCHP GOAL 10: Convenient access to a wide range of healthcare facilities in Cayucos and nearby for all ages and income levels.}

When asked what aspects of the Cayucos community detract from overall wellness, one of the most frequent responses was the lack of healthcare access. Though the vast majority of residents described their personal health as "healthy" or "very healthy", many were concerned about aging problems and chronic diseases. The high median age and high percentage of seniors residents in town, coupled with the lack of healthcare facilities in town and limited transit, presents a healthcare access problem for Cayucos residents. The goal and policies below strive to increase access to healthcare for the wellbeing of the community.

\section{POLICIES}

P. 10.1 Encourage health care facilities. Support existing and potential new health care services in the City through a variety of mechanisms including financial incentives such as reduced permit fees, reduced impact fees, and business license discounts.

P. 10.2 Education and visibility. Increase availability of resources to the community on the availability of health care options and publicly available resources, such as tobacco cessation classes.

P. 10.3 Mobile health care. Promote the use of mobile or remote health care such as clinics on wheels to increase resident's access to preventative care, dental care, and screenings.

\section{ACTION PROGRAMS}

A. 10.1 Encourage local transit providers to establish and maintain routes and services that provide the community with convenient access to health service facilities, where feasible. 


\section{REFERENCES}

Aboelata, M. J. (2004). The Built Environment and Health: 11 Profiles of Neighborhood Transformation. Prevention Institute. Retrieved from http://www.preventioninstitute.org/index.php?option=com_jlibrary\&view=article\&id=114\&lte $\operatorname{mid}=127$

ACTION for Healthy Communities. 2013. Community Foundation San Luis Obispo. Accessed November 14, 2013 at http://www.sloccf.org/community_needs.php.

Air Pollution Control District, San Luis Obispo County (APCD). (2012). 2012-2017 Strategic Plan Update. Retrieved from http://www.slocleanair.org/images/cms/upload/files/B-1.pdf.

American Institute of Stress. (2011). Effects of Stress. Retrieved from http://www.stress.org/topiceffects.htm

Annual Air Quality Report. (2012). San Luis Obispo Air Pollution Control Board (APCD). Accessed at: http://www.slocleanair.org/images/cms/upload/files/2012aqrt-FINAL.pdf.

Bell ML, M. A. Ozone and short-term mortality in 95 US urban communities, 1987-2000. (2010). JAMA 292, 2372-2378.

Binder, S. (2002). Injuries among older adults: the challenge of optimizing safety and minimizing unintended consequences. Injury Prevention 2002; 8 (Suppl IV): iv2-iv4.Accessed April 27, 2014 at http://injuryprevention.bmj.com.ezproxy.lib.calpoly.edu/content/8/suppl_4/iv2.full.pdf+html

Brownson, R. C., Baker, E. A., Housemann, R. A., Brennan, L. K., \& Bacak, S. J. (2001). Environmental and Policy Determinants of Physical Activity in the United States. American Journal of Public Health. 91 (12),1995-2003.doi: 10.2105/AJPH.91.12.1995

California Conference of Local Health Officers and County Health Executives Associates of California (CCLHO-CHEACH).(2013). Chronic disease prevention framework. 3-4. Retrieved from http://www.cdph.ca.gov/programs/cclho/Documents/ChronicDiseaseReportFINAL.pdf

California Department of Education (CDE). (2013). Physical Fitness Testing (PFT). Accessed April 29, 2014 at: http://www.cde.ca.gov/ta/tg/pf/

California Department of Education. (2013). Physical Fitness Testing (PFT). Accessed April 29, 2014 at: http://www.cde.ca.gov/ta/tg/pf/

California Department of Health Services (CDHS) and California Conference of Local Health Officers. County Health Status Profiles: Cayucos, CA. (2011). Accessed February 24, 2014 at http://www.cdph.ca.gov/data/statistics/Pages/DeathProfilesbyZIPCode.aspx. 
California Highway Patrol (CHP). (2014). Statewide Integrated Traffic Records System Records Request, May 29, 2014.

Cao, X., Handy, S.L., \& Mokhtarian, P.L. (2006). The influences of built environment and residential selfselection on pedestrian behavior: evidence from Austin, TX. Transportation. (33), 1-20. Retrieved from http://escholarship.org/uc/item/4jn1w8qn\#page-2

Casagrande, S., et. Al. (2011). Association of Walkability With Obesity in Baltimore City, Maryland. December; 2011101 (Suppl 1): S318-S324

Cayucos Elementary, Elementary. California Healthy Kids Survey, 2009-10: Main Report. (2010). San Francisco: WestEd Health and Human Development Program for the California Department of Education.

Cayucos Elementary, Secondary. California Healthy Kids Survey, 2011-12: Main Report. (2012). San Francisco: WestEd Health \& Human Development Program for the California Department of Education

Centers for Disease Control (CDC) and Prevention, National Center for Injury Prevention and Control. 2013. Injuries and Violence are Leading Causes of Death: Key Data \& Statistics. Accessed February 20, 2014 at http://www.cdc.gov/injury/overview/data.html.

Coburn, J. (2006). Reconnecting with Our Roots: A Critical History of American Planning and Public Health for the Twenty-First Century. Planning Advisory Service Report, 543/544, 23-36. Retrieved from http://search.proquest.com.ezproxy.lib.calpoly.edu/docview/232847968/fulltextPDF?accountid $=10362$

Corburn, J. (2009). Toward the Healthy City: People, Places, and the Politics of Urban Planning. Cambridge, Mass.: MIT Press.

County of San Luis Obispo, Estero Area Plan. (2009). Retrieved from http://www.slocounty.ca.gov/Assets/PL/Area+Plans/Estero+Area+Plan.pdf

County of San Luis Obispo, San Luis Bay Coastal Area Plan. (1988). Retrieved from http://www.slocounty.ca.gov/Assets/PL/Area+Plans/San+Luis+Bay+Coastal+Area+Plan.pdf

County of San Luis Obispo. (2014). General Plan and Ordinances. http://www.slocounty.ca.gov/planning/General_Plan__Ordinances_and_Elements.htm

Craun GF. (1992). Waterborne disease outbreaks in the United States of America: Causes and prevention. Word Health Statistics Quarterly 45:192-99.

Crowe, T.D. (1991). Crime Prevention Through Environmental Design, Stoneham, MA: ButterworthHeinemann. 
Curriero FC, Patz JA, Rose JB, Lele SD. (2001). The association between extreme precipitation and waterborne disease outbreaks in the United States, 1948-1994. Am J Public Health 91:11941199.

Drummond, J. P. (2013, November 8). A history of health + urbanism + architecture. Retrieved from http://www.aia.org/practicing/AIAB100514

Feng, J., Glass, T. A., Curriero, F. C., Stewart, W. F., \& Schwartz, B. S. (2010). The built environment and obesity: A systemic review of the epidemiologic evidence. Health \& Place. 16 (2), 175-190. DOI: 10.1016/j.healthplace.2009.09.008

Furst, Tony. 2012. Memorandum Promoting the Implementation of Proven Safety Countermeasures. January 12, 2012. US Department of Transportation, Federal Highway Administration. Accessed February 21, 2014 at http://safety.fhwa.dot.gov/provencountermeasures/pc_memo.htm)

Gannon JJ, Busse MK. (1989). E. coli and enterococci levels in urban stormwater, river water and chlorinated treatment plant effluent. Water Res 23:1167-1176.

Glanz, K., Sallis, J. F., Saelens, B. E., \& Frank, L. D. (2007). Nutrition environment measures survey in stores (NEM-S): development and evaluation. American Journal of Preventative Medicine. (32) 4, 282-289. Retrieved from http://www.ncbi.nlm.nih.gov/pubmed/17383559

Godbey, G., (2009). Outdoor recreation, health, and wellness: Understanding and enhancing the relationship. Resources For the Future. 9 (21), Retrieved from http://www.rff.org/documents/RFF-DP-09-21.pdf

Gullone, E. 2000. The biophilia hypothesis and life in the 21st century: Increasing mental health or increasing pathology? Journal of Happiness Studies 1, 293-321.

Halonen, J. I. et al. (2010). Ozone and cause-specific cardiorespiratory morbidity and mortality. J Epidemiol Community Health 64, 814-820.

Heal the Bay. (2014). Beach report card. Retrieved at http://www.healthebay.org/our-work/2014beach-report-card.

Hess, P. M., Moudon, A. V., Snyder, M. C., \&Stanilov, K. (1999). Site design and pedestrian travel. Transportation Research Record. 1674, 9-19. Retrieved from http://faculty.washington.edu/moudon/writing\%20docs/sitedesign.pdf

Hodgson, K., (2009). Where food planning and health intersect. Journal of the American Planning Association, August/September 9-13.

Human Impact Partners. (2011). A Health Impact Assessment Toolkit: A Handbook to Conducting HIA, $3^{\text {rd }}$ Edition. Oakland, CA: Human Impact Partners. 
Johns Hopkins Center for a Livable Future, (2010). Food distribution and transport, background reading. Retrieved from: http://www.jhsph.edu/research/centers-and-institutes/teaching-the-foodsystem/curriculum/distribution_and_transport.html

Kawachi, I., Subramanian, S., and Kim, D. (2008). Social capital and health. New York: Springer.

Lee, C., Moudon, A. V. (2004). Physical activity and environment research in the health field: implications for urban and transportation planning practice and research. Journal of Planning Literature. (19), 147-181. Retrieved from http://hmcrc.srph.tamhsc.edu/Literature/PhysicalActivity/PAEnvironmentResearch.pdf

Litman, T. A. (2014). Economic Value of Walkability. Victoria Transport Policy Institute. Retrieved from http://www.vtpi.org/walkability.pdf

Lopez, R., (2004). Urban sprawl and risk for being overweight or obese. American Journal of Public Health. (94) 9, 1574-1579. Retrieved from http://www.ncbi.nlm.nih.gov/pmc/articles/PMC1448496/

Maller, C., Townsend, M., Pryor, A., Brown, P., \& St Leger, L. (2005). Healthy nature healthy people: 'contact with nature' as an upstream health promotion intervention for populations. Health Promotion International. 21 (1), 45-54. doi: doi:10.1093/heapro/dai032

Maller, C., Townsend, M., St Leger, L., Henderson-Wilson, C., Pryor, A., Prosser, P., \& Moore, M. (2009). Healthy parks, healthy people: The health benefits of contact with nature in a park context. The George Wright Forum.26 (2), 51-83. Retrieved from http://www.georgewright.org/262maller.pdf

Mass, J., Verheij, R. A., Spreeuwenberg, P., \& de Vries, S. (2006). Green space, urbanity, and health: how strong is the relation? Journal of Epidemiology \& Community Health. 60, 587-592. doi: 10.1136/jech.2005.043125

Mokdad, A. H., Marks, J. S., Stroup, D. F., \&Gerberding, J. L. (2004). Actual causes of death in the United States, 2000. Journal of the American Medical Association, 291 (10), 1238-1245. Retrieved from www.csdp.org/research/1238.pdf

Moore, L. V., Diez Roux, A.V. (2006) Associations of neighborhood characteristics with the location and type of food stores. Am J Public Health. 96(2), 325-331. doi: 10.2105/AJPH.2004.058040

Newman, O. (1972). Defensible Space: Crime Prevention Through Environmental Design, New York, NA: Macmillian.

Noguera, P. (1995). Reducing and Preventing Youth Violence: An Analysis of Causes and an Assessment of Successful Programs, Harvard Education Review.

Physical Activity Guidelines Advisory Committee. (2008). Physical Activity Guidelines Advisory Committee Report, Washington, DC: U.S. Department of Health and Human Services, 2008. 
Saelens, B. E., Handy, S. L. (2008). Built environment correlates of walking: a review. Med Sci Sports Exerc. 2008; (11), 550-566. DOI: 10.1249/MSS.0b013e31817c67a4.

Sallis, J. F., Millstein, R. A., \& Carlson, J. A. (2011). Community design for physical activity. In A. L. Dannenberg, H. Frumkin, \& R. J. Jackson (Eds.), Making healthy places: Designing and building for health, well-being, and sustainability (pp. 33-49). Washington, DC: Island Press.

San Luis Obispo Air Pollution Control Board (APCD). (2012). Annual Air Quality Report. Accessed at: http://www.slocleanair.org/images/cms/upload/files/2012aqrt-FINAL.pdf.

San Luis Obispo County Parks, Parks Projects. (2002). Retrieved from http://www.slocountyparks.com/information/parkprojects.htm

Space Matters: Planning, designing, building and maintaining for community wellbeing. New Zealand Injury Prevention Strategy. Accessed on April 26, 2014 at: http://nzips.govt.nz/documents/public_and_play_spaces\%20for\%20pdf\%20V5(2).pdf.

Stokols, D. (1992). Establishing and maintaining healthy environments: Toward a social ecology of health promotion. American Psychologist, 47(1), 6-22.

Transportation Research Board, Institute of Medicine of the National Academies. Committee on Physical Activity, Health, Transportation, and Land Use. (2005). Does the built environment influence physical activity: Examining the evidence. (TRB Special Report 282). Retrieved from http://onlinepubs.trb.org/onlinepubs/sr/sr282.pdf

Truong K, Fernandes M, An R, Shier V, Sturm R. (2010). Measuring the physical food environment and its relationship with obesity: evidence from California. Public Health. 2010;124:115-8.

U.S. Census Bureau. (2012). ACS 2012 5-year, Cayucos, CA CDP. Retrieved January 25, 2014, from http://censusreporter.org/profiles/16000US0612132-cayucos-ca/.

United States Environmental Protection Agency (EPA). 2012. Six common air pollutants. Accessed February 22, 2014 at ttp://www.epa.gov/airquality/particlepollution/health.html.

United States Environmental Protection Agency (EPA). (2014). Ways to Reduce Air Pollution. Accessed June 2, 2014 at http://www.epa.gov/air/caa/peg/reduce.html

United States Environmental Protection Agency (EPA). (2012). Stormwater Management Best Practices. Accessed June 2, 2014 at http://www.epa.gov/oaintrnt/stormwater/best_practices.htm. 